Co-projeto de hardware e software de um escalonador de processos para arquiteturas multi-core heterogêneas baseadas em computação reconfigurável

Maikon Adiles Fernandez Bueno 



\title{
Co-projeto de hardware e software de um escalonador de processos para arquiteturas multi-core heterogêneas baseadas em computação reconfigurável
}

\author{
Maikon Adiles Fernandez Bueno
}

Orientador: Prof. Dr. Eduardo Marques

\begin{abstract}
Tese apresentada ao Instituto de Ciências Matemáticas e de Computação - ICMC-USP, como parte dos requisitos para obtenção do título de Doutor em Ciências - Ciências de Computação e Matemática Computacional. VERSÃO REVISADA
\end{abstract}


Ficha catalográfica elaborada pela Biblioteca Prof. Achille Bassi e Seção Técnica de Informática, ICMC/USP, com os dados fornecidos pelo(a) autor(a)

BUENo, MAIKon
Co-projeto de hardware e software de um
escalonador de processos para arquiteturas multi-
core heterogêneas baseadas em computação
reconfigurável / MAIKON BUENO; orientador EDUARDo
MARQUES. -- São Carlos, 2013.
148 p.
Tese (Doutorado - Programa de Pós-Graduação em
Ciências de Computação e Matemática Computacional) --
Instituto de Ciências Matemáticas e de Computação,
Universidade de São Paulo, 2013.
1. Escalonamento. 2. Multi-core. 3.
Heterogêneos. 4. Multiprocessamento. 5. FPGA. I.
MARQUES, EDUARDo, orient. II. Título.


"A paz é a única forma de nos sentirmos realmente humanos." Albert Einstein 



\section{Dedicatória}

Aos meus amados pais, Oronciana e Onival. Ao meu grande irmão, Moacir. A minha amada companheira, Kéteri. 



\section{Agradecimentos}

Primeiramente, agradeço a Deus por ter me dado a graça de viver e por ter me presenteado com minha familia, namorada e amigos que são muito preciosos para mim. Muito obrigado por estar sempre ao meu lado.

Agradeço de modo especial aos meus amados pais que tanto amo, Onival e Oronciana, e ao meu amado irmão Moacir, por todos esses anos de amor, compreensão e amizade. Para mim, os senhores são fontes de inspiração de superação e de força. Apesar da distância e da saudade, sinto que o laço fraternal dessa familia atravessa quilômetros.

Muito obrigado a minha amada Kéteri por toda motivação, compreensão e por suas doses contínuas de amor. Com você ao meu lado, sinto que posso ir a cada dia mais longe, pois o amor está sobre qualquer barreira. Obrigado pelo seu sorriso inspirador e pela sua dedicação. Amo você!

Agradeço ao meu grande orientador, amigo e professor, Eduardo Marques. Muito obrigado pelas discussões técnicas, pelos seus conselhos, pela sua fé, pela sua atenção e pela sua dedicação. Sem o senhor, não haveria hoje esta página para escrever esses agradecimentos.

Agradeço ao meu amigo-irmão Jean Metz por todo o companherismo, conselhos e por todos esses anos de amizade. Agradeço ao meu grande amigo Leonardo Said pela amizade, pelas conversas e risadas diárias e por toda ajuda que me deu na escrita deste trabalho. Muito obrigado ao meu inestimável irmão Luis Henrique por tantos anos dividindo o mesmo espaço e compartilhando idéias, agradeço muito a sua amizade.

Muito obrigado aos meus amigos do peito: Ademir Zanetti, Fernando Silveira, Marco Miranda, Ricardo Ishibashi, Rodrigo Muraro e Tadeu Pasetto. Vocês fazem os dias de trabalho ficarem mais divertidos, obrigado por todo incentivo e amizade.

Agradeço aos meus amigos de trabalho que me ajudaram muito em discussões técnicas para a realização desse trabalho: Yusef Caceres, Marco Miranda, Daniel Araujo e Marcio Menezes. A ajuda de vocês foi essencial, sou muito grato por tudo.

Agradeço também aos meus amigos do LCR. Erinaldo, obrigado pela força na reta final deste trabalho, pode sempre contar comigo! Gustavo, obrigado pelo cabo, acredite se quiser, a partir dele tudo começou a funcionar! Carlão, sempre disposto a ajudar, muito obrigado pelo incentivo e disposição!

Agradeço à secretaria da pós-graduação do ICMC, muito obrigado por toda a ajuda.

Agradeço a Orbisat pelos dias liberados para as disciplinas e também por disponibilizar a placa que foi utilizada nos experimentos. Muito obrigado! 



\section{Abstract}

Heterogeneous multiprocessor architectures have as main objective the extraction of higher performance from processes through the use of appropriate cores to their demands. However, the extraction of higher performance is dependent on an efficient scheduling mechanism, able to identify in real-time the demands of processes and to designate the most appropriate processor according to their resources. This work aims at design and implementations of a model of a scheduler for heterogeneous multiprocessor architectures based on software and hardware, applied to the Linux operating system and the SPARC Leon3 processor as proof of concept. In this sense, performance monitors have been implemented within the processors, which in real-time identifies the demands of processes. For each process, its demand is projected for the other processors in the architecture and then it is performed a balancing to maximize the total system performance by distributing processes among processors. The Hungarian maximization algorithm, used in balancing scheduler was developed in hardware, providing greater parallelism and performance in the execution of the algorithm. The scheduler has been validated through the parallel execution of several benchmarks, resulting in decreased execution times compared to the scheduler without the heterogeneity support. 


\section{Resumo}

As arquiteturas multiprocessadas heterogêneas têm como objetivo principal a extração de maior desempenho da execução dos processos, por meio da utilização de núcleos apropriados às suas demandas. No entanto, a extração de maior desempenho é dependente de um mecanismo eficiente de escalonamento, capaz de identificar as demandas dos processos em tempo real e, a partir delas, designar o processador mais adequado, de acordo com seus recursos. Este trabalho tem como objetivo propor e implementar o modelo de um escalonador para arquiteturas multiprocessadas heterogêneas, baseado em software e hardware, aplicado ao sistema operacional Linux e ao processador SPARC Leon3, como prova de conceito. Nesse sentido, foram implementados monitores de desempenho dentro dos processadores, os quais identificam as demandas dos processos em tempo real. Para cada processo, sua demanda é projetada para os demais processadores da arquitetura e em seguida é realizado um balanceamento visando maximizar o desempenho total do sistema, distribuindo os processos entre processadores, de modo a diminuir o tempo total de processamento de todos os processos. O algoritmo de maximização Hungarian, utilizado no balanceamento do escalonador, foi desenvolvido em hardware, proporcionando paralelismo e maior desempenho na execução do algoritmo. O escalonador foi validado por meio da execução paralela de diversos benchmarks, resultando na diminuição dos tempos de execução em relação ao escalonador sem suporte à heterogeneidade. 


\section{Sumário}

Lista de Figuras $\ldots \ldots \ldots \ldots$. . . . . . . . . . . . xix

Lista de Tabelas . . . . . . . . . . . . . . . . . xxiii

Lista de Algoritmos . . . . . . . . . . . . . . . . . . xxv

Lista de Abreviaturas . . . . . . . . . . . . . . . . . . . . . xxvii

\begin{tabular}{lll}
\hline Introdução & 1
\end{tabular}

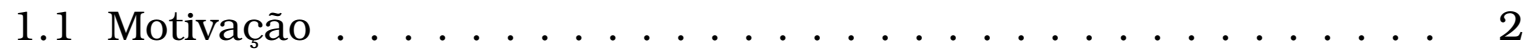

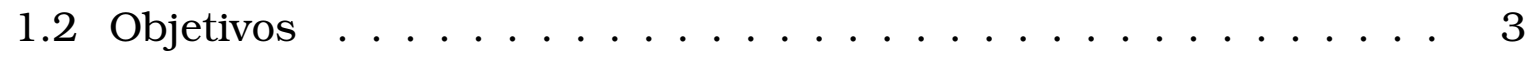

1.3 Organização do documento . . . . . . . . . . . . . . . . 3

2 Multiprocessamento heterogêneo 5

2.1 Fundamentação teórica . . . . . . . . . . . . . . . . . 6

2.1.1 Evolução da arquitetura e do paralelismo do processador . 6

2.1 .2 Multicores heterogêneos . . . . . . . . . . . . 12

2.2 Trabalhos relacionados . . . . . . . . . . . . . . . 15

2.2 .1 Hardware - Modelos de arquitetura . . . . . . . . . . . 15

2.2.2 Software-Organização de sistemas operacionais . . . . . . 21

2.2 .3 Escalonamento e balanceamento de tarefas . . . . . . . . 26

2.2.4 Classificação comparativa dos trabalhos . . . . . . . . . . 36

2.2 .5 Considerações finais . . . . . . . . . . . . . . . . . . . 39

3 Heurística do escalonador 4

3.1 Contexto do modelo . . . . . . . . . . . . . . . 43

3.2 Materiais . . . . . . . . . . . . . . . . . 43

3.3 Motivação . . . . . . . . . . . . . . . . . . . . . . . 43

3.4 Métrica de desempenho . . . . . . . . . . . . . . . . . . 48

3.5 Monitoramento de desempenho . . . . . . . . . . . . 51

3.6 Pesos de desempenho dos processadores . . . . . . . . . . . . 52

3.7 Fluxo dos dados . . . . . . . . . . . . . . . . . 56

3.8 Normalização do histograma de desempenho . . . . . . . . . . . . 59 
3.9 Projeção de desempenho . . . . . . . . . . . . . . . . . 62

3.10Balanceamento . . . . . . . . . . . . . . . 63

3.11 Considerações finais . . . . . . . . . . . . . . . . 65

\begin{tabular}{|lll}
\hline & Co-projeto do escalonador & 67
\end{tabular}

4.1 Modelagem do co-projeto da arquitetura . . . . . . . . . . 67

4.2 Contexto . . . . . . . . . . . . . . . . . . . . . . . 68

4.3 Visão Geral . . . . . . . . . . . . . . . . . . . . . 68

4.4 Monitoramento de desempenho . . . . . . . . . . 70

4.5 Pesos de desempenho dos processadores. . . . . . . . . . 74

4.6 Normalização e projeção de desempenho . . . . . . . . . . . . . . 75

4.7 Balanceamento . . . . . . . . . . . . . . . . . . 77

4.8 Interface com o software . . . . . . . . . . . . . . . . 78

4.9 Suporte do sistema operacional ao escalonamento heterogêneo * 79

4.10 Considerações finais . . . . . . . . . . . . . . 86

5 Implementação do módulo do escalonador 87

5.1 Ambiente $\ldots \ldots \ldots \ldots \ldots$. . . . . . . . . . 88

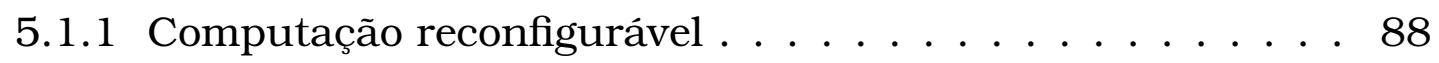

5.1 .2 Processador SPARC-V8 Leon3 . . . . . . . . . . . . . 89

5.1 .3 Build-root-Linux $2.6 .32 \ldots \ldots$. . . . . . . . . . 91

5.1 .4 Escalonador do Linux (a partir da versão 2.6.23) . . . . . . 91

5.1 .5 Plataforma utilizada . . . . . . . . . . . . . . . 93

5.2 Implementação em hardware . . . . . . . . . . . . . . 93

5.3 Implementação em software . . . . . . . . . . . . . . . . . . 104

5.4 Considerações finais . . . . . . . . . . . . . . . . . . . . 112

6 Resultados 113

6.1 Benchmarks. . . . . . . . . . . . . . . . . . . . . . . . . 114

6.2 Modo de execução . . . . . . . . . . . . . . . . . . . . . . 115

6.3 Configurações das arquiteturas $\ldots \ldots \ldots \ldots \ldots$

6.4 Resultados da heurística . . . . . . . . . . . . . . . . . . . . 119

6.5 Resultados para o algoritmo Hungarian em software e em hardware 131

6.6 Resultados do balanceamento . . . . . . . . . . . . . . . . 133

6.7 Resultados das migrações . . . . . . . . . . . . . . . . 135

6.8 Recursos de hardware e consumo de energia . . . . . . . . . . . 135

6.9 Considerações finais . . . . . . . . . . . . . . . . . . . . 136

$\begin{array}{lll}7 \text { Conclusões } & 137\end{array}$

7.1 Contribuições . . . . . . . . . . . . . . . . . . . . . 138

7.2 Trabalhos futuros . . . . . . . . . . . . . . . . . . . . 139 


\section{Lista de Figuras}

2.1 Pipeline com execução ideal |Stallings, 2010] . . . . . . . . . . 7

2.2 Pipeline com stalls relacionados a desvios [Stallings, [2010]] . . . . 8

2.3 Divisão das unidades funcionais em pipeline (Hennessy \& Patterson[2011] . . . . . . . . . . . . . . . . 10

2.4 Tamanhos relativos dos núcleos Alpha $(0.10 \mu \mathrm{m})$ (Kumar et al.,

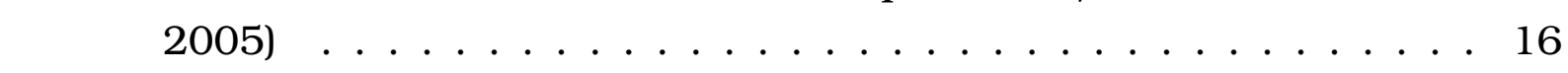

2.5 Comparação em área e throughput de processamento das arqui-

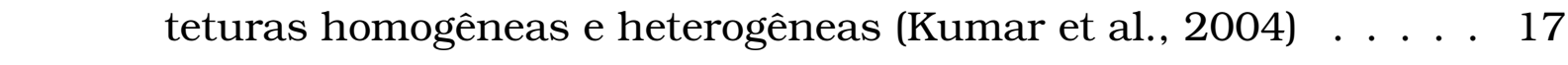

2.6 Arquiteturas de SW/HW para multiprocessadores heterogêneos /Shen \& Pétrot [2009] . . . . . . . . . . . . . . . . . . 18

2.7 Compartilhamento do mesmo conjunto de instruções por todas as unidades de processamento [Shen \& Pétrot, 2009]] . . . . . . 18

2.8 Organização da arquitetura big.LITTLE Processing (ARM, 2011)] . 19

2.9 Arquitetura EXOCHI (Wang et al. [2007) . . . . . . . . . . . 22

2.10 Modelo Multikernel (Baumann et al.,[2009] . . . . . . . . . . . 23

2.11 Benefício da heterogeneidade (escalonamento estático) (Kumar et al. [2004] . . . . . . . . . . . . . . . . . 26

2.12 Exemplo de balanceamento do algoritmo AMPs (Li et al.[2007)] . 30

2.13 Estimativa do impacto no desempenho (Van Craeynest et al., 2012] 31

2.14 Decomposição do CPI em stalls internos e externos (Koufaty et al.,

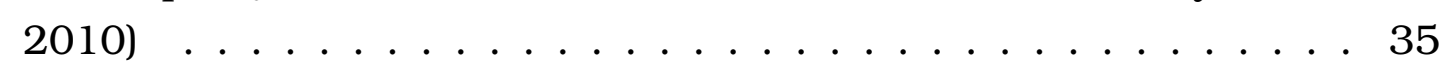

2.15Componentes do escalonador CAMP (Saez et al., 2012] . . . . . 36

3.1 Comportamento do benchmark Dhrystone . . . . . . . . . . . . 45

3.2 Comportamento do benchmark Inversão de Matriz 50x50 . . . . . 45

3.3 Comportamento do benchmark Whetstone . . . . . . . . . . . . 46

3.4 Comportamento do benchmark FBench em CPUO e CPU1 . . . . . 47

3.5 Monitor de desempenho . . . . . . . . . . . . . . . . 52 
3.6 Histograma do comportamento dos benchmarks no timestamp

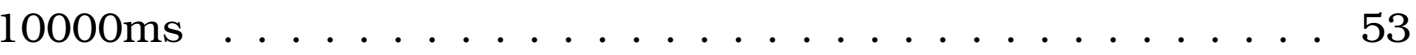

3.7 Exemplo do vetor de pesos de desempenho para CPUO e CPU1 . . 54

3.8 Histograma do comportamento do FBench no timestamp 10000ms para CPU0 e CPU1 . . . . . . . . . . . . . . . . 56

3.9 Vetor de percentagem de cada componente sobre o total de stall

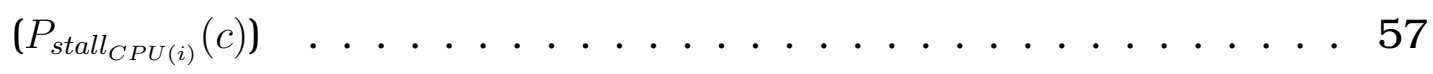

3.10Vetor de pesos de desempenho calculado para cada processador

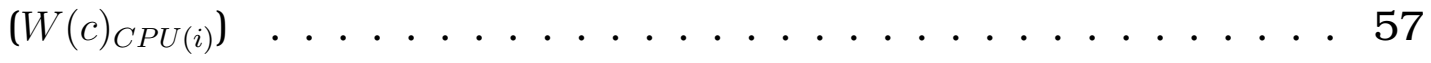

3.11 Fluxograma da heurística $\ldots \ldots \ldots \ldots \ldots$

3.12 Histograma do comportamento do FBench no timestamp 10000ms para CPU0 e CPU1 (ciclos) . . . . . . . . . . . . . . . . . 60

3.13 Normalização do FBench executando sobre os dois processadores CPUO e CPU1 (ciclos) . . . . . . . . . . . . . . . . . . . . 61

3.14 Normalização do FBench executando sobre os dois processadores CPU0 e CPU1 (\%) . . . . . . . . . . . . . . . 61

4.1 Organização dos blocos . . . . . . . . . . . . . . . . . . . . 69

4.2 Comunicação entre os componentes de monitoramento e projeção de desempenho . . . . . . . . . . . . 70

4.3 Interfaces do monitor de desempenho . . . . . . . . . . 71

4.4 Diagrama da forma de onda de um exemplo de interação com D-TLB e D-CACHE . . . . . . . . . . . . . . . . . 73

4.5 Diagrama da forma de onda do monitoramento de instruções de

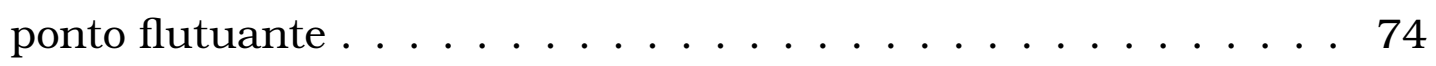

4.6 Organização dos blocos de escalonamento em $\mathrm{HW} \ldots \ldots . . .76$

4.7 Serialização dos dados $\ldots \ldots \ldots \ldots \ldots \ldots$

4.8 Algoritmo Hungarian-Balanceamento em HW . . . . . . . . 77

4.9 Fluxograma da implementação do suporte a escalonador heterogêneo no sistema operacional $\ldots \ldots \ldots \ldots \ldots$. . . . . . 84

5.1 Processador, barramento e componentes da GRLIB (Gaisler, 2013) .......................... 90

5.2 Organização utilizando árvore vermelha e preta (IBM] $[2013 \mathrm{a})]$. . 92

5.3 Placa Xilinx ML507 utilizada para implementação . . . . . . . . . 94

5.4 Comunicação pela interface AMBA AXI Stream . . . . . . . . . . 95

5.5 Diagrama da forma de onda de um exemplo de comunicação utilizando o protocolo AXI Stream . . . . . . . . . . . . . 996

5.6 Processador SPARC V8 - Leon 3 (Gaisler [2013] . . . . . . . . . . 97

5.7 Forma de onda do exemplo de comportamento do monitor de de-

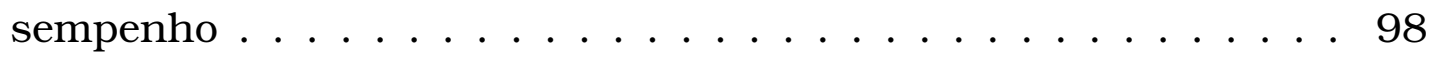


5.8 Componentes da normalização e projeção de desempenho .. . 99

5.9 Blocos em VHDL do algoritmo Hungarian . . . . . . . . . 100

5.10 Suporte a escalonamento heterogêneo no kernel . . . . . . . . . 105

5.11 Alterações realizadas na estrutura que contém os dados dos processos . . . . . . . . . . . . . . . . . 106

5.12 Sequência das chamadas de inicio e final de monitoramento . . . 108

5.13 Designação dos processos aos processadores . . . . . . . . . 110

6.1 Resultados para a Arquitetura 1. . . . . . . . . . . . . . . 123

6.2 Resultados para a Arquitetura 2 . . . . . . . . . . . . . . 125

6.3 Resultados para a Arquitetura 3 . . . . . . . . . . . . . . . . 125

6.4 Resultados para a Arquitetura 4 . . . . . . . . . . . . . . . . 126

6.5 Resultados para todas as arquiteturas . . . . . . . . . . . . . 127

6.6 Resultados para a Arquitetura 1 (sem cache-hot check) . . . . . . 128

6.7 Resultados para a Arquitetura 2 (sem cache-hot check) . . . . . . 129

6.8 Resultados para a Arquitetura 3 (sem cache-hot check) . . . . . . 129

6.9 Resultados para a Arquitetura 4 (sem cache-hot check) . . . . . 131

6.10Resultados para todas as arquiteturas (sem cache-hot check) . . 131

6.11 Resultados para a execução do algoritmo Hungarian em software e em hardware . . . . . . . . . . . . . . . . . . . . . . . 132

6.12 Resultado do escalonamento utilizando balanceamento (algoritmo Hungarian $\ldots \ldots \ldots \ldots \ldots \ldots$. . . . . . . . . . . . . . . . . . . 
Xxii 


\section{Lista de Tabelas}

2.1 Demonstração de consumo e desempenho dos núcleos Alpha . 16

2.2 Demonstração de consumo e desempenho dos Cortex-A15 e CortexA7 (ARM $[2011] \ldots \ldots \ldots \ldots \ldots$

2.3 Comparativo entre os principais algoritmos de escalonamento (Arquitetura) . . . . . . . . . . . . . . . . 37

2.4 Comparativo entre os principais algoritmos de escalonamento (Sistema operacional) . . . . . . . . . . . . . . . 38

2.5 Comparativo entre os principais algoritmos de escalonamento

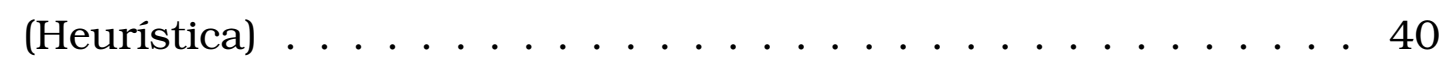

3.1 Configurações para CPU0 e CPU1 . . . . . . . . . . . . . . 44

4.1 Tabela de pesos a ser carregada em memória interna do bloco de escalonamento em hardware. . . . . . . . . . . . . . . . . 74

4.2 Principais registradores utilizados na interface com o software. . 80

5.1 Itens descritos no co-projeto do escalonador. . . . . . . . . . 88

6.1 Configurações da Arquitetura $1 \ldots \ldots \ldots$

6.2 Configurações da Arquitetura $2 \ldots \ldots \ldots \ldots$

6.3 Configurações da Arquitetura $3 \ldots \ldots$. . . . . . . . . . . . . . . . . . 118

6.4 Configurações da Arquitetura 4 . . . . . . . . . . . . . . 119

6.5 Estatísticas para Arquitetura 1 (tempos em $\mathrm{ms}$ ) . . . . . . . . . 121

6.6 Estatísticas para Arquitetura 2 (tempos em $\mathrm{ms}$ ) $\ldots . . . . . . . .123$

6.7 Estatísticas para Arquitetura 3 (tempos em $\mathrm{ms}$ ) $\ldots . . . . . . . .124$

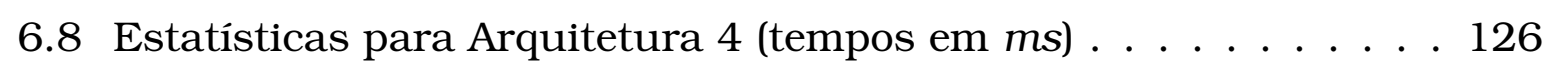

6.9 Estatísticas para Arquitetura 1 sem verificação de cache-hot (tem-

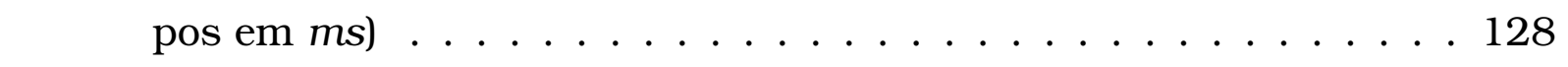

6.10Estatísticas para Arquitetura 2 sem verificação de cache-hot (tempos em $m s) \ldots \ldots \ldots \ldots \ldots \ldots \ldots$ 
6.11 Estatísticas para Arquitetura 3 sem verificação de cache-hot (tem-

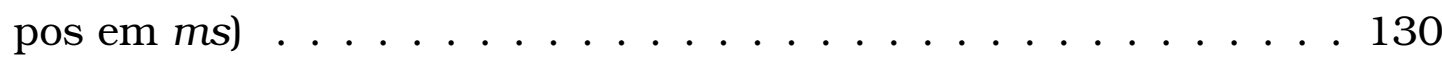

6.12 Estatísticas para Arquitetura 4 sem verificação de cache-hot (tempos em ms $] \ldots \ldots \ldots \ldots \ldots$. . . . . . . . . . . . 130

6.13Estatísticas da execução do algoritmo Hungarian (tempos em us) 132

6.14 Utilização de recursos de hardware . . . . . . . . . . . . . . . 135 


\section{Lista de Algoritmos}

3.1 Algoritmo Hungarian . . . . . . . . . . . . . . . . . . 64 
xxvi 


\section{Lista de Abreviaturas}

ASI Address Space Identifier

ASIC Application Specific Integrated Circuit

CFS Completely Fair Schedule

CLK clock

CPI Cycles (or Clocks) per Instruction

CPU Central Processing Unit

CPUID CPU Identification

DDR Double Data Rate

DMA Direct Memory Access

DSP Digital Signal Processor

DSU Debug Support Unit

DVFS Dynamic Voltage Frequency Scaling

EDF Earliest Deadline First

FFT Fast Fourier Transform

FIFO First In First Out

FPGA Field Programable Gate Array

FPU Floating Point Unit

GPL General Public License

GPU Graphics Processing Unit 
HAL Hardware Abstraction Layer

HASS Het.-Aware Signature-Supported

HDS Heterogeneous Dual-Core Scheduling

HT Simultaneous Multithreading

Hw Hardware

ILP Instruction Level Paralelism

MLP Memory Level Paralelism

IO Input Output

IP Intellectual Property

IPC Instructions per Cycle

ISA Instruction Set Architecture

LLC Last Level Cache

LRR Least Recently Replaced

LRU Least Recently Used

LUT Lookup Table

MCU Microcontroler Unit

MIPS Millions of Instructions Per Second

MLP Memory Level Paralelism

MMU Memory Management Unit

MPI Misses Per Instruction

MPU Microprocessor Unit

PC Program Counter

PCPU Physical CPU

PID Process Identification

PIE Performance Impact Estimation

RAM Random Access Memory

SMP Symmetric Multiprocessing 
SMT Simultaneous Multithreading

so Sistema Operacional

SPEC Standard Performance Evaluation Corporation

SRMMU SPARC Reference MMU

SW Software

TLB Translation Lookaside Buffer

TLP Thread Level Paralelism

VHDL VHSIC Hardware Description Language

VHSIC Very High Speed Integrated Circuits 
XXX 


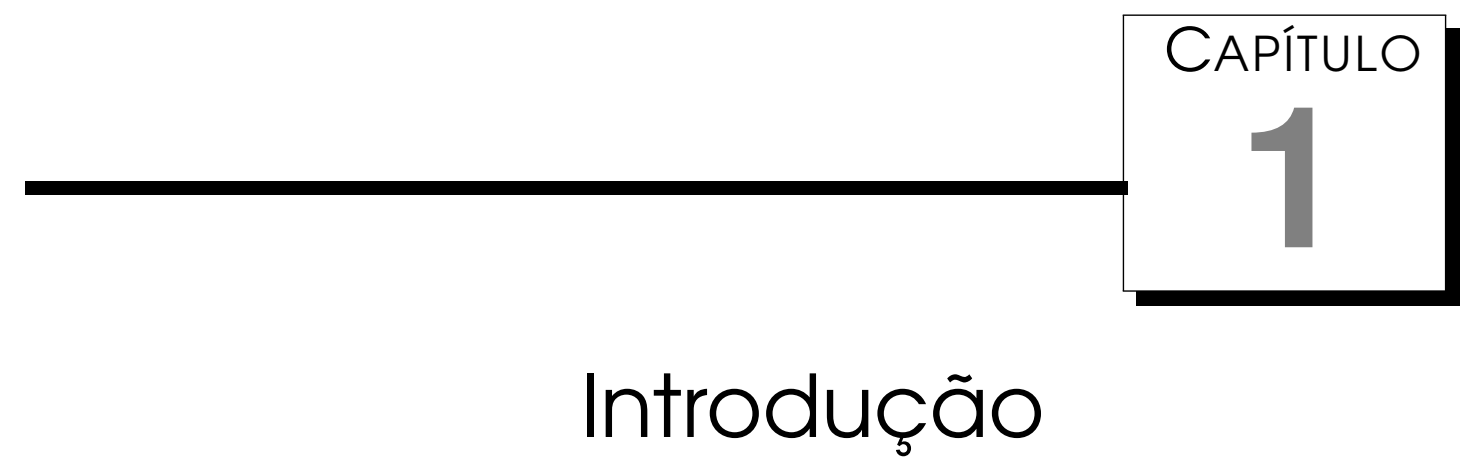

Os processadores tiveram uma grande evolução nos últimos anos, satisfazendo demandas provindas de aplicações que exigem crescente capacidade computacional. Entretanto, o aumento de desempenho por meio da frequência têm exigido esforços para contornar seu principal gargalo, o aumento de consumo de energia. Adicionalmente, o número e a diversidade atual dos processos executando em ambientes corporativos sobre processadores de alto poder computacional, ou mesmo em ambientes embarcados, tendenciam a utilização de replicação de núcleos para a realização mais efetiva da computação requerida. Levando em consideração esses aspectos, pesquisas recentes indicam que a utilização de núcleos heterogêneos em um processador pode diminuir o consumo de energia, como também pode extrair maior desempenho da diversidade dos processos e de suas fases de execução (Petrucci et al., 2012b) (Chen et al., 2013).

Um processador multi-core heterogêneo consiste em um chip contendo um grupo de processadores distintos entre si. Essa distinção pode consistir em uma simples diferença de frenquência entre eles, como também, em diferenças arquiteturais maiores envolvendo até conjuntos de instruções assimétricos.

Em virtude dessa diferença entre arquiteturas, cada processador pode oferecer um desempenho diferente para um mesmo processo executando sobre eles. Com isso, sistemas operacionais modernos que não implementam em seus escalonadores as heurísticas para tratar essa diferença, distribuem os processos entre os processadores como se todos fossem iguais. Consequentemente, processos que poderiam ganhar mais desempenho executando em determinados processadores deixam de ter esses ganhos, fazendo com que o sistema deixe de aproveitar os benefícios da heterogeneidade. 
A associação de processos a processadores que lhes ofereçam maior desempenho, necessita levar em consideração o comportamento do processo ao longo de sua execução, bem como as características de cada arquitetura dos processadores.

Diversas pesquisas atuais, devido à complexidade dessa associação, têm indicado métodos de associação estática entre processos e processadores A associação estática consiste em designar cada processo para o processador que lhe ofereça melhor desempenho, antes que os mesmos sejam executados. No entanto, em ambientes genéricos com uma atividade intensa de execuções de processos distintos, essa abordagem não é aplicável.

Neste trabalho é apresentado um modelo para realizar esse escalonamento em tempo real para qualquer processo em execução. O modelo proposto realiza as migrações dos processos para os processadores cujos recursos lhe ofereçam maior desempenho, sem a necessidade de haver um conhecimento prévio do comportamento dos processos.

A seguir são descritos a motivação, os objetivos e as contribuições deste trabalho. Por fim, são apresentadas a organização e a estrutura dos capítulos.

\subsection{Motivação}

Todas as aplicações possuem demandas particulares de recursos. Essas demandas podem variar entre as aplicações ou mesmo podem variar durante o próprio período de execução de cada uma delas. Enquanto algumas aplicações fazem uma melhor utilização de processadores mais rápidos, como aplicações que realizam muitas operações de ponto flutuante, outras podem se beneficiar de processadores com menor capacidade computacional, como aplicações que realizam muitas interações com dispositivos externos.

Em uma arquitetura contendo diferentes tipos de processadores, uma de suas principais vantagens é a possibilidade de explorar as demandas de recursos exigidos pelas aplicações ou pelas suas fases. Desse modo, com um mecanismo eficiente de escalonamento, uma aplicação, que em um determinado período de sua execução exigir maior demanda em execução de operações de ponto flutuante, pode ser migrada para o processador que possua maior desempenho nessas operações. Consequentemente, seu tempo de execução será menor, deixando o sistema com menor carga computacional para executar mais rapidamente as demais aplicações.

Nesse sentido, com a diminuição da carga do sistema, esse desempenho atingido por meio da exploração da heterogeneidade, também pode trazer outro ganho, a diminuição no consumo de energia. 


\subsection{Objetivos}

O objetivo geral deste trabalho consiste em propor a arquitetura de um escalonador, particionado em hardware e software, que monitore todos os processos em execução, identificando suas principais demandas. A partir delas, o escalonador deve realizar as designações de processadores para cada processo, levando em consideração os recursos de cada processador. A utilização do hardware é primordial em alguns aspectos, tais como o monitoramento das demandas dos processos, pois pela análise dos atrasos dentro do processador é possível saber com maior precisão quais os recursos que estão sendo mais necessários. Por outro lado, a implementação em hardware também pode ajudar a aumentar o desempenho de algumas tarefas, deixando o processador livre para executar os processos sem sobrecarregá-lo com algoritmos que possam ocupar tempo de processamento.

Para realizar essa tarefa, devem ser considerados os seguintes objetivos específicos:

- Estudar as principais organizações das arquiteturas multi-core heterogêneas;

- Identificar, por meio de revisão bibliográfica, as principais heurísticas utilizadas nos escalonadores existentes;

- Propor uma arquitetura para mensurar as demandas dos processos;

- Propor uma arquitetura para realizar as projeções de desempenho de cada processo para cada processador, de modo a maximizar o desempenho;

- Propor uma arquitetura para realizar o balanceamento dos processos, de modo a distribuir os processos uniformemente entre os processadores, sem causar sobrecargas;

- Propor modificações a serem realizadas no sistema operacional para incorporar o escalonador heterogêneo; e

- Validar a toda arquitetura proposta com a implementação em FPGA.

\subsection{Organização do documento}

\section{Capítulo 2}

Neste capítulo é apresentado a evolução do paralelismo e os principais conceitos e definições relacionados ao projeto. Também é apresentado um estudo sobre: as principais arquiteturas heterogêneas existentes, os 
principais sistemas operacionais desenvolvidos para arquiteturas heterogêneas e os principais escalonadores heterogêneos.

\section{Capitulo 3}

Neste capítulo, é proposta a heurística para o escalonamento heterogêneo.

\section{Capitulo 4}

Neste capítulo é apresentado a arquitetura genérica do escalonador, particionado em hardware e software.

\section{Capitulo 5}

Neste capítulo são apresentados os principais detalhes da implementação do escalonador.

\section{Capitulo 6}

Neste capítulo são apresentados os resultados obtidos na avaliação experimental da arquitetura com diversos benchmarks.

\section{Capitulo 7}

São apresentadas as conclusões do projeto e direcionamentos para trabalhos futuros. 


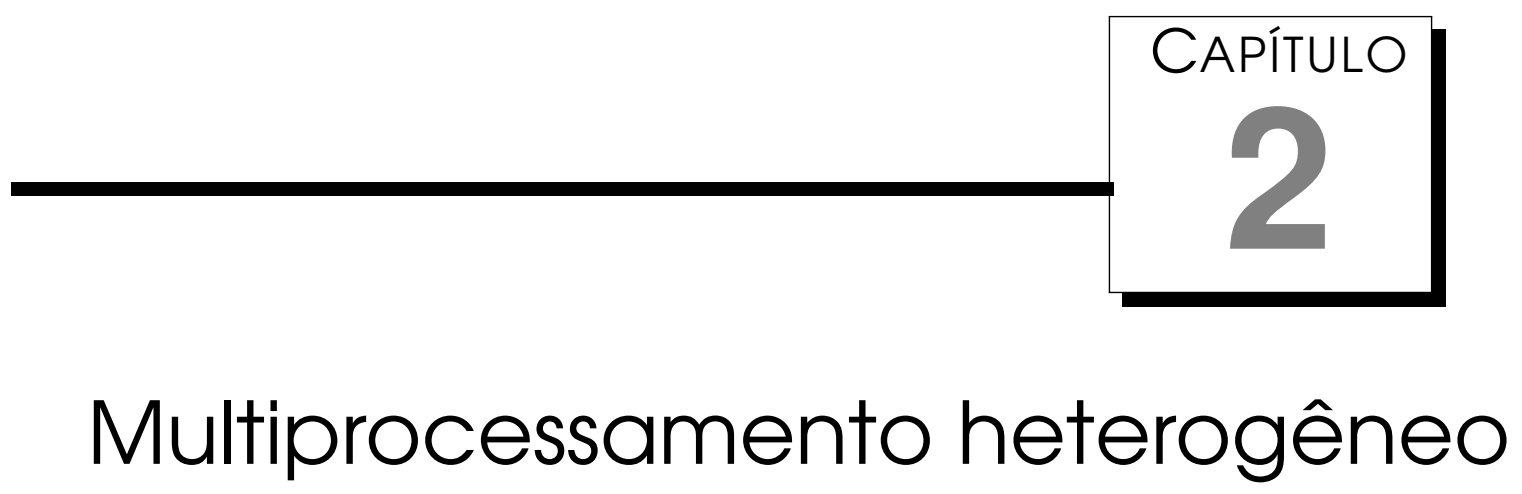

Existe uma tendência na área de arquitetura de processadores em explorar o paralelismo na execução de tarefas (Borkar \& Chien, 2011). Atualmente, com a heterogeneidade dos núcleos, uma associação eficiente de tarefas resulta em um maior desempenho para cada tarefa, como também, um maior throughput para o sistema. Quando se fala em desempenho de processadores, o consumo de energia é um assunto altamente relevante e preocupante. Um dos cenários onde esse fator mais preocupa é o de sistemas embarcados, o qual tem exigido cada vez mais desempenho computacional e menor consumo de energia. Por essa razão, a arquitetura multi-core heterogênea tem ocupado o foco dos principais fabricantes de processadores. Nesse contexto, algumas arquiteturas têm sido desenvolvidas para maximizar o desempenho e diminuir o consumo de energia. No entanto, é necessário que haja um mecanismo eficiente de distribuição de tarefas para alcançar o desempenho requerido. Além disso, existem diversas preocupações no âmbito da transparência relacionada ao sistema operacional e ao software de alto nível.

Nesse contexto, são apresentados neste capítulo os principais conceitos relacionados à evolução do paralelismo em hardware e software correlatos a este trabalho, como também são apresentadas as principais arquiteturas existentes que utilizam núcleos heterogêneos. Em seguida, são descritas algumas soluções que caracterizam a heterogeneidade de modo transparente para software de alto nível. Por fim, neste capítulo são apresentadas as principais propostas para solucionar problemas de escalonamento, inerentes à associação de tarefas aos diferentes núcleos do processador. 


\subsection{Fundamentação teórica}

O aumento do desempenho de sistemas computacionais tem sido o foco de pesquisas intensas por vários anos. Inicialmente, com caráter científico e industrial, diversas arquiteturas de hardware foram propostas e implementadas (Borkar \& Chien, 2011).

Os processadores, principais exemplos dessa evolução, têm seus componentes cada vez menores em área física. Porém, seu número de transistores tem crescido, oferecendo mais recursos e frequências elevadas.

Do mesmo modo, a otimização do paralelismo na execução de instruções tem um papel importante, a qual, aliada ao aumento de recursos e velocidade, oferece maior poder computacional e diminui o gargalo de uma única unidade de processamento.

Atualmente, devido às barreiras físicas enfrentadas no aumento da frequência dos processadores, a otimização do paralelismo tem se tornado o foco principal das pesquisas. Contudo, essa evolução paralela não atinge somente o hardware. Com exemplos que vão desde compiladores que reordenam e retiram dependências de instruções para extração máxima de paralelismo de código, sistemas operacionais modernos com escalonadores que balanceiam a carga de processamento em arquiteturas multiprocessadas, até sistemas distribuídos que oferecem alto poder de processamento e transparência, é demonstrado que a evolução do software não ficou para trás. Nesse contexto, são apresentados nesta seção os principais conceitos relacionados à evolução do paralelismo em hardware e software correlatos a este trabalho.

\subsubsection{Evolução da arquitetura e do paralelismo do processador}

O ganho de desempenho dos processadores tem aumentado em mais de 1000 vezes nos últimos 20 anos (Borkar \& Chien, 2011). Entretanto, esse crescimento não foi atingido somente pelo aumento da velocidade de transistores. Muitas pequenas mudanças na arquitetura do processador, realizadas ao longo do tempo, demonstraram que o ganho ciclo a ciclo na execução de instruções pode representar muito em relação ao desempenho, tanto quanto o aumento da frequência (Flynn, 1995).

A introdução do pipeline de execução foi uma das primeiras mudanças arquiteturais que mais trouxeram ganhos de desempenho e que também motivou diversas outras. Seu funcionamento consiste em utilizar múltiplos estágios para a execução de cada instrução, as quais são particionadas de modo que em cada estágio do pipeline, uma pequena parte da instrução é executada. Os estágios mais utilizados na divisão do pipeline são:

- Busca da instrução: Leitura da próxima instrução a ser executada; 
- Decodificação da instrução: O opcode é extraído da instrução e, de acordo com ele, o restante dos operandos são também decodificados;

- Cálculo de operandos: Cálculo do endereço de cada operando envolvido na instrução. Pode envolver endereçamento indireto por deslocamento de registrador, cálculo de endereço físico de dado presente na memória, entre diversos outros dependendo da arquitetura do processador;

- Busca de operandos: Os dados referenciados pelos endereços dos operandos calculados no passo anterior são buscados. Pode envolver um simples registrador ou um dado externo ao processador, como memória ou disposivos diversos;

- Execução da instrução: A partir dos dados amostrados e a instrução decodificada, o processador pode realizar as operações necessárias requeridas pela instrução. Nesse passo a instrução é efetivamente executada; e

- Escrita de operandos: Os resultados obtidos são escritos em registradores ou posições da memória.

Desse modo, idealmente, o processador tem a possibilidade de executar uma instrução por ciclo, assim como é ilustrado na Figura 2.1;

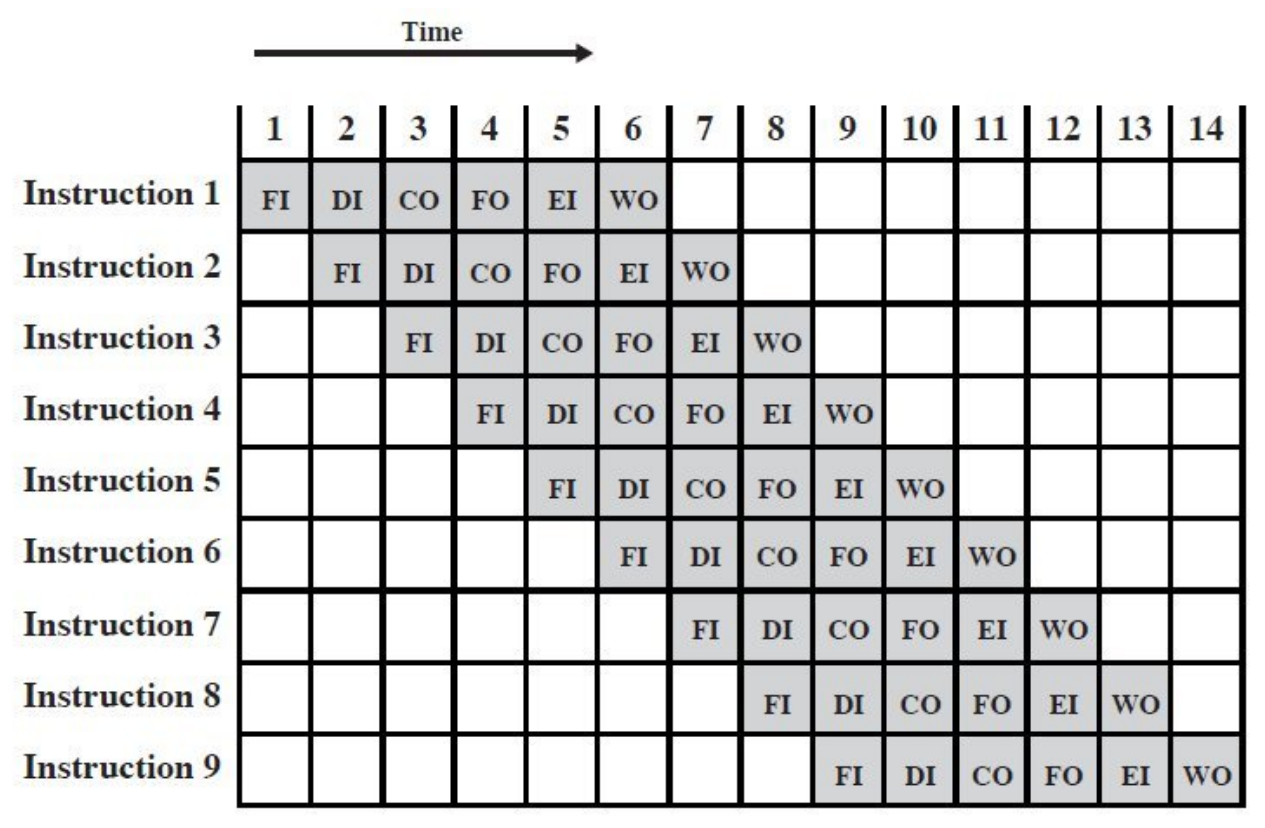

Figura 2.1: Pipeline com execução ideal (Stallings, 2010)

De fato, essa organização pode trazer aumento de desempenho, já que a utilização do pipeline paraleliza diversas funções do processador que antes eram executadas sequencialmente. Por outro lado, na prática, os programas não têm uma execução preditiva, não possuem suas instruções armazenadas 
dentro processador, não necessariamente têm seus endereços calculados em um único ciclo, normalmente também não têm seus dados acessíveis a um ciclo de relógio (tanto para leitura como para escrita) e, por vezes não são capazes de executar as instruções em um único ciclo.

Esses itens citados afetam o desempenho do pipeline fazendo que, na maioria dos casos, a execução de todos os estágios seja parada durante a quantidade de ciclos necessária para resolver o problema em questão. Os ciclos de atraso do pipeline que ocorrem durante a execução de um programa são conhecidos como stalls e, quase sempre, estão relacionados ao acesso a algum tipo de recurso da arquitetura.

Os stalls ocorrem em quase todos os estágios do pipeline e estão ligados a diferentes aspectos.

Um tipo de stall que ocorre com muita frequência é o despendimento de ciclos na execução de algum tipo de instrução de desvio. De acordo com o funcionamento normal do pipeline, as instruções são buscadas sequencialmente e, do mesmo modo, vão ocupando cada estágio do pipeline. Normalmente, quando uma instrução de desvio entra no pipeline, o processador somente sabe se o desvio realmente será tomado quando a instrução chega ao estágio de execução. Assim, caso o desvio ocorra, todas as instruções contidas nos estágios anteriores ao estágio de execução têm possibilidade de estarem inválidas e, consequentemente, ignorada para execução no processador, pois novas instruções devem ser carregadas para a execução. A Figura 2.2 ilustra esse comportamento, demonstrando o modo como a invalidação dos estágios do pipeline ocorre.

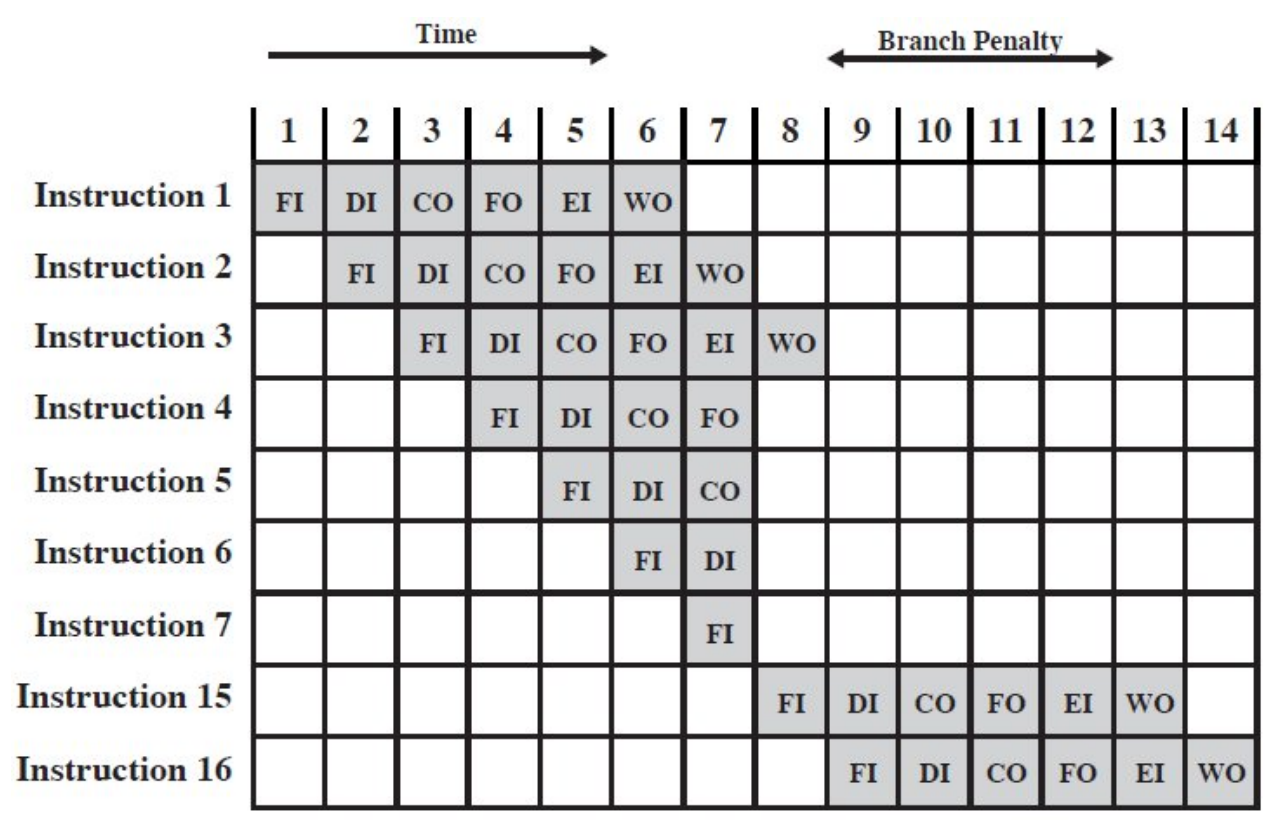

Figura 2.2: Pipeline com stalls relacionados a desvios (Stallings, 2010)

Para tentar diminuir os ciclos gastos com essas instruções, diversas téc- 
nicas têm sido utilizadas, entre as quais podem ser citadas: utilização de múltiplos estágios iniciais, busca antecipada de instruções, desvio atrasado e previsão de saltos, a qual envolve a implementação de diferentes políticas no pipeline do processador.

Outros frequentes stalls que ocorrem estão relacionados com o acesso à memória. A memória normalmente possui uma frenquência de operação menor que o processador, do mesmo modo que o barramento no qual está ligada. Esse fato aliado ao acesso concorrente da memória por DMAs ou outros dispositivos mestres do sistema, pode levar o processador a esperar alguns ciclos até que sua requisição de leitura ou escrita seja atendida. Para diminuir esses ciclos de espera, foram introduzidas as caches de instruções e de dados. As caches ficam localizadas dentro do processador, podem ter diversos níveis e armazenam temporiariamente os dados e instruções procedentes da memória. Seu tempo de acesso é menor que o acesso direto à memória e existem diferentes organizações de como os seus dados devem estar dispostos. Além disso, também existe o conceito de política de substituição, a qual determina quais dados devem ser substituídos por novos dados requeridos. No entanto, apesar de o acesso aos dados e instruções da cache, no nível mais baixo, poderem ser acessados em um único ciclo, o processador ainda não está livre de stalls com o acesso a esses dados.

O tamanho da cache é pequeno em relação à memoria principal e dependendo da quantidade de programas em execução, da quantidade de dados acessados, do tamanho dos programas, dos tipos de saltos executados e do tipo de acesso aos dados, a memória cache pode não suportar o armazenamento temporário de tantos dados e instruções, promovendo a ocorrência de faltas na cache (cache misses). As faltas ocorrem quando os dados requeridos não se encontram na cache, sendo necessário buscá-los na memória principal, gastando ciclos extras para isso.

Os stalls relacionados ao acesso à memória se aplicam a vários estágios do pipeline, apesar de influenciar todos. Dentro do contexto do exemplo citado, os estágios afetados diretamente são: busca de instrução, busca de operandos e escrita de operandos. No entanto, o stall relacionado a acesso a dados não é somente proveniente do acesso aos dados referenciados pelos endereços calculados para instruções e dados. Em arquiteturas que implementam o conceito de memória virtual, a própria tradução de endereço, presente no estágio de cálculo de operandos, pode ser um consumidor de ciclos do pipeline. O componente responsável por realizar a tradução consiste no MMU (Memory Management Unit), que conta com uma cache, conhecida como TLB (Translation Lookaside Buffer), que armazena as entradas de páginas mais recentemente utilizadas (também podem existir outros algoritmos de substituição de 
entradas do TLB). O armazenamento das entradas de páginas virtuais para a tradução rápida em endereço físico ajuda a diminuir os stalls relacionados à tradução de endereços, mas não está livre de também despender ciclos para calcular os endereços requeridos que não se encontram no TLB.

O estágio de execução do pipeline também não está livre do consumo de mais de um ciclo por instrução. Isso se deve ao fato de que o processador não é capaz de executar todas as instruções em um único cicld! Instruções de multiplicação, divisão e ponto flutuante são alguns exemplos de operações que podem afetar o desempenho do pipeline fazendo com que, em muitos casos, a execução de todos os estágios seja parada. Com o objetivo de diminuir a quantidade de stalls nesse estágio, coprocessadores, FPUs (Float Point Unit) e demais unidades funcionais que executam, de fato, essas instruções, também implementam um pipeline interno específico, distribuindo e paralelizando o estágio de execução. A Figura 2.3 ilustra um pipeline com 5 estágios, cujo estado de execução possui diversos outros estágios distribuídos entre as unidades funcionais.

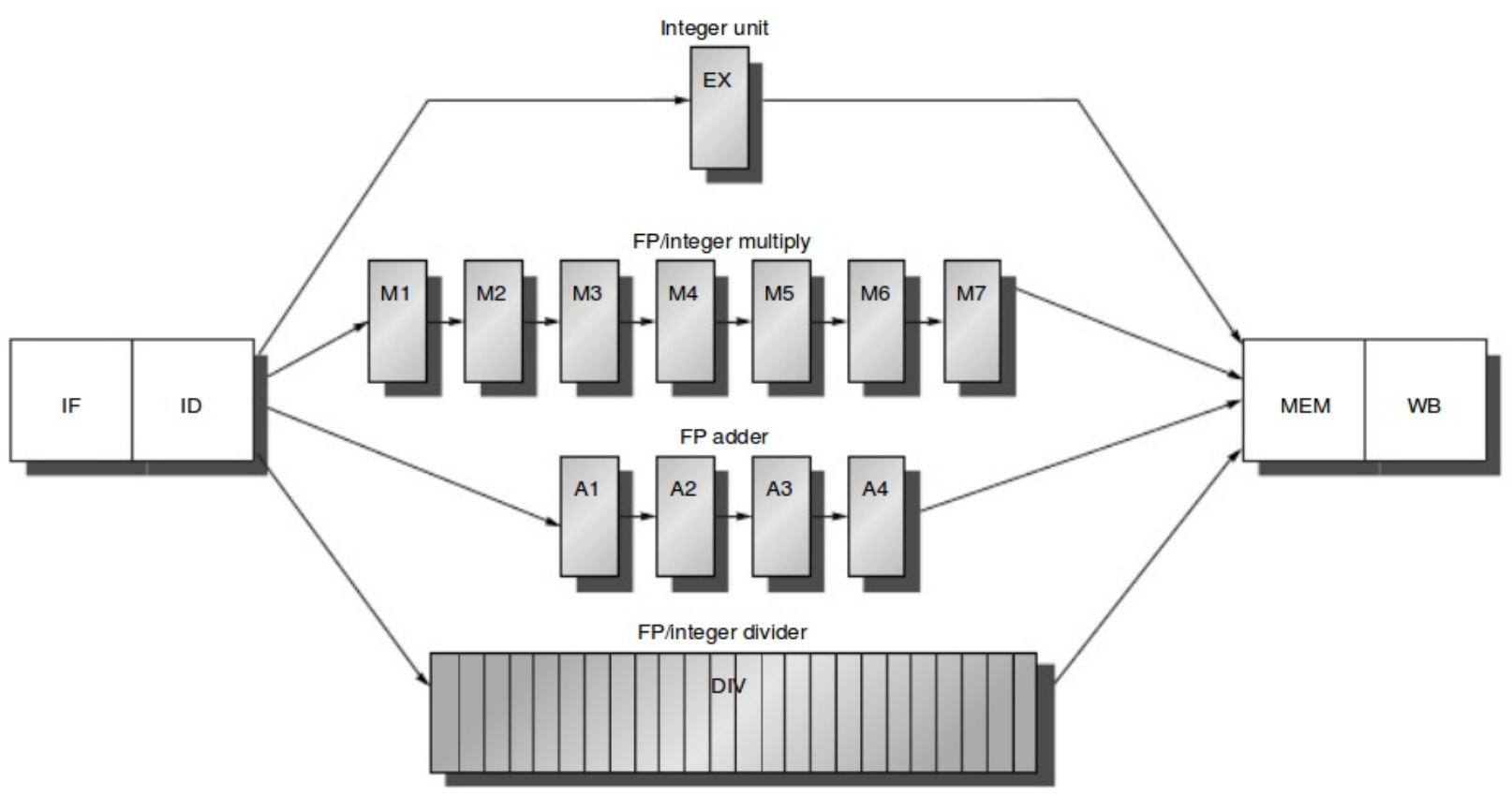

Figura 2.3: Divisão das unidades funcionais em pipeline (Hennessy \& Patterson, 2011)

Assim como mencionado, a maioria dos stalls está relacionada a algum componente, interno ou externo ao processador. Por meio da otimização desses componentes é possível economizar muitos ciclos na execução de um programa. No entanto, não é somente a otimização do hardware que influencia

\footnotetext{
${ }^{1} \mathrm{O}$ aumento de desempenho na execução de instruções está diretamente relacionado ao aumento de recursos lógicos do chip. Em muitos casos, o desempenho alcançado pode não compensar a quantidade de recursos adicionas e, de modo semelhante, pode também não compensar o aumento de consumo de energia resultante desse processo.
} 
positivamente no desempenho. A dependência entre instruções consiste em um dos principais gargalos de qualquer arquitetura de pipeline. Considerando que a dependência é resultado da disposição das instruções entre si, conclui-se que a variação da sequência e da organização delas, de modo que o programa tenha o mesmo resultado, pode influenciar positiva ou negativamente no desempenho da execução. Em virtude disso, muitos compiladores tentam minimizar essa dependência reorganizando a sequência de instruções para obter melhor desempenho por meio da quebra de dependência direta entre instruções sequenciais. Essa abordagem utiliza o tempo gasto com o processamento de uma instrução para executar uma posterior, que não tenha dependência do resultado da anterior. Assim, os ciclos do pipeline são melhor aproveitados, paralelizando a execução (Anderson et al., 1997).

O procedimento de reorganizar instruções, de modo a sofrer menor influência de dependências entre elas, está dentro da área de estudo sobre o paralelismo em nível de instruções, também conhecido como ILP (Instruction-Level Parallelism). Nessa área, não são somente os compiladores que colaboram em retirar dependências. O hardware, por meio da utilização de arquiteturas superescalares, possui uma alta capacidade de executar instruções independentemente por meio da identificação de dependência entre elas. Os processadores superescalares possuem múltiplos e independentes pipelines, onde cada pipeline possui vários estágios, possibilitando múltiplos fluxos de instruções. Assim, diversas instruções são buscadas e podem ser executadas simultaneamente, aproveitando os possíveis stalls referentes às dependências, muitos dos quais retirados por meio de diversas técnicas, como a execução fora de ordem e a renomeação de registradores (Stallings, 2010).

Apesar do aumento de desempenho alcançado com a utilização de técnicas de ILP nas arquiteturas de processadores, a exploração do paralelismo de instruções não é simples de ser alcançada em sua totalidade (Hennessy \& Patterson, 2011). Adicionalmente, o avanço em técnicas de ILP depende de alta utilização lógica dedicada, ocasionando o aumento de transistores e consequentemente o aumento de consumo de energia (Bower et al., 2008). Considerando esses fatos, a arquitetura dos processadores avançou para a exploração de um nível mais alto de paralelismo, o paralelismo em nível de threads (TLP - Thread-Level Parallelism). Nesse sentido, a primeira arquitetura promissora que obteve um bom aproveitamento nesse nível de paralismo foi o SMT $2^{2}$ (Simultaneous Multithreading). O SMT consiste na emissão simultânea de diversas instruções, as quais podem ser provenientes de diferentes threads. Nessa arquitetura, mais instruções estão simultaneamente no pipeline, em comparação com as arquiteturas apresentadas previamente, sendo que

\footnotetext{
${ }^{2}$ Simultaneous Multithreading: Tecnologia também conhecida como HyperThreading (HT) nos processadores Intel.
} 
além da emissão múltipla de instruções, essa arquitetura também aproveita o nível de paralelismo alcançado com o ILP. Consequentemente, o SMT tem a vantagem de melhorar o throughput do sistema por meio da exploração de threads com alto nível de paralelismo. Contudo, essa tecnologia ainda possui a desvantagem da competição por recursos no processador. Isso ocorre devido ao fato de que diferentes threads estão compartilhando recursos tais como as unidades funcionais, TLBs e caches. Como um exemplo de problemas de acesso concorrente, pode ser citado o caso em que alguma falta ocorre na cache, consequentemente, o dado deve ser buscado na memória, podendo ocasionar stalls em todas as threads que também estão dependendo de dados.

Como solução para esses problemas um novo conceito arquitetural foi introduzido: o processador multi-core (Hill \& Marty, 2008). Ao invés das threads compartilharem recursos em um único núcleo de processamento, a tecnologia multi-core possibilita que dois ou mais núcleos idênticos, cada um com seu conjunto de recursos, coexistam em um mesmo chip, fazendo com que as threads possam executar compartilhando menor quantidade de recursos e, evidentemente, alcançar um maior throughput de execução (Bueno, 2007). Essa organização permite um nível superior de paralelismo em relação às arquiteturas previamente apresentadas, que pode ser ainda maior por meio da implementação do SMT em cada um dos núcleos (Akhter \& Roberts, 2006). Com isso, a tecnologia multi-core levou a indústria de processadores a uma das maiores mudanças desde o surgimento da arquitetura 386 de 32 bits (Geer. 2005)

\subsubsection{Multicores heterogêneos}

Conforme mencionado anteriormente, avanços na indústria de semicondutores tornou possivel a integração de vários núcleos em um único chip. Do ponto de vista de desempenho, essa arquitetura oferece o poder de aumentar o throughput de processos que possuem elevada utilização de paralelismo (multithreading) e, consequentemente, pode aumentar também o desempenho do sistema como um todo.

No entanto, a crescente replicação do número de núcleos idênticos, com frequências cada vez mais altas, apesar de trazer maior throughput, ainda não explora a efiência, em sua totalidade, na área de chip ocupada por esses núcleos. O aumento da frequência também traz outro problema, o consumo de energia (Li et al., 2007).

Pesquisas recentes apontam a utilização de arquiteturas com núcleos heterogêneos como uma alternativa para alcançar maior desempenho e menor consumo em relação a núcleos idênticos, ocupando a mesma área de chip (Kumar et al., 2004) (Li et al., 2010) (Petrucci et al., 2012b) (Chen et al., 2013). 
A arquitetura multi-core heterogênea consiste em uma mistura de núcleos que diferem entre si em suas características. Dentre os principais objetivos da heterogeneidade entre cores, podem ser citados:

- Oferecer alto desempenho em processos single-threading: Com a útilização de núcleos assimétricos, podendo cada qual ser otimizado para execução de uma função específica, pode ser extraído maior desempenho da execução de processos que possuem as mesmas características para as quais os processadores são otimizados;

- Aumentar o throughput em processos multithreading: Do mesmo modo que uma aplicação single-threading pode obter maior desempenho se executar em um processador que ofereça desempenho para as funções que esse processo requer, um processo que possui diversas threads pode ter cada uma delas associada com um núcleo que aumente seu desempenho, aumentando assim o throughput do processo; e

- Diminuir o consumo de energia: Uma das técnicas utilizadas em arquiteturas heterogêneas consiste na mistura de núcleos pequenos, de baixo desempenho e consumo, com núcleos maiores, com alto desempenho e maior consumo. Com um escalonamento eficiente, o sistema pode obter um desempenho equivalente ao alcançado com uma arquitetura multicore homogênena, ocupando a mesma área de chip, no entanto, com um reduzido consumo de energia.

De acordo com Srinivasan et al. (2011b), existem 3 tipos de classificações aplicadas às arquiteturas heterogêneas:

- Virtualmente assimétrica: Nesse modelo, fisicamente os núcleos são iguais, no entanto podem diferenciar-se por meio do conceito de DVFS 3 (Dynamic Voltage Frequency Scaling), onde cada núcleo, em um dado instante, pode estar utilizando uma frequência e uma alimentação diferentes. Em geral, o conceito de DVFS é utilizado principalmente em ambientes onde o custo da potência consumida é crítico, tal como em sistemas embarcados. Nessa classe de heterogeneidade, o mesmo conjunto de instruções (ISA Instruction Set Architecture) é utilizado pelos núcleos, porém, o desempenho entre eles diverge devido às diferenças de frequências;

- Fisicamente assimétrica: Os núcleos são diferentes fisicamente, apesar de compartilharem o mesmo conjunto de instruções. Nesse modelo, cada núcleo pode ter uma configuração diferente para caches, unidades de

${ }^{3}$ DVFS - Dynamic Voltage Frequency Scaling: Técnica que busca a economia de energia alcançada por meio do ajuste dinâmico da frequência e tensão do processador. 
ponto flutuante ou, até mesmo, um deles implementar uma arquitetura superscalar. Consequentemente, nesse modelo pode haver uma diferença ampla de desempenho entre os núcleos para diferentes classes tarefas; e

- Arquitetura híbrida: Nessa classificação, os núcleos podem ter diferentes conjuntos de instruções, mas ainda sim, compartilharem uma parte dessas instruções. A ideia principal desse modelo consiste na possibilidade de existirem núcleos específicos para realizarem com maior desempenho uma classe de tarefas, tais como criptografia, processamento de imagem, ou mesmo operações de ponto flutante com alto desempenho.

Apesar das diferenças entre os processadores em arquiteturas heterogêneos, não é somente o hardware que possui desafios nesse modelo. Existem pesquisas que estudam como deve ser a abordagem do sistema operacional frente a esse modelo. Uma das grandes questões está relacionada a como o sistema operacional deve explorar a heterogeneidade da arquitetura. Em alguns casos a heterogeneidade não oferece diferenças suficientes para compensar o suporte dos sistemas operacionais. Além disso, outro ponto é como e quando o sistema operacional deve influenciar. Outra grande questão está relacionada com a exposição da heterogeneidade às aplicações. Nesse caso pode haver transparência absoluta, extraindo o desempenho das aplicações por meio de heurísticas de escalonamento em tempo real. Mas por outro lado, se o sistema operacional expor a heterogeneidade às aplicações, pode haver um benefício de desempenho considerando que a própria aplicação pode apontar quais tipos de recursos lhe trazem maior ganho. Nesse contexto, para aprofundar o estudo e tentar delinear uma melhor solução para suporte às arquiteturas, os sistemas operacionais foram classificados nas seguintes categorias (Reddy et al., 2011):

- Restrito: Nesse modo, quando existem diferenças nos conjuntos de instruções entre os processadores, todo o software executa somente o conjunto compartilhado de instruções entre os processadores. Assim, a visão das aplicações em relação aos processadores distintos é homogênea, como se todos os processadores fossem iguais;

- Híbrido: O sistema operacional expõe a heterogeneidade às aplicações, deixando-as livres para escolher os processadores a serem utilizados em sua execução; e

- Unificado: O sistema operacional expõe parte da heterogeneidade e implementa o controle dos processos sobre os processadores, cuidando principalmente do escalonamento e de eventos de interrupção por opcodes inválidos, migrando automanticamente o processo de processador, sem haver a necessidade de interação com esse processo. 


\subsection{Trabalhos relacionados}

Nesta seção são apresentados os principais modelos de arquiteturas heterogêneas existentes, com ênfase no hardware utilizado para a implementação. Também são abordadas as principais organizações de software utilizadas para a execução paralela nessas arquiteturas heterogêneas. Por fim, são apresentadas as principais pesquisas sobre o escalonamento de tarefas para arquiteturas multiprocessadas heterogêneas.

\subsection{Hardware - Modelos de arquitetura}

Conforme descrito na Seção 2.1.2, uma das abordagens clássicas de heterogeneidade é a utilização de um ou poucos núcleos com alto poder computacional juntamente com vários núcleos menores de baixo poder computacional. Nesse contexto, em (Kumar et al., 2004) está descrito um trabalho pioneiro e um dos mais completos comparativos de desempenho e consumo entre arquiteturas multi-cores homogêneas e heterogêneas.

Esse trabalho apresenta métricas de desempenho e consumo que são utilizadas para associar cada thread no processador que ofereça um desempenho e consumo melhores (nesta seção é descrita apenas a parte envolvida na arquitetura, sendo que os métodos e resultados obtidos desse trabalho são apresentados posteriormente, na Seção 2.2.3. Para tanto, são utilizadas diversas organizações dos processadores Alpha em uma única arquitetura, de modo a mostrar o ganho alcançado na heterogeneidade, utilizando núcleos com o mesmo conjunto de instruções.

Na Figura 2.4 são ilustrados os tamanhos relativos dos principais núcleos Alpha utilizados, onde a soma do tamanho dos núcleos menores é menor que 15\% do tamanho no núcleo EV8. Essa evolução, segundo Kumar et al. (2005), é similar à evolução dos processadores da arquitetura x86 até a data da publicação do artigo relacionado. Desses processadores, foram utilizados o EV5 e o EV6.

Embora o número de transistores, complexidade e consumo tenham aumentado, o desempenho alcançado com os núcleos maiores não seguem a mesma proporção. Segundo Kumar et al. (2005), em testes realizados utilizando a mesma frequência para todos os processadores, resultaram em baixo aumento de desempenho, conforme pode ser observado na Tabela 2.1 .

É importante observar que o aumento de área dos núcleos, em detrimento do baixo desempenho atingido e maior consumo mensurados nesse trabalho, é o fator motivante à utilização da arquitetura heterogênea. Na arquitetura proposta são utilizados os processadores EV5 e EV6, os quais são combinados de modo a demonstrar a equivalência entre área utilizada e desempenho 


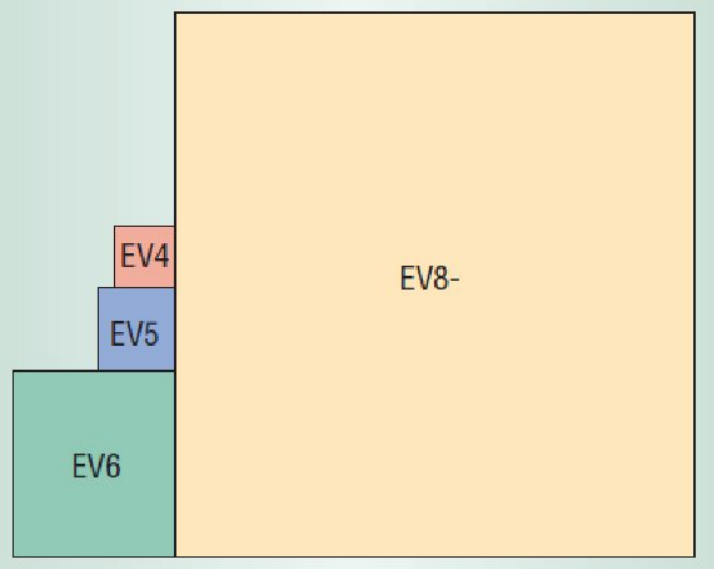

Figura 2.4: Tamanhos relativos dos núcleos Alpha $(0.10 \mu \mathrm{m})$ (Kumar et al., 2005)

Tabela 2.1: Demonstração de consumo e desempenho dos núcleos Alpha

\begin{tabular}{cccc}
\hline \hline Núcleo & $\begin{array}{c}\text { Pico de potência } \\
\text { (Watts) }\end{array}$ & $\begin{array}{c}\text { Potência média } \\
\text { (Watts) }\end{array}$ & $\begin{array}{c}\text { Desempenho } \\
\text { (IPC normalizado) }\end{array}$ \\
\hline EV4 & $4.97 \mathrm{~W}$ & $3.83 \mathrm{~W}$ & 1 \\
EV5 & $9.83 \mathrm{~W}$ & $6.88 \mathrm{~W}$ & 1.83 \\
EV6 & $17.8 \mathrm{~W}$ & $10.68 \mathrm{~W}$ & 1.87 \\
EV8 & $92.88 \mathrm{~W}$ & $46.44 \mathrm{~W}$ & 2.14 \\
\hline \hline
\end{tabular}

atingido para as arquiteturas heterogêneas e homogêneas.

A Figura 2.5 ilustra essas combinações e equivalências. Como pode ser observado, as disposições heterogêneas, em sua maioria, possuem áreas menores que a configuração com núcleos homogêneos que possuem throughput's equivalentes, mas, ainda assim, menores que os heterogêneos equiparáveis (Kumar et al., 2006).

Em resumo, Kumar et al. (2004) mostra que maior desempenho e eficiente consumo podem ser alcançados por meio de núcleos heterogêneos ocupando a mesma área de chip que uma arquitetura semelhante homogênea ocuparia.

O processador Cell, desenvolvido pela IBM, foi um dos primeiros modelos comerciais que implementaram a heterogeneidade. Esse processador possui um núcleo PowerPC hyper-threading (PPE) e oito núcleos especializados (SPE), conectados por meio de um barramento de alta velocidade. O núcleo PPE, responsável pela execução do sistema operacional, coordena o escalonamento dos processos nos SPEs, os quais são responsáveis por operações de ponto-flutuante específicas, cálculos envolvendo matrizes, computação científica, além de processamento multimídia (IBM, 2013b).

No trabalho publicado por Li et al. (2009), uma arquitetura semelhante ao Cell é apresentada. Um núcleo centraliza o recebimento das instruções e rea- 


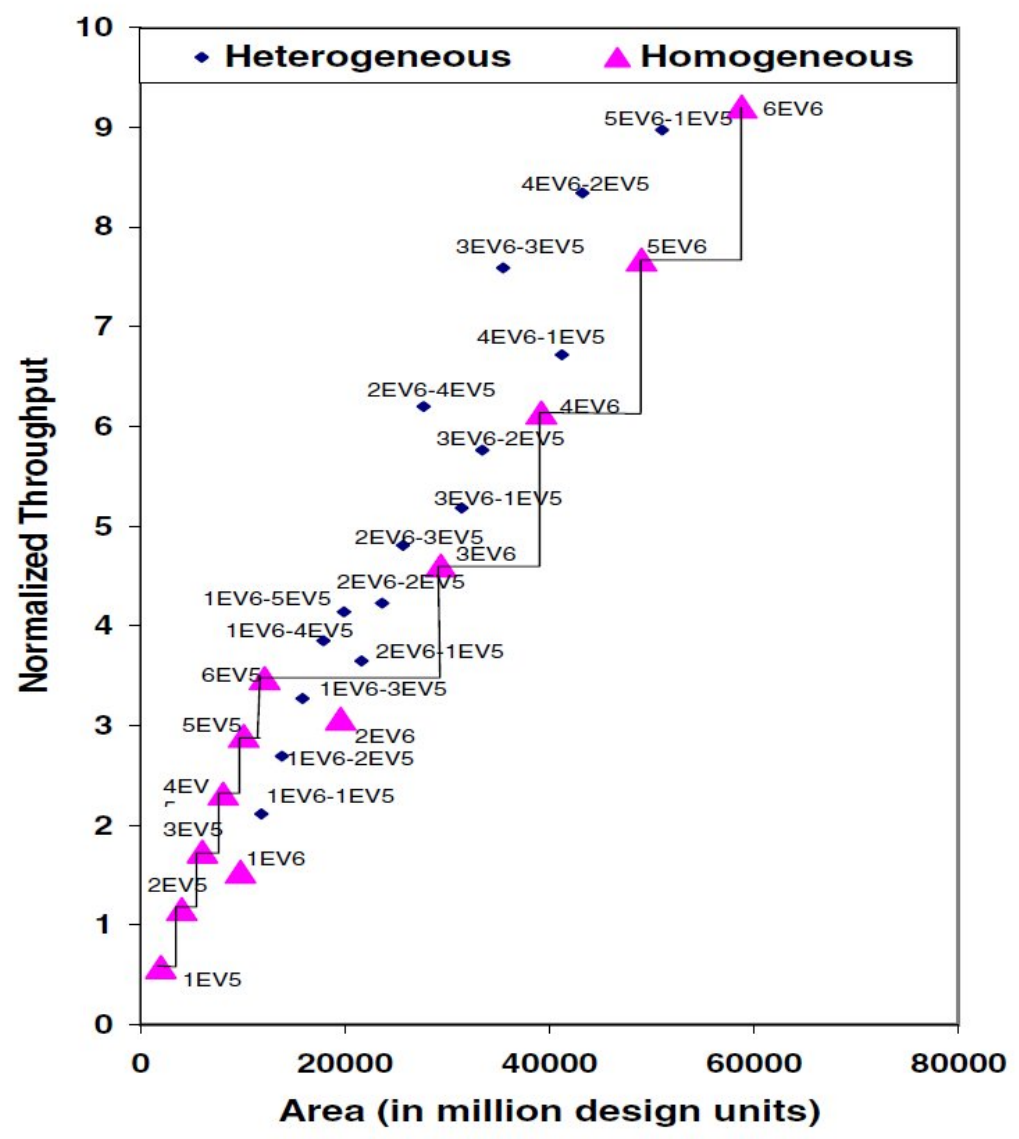

Figura 2.5: Comparação em área e throughput de processamento das arquiteturas homogêneas e heterogêneas (Kumar et al., 2004)

liza os escalonamento delas, enviando-as para outros quatro núcleos que são responsáveis por executar efetivamente as instruções. O propósito principal desse trabalho é aumentar o desempenho de processos por meio de um detector de loop, localizado entre a cache de instruções e o processador principal. O detector, a partir da identificação de instruções de salto (branch), tenta identificar um loop, armazendo as instruções relacionadas, de modo a executá-las mais rapidamente.

Outro tipo de plataforma utilizada em arquiteturas multiprocessadas heterogêneas está ilustrada no topo da Figura 2.6. Nesse modelo, para cada conjunto de processadores homogêneos (MCU - Microcontroler Unit, DSP Digital Signal Processor ou MPU - Microprocessor Unit), existe um sistema operacional. A diferença entre os conjuntos de instruções de MCUs e DSPs e processadores genéricos impossibilita a existência de um único sistema operacional executando sobre todos os tipos de unidades de processamento, tornando inapta a migração de tarefas entre os mesmos.

A abordagem sugerida por Shen \& Pétrot (2009) explora a característica de compartilhamento de um conjunto de instruções entre os processadores, fazendo com que todas as unidades de processamento possuam um mesmo 


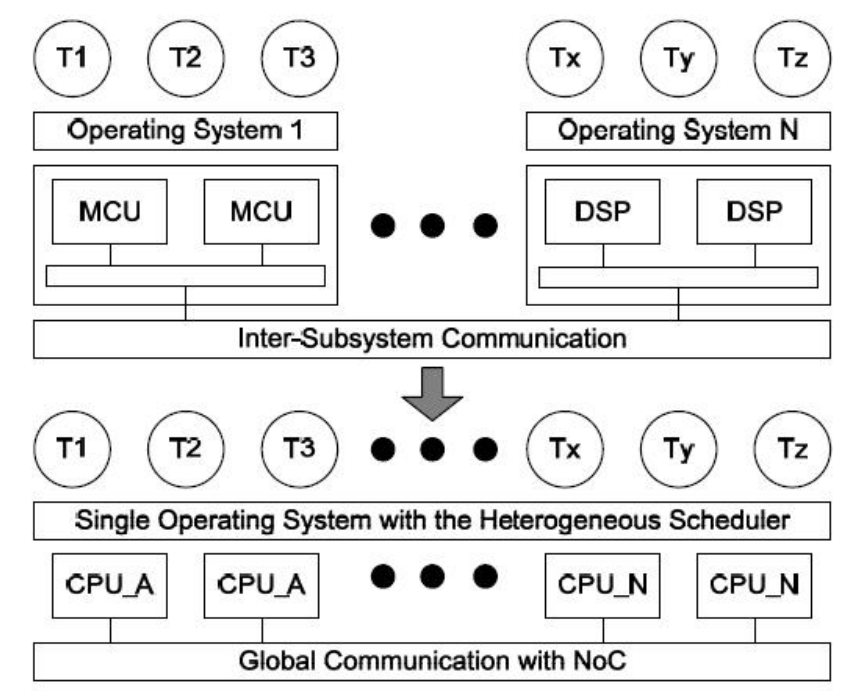

Figura 2.6: Arquiteturas de SW/HW para multiprocessadores heterogêneos (Shen \& Pétrot, 2009)

conjunto de instruções comum, apesar de poderem implementar instruções diferentes. A parte inferior da Figura 2.6 representa a arquitetura proposta por esse trabalho, na qual podem existir várias unidades de processamento conectadas por uma NoC - Network-on-Chip, onde cada unidade executa um processo diferente. Nessa organização, todos os processadores possuem um conjunto diferente de instruções, ao mesmo tempo que compartilham um conjunto comum delas. A ilustração desse compartilhamento está apresentada na Figura 2.7. A intersecção de todos os conjuntos de instruções forma o conjunto comum entre todos os processadores. Esse conjunto comum é utilizado para codificação do sistema operacional, o qual é único e executa sobre todos os processadores. A partir desse conjunto e do sistema operacional, fica mais fácil implementar a migração de tarefas entre os processadores.

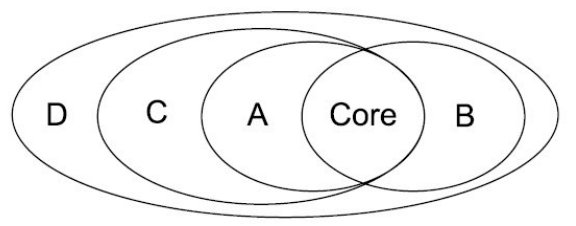

Figura 2.7: Compartilhamento do mesmo conjunto de instruções por todas as unidades de processamento (Shen \& Pétrot, 2009)

No entanto, diferente do sistema operacional, os processos podem ter instruções fora do conjunto de intersecção. De acordo com Shen \& Pétrot (2009), nesses casos, o escalonador deve associar uma determinada tarefa ao processador que contém o conjunto de instruções que essa tarefa utiliza.

Portanto, pode-se concluir que essa arquitetura prioriza o escalonamento e a migração de tarefas entre os processadores, bem como trata a troca de contexto, apesar de existirem direrentes conjuntos de instruções e, inclusive, 
no caso de possuírem registradores extras implementados por processadores diferentes.

Segundo pesquisadores da Intel $4^{4}$ (Li et al., 2010), o modelo de organização, que utiliza processadores heterogêneos com um conjunto de instruções em comum ou até mesmo idênticos, deve ser um dos mais utilizados no futuro. Esse modelo possibilita que sejam utilizadas instruções específicas para um tipo de processamento, sem haver tanto esforço do lado do software para superar essas diferenças.

Nesse contexto, encontra-se a arquitetura big.LITTLE Processing, desenvolvida pela ARM 5 (ARM, 2011). Dois processadores com arquiteturas idênticas são utilizados, o Cortex-A15 e o Cortex-A7, conforme ilustrado na Figura 2.8. Consequentemente, um processo pode executar de modo consistente em ambos processadores, embora alcance diferentes desempenhos e consumos. A Tabela 2.2 apresenta os ganhos de desempenho e consumo alcançados em ambos os processadores para 5 benchmarks.

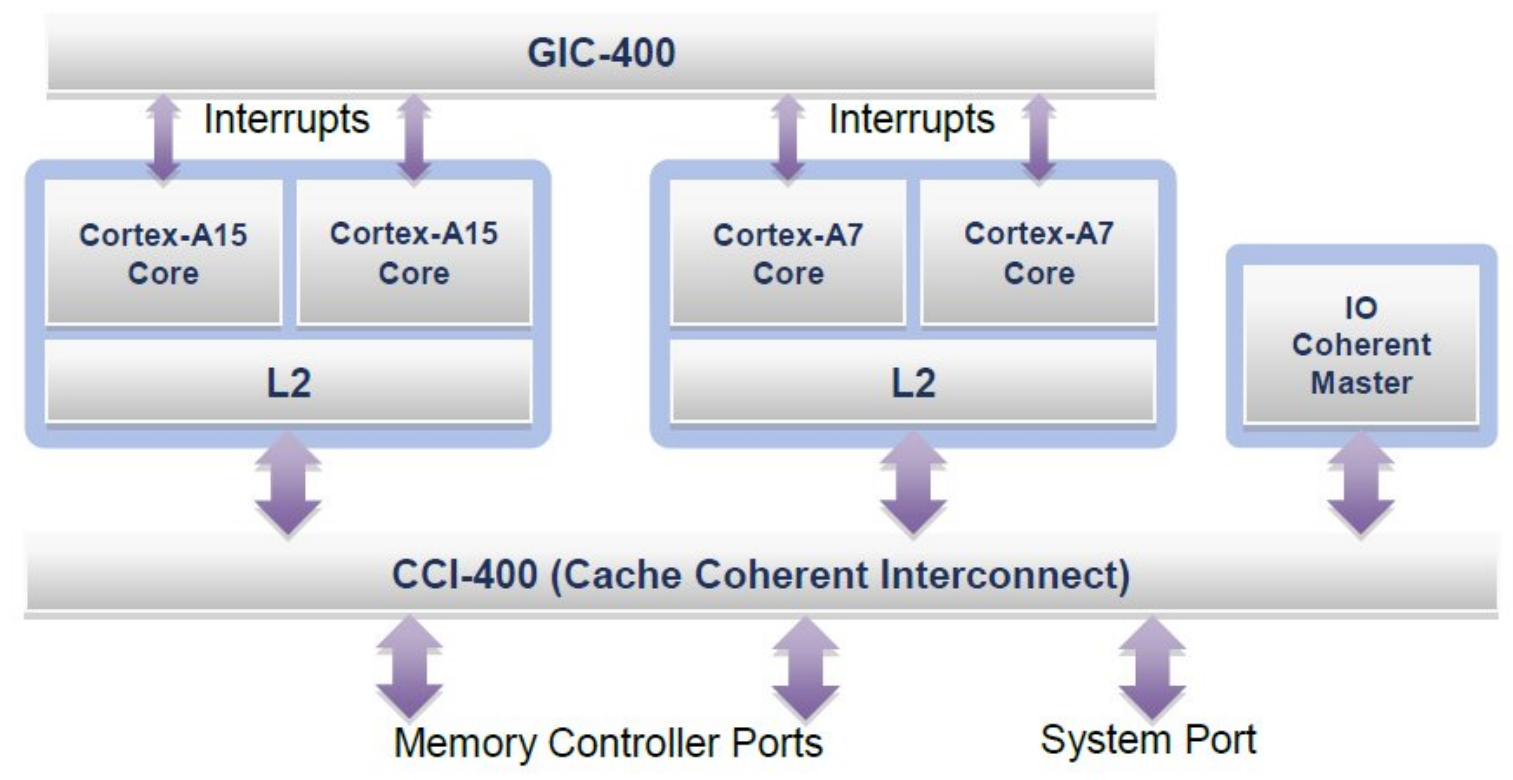

Figura 2.8: Organização da arquitetura big.LITTLE Processing (ARM, 2011)

Pode-se notar que o desempenho do Cortex-A15 pode chegar a 3x o desempenho do Cortex-A7. No entanto, o ganho de consumo no Cortex-A7 pode chegar perto de $4 \mathrm{x}$ em relação ao Cortex-A15.

Entre os processadores há um controlador comum de interrupções que permite que elas sejam migradas entre qualquer núcleo presente no CortexA15 ou Cortex-A7. Ambos os processadores estão conectados por meio de um barramento, conhecido como AMBA 4 - ACE. Esse barramento utilizado no big.LITTLE Processing possui uma extensão que oferece suporte a coerência

\footnotetext{
${ }^{4}$ Intel: http://www.intel.com

${ }^{5}$ ARM: http://www.arm.com
} 
Tabela 2.2: Demonstração de consumo e desempenho dos Cortex-A15 e Cortex-A7 (ARM, 2011)

\begin{tabular}{ccc}
\hline \hline & $\begin{array}{c}\text { Cortex-A15 vs Cortex-A7 } \\
\text { (Desempenho) }\end{array}$ & $\begin{array}{c}\text { Cortex-A7 vs Cortex-A15 } \\
\text { (Eficiência de consumo) }\end{array}$ \\
\hline Dhrystone & $1.9 \mathrm{x}$ & $3.5 \mathrm{x}$ \\
FDCT & $2.3 \mathrm{x}$ & $3.8 \mathrm{x}$ \\
IMDCT & $3.0 \mathrm{x}$ & $3.0 \mathrm{x}$ \\
MemCopy L1 & $1.9 \mathrm{x}$ & $2.3 \mathrm{x}$ \\
MemCopy L2 & $1.9 \mathrm{x}$ & $3.4 \mathrm{x}$ \\
\hline \hline
\end{tabular}

de cache entre os processadores, desenvolvido especificamente para atender processadores heterogêneos (Stevens, 2011).

A NVIDIA 6 , atualmente, um dos fabricantes mais importantes do setor de processamento gráfico, também lançou uma arquitetura heterogênea, chamada de Multiprocessador Tegra (NVIDIA, 2010). A Tegra consiste em uma arquitetura heterogênea composta por 8 processadores independentes para gráficos, codificação e decodificação de vídeo, processamento de imagem, processamento de áudio, gerenciamento de energia e funções de propósito geral. O gerenciamento de energia é capaz de manter somente um processador ligado, requerido por uma tarefa específica, enquanto mantém os demais desligados. Cada processador possui instruções, caches, frequências e circuitos otimizados para cada tarefa especifica, utilizando monitores de desempenho para medir a atividade do sistema (NVIDIA, 2010).

De modo similar, outros processadores têm sido desenvolvidos, seguindo o mesmo conceito de compartilhamento do conjunto de instruções Qualcomm, 2011) (Texas Instruments, 2011). Por outro lado, diversas pesquisas têm sido realizadas em relação a arquiteturas multiprocessadas com diferentes conjuntos de instruções. Recentemente, o consórcio HSA7, formado por grandes fabricantes de processadores e dispositivos móveis, lançou um conjunto de instruções virtuais, chamado HSAIL, cujo objetivo é formalizar um conjunto de instruções em comum e tornar mais transparente a heterogeneidade. $O$ HSAIL é desenvolvido especialmente para processamento paralelo, cuja principal característica é a possibilidade de tradução em tempo real para conjuntos de instruções nativas (HSA, 2013).

Apesar do aumento de pesquisas em processadores, protocolos, barramentos, caches snooping, ou até mesmo arquiteturas inteiras que possibilitem um balanço aprimorado entre consumo e desempenho, acredita-se que o maior desafio da heterogeneidade encontra-se no software (Guerin \& Petrot, 2009) (Senouci et al., 2008). Esse fato não se deve somente aos requisitos de transparência atribuídos ao sistema operacional em relação ao conjunto de instru-

\footnotetext{
${ }^{6}$ NVIDIA: http://www.nvidia.com

${ }^{7}$ HSA - http://hsafoundation.com/
} 
ções ou detalhes intrínsecos de arquitetura. A complexidate envolve diversas outras atividades, como gerenciamento de interrupções, migração de processos entre processadores e cores, associação de tarefas com os processadores e o balanceamento dessas tarefas. Nas próximas seções estão descritas as principais pesquisas relacionadas aos desafios que tangem a implementação do software para arquiteturas multiprocessadas heterogêneas.

\subsubsection{Software - Organização de sistemas operacionais}

Um dos primeiros modelos de organização de software adotado para arquiteturas heterogêneas foi o particionamento offline. Nesse modelo, as aplicações são previamente designadas a serem executadas nos processadores que fornecem maior desempenho às funções requeridas por cada tarefa. Os sistemas operacionais seguiram o mesmo caminho, sendo executados separadamente, um para cada processador distinto.

Seguindo essa abordagem, a proposta descrita por Chen \& Liu (2006) apresenta um sistema operacional chamado de Microkernel Simétrico Embarcado, cujo objetivo é fornecer um mecanismo padrão de comunicação entre os processos executando sobre diferentes processadores. A arquitetura utilizada possui dois processadores distintos que executam, cada qual, uma instância do sistema operacional. A comunicação é realizada por meio de uma memória compartilhada e, também, por interrupções inter-CPUs. Apesar da aparente simplicidade, esse é um dos modelos mais comuns de organização de sistemas operacionais sobre processadores distintos.

De maneira similar, o trabalho apresentado por Senouci et al. (2008) também tem seu foco voltado à comunicação entre processadores distintos. Sua proposta é a implementação de um middleware para gerenciar a comunicação e sincronização entre os processadores, os quais podem estar executando diferentes sistemas operacionais e diferentes tarefas. Parte desse middleware é implementado em software e outra parte em hardware (um FPGA é utilizado como prova de conceito). Os processos utilizam primitivas padrões dos sistemas operacionais para se comunicar, porém, os meios são implementados em hardware, sendo transparente aos processos devido ao middleware. Com isso, esse modelo proporciona que processadores distintos, com sistemas operacionais distintos, possam se comunicar e sincronizar suas atividades.

Já o processador Cell, descrito na seção anterior, implementa uma abordagem diferente. O PPE, processador de propósito geral e com alto poder computacional, é o único responsável pela execução do sistema operacional. Os SPEs, processadores de propósitos específicos e com o mesmo conjunto de instruções, têm a função de executar as tarefas designadas pelo sistema operacional. Esse modelo de execução do sistema operacional por um único 
processador, implementado no processador Cell, deixa o sistema operacional mais simples, sem a necessidade de balancear a execução das tarefas entre os SPEs, já que as tarefas são estaticamente designadas. No entanto, assim como no caso de sistemas operacionais distintos para processadores distintos, esse modelo implementado possui a desvantagem da necessidade do particionamento prévio das tarefas entre os processadores (Gschwind, 2007).

No caso de arquiteturas heterogênas com processadores especializados, a designação estática é desvantajosa, já que não possibilita o sistema operacional de balancear a carga entre processadores, como também exime aproveitamento das fases dos processos para designá-los de acordo com o desempenho ou eficiência de consumo que os processadores oferecem.

Um exemplo clássico de designação dinâmica consiste no framework CUDA, fornecido pela NVIDIA. O intuito desse framework é utilizar as GPUs, otimizadas para alto desempenho na computação de funções de ponto flutuantes, de modo a obter maior desempenho em tarefas que se enquadram nesse contexto, além de aumentar o paralelismo nas tarefas. Para tanto, são fornecidas APIs aos desenvolvedores que podem escolher quais partes de seus códigos devem ter seu desempenho otimizado NVIDIA (2013).

O EXOCHI, uma arquitetura proposta por pesquisadores da Intel (Wang et al., 2007), aborda a organização do sistema operacional para aumentar o desempenho da utilização de aceleradores juntamente com processadores genéricos (Figura 2.9). A abordagem proposta reduz camadas de software que fazem interface entre aplicações e os aceleradores utilizados por elas, como também propõe uma comunicação mais eficiente entre as aplicações por meio de compartilhamento de memória real, sem necessidade de emular esse compartilhamento em software.

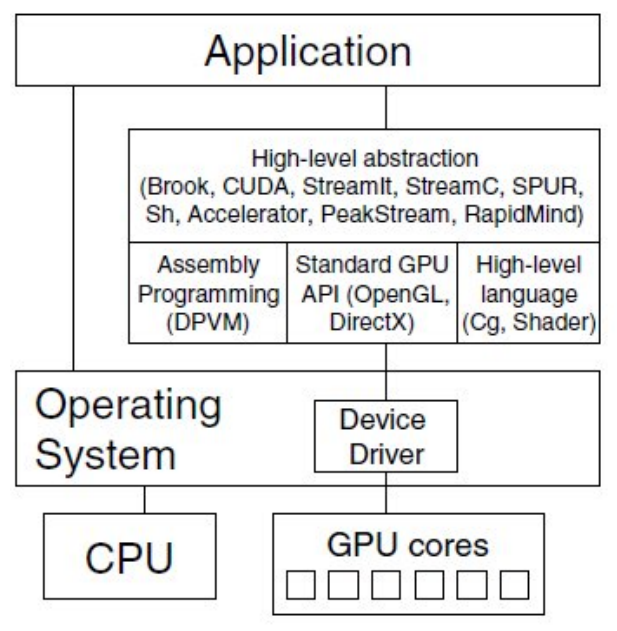

(a) GPGPU

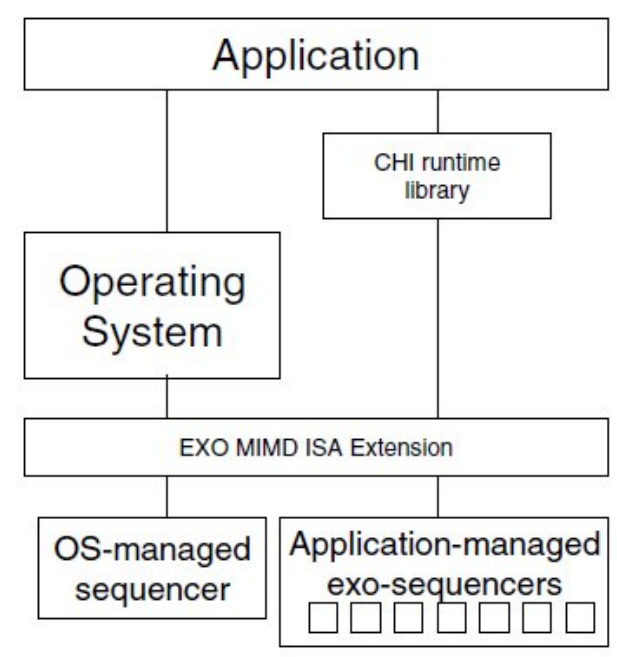

(b) $\mathrm{EXOCHI}$

Figura 2.9: Arquitetura EXOCHI (Wang et al., 2007) 
O sistema operacional proposto por pesquisadores da Intel, Li et al. (2008), considera todos os processadores como se fossem iguais do ponto de vista de execução, ou seja, o sistema operacional executa sobre todos os processadores, apesar de serem diferentes. Nesse trabalho, os conjuntos de instruções dos processadores são semelhantes, com um pequeno conjunto de instruções específicas de cada processador, seguindo a arquitetura híbrida e fisicamente assimétrica, conforme mencionado na Seção 2.1 .2 .

O foco principal apresentado por Li et al. (2008) consiste na migração de processos. Assim que uma instrução não suportada pelo processador tenta ser executada, é gerada uma exceção, a qual é capturada pelo sistema operacional. Após a ocorrência da exceção, o sistema operacional realiza a migração do processo que a causou para executar em outro processador. No estudo de caso, foi utilizado o sistema operacional Linux 2.6.20 e dois processadores quad-core, Intel Xeon X5355 e Intel E5440, com diferentes frequências de operação e arquiteturas.

A migração é realizada por meio de uma mudança no kernel em relação à máscara de afinidade. Quando um processo executa uma instrução não existente no conjunto de instruções do processador que o executa, o cpuid daquele processador é retirado da máscara. Assim, quando há necessidade de balanceamento, o sistema operacional não deixa que o processador que não tenha seu cpuid na máscara do processo o execute. No entanto, para evitar que um processo fique sempre em um único processador (podendo aumentar a carga do processador devido a quantidade grande de processos em sua fila), o trabalho em questão implementou um quantum, o qual consiste em um tempo, que quando alcançado, o sistema operacional restaura o valor original da máscara de afinidade do processo (todos os processadores podem executá1o) Li et al. (2010).

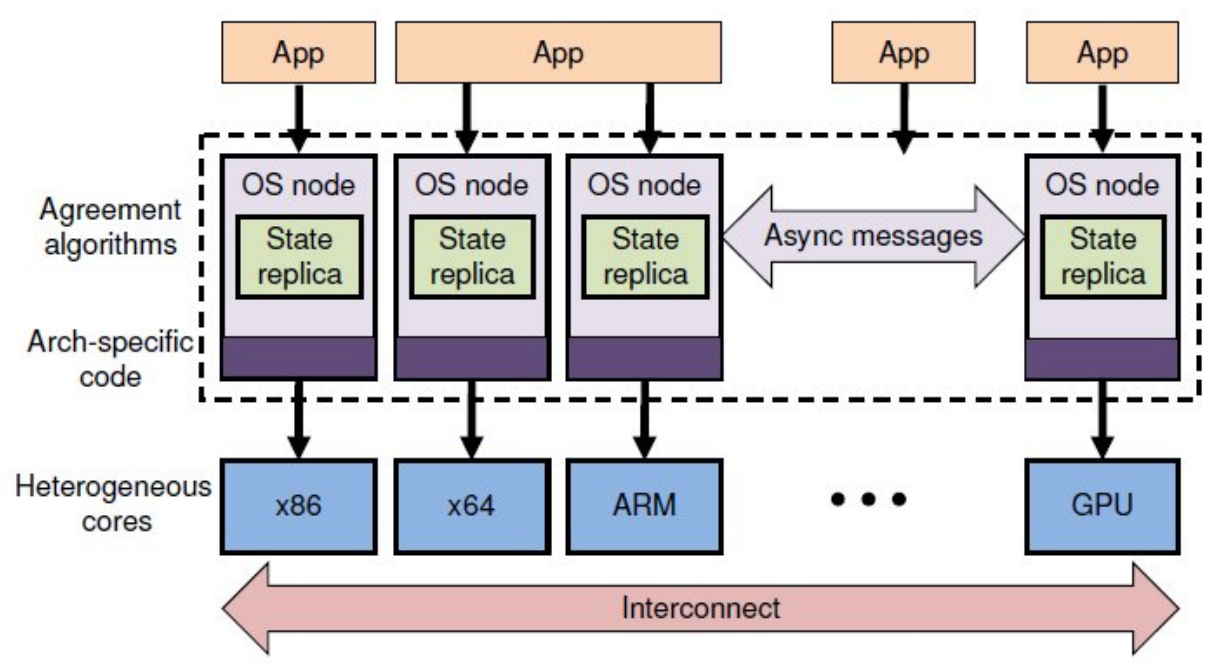

Figura 2.10: Modelo Multikernel (Baumann et al., 2009) 
O Multikernel, sistema operacional proposto por Baumann et al. (2009), utiliza a abordagem semelhante aos sistemas distribuídos para oferecer transparência à heterogeneidade dos processadores, conforme ilustrado na Figura 2.10. Existe um sistema operacional para cada processador (chamado de nó) e as aplicações comunicam-se por meio de uma camada de comunicação oferecida pelo sistema operacional. Essa comunicação é explicitamente realizada por meio de mensagens, sendo que nenhuma memória é utilizada nessa arquitetura. Segundo Baumann et al. (2009), a utilização de mensagens é um mecanismo mais rápido que a memória compartilhada por não depender de mecanismos de coerência de caches para manter os dados da memória consistentes. Por outro lado, esse modelo replica todos os estados dos sistemas operacionais em todos os nós, utilizando o conceito de escalabilidade. A heterogeneidade é abstraída por meio do conceito de cpu-drivers, camada responsável por implementar a parte do sistema operacional específica para cada processador.

Pesquisadores da Microsoft 8 propuseram um tipo de sistema operacional com o conceito de satellite kernels (Nightingale et al., 2009). Helios, como é conhecido, exporta as abstrações de cada processador expondo suas métricas de afinidade, de modo que programador saiba qual é o satellite kernels que melhor se adapta às suas necessidades. A comunicação entre processos é realizada por meio de troca de mensagens, que também é utilizada para acesso a serviços de dispositivos. Para obter transparência para as aplicações, o Helios adota o conceito de compilação em duas fases, onde o programa é compilado, primeiramente, para uma linguagem intermediária e, posteriormente, compilado para a arquitetura alvo onde será executado.

No trabalho apresentado por Agron \& Andrews (2009) é proposto um sistema operacional que utiliza o conceito de microkernel baseado em hardware, cujo principal objetivo é oferecer ao desenvolvedor uma interface padronizada POSIX a qual pode ser utilizada independente de arquitetura. Nesse modelo, são implementados em hardware gerenciadores de threads (armazenam o estado das threads do sistema), escalonador, váriaveis condicionais, memória compartilhada e gerenciador de sincronização. A implementação desse projeto em hardware foi realizada em FPGA, utilizando os processadores Microblaze e PowerPC como prova de conceito.

Já o trabalho proposto por Guerin \& Petrot (2009) aborda um framework para desenvolvimento rápido de sistemas heterogêneos. Nesse trabalho é utilizado o sistema operacional DNA contendo mecanismos básicos de comunicação inter-processos, juntamente com uma camada de abstração de hardware (HAL- Hardware Abstraction Layer), cuja encapsulação maximiza sua porta-

\footnotetext{
${ }^{8}$ http://www.microsoft.com
} 
bilidade. Esse trabalho está relacionado a um framework para rápida prototipagem de sistemas heterogêneos e, portanto, não trata de problemas comuns em tais sistemas, tal como a diferença no conjunto de instruções e migração de processos.

A migração de processos entre diferentes processadores é um dos principais problemas a serem tratados por sistemas operacionais que executam sobre uma arquitetura onde os processadores possuem instruções ou mesmo registradores diferentes.

Com o intuito de simplificar a tarefa de migração de processos entre processadores, o trabalho proposto por Georgakoudis et al. (2013) apresenta a idéia de reescrita do binário em tempo real durante a migração de threads, enquanto que outros trabalhos, tais como Adve et al. (2003) e (HSA, 2013), apresentam, respectivamente, um conjunto de instruções virtual e uma linguagem intermediária para arquiteturas heterogêneas, com o objetivo de trazer mais simplicidade ao sistema operacional durante a migração de processos. No entanto, no caso dos dois últimos exemplos, pode trazer maior complexidade ao hardware.

Desafios adicionais também podem ser encontrados em arquiteturas como big.LITTLE Processing (ARM, 2011). Essa arquitetura contém dois processadores distintos, o Cortex-A7 e o Cortex-A15, onde somente um dos processadores pode executar o sistema operacional e as aplicações em um dado momento. Dependendo da carga requerida pelas aplicações, pode ser necessário que a execução das tarefas seja realizada no processador que oferece mais desempenho ou no processador que oferece maior economia de energia. Nesses casos, a migração de tarefas é invocada, movendo tanto o sistema operacional quanto as tarefas para serem executados em outro processador.

Apesar dos desafios relacionados às diferenças dos processadores ocuparem grande foco de pesquisas recentes em sistemas operacionais, de modo a tornar essas diferenças transparentes ao usuário, deve-se manter em mente as principais motivações da heterogeneidade de processadores: aumento de desempenho e diminuição do consumo.

Um sistema que aproveite sua heterogeneidade explorando o desempenho de processadores de alto desempenho, balanceando a execução de processos para reduzir consumo, somente pode atingir esses objetivos por meio de algoritmos de escalonamento com políticas específicas para arquiteturas heterogêneas.

Conforme Gupta et al. (2012), políticas de escalonamento para uniprocessadores ou multiprocessadores homogêneos não se aplicam a sistemas heterogêneos. Nesse contexto, na próxima seção, são apresentados algoritmos e politicas aplicados a arquiteturas heterogêneas. 


\subsubsection{Escalonamento e balanceamento de tarefas}

A pesquisa publicada por Kumar et al. (2004), conforme mencionado na Seção 2.2.1, foi um dos trabalhos precursores na área de processadores heterogêneos. O autor realiza testes utilizando processadores com tamanhos, capacidade de processamento e consumo de energia diferentes. O estudo aponta que a utilização do IPC como métrica não é confiável, pois favorece processos que tenham um IPC maior, enquanto que os demais processos não são considerados. Devido a esse fato, o trabalho utiliza o conceito de speedup ponderado, que consiste na soma aritmética dos IPCs de todos os processos sendo executados, dividido pelo IPC de cada processo. Conforme Kumar et al. (2004), essa métrica dificilmente favorece processos com alto IPC desconsiderando processos com IPC menores. Foi primeiramente realizado um estudo sobre os benefícios de um escalonamento ótimo em uma arquitetura heterogênea, cujos resultados estão ilustrados no gráfico da Figura 2.11. São utilizadas três configurações distintas de processadores, sendo que as três ocupam espaço semelhante no chip. Para cada quantidade de threads o speedup ponderado é mensurado. O resultado aponta que a utilização de configuração de processadores heterogêneos (3 EV6's e 5 EV5's) apresenta um speedup superior na maior parte do tempo, sendo inferior na medida que a quantidade de threads cresce abundantemente. Esse ponto de inferioridade ocorre devido à necessidade de enfileirar as threads para execução posterior, devido a número de processadores reduzidos em relação à configuração que possui 20 EV5's. Esse resultado foi alcançado por meio de designação estática, com o objetivo de demonstrar a necessidade de uma boa política de escalonamento em uma arquitetura heterogênea.

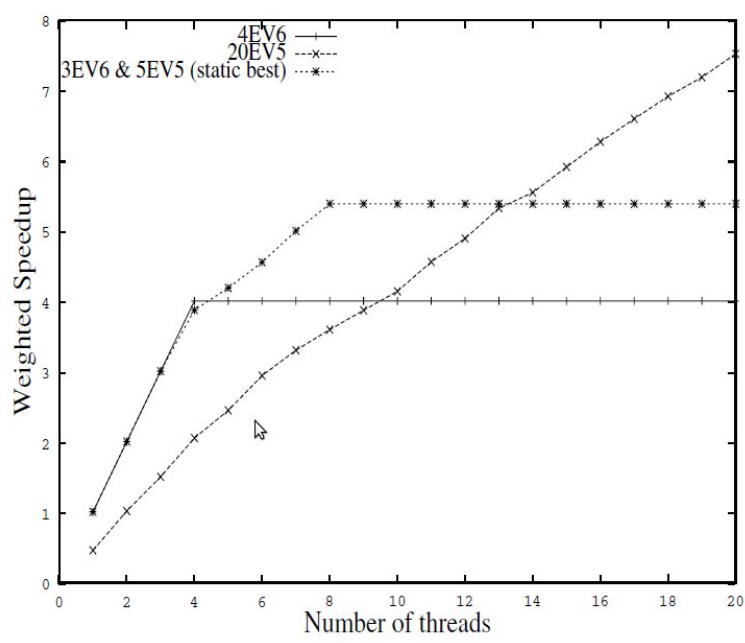

Figura 2.11: Benefício da heterogeneidade (escalonamento estático) (Kumar et al., 2004)

Contudo, o escalonamento necessita ser dinâmico para atender as varia- 
ções de necessidades de recursos que os processos exigem durante o tempo de execução. O trabalho (Kumar et al., 2004) é baseado na amostragem em tempo de execução para determinar os pesos utilizados para designação de cores aos processos. Para tanto, foram testadas três abordagens diferentes:

- Amostra uma vez: Cada processo executa uma única vez sobre cada tipo de processador com o intuito de medir seu speedup ponderado;

- Média de amostragem: Cada thread executa ao menos uma vez sobre cada tipo de processador. Nesse caso, o algoritmo utiliza em sua heurística a média dos valores de speedup ponderados que foram mensurados em suas execuções; e

- Amostragem de escalonamento: O escalonador realiza diferentes designações de processadores para cada processo, sendo que é realizada uma amostragem do speedup total e escolhida a melhor designação para ser utilizada pelo escalonador.

Dentre essas três abordagens, Kumar et al. (2004) aponta a utilização da média de amostragem como o melhor custo benefício. Essas medidas não são realizadas durante o tempo inteiro de execução, o trabalho também estuda dois tipos de momentos para realizar a amostragem para atualizar o escalonamento, os quais são: amostragem periódica, realizada por meio de um temporizador, e amostragem baseada em eventos que indicam mudanças no desempenho do sistema.

Contudo, o trabalho apresentado por Kumar et al. (2004) tem sua análise de desempenho e de redução de energia voltada especialmente a cada thread, ao invés de buscar uma otimização global do sistema, considerando todas as threads em execução.

O trabalho proposto por Becchi \& Crowley (2006) tem uma abordagem semelhente à abordagem de Kumar et al. (2004) (inclusive, é utilizado o mesmo conjunto de processadores para os testes). São comparados quatro mecanismos distintos de designação de processadores:

- Designação estática aleatória: Os processadores são aleatoriamente designados para os processos, mas de modo estático, sem levar em consideração qualquer conhecimento prévio sobre o comportamento dos processos;

- Designação estática: Os processos têm sua carga previamente conhecida, de modo que os processadores são designados a cada processo levando em conta esse conhecimento prévio; 
- Designação dinâmica Round-robin: Evita que threads que possuem um baixo IPC sejam desfavorecidas. Para isso é determinado que cada thread execute em um processador por um tempo determinado; e

- Designação dinâmica guiada por IPC: Leva em consideração o IPC relacionado a cada thread executando sobre cada processador para a designação de qual processador é mais apropriado.

Nesse trabalho, o IPC é utilizado como principal métrica para determinar a designação de processadores, para o qual não é proposto um mecanismo de predição, sendo necessário que uma determinada thread execute sobre os diferentes tipos de processadores para se obter o IPC. Em comparação com o trabalho anterior, em Becchi \& Crowley (2006) é realizada uma menor quantidade de migrações para se obter a métrica requerida.

Esse estudo aponta que a designação dinâmica beneficia a utilização da arquitetura heterogênea devido ao alto aproveitamento dos processadores maiores e também melhor distribuição de threads sobre processadores de diferentes configurações. Assim, de acordo com Becchi \& Crowley [2006), a designação dinâmica é um simples mecanismo. Porém, o suficiente para extrair desempenho desse tipo de arquitetura, principalmente no caso de baixo nível de paralelismo entre threads.

Nos dois trabalhos mencionados anteriormente, Kumar et al. (2004) e Becchi \& Crowley (2006), são necessárias amostragens de desempenho, as quais são realizadas por meio de migrações de threads entre processadores, de modo a mensurar seu desempenho nas diferentes arquiteturas de processadores. Essa amostragem traz uma confiabilidade melhor do desempenho mensurado e, consequentemente, da designação realizada pelo algoritmo de escalonamento. No entanto, a migração traz impacto ao desempenho desses processos, principalmente devido ao desbalanceamento e à troca de contexto envolvidos nas migrações.

Uma outra abordagem, considerada mais simples, porém, relativamente eficiente (em alguns casos), propõe o escalonamento considerando um conhecimento prévio da carga exigida por cada tarefa. O algoritmo HASS (Het.-Aware Signature-Supported) considera que cada aplicação possua uma assinatura contendo um sumário arquitetural das necessidades da aplicação (Shelepov et al., 2009). Esse sumário, no início da execução da aplicação, é lido pelo escalonador e utilizado para designar o melhor processador de acordo com as características físicas disponíveis e as características exigidas. Nessa abordagem, o sumário não considera diferentes threads, sendo estas atribuídas à aplicação como um todo. Segundo Shelepov et al. (2009), o sumário é gerado de modo offline, por meio da execução de um profile sobre a aplicação compilada. Não há necessidade de envolvimento direto do programador na geração 
do sumário, apesar de recomendado. O trabalho sugere que o sumário seja incorporado no binário, apesar de implementá-lo de modo hard-coded para aferir os resultados. Outra sujestão é a incorporação do profile no compilador, sendo o sumário gerado e encapsulado automaticamente no binário da aplicação.

Além do HASS, esse trabalho também implementa o algoritmo proposto por Becchi \& Crowley (2006), mencionado anteriormente, com o intuito de comparar os resultados e provar a melhora de desempenho que pode ser alcançada utilizando a abordagem de conhecimento prévio da carga exigida pelas aplicações. Esse trabalho tem seu foco voltado para os ganhos alcançados sem a necessidade de causar sobrecarga no sistema devido a migração de tarefas. Outro ganho apresentado é a facilidade de implementação. Porém, tem seu escopo limitado e não considera o mudança dinâmica nas fases de execução de um processo, como também requer cooperação e possível interação com o desenvolvedor para geração de assinaturas utilizadas no escalonamento.

Algumas outras abordagens de escalonadores utilizando conhecimento prévio do comportamento dos processos (offline) podem ser encontradas em Singh \& Singh (2011) e Sondag et al. (2007).

Diferente das abordagens anteriores, o escalonador AMPs (Asymmetric Multiprocessor Scheduler), proposto por pesquisadores da Intel, tem seu foco voltado ao balanceamento das threads em uma arquitetura heterogênea, baseada principalmente no modelo de um processador com maior capacidade computacional e um ou mais processadores de menor capacidade computacional (Li et al., 2007). O AMPs tenta assegurar que a carga de trabalho em cada processador seja proporcional ao poder computacional que ele suporta. Para tanto, o poder computacional de cada processador pode ser quantificado por meio de benchmarks, ou mesmo, como é feito nesse trabalho para testes, por meio de ajuste das frequências dos processadores, de modo que se obtenha um poder computacional $P x^{\prime}$ aproximado para cada processador $x$. No entanto, é necessário quantificar o poder computacional $P$ de cada processador em relação aos outros. Para isso, é escolhida a menor carga computacional $\left(P x_{m i n}^{\prime}\right)$, sendo o $P x$ de cada processador o seu $P x^{\prime}$ dividido pelo $P x_{m i n}^{\prime}$. No modelo proposto, para simplificação, é considerado que uma unidade de tempo em um processador com $P=x$ é equivalente a $x$ unidades de tempo em um processador com $P=1$. A carga computacional que cada processador terá associada a si é inversamente proporcional ao $P$ desse processador. Essa carga computacional é controlada por meio das filas de execução de cada processador, sendo que o tamanho de cada fila varia de acordo com a capacidade computacional do processador ao qual está relacionado. A designação do processador a ser utilizado para executar um processo é realizada pelo escalonador, cujo princi- 
pal foco é manter o balanceamento do sistema e também oferecer o conceito de fairness (justiça), fazendo com que threads com a mesma prioridade obtenham a mesma proporção de poder computacional. O escalonador utiliza a abordagem de designar primeiramente o processador com a maior capacidade computacional para as tarefas, de modo a aproveitar sua capacidade computacional, evitando que esse processador fique ocioso. Essa abordagem é conhecida como Faster-Core-First Scheduling. Dois exemplos demonstrando a atuação do balanceamento do algoritmo AMPs estão ilustrados na Figura 2.12.

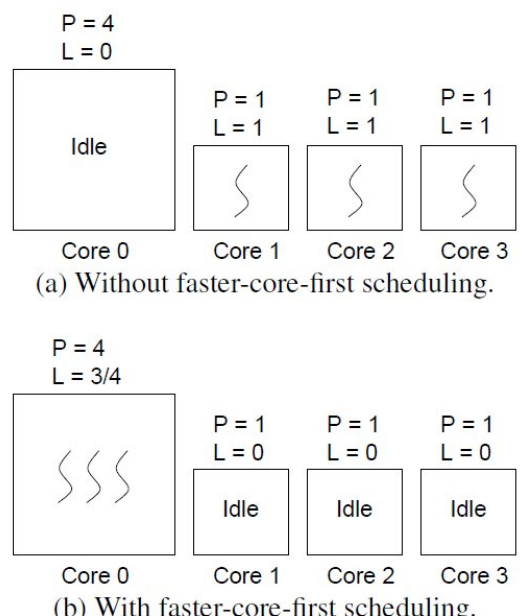

Figura 2.12: Exemplo de balanceamento do algoritmo AMPs (Li et al., 2007)

No primeiro exemplo, o processador com maior capacidade computacional $(P=4)$ está ocioso, sendo que os demais processadores, com menor capacidade computacional $(P=1)$, possuem uma thread em execução, cada. De modo a obter maior throughput, ocupando o processador com carga computacional maior, foram estudadas duas opções: mover para o processador maior uma das threads em execução nos processadores menores, de modo que seja executada 4 vezes mais rápida (e, posteriormente, mover as demais de acordo com o término de execução de cada uma), ou mover todas as 3 threads para executarem $3 / 4$ vezes mais rápidas no processador maior. Os estudos dessas duas abordagens relacionadas por Li et al. (2007) apontam que a abordagem de mover uma thread por vez pode ter um ganho $32 \%$ no tempo total de execução. No entanto, o trabalho adota a segunda abordagem por favorecer fairness e também por simplificar a visão do sistema operacional em relação arquitetura heterogênea, fazendo com que seja mais parecida com a arquitetura multiprocessada homogênea.

No tipo de arquitetura composta por um processador de grande capacidade computacional (big-core) e um ou mais processadores com capacidade computacional inferior, em geral, os processadores menores oferecem bom desempenho a processos com alto nível de paralelismo (TLP - Thread Level Paralelism ou ILP - Instruction Level Paralelism), enquanto que o processador 
maior oferece maior desempenho a processos com alto grau de computação ou que tenham alto nível de MLP (Memory Level Paralelism). Nesse contexto, o trabalho proposto por Van Craeynest et al. (2012) apresenta o modelo de estimativa do impacto no desempenho, denominado PIE (Performance Impact Estimation). Tal modelo busca realizar a predição do desempenho de uma determinada tarefa nos processadores existentes, associando tal processo ao processador que lhe ofereça maior desempenho, segundo sua estimativa.

No modelo PIE, são coletadas medidas de desempenho do processo em tempo de execução em qualquer um dos processadores onde o processo é executado. Tais medidas são: CPI stack, MLP e ILP. Por meio delas, o algoritmo realiza uma estimativa que associa o impacto do processo no desempenho ao MLP ou ILP. Tais medidas são coletadas periodicamente, alimentando o algoritmo que atualiza o mapeamento de processos/processadores constantemente. Para a estimativa, somente dois componentes da CPI stack são utilizados, os quais são $C P I_{b a s e}$ e $C P I_{m e m}$, como pode ser visto na Equação 2.1 .

$$
C P I=C P I_{b a s e}+C P I_{m e m}
$$

A Figura 2.13 ilustra o relacionamento entre o MLP e ILP alcançados em ambos os processadores. O modelo decompõe a Equação 2.1 em uma série de outras equações, relacionando o desempenho de cada processador em função dos fatores de MLP e ILP. Desse modo, o escalonador pode designar um determinado processo para executar sobre o processador que lhe ofereça maior desempenho.

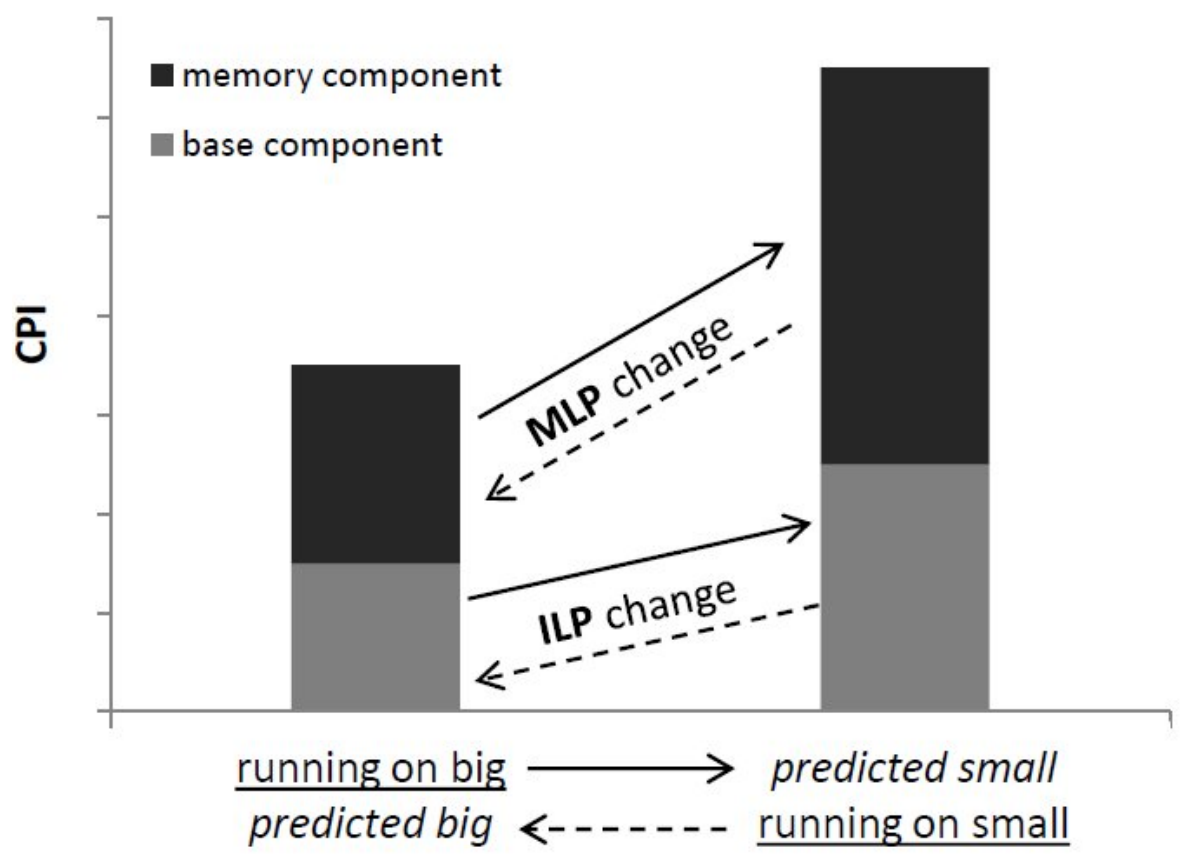

Figura 2.13: Estimativa do impacto no desempenho (Van Craeynest et al., 2012) 
Em uma arquitetura composta por um processador de propósito geral e um ou mais co-processadores apropriados para execução de tarefas específicas (Seção 2.2.1), a preempção de processos executando sobre o co-processador pode trazer uma sobrecarga significativa no tempo de execução. Esse fato se deve ao número de registradores, estágios de pipeline e flushes de caches no co-processador. Por outro lado, a não preempção pode causar problemas em sistemas em tempo real, que possuem tarefas com tempos predefinidos de início ou término. Buscando diminuir o tempo gasto com a preempção, obedecer restrições de tempo de tarefas em tempo real e também tratar a precedência de execução de tarefas com desempenho, o trabalho proposto por Chen et al. (2013) propõe um algoritmo de escalonamento em tempo real, chamado HDS (Heterogeneous Dual-Core Scheduling), composto por duas políticas distintas, uma para o processador de propósito geral e a outra política para o co-processador.

O algoritmo HDS assume o conceito de tarefas e subtarefas, onde as tarefas são necessariamente executadas pelo processador, e as subtarefas (disparadas por alguma tarefa) são executadas pelo co-processador ou processador. A designação da unidade de processamento a ser utilizada por uma subtarefa é estática, ou seja, previamente já se sabe se a subtarefa será executada no processador ou no co-processador. Adicionalmente, esse algoritmo assume que para cada tarefa, sejam previamente definidas as restrições de tempo, as quais são: tempo de chegada (início da execução), tempo de execução máximo (pior caso), tempo de resposta e deadline da tarefa (tempo de término).

Todas as tarefas iniciam sua execução no processador, sendo que as subtarefas predefinidas a serem executadas no co-processador são vistas pelo processador como tarefas suspensas, até que terminem sua execução no coprocessador. Todas as tarefas executadas no escalonador do processador estão sobre a abordagem do algoritmo EDF (Earliest Deadline First), onde as tarefas com tempos de término próximos são as próximas a serem escalonadas para a execução.

A política de escalonamento no co-processador adota a abordagem de pontos de preempção. Essa abordagem insere pontos no tempo, durante a execução de uma subtarefa, onde é permitido que essa subtarefa sofra uma preempção. Isso deve ocorrer quando uma subtarefa com o deadline mais próximo que a subtarefa em execução esteja esperando pela execução. Essa abordagem é destinada a evitar que deadlines sejam atingidos nas subtarefas executadas no coprocessador quando a preempção é evitada devido à sobrecarga da troca de contexto.

O método Kinship, proposto recentemente por pesquisadores da Intel Gupta et al. 2013), avalia os processos dinamicamente de acordo com os tipos de re- 
cursos mais requisitados, combinando esses processos com os recursos disponiveis no sistema. O Kinship é utilizado para escalonar processos do sistema operacional como também CPUs virtuais de máquinas virtuais (VCPUs - Virtual machines' Virtual CPU's). Esse termo é utilizado para designar as entidades a serem escalonadas. Do outro lado, é utilizado o conceito de CPUs físicas (PCPU - Physical CPU) para denominar as unidades de processamento.

O método proposto por esse trabalho utiliza as características existentes no hardware e a carga de cada processo para gerar a métrica Kirship, a qual consiste em um número que reflete a melhor combinação atual entre VCPUs e PCPUs. Os parâmetros utilizados para calcular a métrica são calculados em tempo real, e também fornecidos previamente pelo usuário.

A assimetria considerada por esse método abrange dois conjuntos:

- Assimetria de desempenho: Cobre a variação de poder de processamento devido a diferenças de frequência, execução in-order ou out-of-order, tamanho da cache, etc. Em resumo, são diferenças que o software não enxerga e não necessita saber para executar normalmente; e

- Assimetria funcional: Processadores customizados (aceleradores) com diferentes conjuntos de instruções.

As assimetrias desempenho e funcional podem fazer com que um conjunto de diversos tipos de recursos possa variar entre cada PCPU do sistema. Nesse trabalho, o conjunto de recursos considerado é composto pelos seguintes elementos: cache, memória, CPU e I/O.

Durante a execução de um VCPU, a utilização de cada um dos recursos anteriores é medida e acumulada para cada VCPU. Do mesmo modo, também é medida a utilização de cada um dos recursos de um PCPU considerando todos os VCPUs que executem sobre ele, de modo que o método saiba o quanto cada recurso de cada PCPU está sendo utilizado. Essas medidas são levadas em consideração no cálculo da métrica Kirship, utilizada para determinar qual PCPU é melhor para cada VCPU.

O método também considera a limitação de PCPUs que podem executar um determinado VCPU. Em casos onde existem PCPUs com diferenças em conjuntos de instruções, um PCPU não compativel com um VCPU pode ser retirado do grupo de execução desse VCPU (o resultado da métrica Kirship nesse caso é um número negativo muito pequeno, fazendo com que o VCPU em questão não seja escolhido pelo escalonador).

Também é considerado no cálculo da métrica um conjunto de pesos fornecido pelo usuário, quantificando previamente a utilização de cada recurso (cache, memória, CPU e I/O) para um determinado VCPU. 
Um outro tipo de abordagem proposto por pesquisadores da Intel, consiste na utilização do hardware para auxiliar o escalonador durante a escolha do processador a ser designado a um processo. Tal arquitetura é abordada superficialmente em Srinivasan et al. (2011b) e Srinivasan et al. (2011a), e detalhada na patente Iyer et al. (2012).

A arquitetura proposta possui componentes implementados no processador que são responsáveis por monitorar os processos com o intuito de extrair medidas de desempenho, tais como CPI e MPI Misses Per Instruction, para serem armazenadas e posteriormente utilizadas para predizer o desempenho em outros processadores e, consequentemente, designar o melhor processador para uma determinada tarefa (Iyer et al., 2012). Os componentes implementados em hardware dessa arquitetura são:

- Performance counters: Componente responsável por monitorar um processo fornecendo informações relacionadas à decomposição do CPI stall durante a execução, ou seja, qual tipo de recurso o processo está consumindo mais, ou perdendo mais ciclos;

- Monitor de desempenho: Monitora o processo obtendo seu desempenho e também uma estimativa, baseada em sua CPI, do desempenho do mesmo processo em outros processadores, levando-se em consideração também o consumo de energia; e

- Tabela de histórico de desempenho: Armazena o histórico de desempenho de cada processo em cada processador. Essa tabela é utilizada pelo escalonador do sistema operacional para obter as métricas utilizadas na escolha do melhor processador.

A métrica adotada pelo componente de lógica de controle é a decomposição do CPI stall, mensurado na execução do processo, em base (ciclos úteis de processamento) e ciclos despendidos em operações relacionadas à memória e à cache. O desempenho de um processo é medido nos demais processadores por meio dessa decomposição, levando em consideração fatores de escala em relação aos processadores.

Com os desempenhos mensurados e estimados, é realizado um ordenamento de tarefas por esse fator de desempenho, sendo o processador de maior capacidade computacional designado aos processos que possam maximizar o desempenho.

Outro trabalho, também proposto por pesquisadores da Intel (Koufaty et al. 2010), propõe a estimativa de desempenho de cada processo em cada processador, por meio da decomposição do CPI em stalls internos e externos (Figura 2.14. 


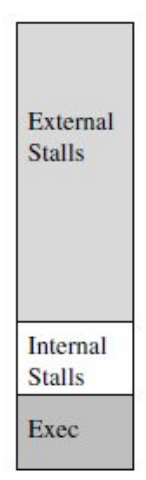

Big core

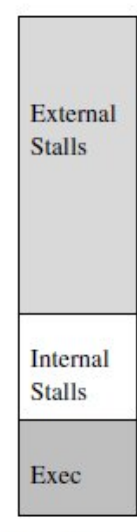

Small core

(a) CPI dominated by external stalls, small core bias
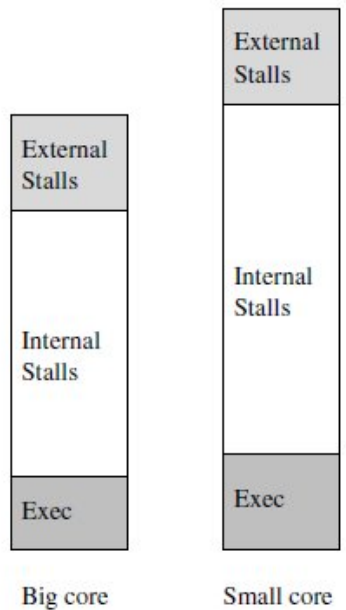

Small core

(b) CPI dominated by internal stalls, small core bias

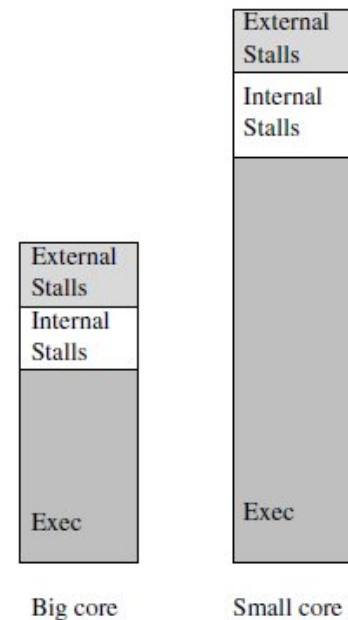

(c) CPI dominated by execution cycles, big core bias

Figura 2.14: Decomposição do CPI em stalls internos e externos (Koufaty et al., 2010)

Os stalls internos são causados por latências internas do processador, como cache, TLB, saltos não previstos, entre outros. Por outro lado, os stalls externos identificam latência com acesso a recursos externos ao processador. No escalonador proposto por Koufaty et al. (2010), os processos que possuem uma quantidade dominante de stalls internos ou externos devem executar no processador com menor desempenho. Consequemente, os processos que possuem uma quantidade dominante de ciclos efetivos devem executar no processador que possui maior desempenho. Essas métricas são retiradas por monitores em hardware. No entanto, segundo Koufaty et al. (2010), devido à dificuldade de implementação de monitores de desempenho em arquiteturas out-of-order, as métricas relacionadas a stalls externos são estimadas de acordo com as requisições fora do último nível de cache (LLC - Last Level Cache). Essas estimativas, segundo o próprio autor, são empíricas e não precisas, sendo utilizadas como uma aproximação para traçar um threshold para qualificar o processo entre os processadores.

No escalonador CAMP proposto por Saez et al. (2012), é utilizada uma arquitetura composta por dois processadores, um com alto desempenho computacional, e outro com menor quantidade de recursos. Nesse trabalho, o escalonamento é realizado levando em consideração os paralelismos em nível de threads e de instruções (TLP e ILP), qualificando os processos que possuem um alto nível de ILP, para executar no processador com alto desempenho, enquanto que o processador com menor desempenho é utilizado para executar os processos com maior paralelismo (Figura 2.15). Para isso, é utilizada uma projeção levando em consideração o comportamento do processo no proces- 
sador atual, sem necessitar de amostragem de todos os processadores para a aquisição das métricas . O cálculo das métricas para classificar os processos em TLP dominante ou ILP dominante é realizado em tempo real, levando em consideração dados como IPC, faltas nas caches e stalls relacionados à latência de execução de instruções em geral. Essas medidas são amostradas de um monitor de desempenho, cujas leituras são realizadas a cada 200 milissegundos, no caso do experimento realizado.

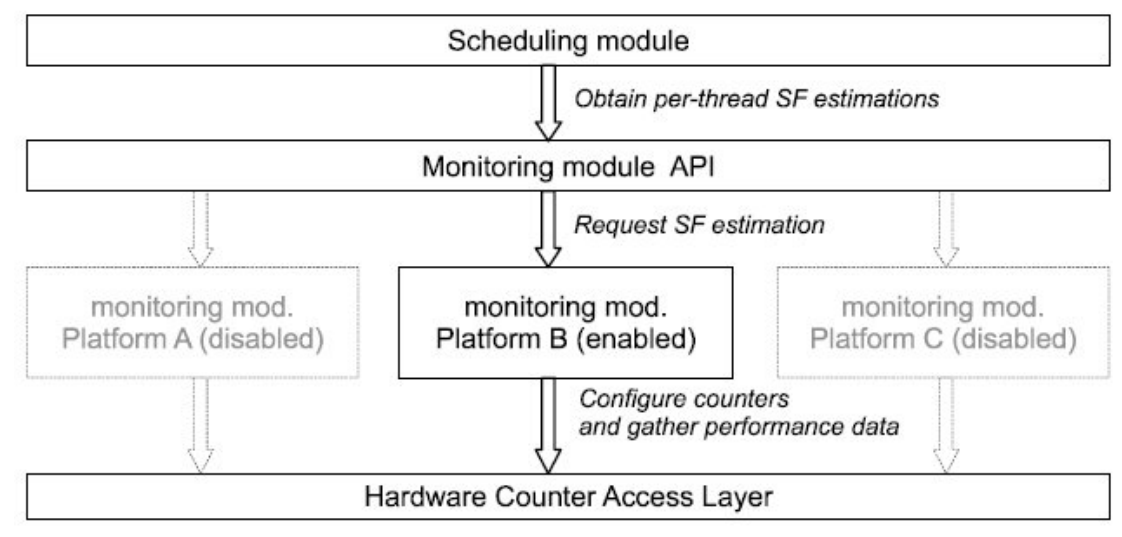

Figura 2.15: Componentes do escalonador CAMP (Saez et al., 2012)

Seguindo também o propósito de associar o processador com maior desempenho ao processo que tem um alto índice de IPC, o trabalho proposto por Petrucci et al. (2012b) apresenta um modelo de otimização de consumo de energia que leva em consideração o IPC e as faltas na cache LLC. Tal modelo propõe a execução períodica do monitoramento de cada processo, por meio de monitores de desempenho em hardware. Após obter os dados, o algoritmo calcula a predição com base em seu modelo, realizando as migrações de processos de acordo com a associação realizada entre processo/processador. A partir do modelo proposto, é possivel estimar a carga dos processadores, podendo-se determinar o desligamento momentâneo de um processador com o objetivo de diminuir seu consumo de energia (Petrucci et al., 2012a). No mesmo contexto, outra abordagem proposta por Cong \& Yuan (2012) também utiliza monitores de desempenho para realizar uma associação dentre processo/processador, de acordo com o consumo de energia.

\subsubsection{Classificação comparativa dos trabalhos}

Com o objetivo de situar o presente trabalho e classificar os trabalhos existentes relacionados ao escalonamento em arquitetuturas heterogêneas, nesta seção são apresentadas as principais características relacionadas a três classes que definem o contexto dos trabalhos: a arquitetura, sistema operacional e heurística do escalonador. A partir dessas características, é realizada uma 
comparação entre as principais publicações relacionadas ao escalonamento heterogêneo descritas neste capítulo.

No contexto de arquitetura, as seguintes características podem ser relacionadas:

- Modelo: Define o tipo da arquitetura assimétrica utilizada pelo projeto. As arquiteturas existentes são: virtualmente assimétrica, fisicamente assimétrica e híbrida;

- Implementação: Muitos trabalhos apresentados não possuem implementação, obtendo resultados por meio de simulação. Nessa característica cada projeto é classificado como implementado ou simulado; e

- Numéro de CPUs: Quantidade de processadores na arquitetura utilizados para avaliação experimental.

A Tabela 2.3 apresenta essas caraterísticas para os principais escalonadores, atualmente, para arquiteturas heterogêneas.

Tabela 2.3: Comparativo entre os principais algoritmos de escalonamento (Arquitetura)

\begin{tabular}{|c|c|c|c|}
\hline Referência & Modelo & $\begin{array}{c}\text { Avaliação } \\
\text { Experimental }\end{array}$ & CPUs \\
\hline Kumar et al. 2004 & Fisicamente Assimétrico & Simulado & Vários \\
\hline Becchi \& Crowley 2006 & Fisicamente Assimétrico & Simulado & Vários \\
\hline Shelepov et al. 2009 & Fisicamente Assimétrico & Implementado & 4 \\
\hline Li et al. 2007 & Arquitetura Híbrida & Implementado & $2(4)+2(4)$ \\
\hline Van Craeynest et al. 2012 & Fisicamente Assimétrico & Implementado & 2 \\
\hline Chen et al. 2013 & Fisicamente Assimétrico & Simulado & 2 \\
\hline Gupta et al. 2013 & Fisicamente Assimétrico & Implementado & 6 \\
\hline Srinivasan et al. $2011 \mathrm{~b}$ & Fisicamente Assimétrico & Implementado & 2 \\
\hline Koufaty et al. 2010. & Fisicamente Assimétrico & Implementado & 2 \\
\hline Saez et al. 2012 & Fisicamente Assimétrico & Implementado & 2 \\
\hline Petrucci et al. $2012 \mathrm{~b}$ & Fisicamente Assimétrico & Implementado & 2 \\
\hline Presente trabalho & Fisicamente Assimétrico & Implementado & 2 \\
\hline
\end{tabular}

No contexto de sistema operacional, as seguintes características podem ser relacionadas:

- Modelo: Conforme descrito na Seção 2.1.2, um sistema operacional que oferece suporte a arquiteturas heterogêneas pode ser caracterizado como: restrito, híbrido e unificado;

- Implementado: Essa característica indica se o sistema operacional é proposto, simulado ou implementado; e

- Nome: Em geral, o suporte oferecido por sistemas operacionais a arquiteturas heterogênas é estendido de algum sistema operacional existente. Essa característica indica o nome do sistema operacional estendido. 
Tabela 2.4: Comparativo entre os principais algoritmos de escalonamento (Sistema operacional)

\begin{tabular}{|c|c|c|c|}
\hline Referência & Implementado & Modelo & Nome \\
\hline Kumar et al. 2004 & Não & - & - \\
\hline Becchi \& Crowley 2006 & Não & - & - \\
\hline Shelepov et al. 2009 & Sim & Restrito & Solaris \\
\hline Li et al. 2007 & Sim & Híbrido & Linux \\
\hline Van Craeynest et al. (2012) & Não & - & - \\
\hline Chen et al. 2013 & Não & - & - \\
\hline Gupta et al. 2013 & Sim & Restrito & Linux \\
\hline Srinivasan et al. $2011 \mathrm{~b}$ & Sim & - & Próprio escalonador \\
\hline Koutaty et al. 2010 & Sim & Restrito & Linux \\
\hline Saez et al. 2012 & Sim & Restrito & Solaris \\
\hline Petrucci et al. $2012 \mathrm{~b}$ & Sim & Restrito & Linux \\
\hline Presente trabalho & Sim & Restrito & Linux \\
\hline
\end{tabular}

Na Tabela 2.4 são apresentadas as características do sistema operacional utilizado em cada escalonador.

No contexto de escalonamento, as seguintes características podem ser relacionadas:

- Ganho: Indica se o ganho do algoritmo em questão é relacionado a cada processo ou tenta aumentar o desempenho global do sistema;

- Foco do ganho: O aumento de desempenho e diminuição do consumo de energia são as principais motivações das arquiteturas heterogêneas. Nesta característica, cada algoritmo é classificado de acordo com seu foco, desempenho ou consumo;

- Algoritmo: Muitos algoritmos necessitam de conhecimento prévio da carga dos processos para então escalonar estaticamente o processo. Assim, esta característica classifica o escalonador como online ou offline;

- Baseado em Amostragem: Muitos algoritmos necessitam que os processos executem sobre cada tipo de processador para obter seu desempenho. Esta classificação indica se o escalonador necessita ou não da amostragem em vários processadores;

- Métrica: Indica a métrica para medir desempenho no algoritmo, considerada na heurística para futura tomada de decisão. A principais métricas são: IPC, IPS, MIPS, CPI, entre outras;

- Ambiente: Assim como no caso da arquitetura e do sistema operacional, muitos trabalhos apresentam resultados de ambientes simulados. Nesta característica o escalonador é classificado em simulado ou implementado;

- Balanceamento: Indica se o algoritmo implementa ou não uma heurística de balanceamento; 
- Monitor de desempenho: Alguns algoritmos utilizam monitores de desempenho em hardware para realizar as estimativas de desempenho; e

- Implementação em hardware: Indica se o escalonador em questão utiliza componentes próprios implementados em hardware para estimar desempenho ou guiar o escalonamento/balanceamento.

A Tabela 2.5 descreve as principais caraterísticas relacionadas a heurística adotada para cada escalonador proposto.

\subsubsection{Considerações finais}

Neste capítulo foi apresentada resumidamente a evolução do paralelismo desde as primeiras arquiteturas de processadores até as arquiteturas heterogêneas, que combinam diferentes processadores em uma mesma arquitetura.

Uma das principais vantagens da exploração da heterogeneidade de processadores consiste em uma adaptação eficiente entre tipos de processos e processadores, tendo como objetivo maior desempenho e menor consumo de energia. Como apresentado neste capítulo, existem diferentes métodos propostos com esse objetivo, que variam desde heurísticas que realizam suas associações pela simples obtenção do tempo de uso do processador por um processo, até heurísticas implementadas em hardware que levam em consideração desempenho e consumo nos cálculos para a realização da associação.

Conforme pode ser observado, existe uma tendência atual em explorar as arquiteturas com processadores compartilhando o mesmo conjunto de instruções. Esse tipo de arquitetura tem menor sobrecarga em mudanças relacionadas ao suporte da heterogeneidade nos sistemas operacionais e constitui um dos primeiros passos para gerenciar arquiteturas mais complexas envolvendo processadores com diferentes conjuntos de intruções e registradores (Bower et al., 2008) (Van Craeynest \& Eeckhout, 2013) Georgakoudis et al. (2013). 


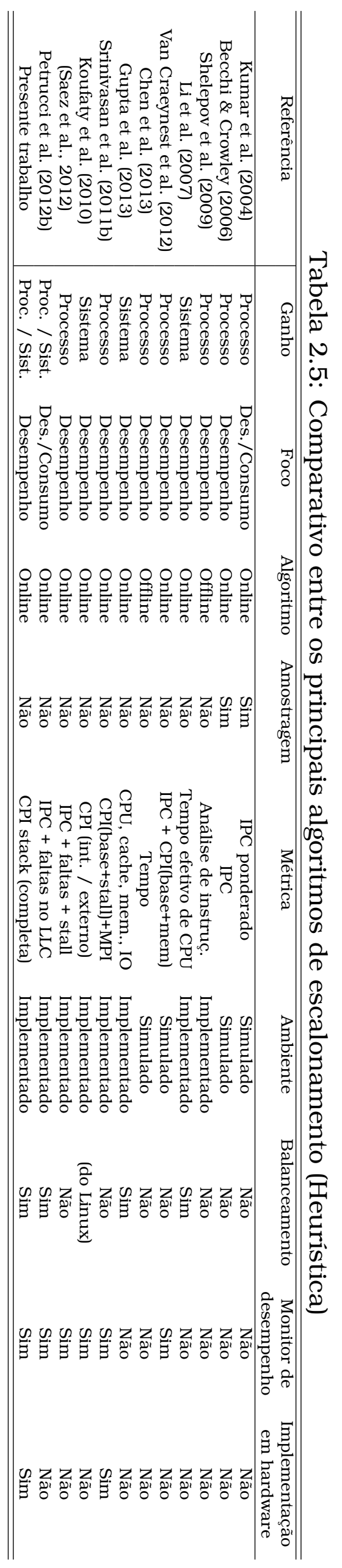




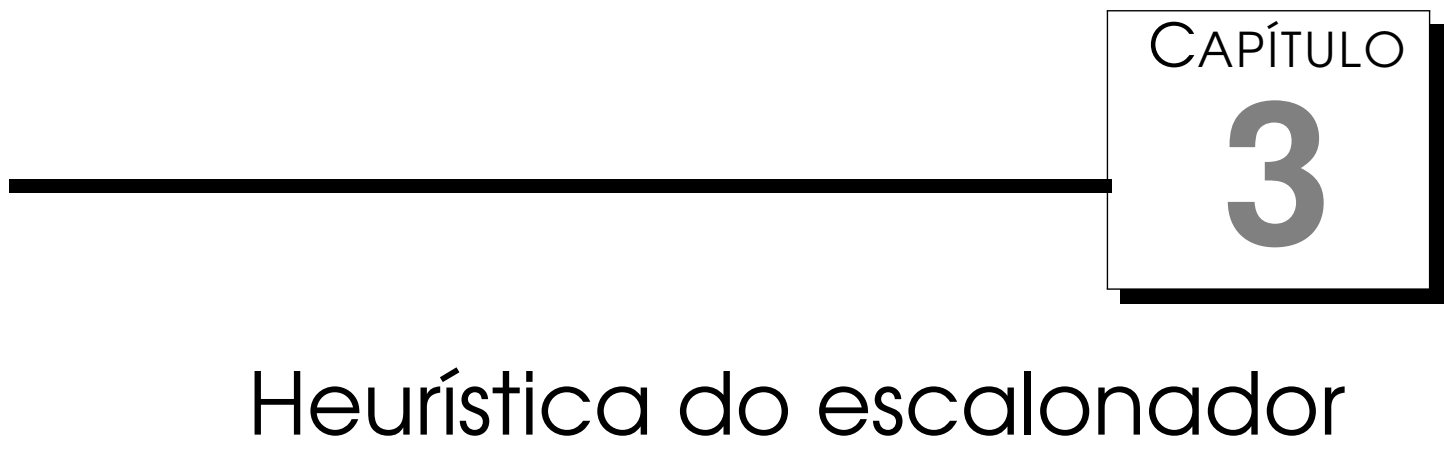

Como mencionado previamente, diversas pesquisas, e até mesmo produtos comerciais, indicam as arquiteturas com processadores heterogêneos como sendo uma tendência na busca de maior desempenho e menor consumo de energia. No entanto, para efeito do aproveitamento da heterogeneidade de modo a alcançar os objetivos citados, é necessária a utilização de métodos efetivos de escalonamento que busquem maximizar o desempenho e/ou diminuir o consumo. Para tanto, essa tarefa deve ser realizada levando em consideração as características inerentes à arquitetura de hardware utilizada, como também as características das cargas computacionais que nela executam.

A consideração desses dois itens no escalonamento não é uma tarefa simples, já que envolve uma necessidade de projeção de desempenho do processo entre os processadores, alcançada por amostragem ou por cálculos que consideram as características das arquiteturas. Como prova, muitas pesquisas têm sido desenvolvidas utilizando a abordagem de associação offline entre processadores e processos, onde previamente os processos já são associados aos processadores, antes mesmo de começarem a executar. No entanto, tal abordagem é restrita a ambientes com processos conhecidos e não são aplicáveis a ambientes genéricos, tal como um computador pessoal, onde o comportamento dos processos são indefinidos antes de começarem a executar e, adicionalmente, nem ao menos existe um conhecimento prévio de qual processo deve executar.

Além desse fato, grande parte dos escalonadores propostos, classificada dentro da abordagem online que qualifica o processo em tempo de execução, não considera o balanceamento de desempenho do sistema como um todo, privando-se apenas a escolher para a execução o processador que melhor se 
adequa às características do processo em questão. Esse método pode garantir a diminuição do tempo efetivo de utilização do processador pelo processo, porém, não garante necessariamente que o tempo real de sua execução seja menor, já que a heurística adotada pode indicar a vários processos o mesmo processador, aumentando sua carga de processamento e, consequentemente, aumentando o tempo real de execução de todos os processos que executam sobre esse mesmo processador.

Neste capítulo é apresentada a heurística utilizada no escalonamento, a qual se baseia no monitoramento de desempenho em tempo real dos processos em execução para realizar uma estimativa de projeção de desempenho de todos os processos para todos os processadores. A partir das projeções, é realizado um balanceamento utilizando um algoritmo de otimização combinatória, o qual realiza a associação sub-ótima entre processos e processadores, buscando maximizar o desempenho do sistema. Com esse objetivo, este projeto define os seguintes pontos de atuação:

- Determinar a métrica de avaliação de desempenho do processo: Antes de realizar a associação entre processos e processadores, deve ser definido que tipo de métrica deve ser levado em consideração para a realizar a medida de desempenho do processo;

- Avaliar o desempenho do processo: A heurística deve definir como o desempenho do processo deve ser mensurado de acordo com a métrica definida;

- Determinar a métrica de avaliação do processador: A arquitetura de cada processador deve ser avaliada, de modo que o resultado da avaliação tenha equivalência com a métrica utilizada na avaliação do processo. Isso se deve ao fato da necessidade de haver um modo de realizar uma comparação entre recursos necessários pelos processos e recursos existentes nos processadores;

- Avaliar a arquitetura do processador: De acordo com a métrica definida, também faz parte dos objetivos da heurística do projeto, a definição do procedimento de mensuração do desempenho da arquitetura; e

- Associar processador e processo: A partir da métrica de avaliação de desempenho de processos e processadores, o propósito principal da heurística é determinar o modo que a associação deve ser realizada visando a maximização do desempenho dos processos do sistema.

Esses pontos são abordados, por meio de exemplos de comportamentos reais de benchmarks, com o objetivo de demonstrar os motivos das principais decisões tomadas. 


\section{1 Contexto do modelo}

A heurística de escalonamento descrita neste trabalho pode ser aplicada aos tipos de arquitetura fisicamente assimétrica e híbrida, ou seja, o modelo considera uma arquitetura com processadores de configurações distintas, não necessariamente compartilhando um conjunto idêntico de instruções.

Este trabalho apresenta uma heurística que considera medidas de desempenho dos processos sendo realizadas continuamente e em tempo real, classificada dentro do grupo dos algoritmos online de escalonamento. O principal objetivo desse monitoramento é maximizar o desempenho global dos processos, como também em particular para cada processo. Ganhos relacionados ao consumo não são abordados na heurística descrita.

Outra consideração importante consiste na política de ordenação da execução dos processos. O objetivo principal da heurística apresentada neste projeto é a associação entre processadores e processos com o intuito da maximização do desempenho, priorizando a demonstração de como associação de características entre eles deve ser realizada. Com isso, este estudo não aborda a ordem em que os processos devem ser executados. Como poderá ser visto posteriormente, a ordem da execução pode ser dada pelo escalonador padrão do sistema operacional em que esta heurística é implementada.

\subsection{Materiais}

Nesta seção são utilizados os seguintes benchmarks como exemplos: Dhrystone, Whetstone, FBench e inversão de matrizes. Os objetivos de cada um desses benchmarks estão descritos em detalhes no Capítulo 6 .

Nos exemplos citados posteriormente, esses benchmarks são executados utilizando o sistema operacional Linux (kernel 2.6.36) sobre dois processadores SPARC V8 - Leon 3 (definidos como CPUO e CPU1). Os dois processadores possuem configurações distintas, com o objetivo de gerar as diferenças nas execuções tratadas nesta seção. O conjunto de configurações de cada processador está descrito na Tabela 3.1 .

As decomposições dos stalls dos benchmarks apresentados nesta seção foram adquiridas por meio do componente de monitoramento de desempenho, implementado conforme arquitetura descrita na Seção 4.4 .

\subsection{Motivação}

As figuras a seguir ilustram o comportamento de três benchmarks durante seus períodos de execução. O comportamento bem definido do benchmark 
Tabela 3.1: Configurações para CPUO e CPU1

\begin{tabular}{ccc}
\hline \hline Recurso & CPUO & CPU1 \\
& (SPARC V8 - Leon 3) & (SPARC V8 - Leon 3) \\
\hline Frequência & $80 \mathrm{Mhz}$ & $80 \mathrm{Mhz}$ \\
Suporte a Branch Prediction & Sim & Não \\
Latência da multiplicação & 2 ciclos & 5 ciclos \\
Cache de dados & 4 sets / way 1KB & 1 sets / way 1KB \\
Cache de instruções & 4 sets / way 1KB & 1 sets / way 1KB \\
FPU & FPU-LITE & FPU FULL \\
\hline \hline
\end{tabular}

Dhrystone, ilustrado na Figura 3.1, demonstra que mais de 50\% de seu tempo de execução foi gasto com faltas na cache de instruções, sendo que, em média, apenas $20 \%$ de seu tempo de execução foram dedicados a operações realmente efetivas. De modo similar, o benchmark de inversão de matrizes (Figura 3.2) apresenta um comportamento bem definido a partir de um certo tempo. Podese notar que no início de sua execução houve um pico de tempo despendido com faltas na cache de instruções. Em seguida, após um período, esse gasto com a cache de instruções foi diminuindo e se estabilizando, enquanto que gastos com cache de dados devido às leituras/escritas de memória e cálculos utilizando a FPU foram tomando espaço. A Figura 3.3 ilustra o comportamento do benchmark Whetstone, onde se pode notar um dinamismo maior de requisições de recursos durante seu período de execução, em comparação com Dhrystone e inversão de matrizes. O tempo despendido com instruções de ponto-flutuante permanece acima dos 30\% em grande parte de seu tempo, sendo que no início de sua execução pode-se notar que houve uma fatia próxima de 50\% de tempo despendido com cálculos na FPU.

Analisando esses exemplos, é possível afirmar que o tempo gasto com a execução de instruções de ponto-flutuante, acessos a cache, execução de instruções de salto, entre outros, pode variar de acordo com o algoritmo implementado e também pode variar de acordo com o tempo. Dos exemplos ilustrados previamente, em nenhum dos casos a percentagem gasta com computação efetiva (cpi_comp_base) é maior que o tempo gasto com acesso a recursos (memória, cache, FPU, entre outros). Nesse sentido, conclui-se que diminuindo o tempo gasto com os stalls (percentagem do tempo gasto com computação não efetiva) pode-se também diminuir o tempo total de execução.

No entanto, os atrasos não estão associados exclusivamente ao programa, eles são diretamente dependentes da arquitetura onde o programa é executado, ou seja, os atrasos dependem das memórias, barramento, processador e demais dispositivos, dos quais, o processador é considerado o principal recurso determinante de desempenho. Considerando o comportamento do benchmark Drystone, apresentado na Figura 3.1. pode-se afirmar que a maior 


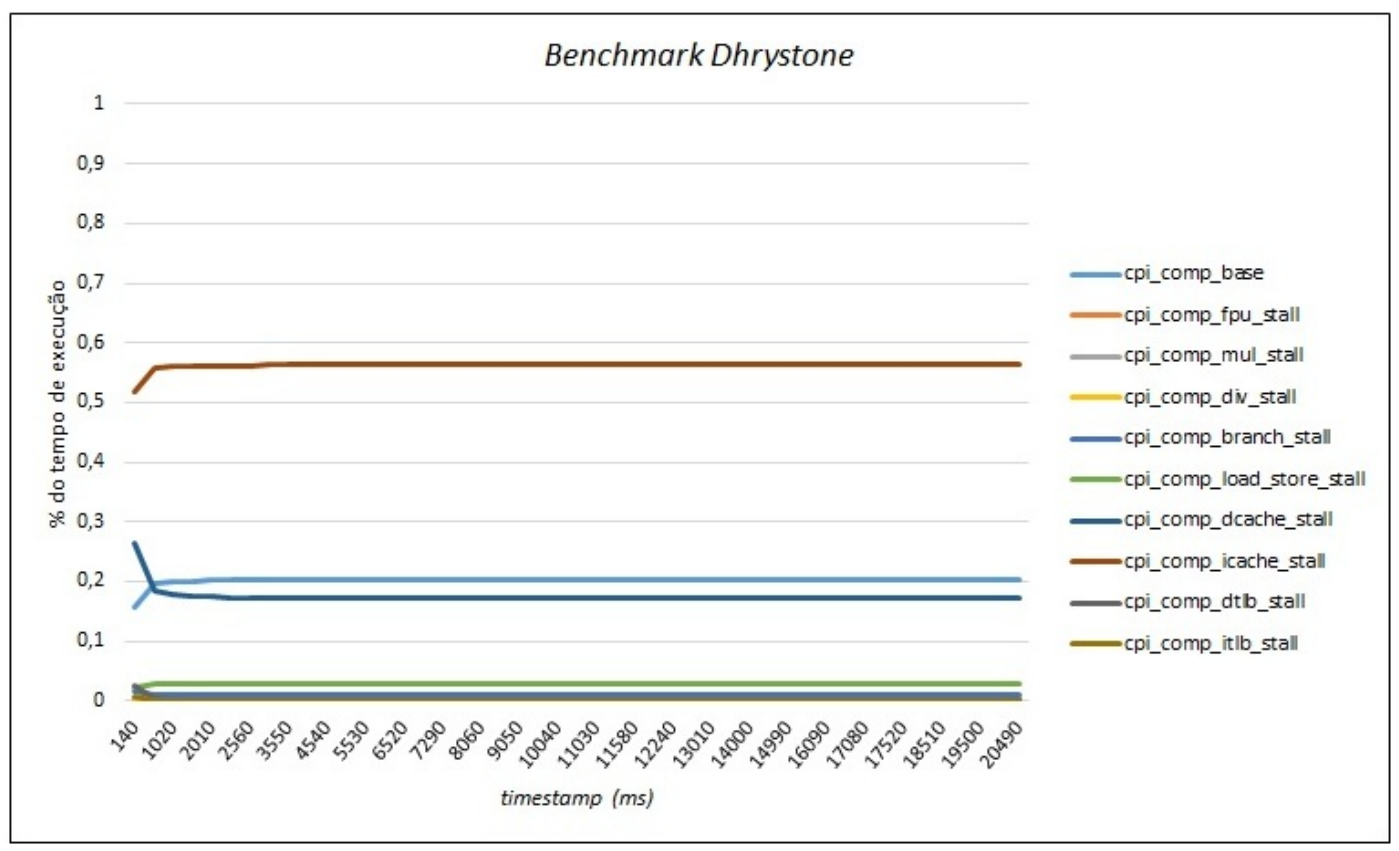

Figura 3.1: Comportamento do benchmark Dhrystone

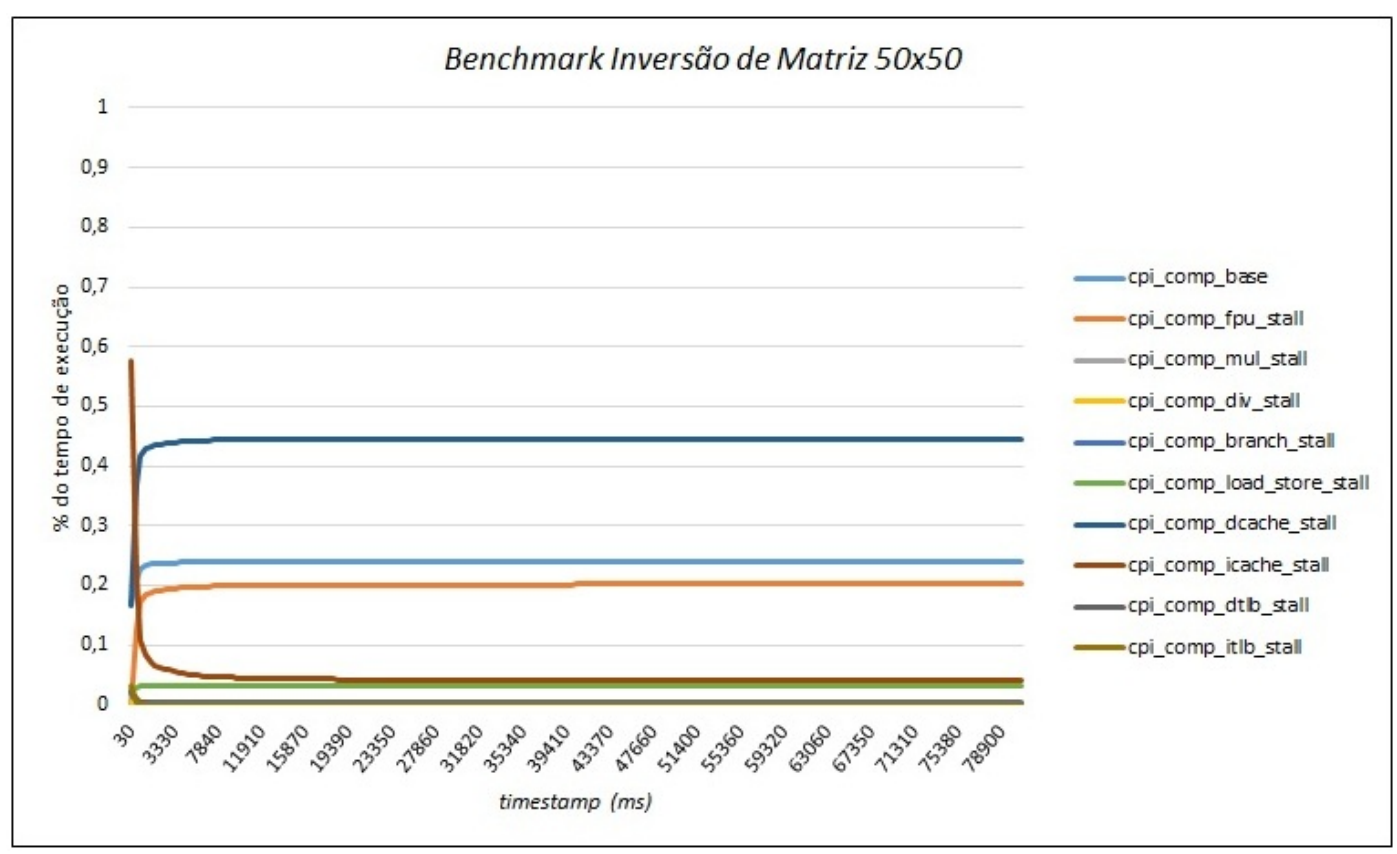

Figura 3.2: Comportamento do benchmark Inversão de Matriz 50x50 


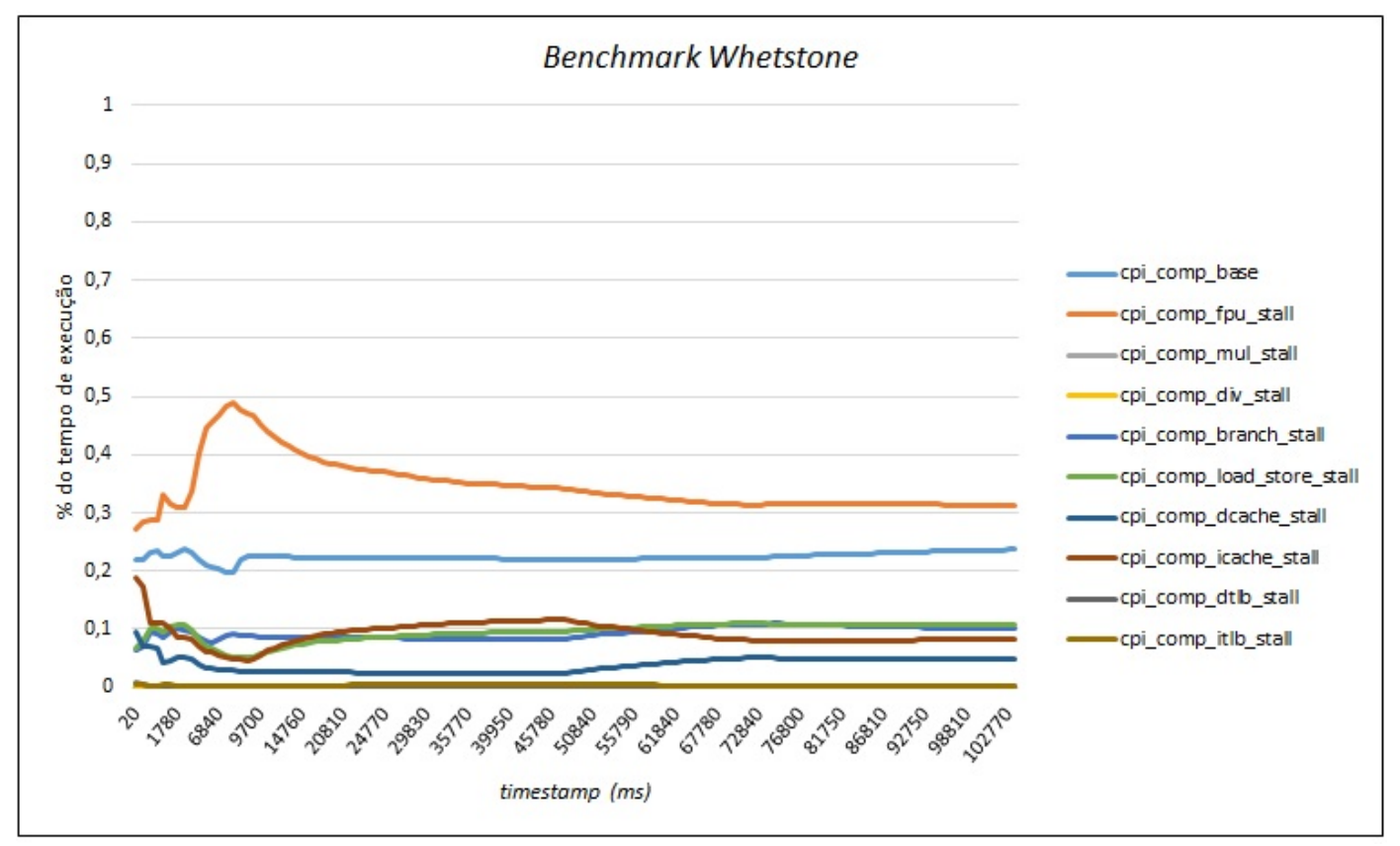

Figura 3.3: Comportamento do benchmark Whetstone

quantia de tempo é gasta com faltas na cache de instruções, conforme mencionado previamente. Consequentemente, aumentando-se o tamanho da cache de instruções, essa percentagem média gasta com acesso a cache de instruções pode diminuir, diminuindo também o tempo total gasto com a execução desse benchmark. Nesse contexto, a Figura 3.4 ilustra um comportamento semelhante relacionado ao benchmark FBench. Nesse exemplo, o FBench foi executado sobre dois processadores com arquiteturas distintas, contudo, com a mesma arquitetura de barramento e demais dispositivos. Apesar de ser o mesmo benchmark, os resultados das execuções sobre os processadores distintos são totalmente diferentes. Conforme pode ser visto, o tempo de execução do FBench na CPUO levou aproximadamente $58 \%$ do tempo gasto para a execução na CPU1. Com isso, pode-se afirmar que existem diferenças consideráveis nas arquiteturas dos dois processadores.

Conforme a Tabela 3.1, a cache da CPUO é quatro vezes maior que a cache da CPU1, tanto para instruções quanto para dados. Outra diferença importante consiste na FPU utilizada. Na CPUO a FPU-LITE, em comparação com a FPU FULL na CPU1, é um componente reduzido em termos de tamanho e também possui um desempenho inferior que FPU FULL. Segundo o fabricante GAISLER 1, a FPU FULL pode ter um desempenho em torno de $20 \%$ maior que a FPU LITE. Essas diferenças arquiteturais entre os dois processadores refletem também no resultado do processamento do algoritmo.

Na Figura 3.4 pode-se observar que no início da execução do FBench, aproximadamente $45 \%$ do tempo de execução estavam sendo gastos com faltas na

\footnotetext{
${ }^{1}$ Intel: http://www.gaisler.com
} 


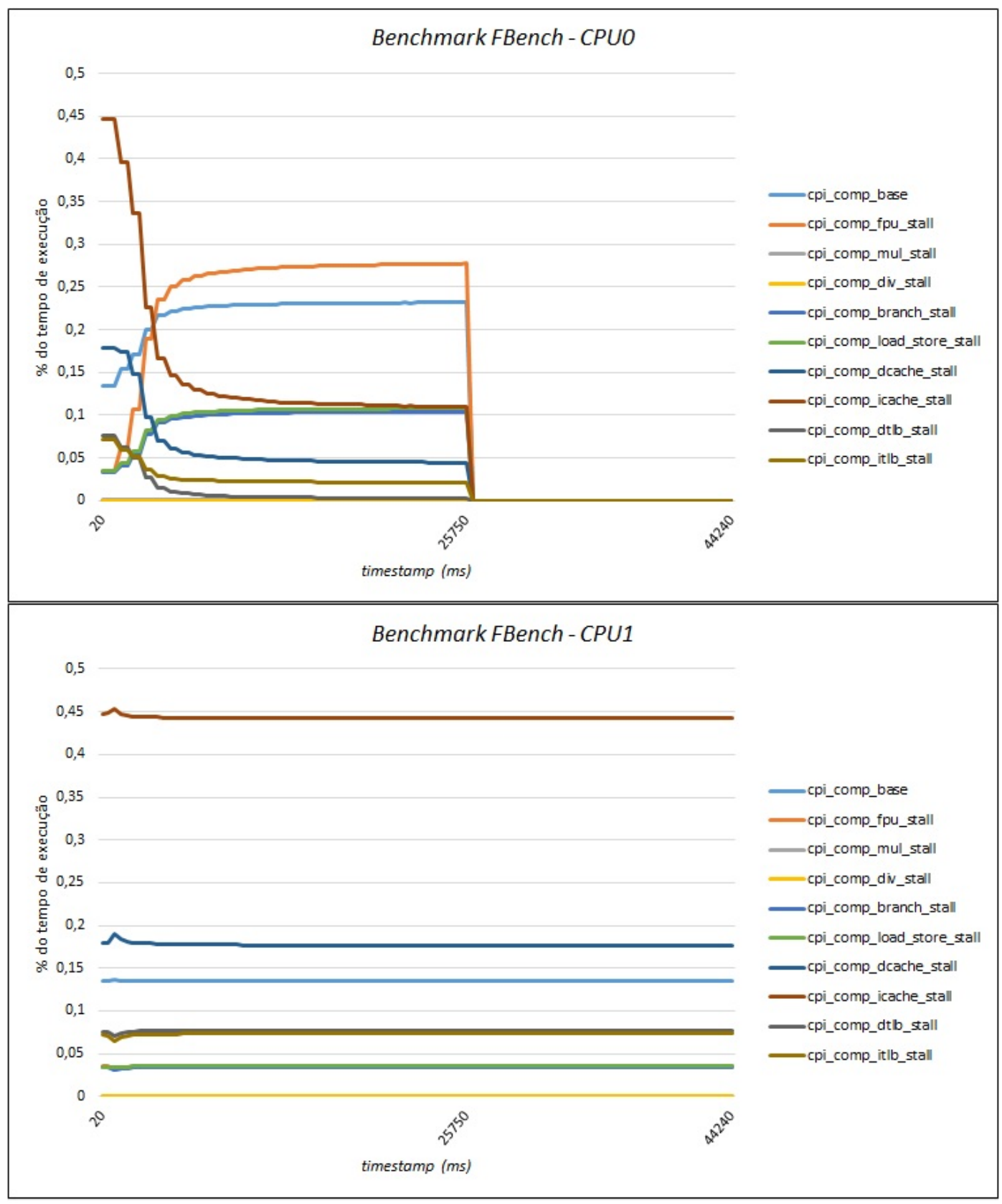

Figura 3.4: Comportamento do benchmark FBench em CPUO e CPU1 
cache de instruções. Tal comportamento também pode ser observado na execução do mesmo algoritmo sobre a CPU1, mas ao contrário da CPUO, a taxa aproximada de $45 \%$ de utilização do tempo do processador se manteve durante toda sua execução, enquanto que na CPUO essa quantia foi decrescendo na medida em que a cache acomodava as novas instruções. Por outro lado, a quantia de tempo utilizada para computação de instruções de ponto flutuante aumentou na CPUO, chegando a 27\%, enquanto se mateve estável na CPU1, ficando em torno de 3\%. Apesar da FPU utilizada na CPU1 possibilitar mais de $20 \%$ de ganho de desempenho na execução de instruções de ponto flutante, sua cache é seu grande gargalo, ocupando cerca de $45 \%$ do tempo de execução do FBench. Esse fator, também aliado ao bom desempenho da cache de dados da CPUO, faz com que o componente cp_comp_base desse processador seja $23 \%$ contra $13 \%$ da CPU1, determinando o desempenho superior oferecido pela CPUO.

Esses exemplos demonstram que cada processo pode ter um comportamento diferente em cada processador, podendo ser mais eficiente dependendo das configurações do processador e dos recursos requeridos pelo algoritmo. O escalonamento proposto por este trabalho explora esse comportamento distinto entre os processos, como também o comportamento dinâmico de cada processo durante seu tempo de execução, com o objetivo de melhor aproveitamento do hardware sobre o qual tais processos executam.

Contudo, para explorar o comportamento de um processo, é necessária a definição de uma métrica de desempenho capaz de representar essa variação dinâmica.

\subsection{Métrica de desempenho}

Em uma arquitetura heterogênea, um escalonador específico para associar processos a processadores, de acordo com as características de ambos, deve possuir uma medida de desempenho que qualifique tanto o processo quanto o processador, de modo a ser capaz de realizar a associação.

A métrica abordada por este trabalho consiste no CPI stack, que compreende a decomposição do número de ciclos gastos para executar as instruções em componentes de stall. Esses componentes demonstram onde o processador está gastando mais tempo para executar um determinado processo. É importante considerar que neste projeto o CPI é decomposto para cada processo, ou seja, não é aplicado globalmente, mas somente sobre os processos que são nessários monitorar, obtendo-se assim uma medida mais precisa para a projeção de desempenho.

A decomposição do CPI deve ser realizada utilizando componentes que es- 
tão ligados diretamente às configurações que possivelmente podem diferenciar entre as arquiteturas dos processadores utilizados. Como exemplo, pode-se citar a memória cache. A quantidade de cache disponivel é uma das configurações que mais podem mudar entre processadores e, consequentemente, pode ser uma das configurações que mais influenciam na execução dos processos, podendo haver mais ou menos ciclos gastos com o componente de cache. Assim, neste projeto, os principais componentes relacionados a alguma configuração do processador que possa ocasionar ciclos de stall são considerados na decomposição do CPI.

Os componentes de stall podem variar de acordo com a arquitetura adotada. Alguns processadores podem não ter recursos que outros mais modernos possuem, devido a esse fator, os componentes escolhidos para decompor o CPI estão diretamente relacionados à arquitetura utilizada. Dos exemplos mais comuns de componentes que podem causar stall nos processos, os seguintes podem ser citados:

- cpi_comp_base: Este componente não é um stall, ele compreende a quantidade de ciclos gastos efetivamente com a execução de instruções. A decomposição de CPI considera os ciclos efetivos, sendo que os atrasos são considerados nos componentes a seguir;

- cpi_comp_fpu_stall: As instruções de ponto flutuante podem causar impacto no desempenho de processos que as utilizem em grande quantidade. Esse impacto pode ser diferente em processadores que implementam FPU's diferentes, com mais ou menos recursos para executar essas instruções;

- cpi_comp_mul_stall: A multiplicação pode envolver vários ciclos de latência para se obter o valor final. Essa latência depende da implementação e do processor; por isso também faz parte dos componentes que envolvem stall;

- cpi_comp_div_stall: Uma divisão pode levar vários ciclos para ser executada, podendo variar de acordo com o método de divisão implementado no processador;

- cpi_comp_load_store_stall: O atraso relacionado ao acesso à memória pode estar relacionado a diversos fatores, entre eles podem ser citados: falta ocorrida em alguns dos niveis de memória cache, latência de acesso à memória devido a barramento, memória ocupada com operações de DMA, memória executando mecanismo de refresh, ou mesmo a falta da referência na TLB nos casos de processadores com MMU. Analisandose tais exemplos, pode-se concluir que os atrasos relacionados a barra- 
mento ou inerentes à memória em si podem ser considerados comuns a todos os processadores, não havendo necessidade de considerá-los. Contudo, considerando os casos de faltas ocorridas nos níveis de caches ou faltas ocorridas na TLB de dados, pode-se concluir que o componente cpi_comp_load_store_stall pode estar diretamente relacionado a esses componentes. Contudo, este projeto considera tal componente como sendo o atraso relacionado especificamente com dependências diretas encontradas no pipeline. As dependências podem ser minimizadas por meio da compilação, como também em tempo de execução pelo processador, especificamente por meio da execução out-of-order das instruções. Essa característica pode ser implementada de vários modos, sendo que os processadores podem ou não implementá-la. Portanto, pode-se considerar que os ciclos pertencentes ao componente cpi_comp_load_store_stall estão relacionados à dependência de instruções no pipeline;

- cpi_comp_branch_stall: Do mesmo modo que o componente cpi_comp_load_store_stall, o cpi_comp_branch_stall não é considerado uma dependência direta dos componentes de atraso de cache e TLB de instruções. Processos que executam diversos saltos podem ter seu desempenho melhorado por processadores que implementam métodos avançados de detecção de saltos ou mesmo de detecção de loops. Como essa implementação pode variar, esse componente é considerado na lista de componentes para a decomposição do CPI como sendo o atraso envolvido no cancelamento e carregamento de instruções no pipeline devido a ocorrência de saltos;

- cpi_comp_dcache_L(x)_stall: Em um sistema, pode haver diferentes niveis de cache de dados em seus processadores, sendo que cada nível pode ter diferentes tamanhos. Essa característica tem uma influência alta sobre a execução da maioria dos processos, podendo ocasionar latências maiores ou menores. Devido a esse fato, os atrasos relacionados a cache são também considerados na decomposição do CPI;

- cpi_comp_icache_L(x)_stall: Assim como a cache de dados, a cache de instruções pode ter diferentes níveis, sendo que cada um desses níveis pode ter um tamanho diferente. Tal característica também pode influenciar no desempenho dos processos;

- cpi_comp_dtlb_L(x)_stall: Processos que executam sobre processadores que possuem MMU podem ter seu desempenho afetado somente pelo fato de utilizarem endereços virtuais para acessar seus dados. Esse comprometimento se deve à configuração utilizada para a TLB de dados que em 
casos de falta das referências requisitadas, pode ocasionar diversos ciclos de latência; e

- cpi_comp_itlb_L(x)_stall: Em processadores que utilizam MMU, as referências utilizadas em instruções de call também são endereços virtuais e, do mesmo modo, necessitam do auxílio da TLB de instruções na tradução para endereço físico.

É importante considerar que esta heurística está relacionada às arquiteturas heterogêneas fisicamente assimétrica e híbrida. Desse modo, não são consideradas neste estudo a diferença de frequência entre processadores, tal como a presença da característica DVFS (Dynamic Voltage Frequency Scaling), devido a essa diferença pertencer ao modelo de arquitetura heterogênea virtualmente assimétrica.

Nas próximas seções, esses componentes citados acima estão presentes nos exemplos. Contudo, nos casos dos componentes relacionados às caches e TLBs, somente é considerado um único nível. Isso se deve ao fato de que o processador utilizado neste projeto tem somente um único nível de cache para dados, instruções, e TLB de dados e de instruções.

\subsection{Monitoramento de desempenho}

Os componentes citados anteriormente consistem na base para o cálculo dos desempenhos de processos e das arquiteturas dos processadores, como também da projeção de desempenho de todos os processos sobre todos os processadores utilizados no balanceamento. Por esse fato, é necessário que haja um método de extração dessa decomposição de CPI dos processos em execução. Esta tarefa deve ser realizada por meio de um componente denominado monitor de desempenho, ilustrado na Figura 3.5 .

Como um dos objetivos do escalonamento deste projeto é realizar o monitoramento em tempo real, considera-se que o monitor de desempenho deve estar localizado dentro do processador, de modo a receber as informações relacionadas à execução do processo corrente. Entre as informações recebidas pelo monitor, deve haver dados de controles provindos das caches e das TLBs, para que a decomposição tenha um resultado mais apurado. Como pode ser visto na Figura 3.5, a entrada do monitor compreende sinais de controle relacionados ao momento em que deve ser iniciado ou parado o monitoramento. A saída do monitor consiste nos componentes de CPI já decompostos.

A Figura 3.6 ilustra um exemplo dessa decomposição. Durante a execução dos benchmarks Whetstone, Dhrystone e Inversão de matrizes, os componentes de CPI são decompostos no timestamp de 10000ms, gerando um histograma que demonstra o quanto os processadores estão gastando em termos 


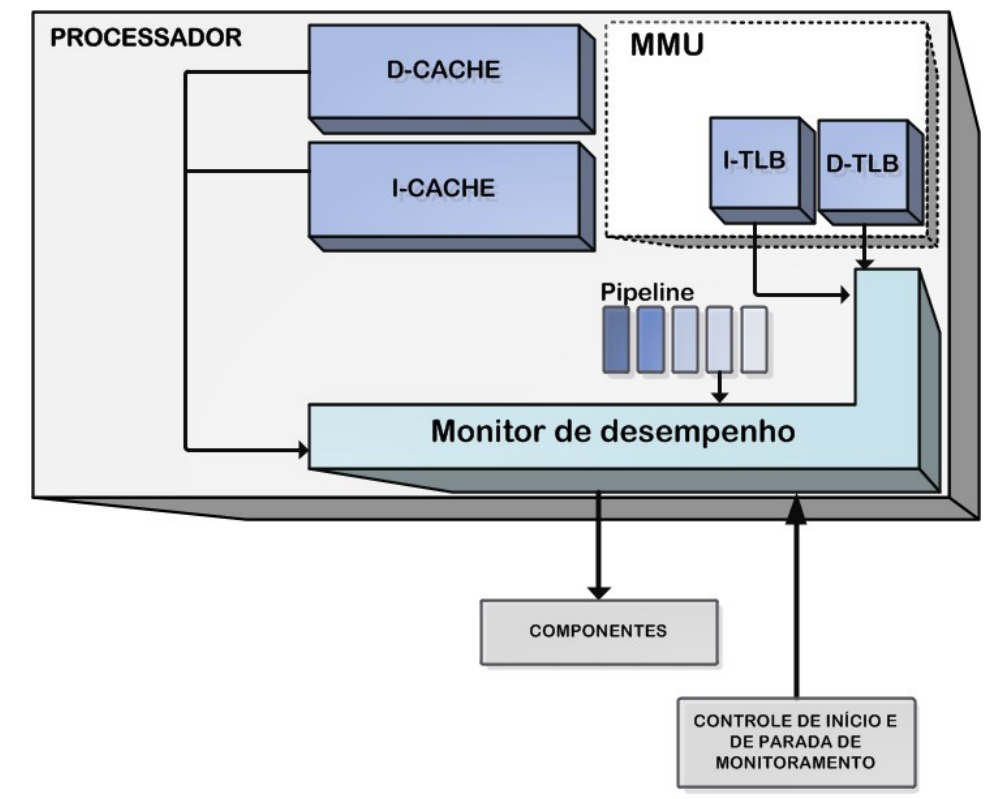

Figura 3.5: Monitor de desempenho

de tempo para cada componente da CPI dos três benchmarks. Com a obtenção desse histograma constantemente, é possivel acompanhar o dinamismo de todos os processos em execução, com o intuito de mensurar quais recursos estão sendo mais necessários naquele momento, como também, obter a medida dos pesos de todos os componentes sobre o desempenho de cada processo.

Os detalhes relacionados com a implementação do componente de monitoramento de desempenho estão descritos na Seção 5.2 .

\subsection{Pesos de desempenho dos processadores}

A mesma métrica de decomposição do CPI em componentes também é utilizada para qualificar o desempenho de um processador em relação com os demais processadores da arquitetura, qualificando-o por meio dos pesos de cada componente do CPI. Como exemplo, podem ser citados os processadores da Tabela 3.1, onde a CPU1, por ter uma FPU FULL pode ter um peso para o componente cpi_comp_fpu_stall acima de 20\% do mesmo componente para a CPU0, qualificando-o superior para execução de instruções de pontoflutuante. Sendo assim, cada processador tem vetor de pesos de desempenho, onde cada peso (cada componente da decomposição) consiste na percentagem de desempenho em que o processador em questão é melhor ou pior que os demais. Considerando um componente com peso de $100 \%$ para a CPUO e o mesmo componente com peso de $80 \%$ para a CPU1, significa que para esse componente a CPU1 tem um desempenho 20\% inferior que a CPUO. Na Figura 3.7 encontra-se ilustrado um exemplo hipotético da atribuição dos pesos de desempenho para dois processadores, CPUO e CPU1. Os componentes que 


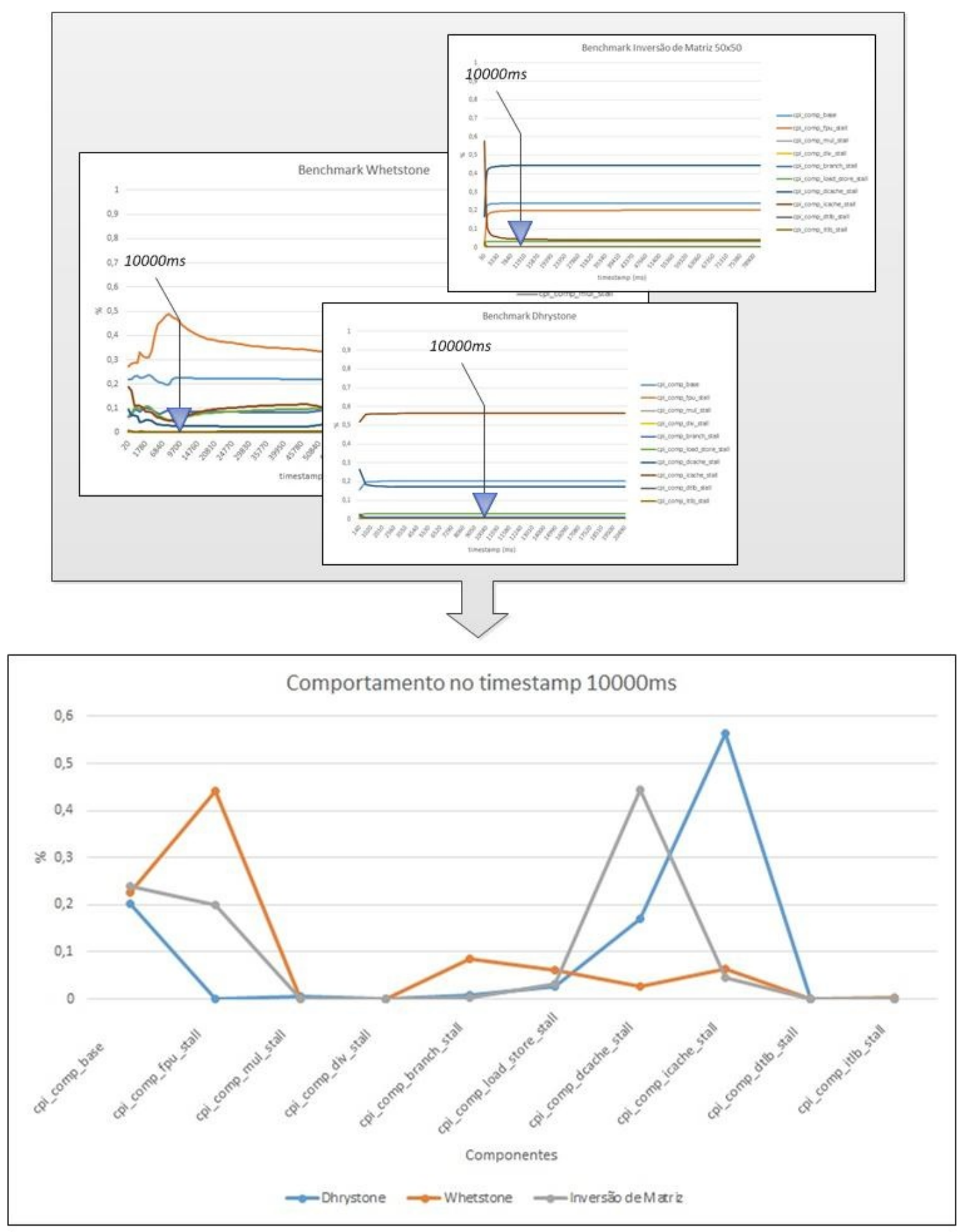

Figura 3.6: Histograma do comportamento dos benchmarks no timestamp $10000 \mathrm{~ms}$ 
possuem pesos iguais para ambos processadores denotam que as configurações de arquitetura que afetam tais componentes são semelhantes ou iguais para os processadores. Conforme apresentado, também se deve considerar que, para cada componente, sempre existe um processador que possui peso de 100\%, admitindo-se desempenho máximo daquele processador para tal componente, dentre todos os processadores da arquitetura.

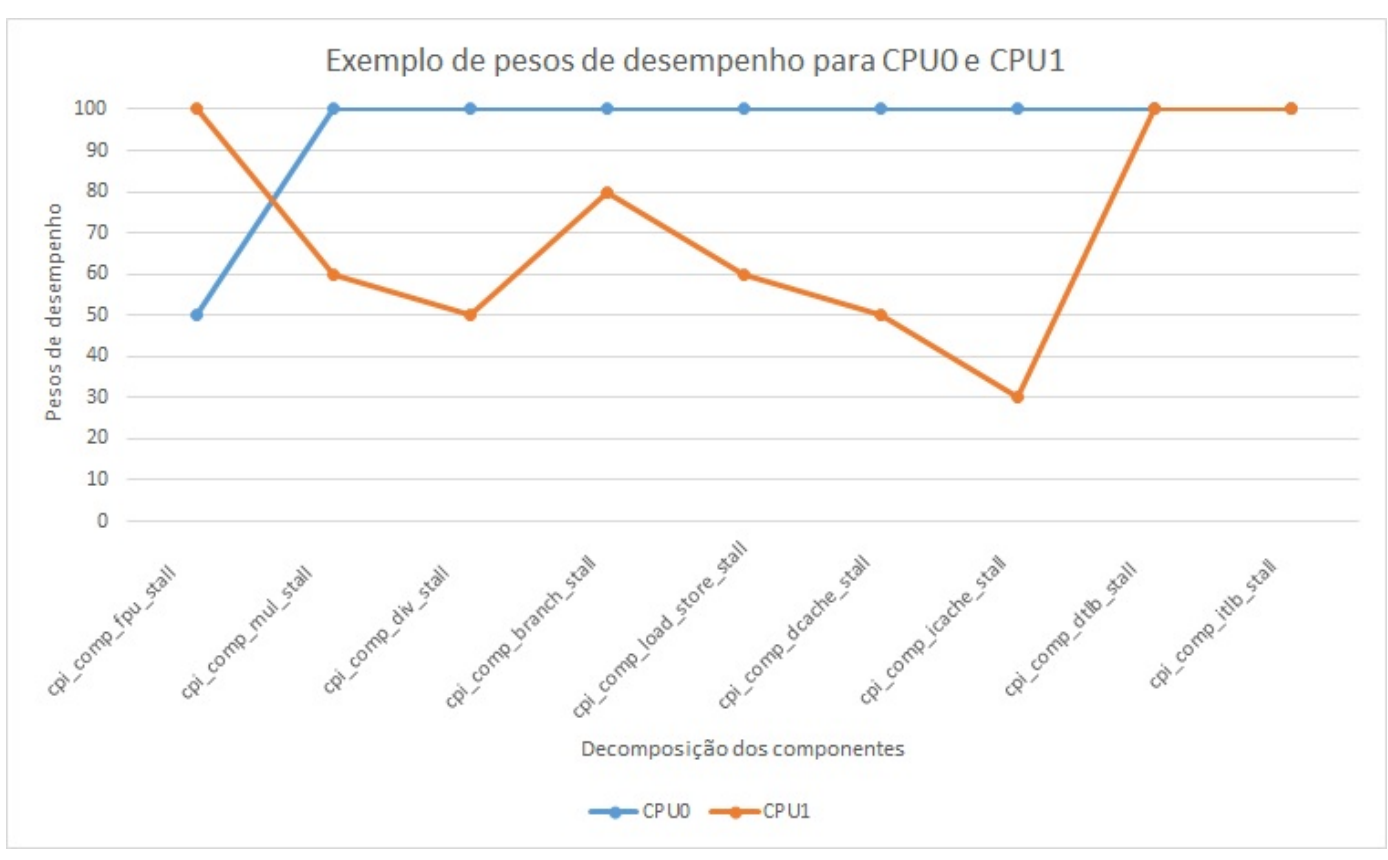

Figura 3.7: Exemplo do vetor de pesos de desempenho para CPUO e CPU1

Como a configuração do hardware é fixa, ou seja, não varia durante o tempo, este projeto considera que os vetores de pesos de desempenho sejam atribuidos manualmente pelo arquiteto do sistema ou calculados automaticamente por meio de uma calibração em software realizada uma única vez para cada arquitetura. Esse vetor de pesos é utilizado pelo algoritmo para realizar uma projeção de desempenho dos processos em todos os processadores, sem necessitar de amostragem prévia da execução do processo em todos os processadores, conforme descrito no Capítulo 2,

É importante considerar que o vetor de pesos de desempenho considera somente os componentes influenciáveis no desempenho, os quais são os componentes de stall. Conforme ilustrado na Figura 3.7, pode-se notar que o cpi_comp_base não é considerado. Isso se deve ao fato de que esse componente está relacionado com a quantidade efetiva de ciclos utilizada para execução e não consiste em um componente de stall.

Como mencionado anteriormente, o comportamento de diferentes benchmarks executando sobre um mesmo processador pode resultar em decomposições de CPI proporcionalmente diferentes, já que cada recurso tem um peso de desempenho diferente para cada benchmark. Devido a esse fator, deve-se considerar diferentes benchmarks para realizar a calibração, de modo que se 
obtenha uma média da decomposição de stall de cada benchmark. Para cada processador, a decomposição de stalls de todos os benchmarks é armazenada, obtendo-se um vetor de médias de stalls considerando todos os benchmarks, a partir do qual o vetor de desempenho é calculado.

O método proposto para o cálculo dos pesos via software é descrito abaixo. Contudo, como a calibração por software considera um ou mais processos executando cada vez em um processador, para efeito de simplificação das fórmulas, o método proposto abaixo considera que somente um processo execute sobre os processadores.

Considerando $C$ como o conjunto contendo a decomposição dos stalls para a $C P U(i)$, onde $i \in\{0 . . n-1\}$, sendo que $n$ consiste no número de processadores da arquitetura:

$$
\begin{aligned}
& C_{C P U(i)}=\left\{c p i \_c o m p \_f p u \_s t a l l, c p i \_c o m p \_m u l \_s t a l l,\right. \\
& \text { cpi_comp_div_stall,cpi_comp_branch_stall, } \\
& \text { cpi_comp_load_store_stall,cpi_comp_dcache_stall, } \\
& \text { cpi_comp_icache_stallcpi_comp_dtlb_stall, } \\
& \text { cpi_comp_itlb_stall\} }
\end{aligned}
$$

O $S_{C P U(i)}$ é o total de tempo despendido em stalls no processador $C P U(i)$ :

$$
S_{C P U(i)}=\sum^{c \in C_{C P U(i)}} c p i(c)
$$

Para cada processador $(C P U(i)), P_{\text {stall }_{C P U(i)}}(c)$ consiste na percentagem de stall do componente $c$ sobre o total de atraso $S_{C P U(i)}$ da $C P U(i)$ :

$$
\begin{array}{r}
P_{\text {stall }_{C P U(i)}}(c)=\frac{c p i(c)}{S_{C P U(i)}} \\
\text { onde, } c \in C_{C P U(i)}
\end{array}
$$

A Equação 3.4 consiste no cálculo final do peso, sendo $W(c)_{C P U(i)}$ o peso do componente $c \in C_{C P U(i)}$ do $C P U(i)$ :

$$
W(c)_{C P U(i)}=\frac{\min \left(P_{\text {stall }_{C P U(0 . . n-1)}}(c)\right)}{P_{\text {stall }_{C P U(i)}}(c)}
$$

Como exemplo, as equações para cálculo do vetor de peso de desempenho para cada processador são aplicadas a seguir sobre o histograma de comportamento do benchmark FBench no timestamp 10000ms. A Figura 3.8 ilustra o histograma de execução do benchmark sobre os dois processadores (mesma execução ilustrada na Figura 3.4). Os componentes apresentam a percenta- 
gem que afeta o tempo total de execução.

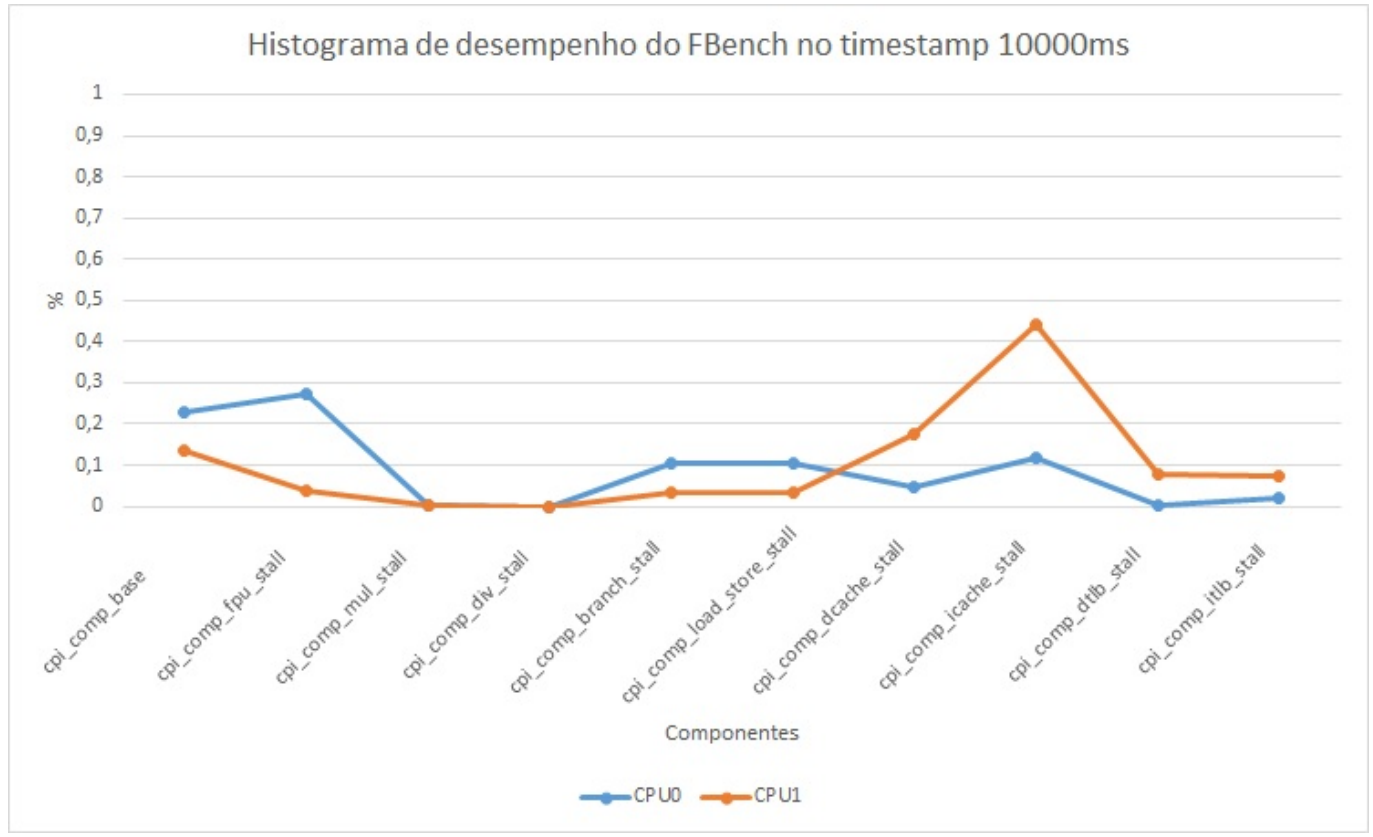

Figura 3.8: Histograma do comportamento do FBench no timestamp 10000ms para CPUO e CPU 1

Na Figura 3.9, os dados do histograma são colocados em função do total do atraso, segundo a Equação 3.3. Com isso, o componente cpi_comp_base é desconsiderado, fazendo com que cada componente implique não mais na percentagem total, mas sim na percentagem sobre o atraso total.

A partir do vetor de percentagem de cada componente e dos componentes de stall originais, a Equação 3.4 é utilizada para calcular o vetor de peso de desempenho de ambos os processadores, conforme ilustrado na Figura 3.10 .

\subsection{Fluxo dos dados}

A partir dos pesos de desempenho dos processadores calculados por meio de calibração, juntamente com a constante decomposição de stalls fornecidos pelo monitores de desempenho para todos os processos em execução, é possível realizar a projeção de desempenho. A Figura 3.11 ilustra como essas informações são utilizadas para gerar o resultado final contendo o conjunto de associações entre processadores e processos que maximiza o desempenho total.

Inicialmente, o fluxograma demonstra o paralelismo entre os monitores de desempenho, os quais estão continuamente decompondo os stalls dos processos que executam nos processadores em que estão localizados. O conjunto de decomposições de stalls consiste na entrada do bloco de normalização, cuja resposabilidade é retirar as influências inseridas nos componentes de stall dos 


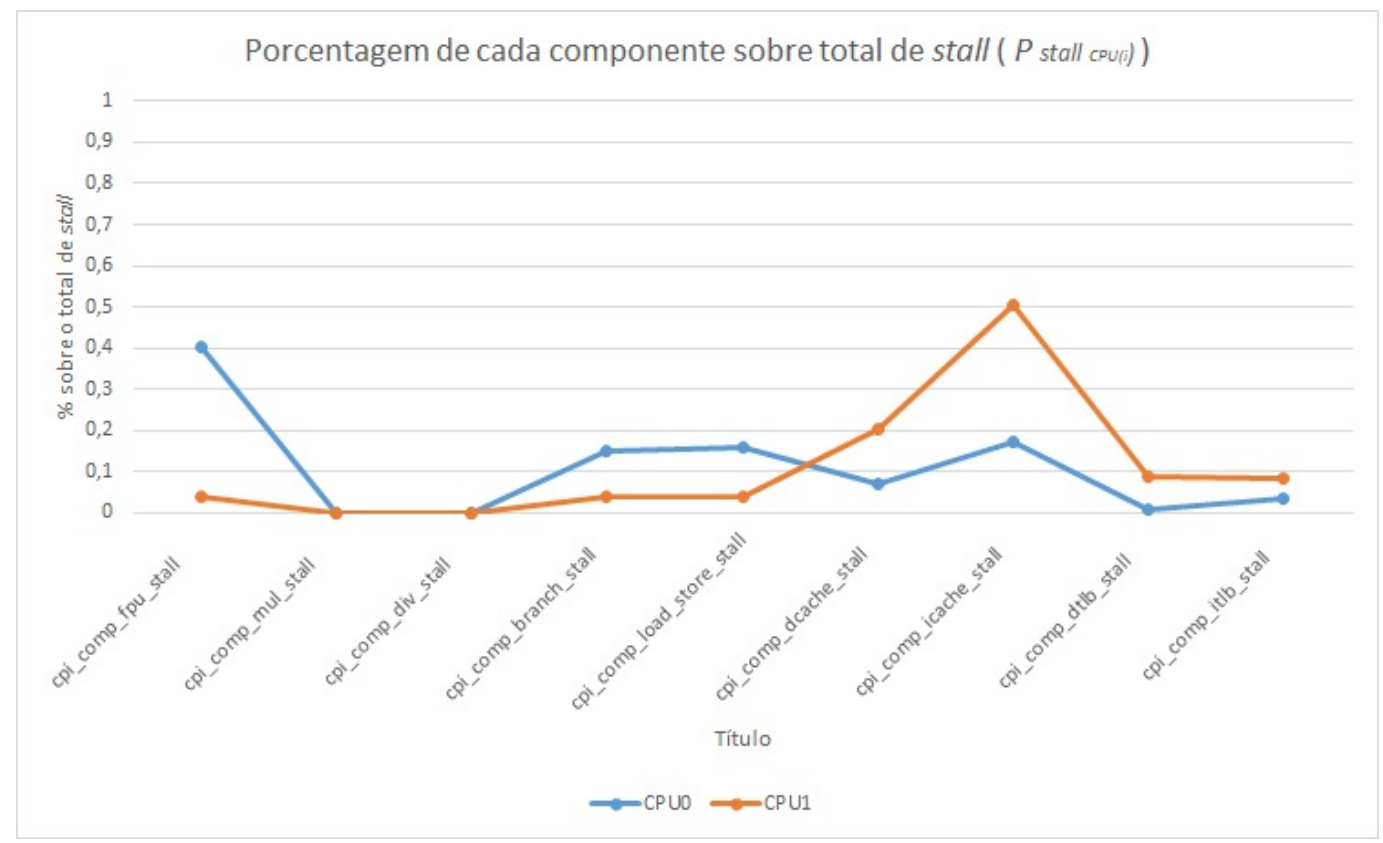

Figura 3.9: Vetor de percentagem de cada componente sobre o total de stall $\left(P_{\text {stall }_{C P U(i)}}(c)\right)$

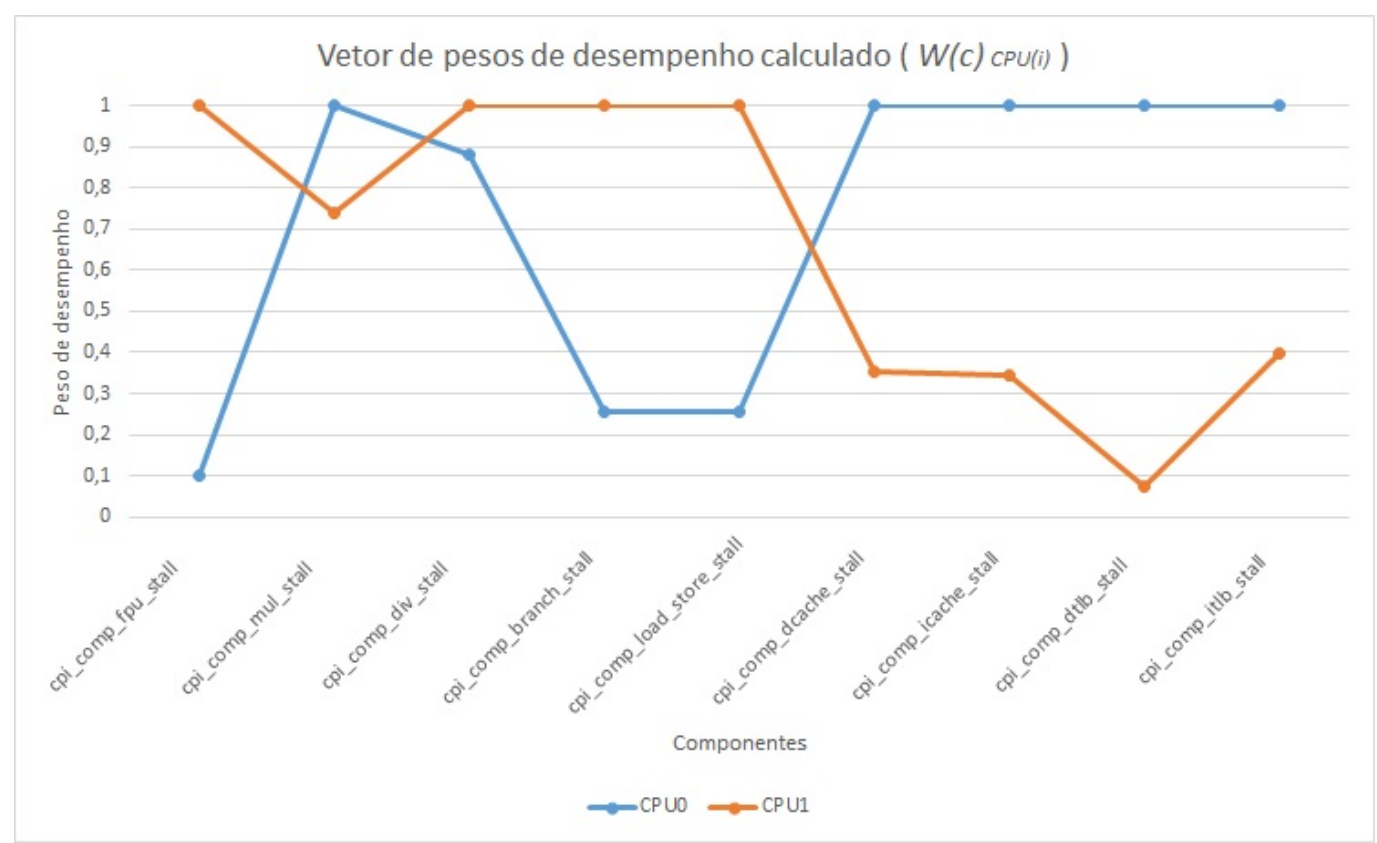

Figura 3.10: Vetor de pesos de desempenho calculado para cada processador $\left(W(c)_{C P U(i)}\right)$ 
processos, inseridas pelas arquiteturas dos processadores nos quais eles são executados. Para essa normalização, os vetores de desempenho dos processadores são considerados no cálculo, conforme descrito adiante neste capítulo. Com os desempenhos normalizados, o método de projeção de desempenho é executado, também levando em consideração os pesos de desempenho dos processadores. O resultado final da projeção consiste em uma matriz de valores, contendo as projeções de desempenho de todos os processos para todos os processadores. A partir dessa matriz de projeções, o método de maximização deve retornar o conjunto de associações que maximiza todas as projeções realizadas.

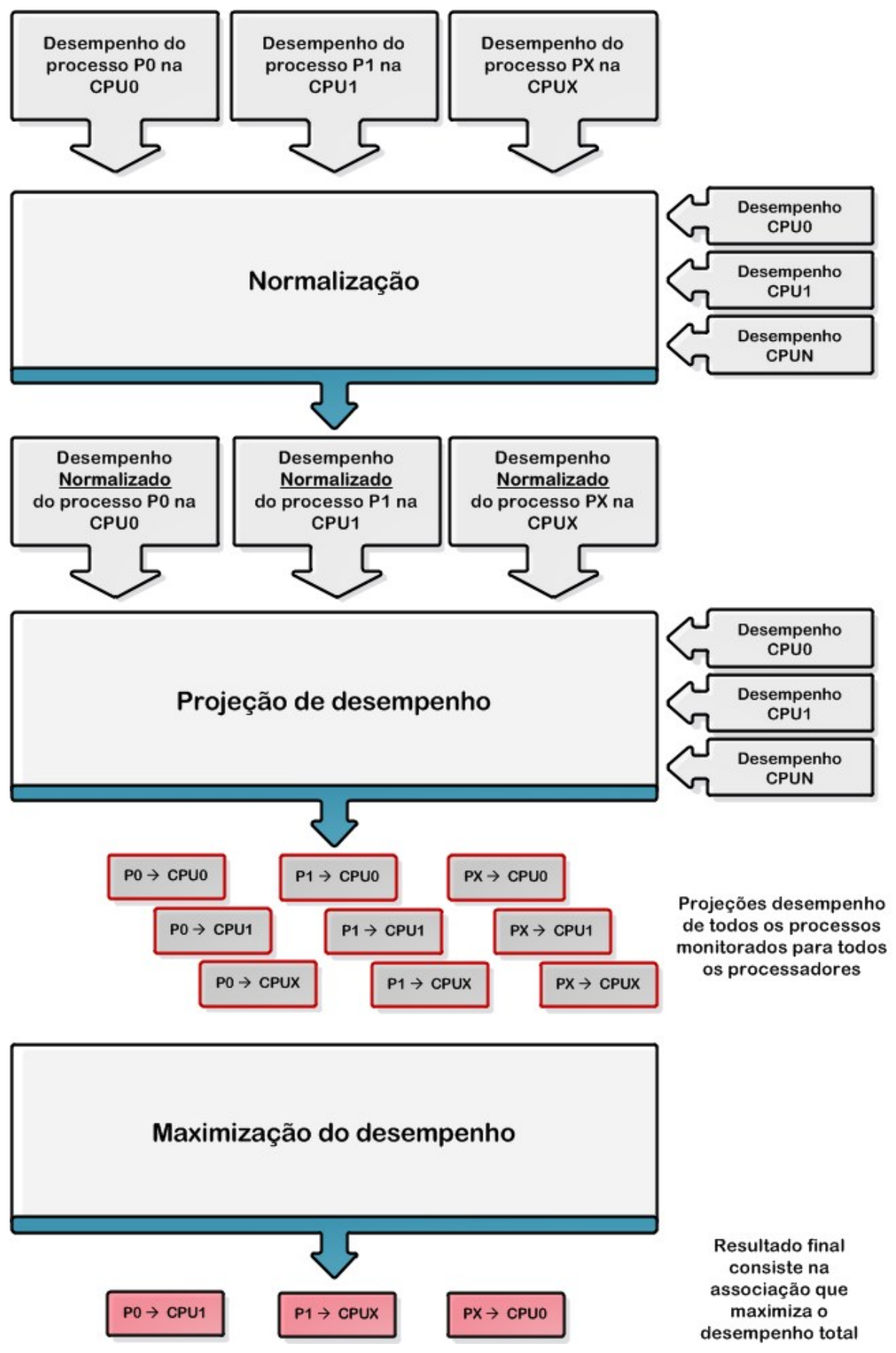

Figura 3.11: Fluxograma da heurística 
Apesar de o exemplo contido na Figura 3.11 ilustrar somente um processo para cada processador, a heurística descrita por este projeto considera todos os processos considerados para o sistema.

\subsection{Normalização do histograma de desempenho}

Com o intuito de realizar a projeção de desempenho, o histograma de execução atual do processo é utilizado em conjunto com o vetor de pesos de desempenho. No entanto, antes de comparar a decomposição do CPI de um processo com os vetores de pesos de desempenho da arquitetura, é necessário considerar a diferença de comportamento da decomposição do CPI do processo em cada processador.

Como mencionado anteriormente, quando um processo executa sobre processadores com arquiteturas diferentes, sua distribuição de stalls pode também alterar. Considerando o exemplo da Figura 3.4, o benchmark FBench, quando executado sobre a CPUO, tem um tempo maior gasto com a execução de instruções de ponto flutuante. O mesmo benchmark executado sobre a CPU 1 possui um índice maioritário de stall em faltas na cache de instruções. Em ambos os casos, os histogramas das decomposições do CPI são influenciados pelas arquiteturas nas quais os processos relacionados executam (Figura 3.8. Desse modo, essa dependência implica que os dados do histograma de desempenho de um determinado processo, antes de serem considerados na projeção de desempenho, devem ser normalizados, de acordo com a influência da arquitetura onde o processo está sendo executado. A normalização proposta por este trabalho faz com que a distribuição do stall gerado em tempo real por cada processador, onde existe um componente de monitor de desempenho, seja minimizado de acordo com o peso de desempenho do processador que executa o processo. Como exemplo, considere uma arquitetura que possui dois processadores (CPUO e CPU1), sendo que a CPUO possui como peso da componente de FPU (cpi_comp_fpu) o valor 1, enquanto que, na CPU1, o mesmo componente tem peso 0.5. Guando os dados de um determinado processo forem amostrados da saída do monitor de desempenho, hipoteticamente, o componente cpi_comp_fpu da CPUO tem o valor de 500 (ciclos), enquanto que na CPU 1 possui o valor 1000 (ciclos). Pelo vetor de desempenho, entende-se que a CPU1 possui 50\% de desempenho em relação à CPUO para este componente, de tal forma que a normalização proposta, baseada na minimização de tempo, implica que o valor de 1000 ciclos seja reduzido para 500 devido ao peso de $50 \%$ de desempenho. A Equação 3.5 é utilizada para realizar essa minimização por meio do peso de desempenho da $C P U(i)$, onde $N(c)_{C P U(i)}$ consiste na normalização do componente $c$ da $C P U(i)$ : 


$$
\begin{array}{r}
N(c)_{C P U(i)}=W(c)_{C P U(i)} * c p i(c) \\
\text { onde, } c \in C_{C P U(i)}
\end{array}
$$

Para representar a normalização, a Figura 3.8, que representa o histograma de execução em termos de percentagem no timestamp 10000ms do FBench, é ilustrada na Figura 3.12 em termos de quantidade de ciclos, mensurados por meio do monitor de desempenho em cada processador. Para demonstrar esse exemplo, o benchmark foi executado duas vezes, uma vez em cada processador.

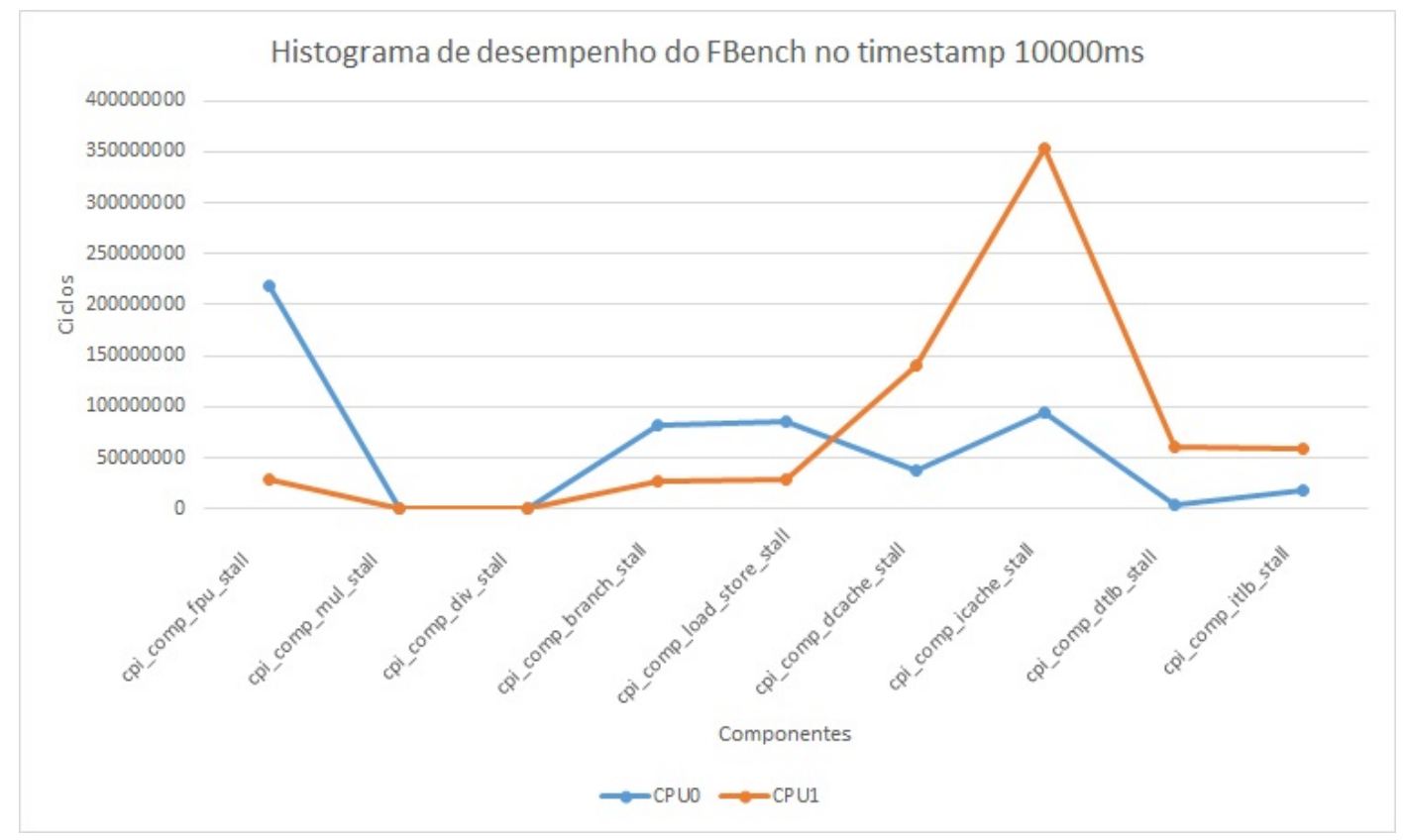

Figura 3.12: Histograma do comportamento do FBench no timestamp 10000ms para CPUO e CPU1 (ciclos)

A partir dos componentes de stall apresentados na Figura 3.10 para ambos processadores, os vetores de pesos calculados e apresentados como exemplo na Figura 3.10 são utilizados para normalizar o histograma, cuja saída é ilustrada na Figura 3.13. De modo geral, o histograma de execução do benchmark é amostrado pela CPUO da saída do monitor de desempenho e, a partir de seu vetor de pesos de desempenho, $W(c)_{C P U(0)}$, para $c \in C_{C P U(0)}$, seu novo histograma, agora normalizado, é gerado.

Após a normalização, no exemplo apresentado, pode-se perceber que cada componente do histograma é proporcional para ambos processadores. Tal comportamento é melhor visualizado por meio da representação do resultado das normalizações em termos de percentagem, ilustrado na Figura 3.14.

É importante observar que essa proporção só é alcançada no caso ideal, quando o histograma a ser normalizado também é utilizado para cálculo dos 


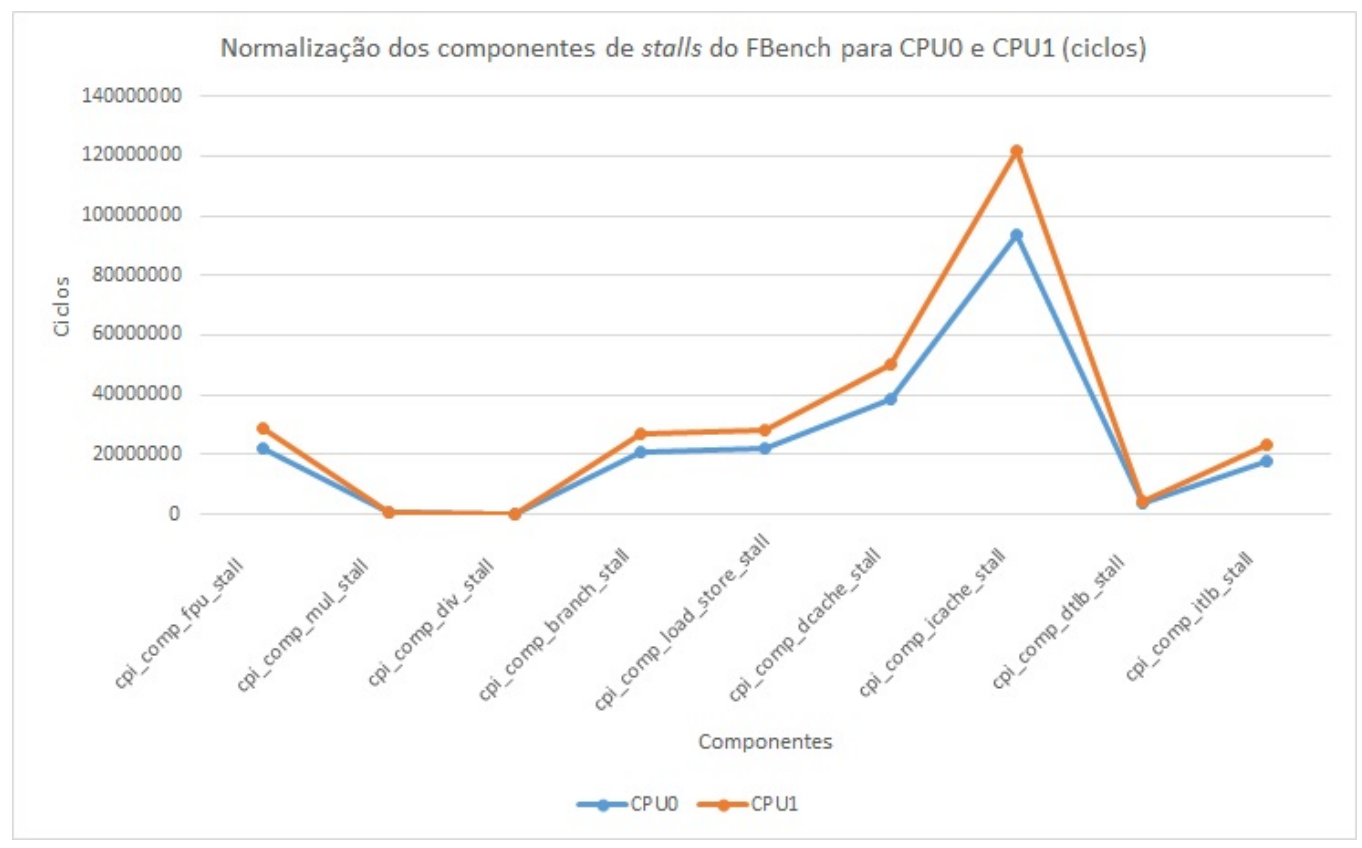

Figura 3.13: Normalização do FBench executando sobre os dois processadores CPUO e CPU1 (ciclos)

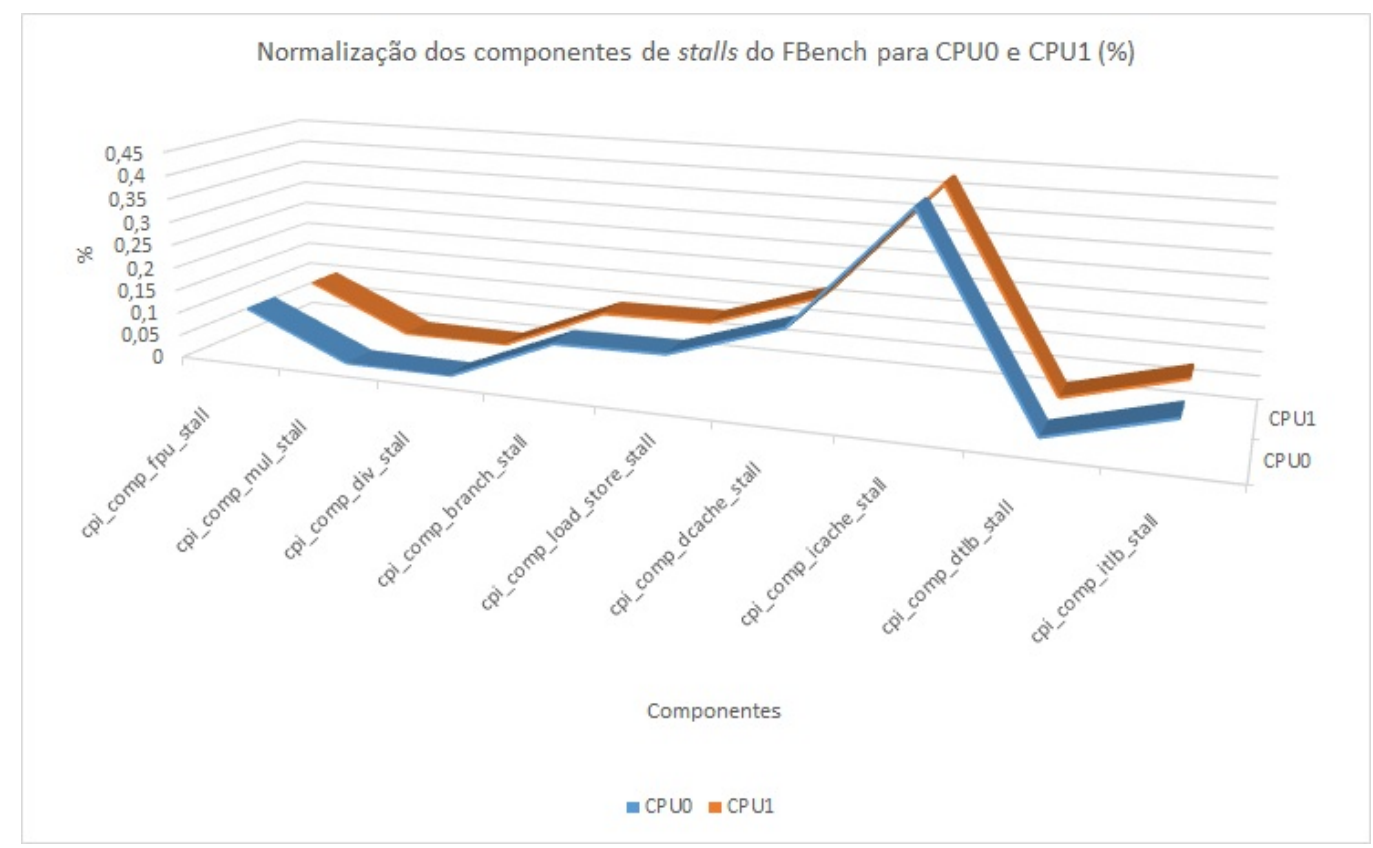

Figura 3.14: Normalização do FBench executando sobre os dois processadores CPUO e CPU1 (\%) 
pesos dos componentes de desempenho dos processadores, como foi apresentado nos exemplos anteriores. Na implementação realizada neste trabalho, os pesos de desempenho de cada processador são calculados levando em consideração os comportamentos de diversos benchmarks, que executam sobre os processadores de modo idêntico, um processador por vez, como descrito na Seção 3.6 ,

\subsection{Projeção de desempenho}

Considerando que o processo $p$ execute sobre a $C P U(i)$, o histograma de execução é amostrado no tempo $t$ da saída do monitor de desempenho localizado na $C P U(i)$. Esse histograma é formado pelo vetor de componentes de stall $\operatorname{cpi}(c)$ (onde $c \in C_{C P U(i)}$ ), que passa pela normalização, formando um novo histograma normalizado formado por $N(c)_{C P U(i)}$ (onde $c \in C_{C P U(i)}$ ). A partir desse histograma normalizado, é possivel realizar uma projeção de desempenho a partir da $C P U(i)$ para um outro processador da arquitetura $(C P U(i) \rightarrow C P U(x))$. Tal projeção é dada pela Equação 3.6:

$$
P R O J_{C P U(i) \rightarrow C P U(x)}=\sum^{c \in C_{C P U(i)} ; c^{\prime} \in C_{C P U(x)}} N(c)_{C P U(i)} * W\left(c^{\prime}\right)_{C P U(x)}
$$

A projeção é alcançada por meio do produto escalar do histograma normalizado amostrado no tempo $t$ do processo $p$ com o vetor de desempenho do processador cujo desempenho deseja-se calcular.

Considerando o exemplo da execução do FBench na CPUO e na CPU1 apresentado anteriormente, a partir do histograma normalizado representado na Figura 3.13, as projeções alcançadas por meio da Equação 3.6, aplicando-se os pesos calculados representados na Figura 3.10, para CPUO e CPU1, são apresentadas a seguir.

A partir da execução de FBench na CPUO, as projeções no tempo $t=10000 \mathrm{~ms}$ são dadas por:

- $P R O J_{C P U(0) \rightarrow C P U(0)}=167409775$ (100\%)

- $P R O J_{C P U(0) \rightarrow C P U(1)}=118620129$ ( $\left.71 \%\right)$

A partir da execução de FBench na CPU1, as projeções no tempo $t=10000 \mathrm{~ms}$ são dadas por:

- $P R O J_{C P U(1) \rightarrow C P U(0)}=217245329(100 \%)$

- $P R O J_{C P U(1) \rightarrow C P U(1)}=153931686$ ( $\left.71 \%\right)$ 
Ambas as projeções do exemplo citado apontam que no tempo $t$ da execução do processo $p$, de acordo com o histograma de execução e dos pesos de desempenho dos processadores, a CPUO é apontada como o processador que oferece aproximadamente 30\% de desempenho superior sobre a CPU1.

Este projeto propõe a realização da projeção em tempo real de todos os processos em execução para qualquer processador da arquitetura. Com isso, o escalonador tem uma medida de desempenho do processo atual em execução para todos os processadores, de modo a escolher o processador que ofereça o maior desempenho para a próxima execução do processo.

\subsection{Balanceamento}

Assim como apresentado na Figura 3.11, o último passo da heurística deste projeto consiste no balanceamento de desempenho. O objetivo dessa etapa consiste em distribuir os processos sobre as CPUs da arquitetura, de modo que o resultado final dessas associações seja a maximização do desempenho do sistema como um todo. O resultado da etapa de projeção, confome Figura 3.11, consiste em uma matriz de projeções de todos os processos para todos os processadores. Essa matriz pode ser modelada do seguinte modo: as colunas estão relacionadas aos processadores e cada uma das linhas representa as projeções de desempenho de um processo para cada um dos processadores. Nesse contexto, a matriz A, a seguir, representa um exemplo hipotético de uma matriz de projeção de desempenho, composta por três processos (linhas), três processadores (colunas), onde cada elemento corresponde a uma projeção de desempenho. Os elementos destacados na matriz correspondem aos valores máximos de desempenho escolhidos. Essa associação deve ser realizada de modo que somente um elemento seja selecionado na linha e coluna, levando em consideração que a associação final deve compreender o somatório máximo dos elementos escolhidos. O resultado é um conjunto de associações entre processos e processadores balanceado e com desempenho maximizado.

$$
A=\left[\begin{array}{ccc}
12 & 1 & 1 \\
4 & 5 & 7 \\
2 & 6 & 5
\end{array}\right]
$$

A escolha das projeções que maximizam o desempenho é considerada um problema clássico do campo da programação linear, nomeado problema de designação. Existem diversos algoritmos com o objetivo de alcançar um conjunto maximizado de designações (associações). No entanto, como um dos objetivos deste projeto é realizar a tarefa de maximização em tempo real, considerando o fato que esses algoritmos normalmente tem uma complexidade que chegam 
a ordem $\mathrm{O}\left(n^{3}\right)$ e $\mathrm{O}\left(n^{4}\right)$, é necessário que o algoritmo escolhido para realizar tal tarefa tenha um bom desempenho para ser implementando em hardware, buscando ganhar desempenho na maximização deixando os processadores livres para executarem outras tarefas.

Nesse contexto, este projeto considera dois algoritmos discretos clássicos, o algoritmo Auction e o algoritmo Hungarian(Bertsekas, 1992) (Kuhn \& Yaw, 1955).

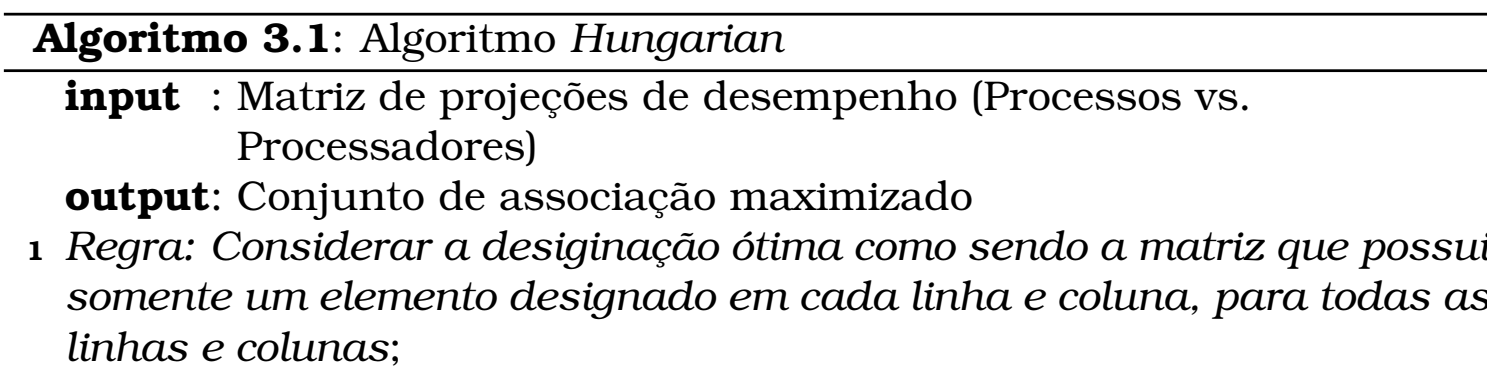

- Passo 1: A partir da matriz original, para cada linha, procurar seu menor elemento e subtraí-lo dos demais elementos da mesma linha;

- Passo 2: Para cada coluna, procurar seu menor elemento e subtraí-lo dos demais elementos da mesma coluna;

- Passo 3: Realizar designações a partir dos elementos que possuem valor 0 . Se encontrou a designação ótima o procedimento é terminado, senão continue;

- Passo 4: Marque todas as linhas que possuem designação e, em seguida, selecione todas as colunas que possuem zero nas linhas marcadas;

- Passo 5: A partir do resultado do Passo 4, marque cada linha que tem uma designação em uma coluna marcada;

- Passo 6: Repetir os passos 4 e 5 até que nenhuma linha ou coluna possa ser marcada;

- Passo 7: Trace uma linha imaginária sobre cada linha da matriz não selecionada nos passos anteriores e também sobre as colunas selecionadas;

- Passo 8: Selecione o minimo elemento da matriz que não esteja sob o traço imaginário. Subtraia esse elemento de todos os elementos que não estão sob o traço e some o mesmo elemento a todos os elementos que estão sob a intersecção do traço;

- Passo 9: Vá para o Passo 3;

Segundo Narayanan et al. (2000), o algoritmo Hungarian é superior em desempenho em relação ao algoritmo Auction, como também ocupa menor espaço em memória. Em (Zhu et al., 2012), o algoritmo Auction é implementado 
em FPGA, ocupando grande quantidade de recursos, apesar de alcançar um bom desempenho.

Neste trabalho foi adotado o algoritmo Hungarian, principalmente pelo fato de utilizar somente operações de soma e subtração de números inteiros, facilitando sua implementação em hardware.

$\mathrm{O}$ algoritmo Hungarian original tem o objetivo de realizar as designações de modo a minimizar o somatório total dos pesos designados. Contudo, pode ser facilmente modificado para a maximização, requisito principal desta heurística. O algoritmo hungarian é descrito em Algoritmo 3.1 .

\subsection{Considerações finais}

A heurística abordada neste capítulo compreende a obtenção das projeções de desempenho de todos os processos para todos os processadores. Essas projeções são calculadas de acordo com os comportamentos mensurados por meio do monitor de desempenho, localizado dentro do processador, o qual calcula os ciclos gastos em todos os componentes de CPI. Desse modo, a execução de todos os processos é acompanhada em tempo real, ciclo por ciclo. Obtendo-se assim, as medidas comportamentais utilizadas na designação dos processadores que melhor se adequam aos comportamentos atuais dos processos. 


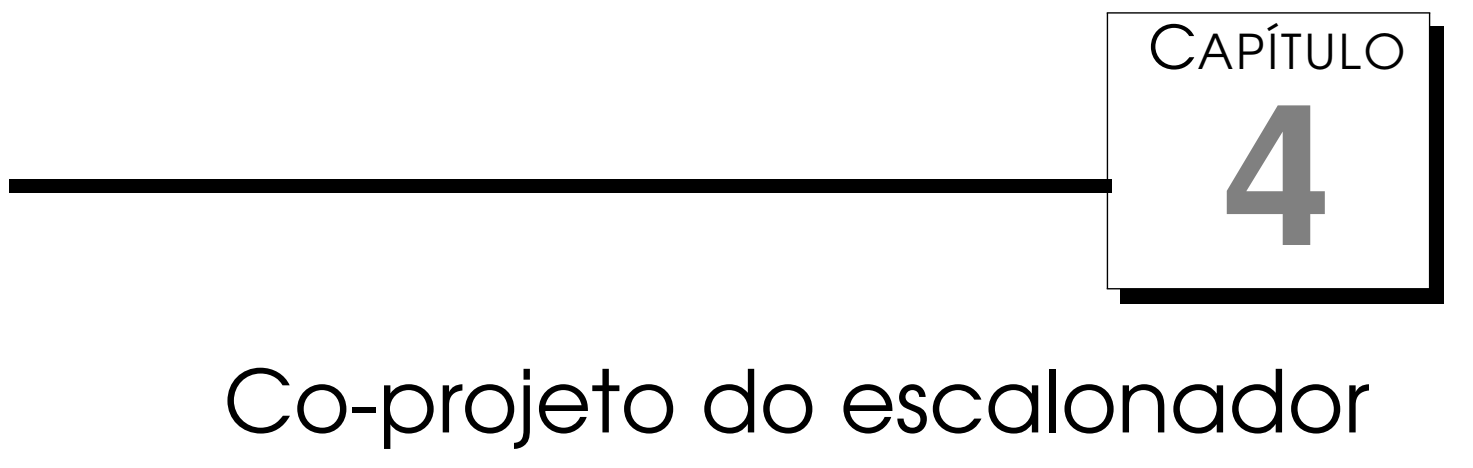

Neste capítulo são abordados os principais componentes do modelo proposto para a implementação da heurística descrita no Capítulo 3. A abordagem adotada para a modelagem consiste no co-projeto de hardware e software, na qual os componentes a serem implementados são divididos entre as duas camadas (hardware e software) de acordo com os requisitos do sistema. Neste capítulo são apresentados os principais requisitos considerados no co-projeto que delinearam a divisão em camadas. Na sequência, será detalhado cada componente da arquitetura proposta para implementação da heurística, assim como, são propostas soluções para problemas conhecidos envolvidos na implementação de suporte da heterogeneidade nos processadores e nos sistemas operacionais.

\subsection{Modelagem do co-projeto da arquitetura}

O particionamento em hardware e software da arquitetura do escalonador fornece ao sistema grandes benefícios de desempenho e maior precisão nas designações entre processos e processadores.

Um dos principais objetivos de implementar as tarefas em hardware, é a possibilidade de processamento em tempo real das informações dos processos adquiridas do processador no momento em que estão sendo executados. Com isso, é possível obter uma imagem atual do comportamento do processo e acompanhar seu dinamismo durante seu tempo de execução. Além disso, algoritmos de maximização podem ocupar grande parte do tempo de uso do processador. A implementação em hardware faz com que esse tempo seja destinado à execução de tarefas ao invés da execução do escalonador. 
Outro objetivo é o paralelismo de execução. Enquanto o processo está executando, o algoritmo de escalonamento está analisando seu comportamento e atribuindo-lhe o processador que melhor se adapta às suas necessidades. Com isso é possivel que, ao fim da execução do processo, já se obtenha o resultado final da designação, retirando do processador a necessidade de executar os algoritmos e gastar diversos ciclos com o escalonamento. Essa característica de paralelismo aliada ao desempenho fornecido na execução de tarefas em hardware, atua fortemente no aumento do desempenho sistema como um todo.

\subsection{Contexto}

O modelo de arquitetura proposto aplica-se principalmente ao ambiente embarcado, o qual possui recursos limitados devido a alta exigência de consumo reduzido de energia. Consequemente, os processadores e demais componentes da arquitetura também possuem recursos reduzidos e atuam em uma frequência mais baixa quando comparados com componentes em hardware de alto desempenho.

\subsection{Visão Geral}

No co-projeto apresentado neste capítulo, o particionamento entre hardware e software baseia-se principalmente nos seguintes requisitos:

- Desempenho: Alguns componentes podem ser classificados para terem sua implementação em hardware devido a exigência de desempenho. Em alguns casos, algoritmos implementados dentro do sistema operacional podem degradar o desempenho do sistema inteiro, sendo necessária a implementação na camada de hardware para realizar a tarefa paralelamente a execução dos processos, alcançando maior desempenho também devido as operações realizadas em hardware dedicado serem mais rapidas.

- Flexibilidade: Estruturas ou algoritmos que necessitam de flexibilidade, salvo o caso de exigência de alto desempenho, podem estar propensas a serem implementadas em software; e

- Competência: A classificação pode ser realizada considerando a finalidade do componente a ser implementado. Em casos como o monitor de desempenho, o único componente da arquitetura que tem condições de passar as informações necessárias para mensurar os componentes de 
stall é o processador, nesse caso, necessariamente, a sua implementação deve ser em hardware.

A Figura 4.1 ilustra a divisão em camadas dos principais componentes descritos neste projeto.

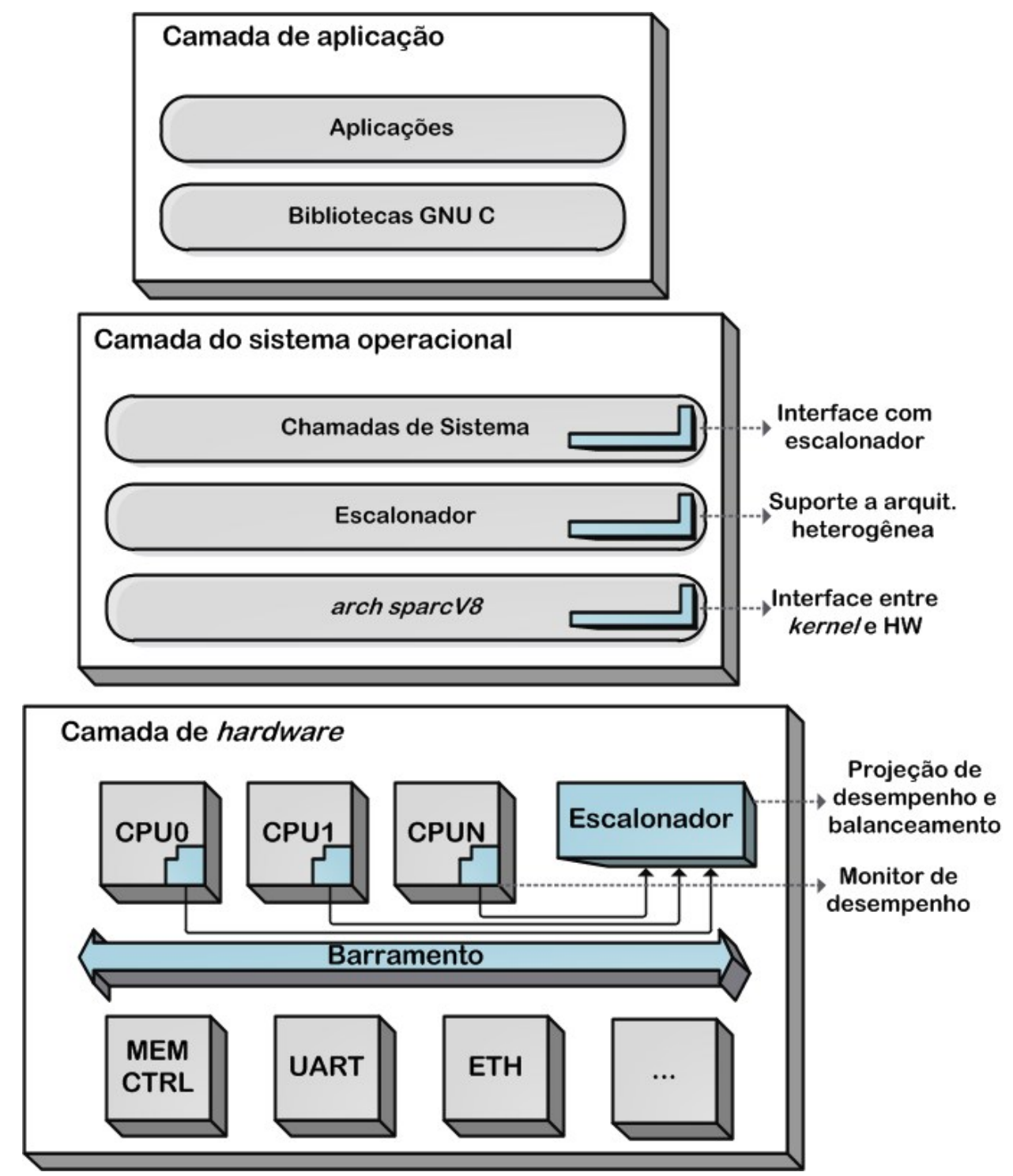

Figura 4.1: Organização dos blocos

Em cada processador deve existir um componente destinado a monitorar a execução das instruções e em tempo real medir o desempenho de cada processo, apontando onde o processo está gastando mais ciclos para executar. Esses monitores comunicam-se diretamente com o bloco de projeção de desempenho, responsável por mensurar quanto cada processo pode ganhar ou perder em desempenho se executar em outro processador. A Figura 4.2 ilustra essa comunicação entre os componentes. 


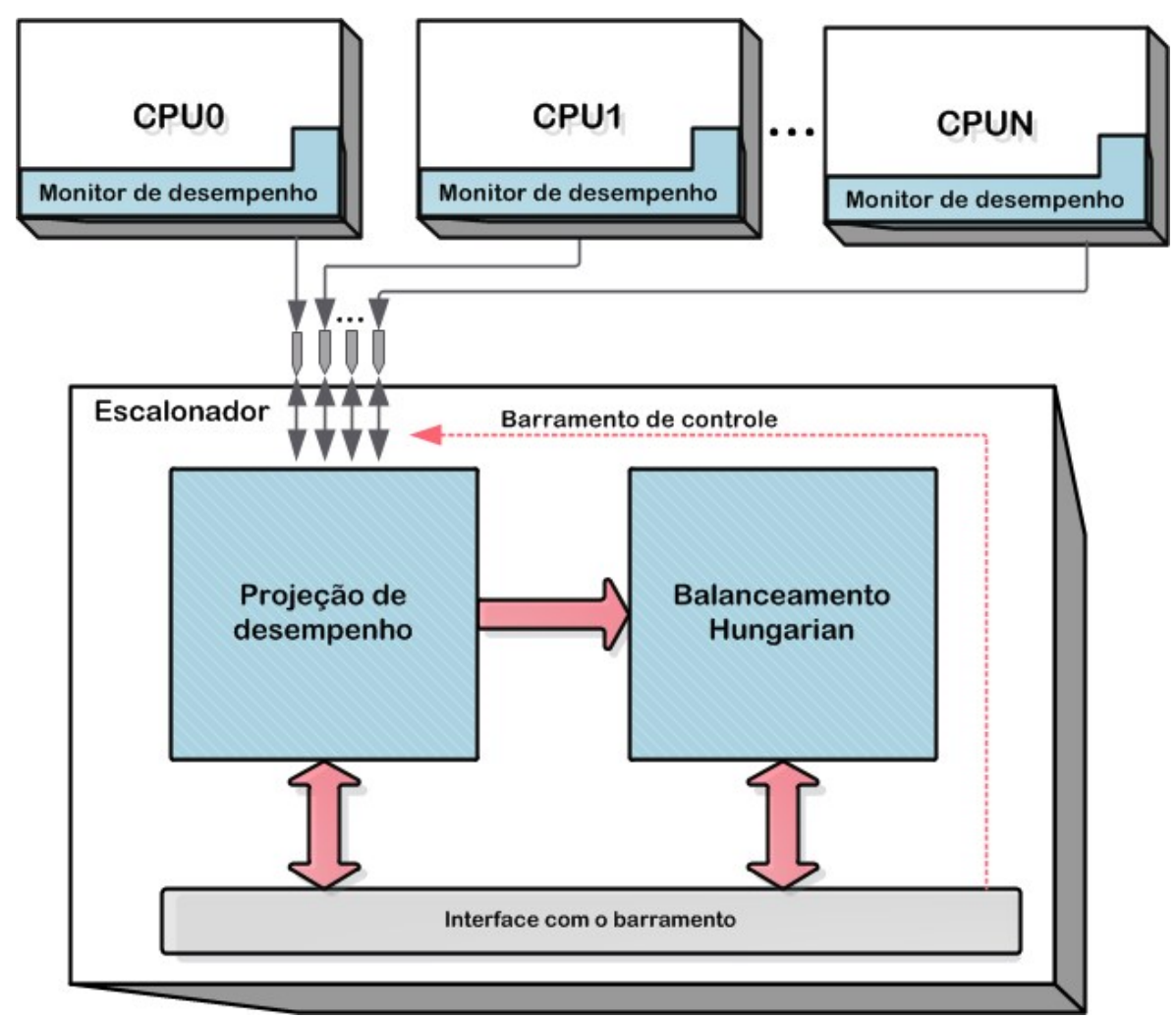

Figura 4.2: Comunicação entre os componentes de monitoramento e projeção de desempenho

\subsection{Monitoramento de desempenho}

Conforme descrito na Seção 3.5, o objetivo do monitor de desempenho é acompanhar a execução de um processo, obtendo componentes decompostos do CPI que refletem o comportamento de tal processo. Entre esses componentes, o cpi_comp_base consiste na quantidade de ciclos efetivos para a computação realizada até o momento de sua leitura do monitor, enquanto que os demais componentes refletem os ciclos ocupados com eventos de faltas nas memórias internas ou latência de processamento.

A construção de um monitor desempenho cuja saída consiste na CPI stack não é uma tarefa simples, já que exige intenso monitoramento do pipeline do processador e demais componentes para alcançar uma decomposição mais próxima do real. Um dos principais problemas envolvidos nessa atividade é o tratamento do ILP (Instruction Level Paralelism) e do MLP (Memory Level Paralelism). Essas características estão presentes em processadores e compiladores, os quais, por meio de reorganização da ordem de execução de instruções, mascaram as latências causadas por elas. Em processadores superescalares com processamento out-of-order, a tarefa de monitoramento é ainda mais complexa (Eyerman \& Eeckhout, 2009) (Koufaty et al., 2010).

É importante considerar que existem diferentes tipos de monitores de desempenho, muitos implementados em processadores comerciais. No entanto, 
a maioria não possui como saída, o CPI stack, o qual é o principal requisito da heurística deste projeto. Dentro desse contexto, considerando que a implementação desses monitores para arquiteturas superscalares out-of-order é complexa e retorna resultados imprecisos de acordo com Allam et al. (2012), este projeto propõe a implementação de um monitor de desempenho apropriado para arquiteturas de processadores cuja execução é in-order.

Considerando que não há reordenação de instruções pelo processador, a principal abordagem adotada por este monitor consiste em realizar uma contagem do tempo de execução de cada instrução. Porém, assim como abordado na Seção 3.5, para uma medida mais precisa, é necessário que existam interfaces com outros componentes do processador. Essas interfaces estão ilustradas na Figura 4.3 .

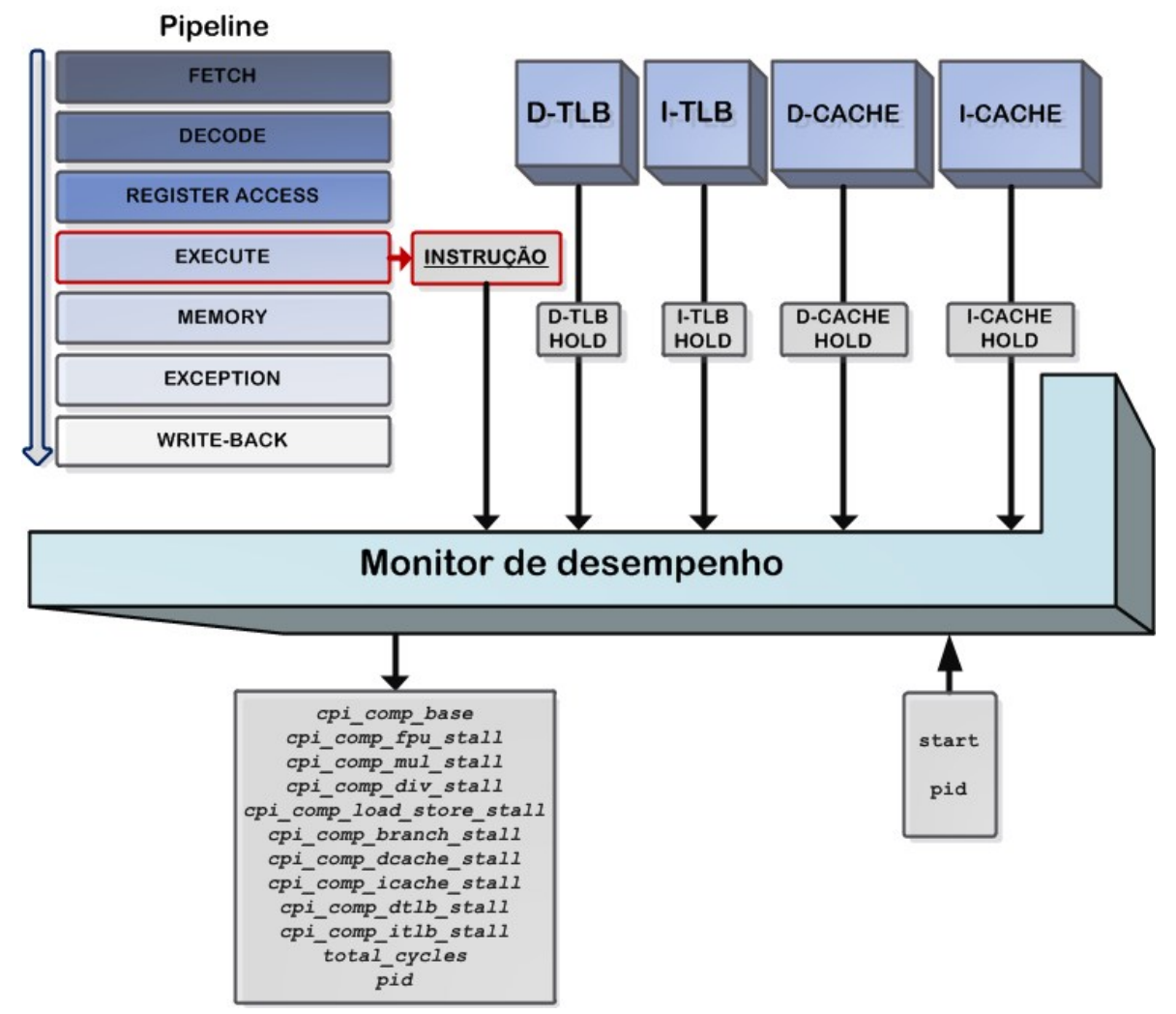

Figura 4.3: Interfaces do monitor de desempenho

O monitor de desempenho deve receber do processador a instrução corrente do estágio de execução de seu pipeline. Isso se deve ao fato que nesse estágio, a decisão tomada um ciclo antes pode invalidar automaticamente a instrução no ciclo corrente, no caso da execução de uma branch. Diferente de outros estágios, como por exemplo o estágio de fetch, em que terá a nova instrução independente do branch na instrução anterior ser efetivado. Paralelamente, os componentes D-TLB, I-TLB, D-CACHE e I-CACHE devem enviar ao monitor um sinal que identifica o período da execução afetada por uma falta ocorrida. A Figura 4.4 ilustra um exemplo hipotético contendo a interface 
com esses componentes, ilustrando também como deve ser o comportamento do monitor para a decomposição de três componentes: cpi_comp_dtlb_stall, cpi_comp_dcache_stall e cpi_comp_load_store_stall. O sinal CLK consiste no relógio principal do processador. O sinal start é externo ao bloco de monitoramento, provindo de alguma interface com o barramento principal. Esse sinal indica o momento em que o monitor deve iniciar seu funcionamento, o qual deve ficar em alto no inicio da execução de cada processo. Como o processador executa instruções sequencialmente e não tem conhecimento sobre o início de execução de processos, é tarefa do escalonador do sistema operacional definir o momento em que o monitor deve iniciar ou terminar seu funcionamento. A instrução é provida pelo estágio de execução do pipeline do processador, sendo que o sinal de valid_instruction indica se tal instrução deve ou não ser executada pelo processador. Sempre que existe um falta de cache ou uma latência para a completude de instruções de ponto flutuante, entre outros exemplos, este sinal é habilitado indicando ao processador que a instrução não é válida para ser executada.

Após a chegada de uma instrução válida, ocorre a decodificação, processo no qual o opcode é extraído, sendo a instrução classificada. No ciclo posterior a decodificação, o sinal relacionado ao tipo de instrução é habilitado. No caso do exemplo da Figura 4.4, o sinal load_store_instruction fica em alto no ciclo após a decodificação, indicando que uma instrução de load/store acabou de entrar para a execução. Pode-se perceber, que o sinal valid_instruction fica em baixa logo após o primeiro ciclo da instrução. Esse comportamento indica a ocorrência de um stall, momento no qual o processador não está efetivamente executando uma instrução, mas está dependendo de algum resultado ou latência de carregamento para continuar sua execução. Os dois sinais, $D$ TLB-hold e D-CACHE-hold, são providos pela TLB de dados e cache de dados, respectivamente. Quando um desses sinais está em alta, houve a ocorrência de uma falta. No caso do exemplo da Figura 4.4, durante o período de falta, o processador não executa instruções pois está dependendo da leitura do endereço físico, provido pela MMU onde o TLB está localizado, para então poder ler o dado requerido da memória. Porém, o exemplo ilustra a situação que após a ocorrência da falta na TLB, com o endereço físico já conhecido, ocorre uma falta na cache para este endereço. Sendo assim, mais ciclos são despendidos até a leitura do dado na memória.

Todos os ciclos gastos com stalls são contabilizados nos componentes que, no caso do exemplo da Figura 4.4, são: cpi_comp_dtlb_stall, cpi_comp_dcache_stall e cpi_comp_load_store_stall. Quando o sinal D-TLB-hold está em alta, é incrementado o contador relacionado ao componente de stall da TLB de dados. Do mesmo modo ocorre para o sinal D-CACHE-hold, o qual é contabilizado por 


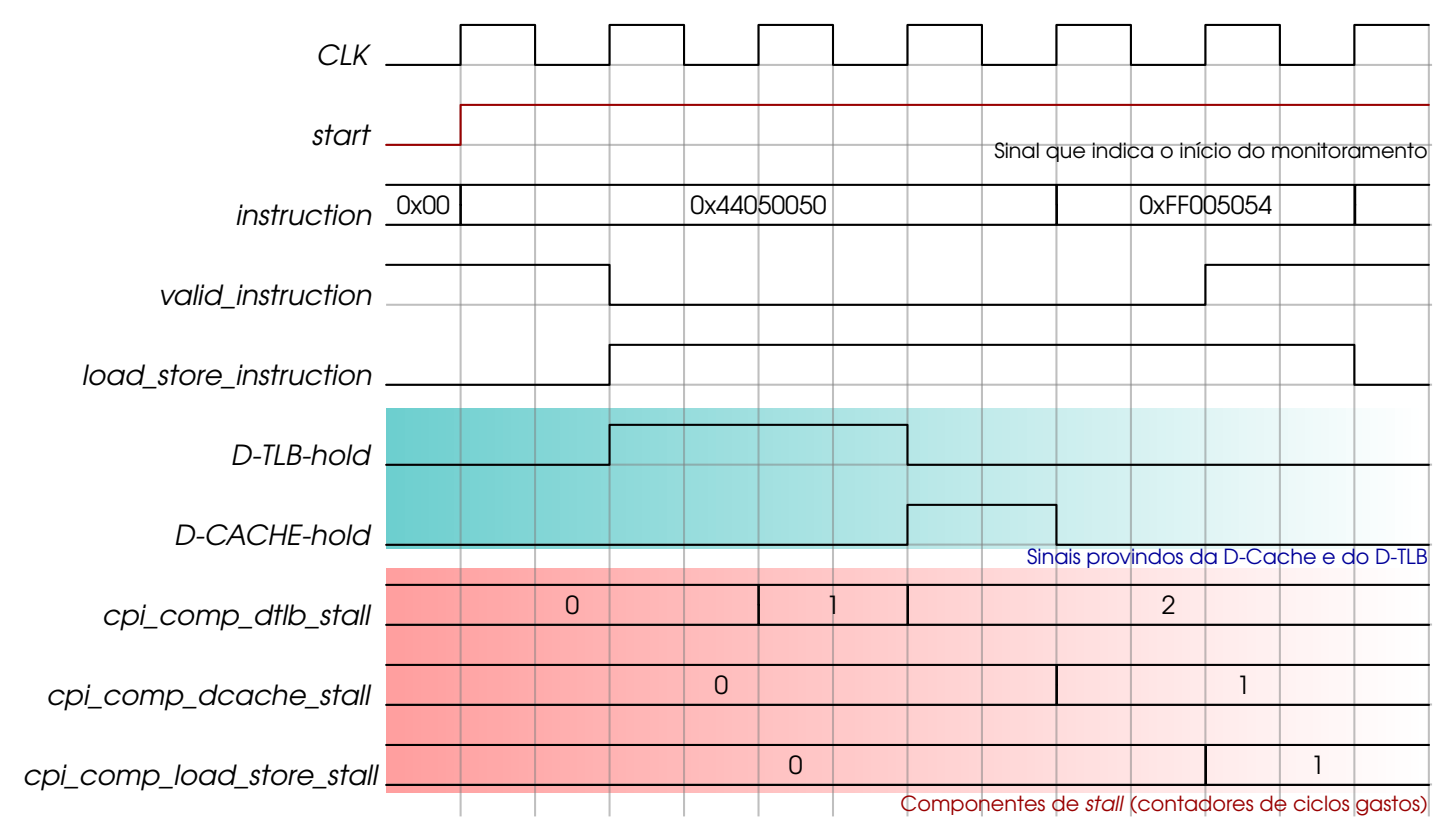

Figura 4.4: Diagrama da forma de onda de um exemplo de interação com D-TLB e D-CACHE

meio do componente cpi_comp_dcache_stall. Pode-se perceber nesse exemplo, que logo após a descida do sinal D-CACHE-hold, o processador permanece um ciclo ainda em estado inválido. Esse ciclo é interpretado como sendo a latência do pipeline. Essa latência pode ocorrer onde existem dependências de dados entre duas instruções sequenciais ou, principalmente, em casos de saltos onde o processador gasta ciclos invalidando instruções já carregadas para carregar novas instruções em seu pipeline. Assim como mencionado na Seção 3.5, o compoente cpi_comp_load_store_stall consiste nesse tempo de latência do pipeline. que ocorre principalmente entre instruções onde a instrução corrente depende do dado carregado pela instrução anterior.

Assim como no caso de instruções de load/store as instruções de saltos também possuem o mesmo tipo de abordagem, com interfaces com a cache de instruções e TLB de instruções.

A Figura 4.5 ilustra um exemplo mais simples, onde não é considerada a interação com componentes externos. Seguindo a premissa de execução em ordem, aplica-se o mesmo método de monitoramento do exemplo anterior. A instrução válida é decodificada, sendo classificada como uma instrução de ponto flutuante. A partir desse momento é realizada uma contagem de ciclos em que a instrução permanece inválida, estado no qual o processador encontra-se em espera pelo resultado. Assim que o sinal valid_instruction volta a ficar em alta, o contador para de incrementar, e uma nova instrução é decodificada. Essa abordagem pode ser utilizada em outros tipos de componente, tais como divisão e multiplicação.

O modelo de arquitetura para o monitor de desempenho proposto nessa se- 


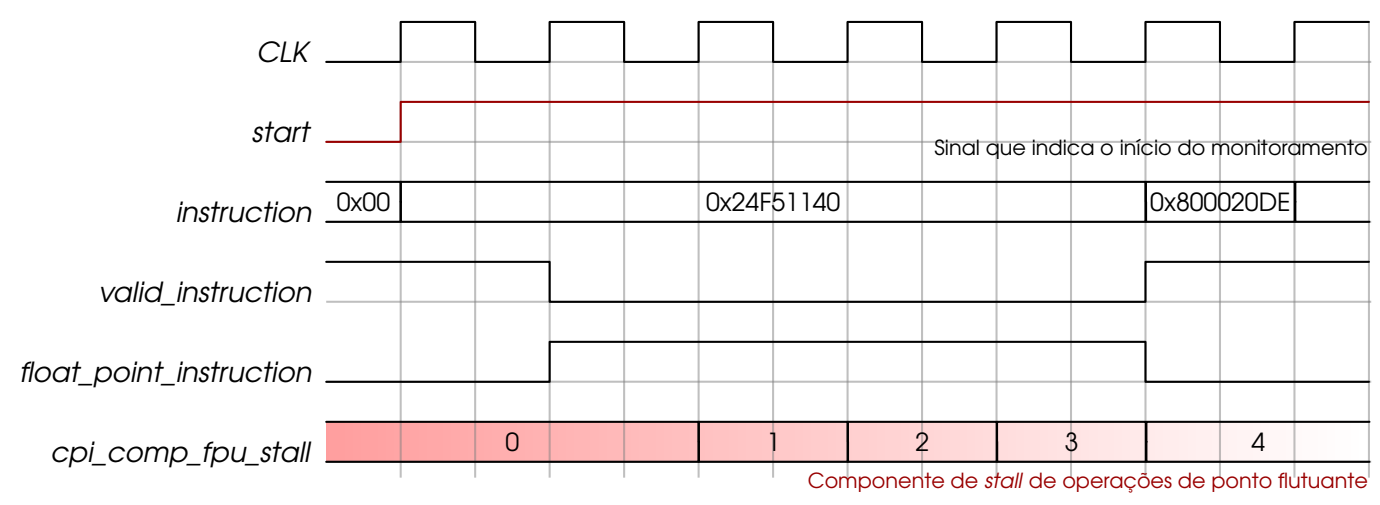

Figura 4.5: Diagrama da forma de onda do monitoramento de instruções de ponto flutuante

ção, é estritamente aplicável a processadores com fluxo de execução in-order. Evidentemente, cada processador possui uma arquitetura diferente para a execução de instruções. Este modelo de monitoramento propõe um caso geral, que pode ser aplicado para a maioria dos casos de processadores e classes de stalls.

\subsection{Pesos de desempenho dos processadores}

Conforme mencionado na Seção 3.6, os vetores de pesos dos processadores devem ser calculados por meio de calibração em software e são utilizados nos cálculos de normalização e projeção de desempenho. Como os componentes responsáveis por esses cálculos são implementados em hardware (Figura 4.1), esses vetores devem ser armazenados dentro do bloco do escalonador, de modo que os componentes que realizam a normalização e projeção possam ler os valores dos pesos. Esse armazenamento deve ser realizado por meio de uma memória interna do escalonador em hardware, cuja a estrutura deve respeitar a Tabela 4.1 ;

Tabela 4.1: Tabela de pesos a ser carregada em memória interna do bloco de escalonamento em hardware

\begin{tabular}{lllc}
\hline \hline Componente & CPUO & CPU1 & CPUN \\
\hline cpi_comp_fpu_stall & peso(fpu, cpu0) & peso(fpu, cpu1) & $\ldots$ \\
cpi_comp_mul_stall & peso(mul, cpu0) & peso(mul, cpu1) & $\ldots$ \\
cpi_comp_div_stall & peso(div, cpu0) & peso(div, cpu1) & $\ldots$ \\
cpi_comp_load_store_stall & peso(lo/st, cpu0) & peso(lo/st, cpu1) & $\ldots$ \\
cpi_comp_branch_stall & peso(branch,cpu0) & peso(branch,cpu1) & $\ldots$ \\
cpi_comp_dcache_stall & peso(dcache,cpu0) & peso(dcache,cpu1) & $\ldots$ \\
cpi_comp_icache_stall & peso(icache,cpu0) & peso(icache,cpu1) & $\ldots$ \\
cpi_comp_dtlb_stall & peso(dtlb,cpu0) & peso(dtlb,cpu1) & $\ldots$ \\
cpi_comp_itlb_stall & peso(itlb,cpu0) & peso(itlb,cpu1) & $\ldots$ \\
\hline \hline
\end{tabular}




\subsection{Normalização e projeção de desempenho}

O monitor de desempenho de cada processador está continuamente disponibilizando a decomposição de stall de seu processo corrente em execução. A projeção de desempenho leva em consideração as decomposições para realizar as projeções de desempenho nos outros processadores, de acordo com o vetor de peso de desempenho. A organização dos blocos implementados em hardware, que realizam essa projeção, está apresentada na Figura 4.6.

A abordagem de processamento utilizada para a arquitetura de projeção segue o fluxo serial de cálculos. Tal abordagem foi adotada por diminuir o espaço lógico ocupado na FPGA, sem haver perdas consideráveis na precisão da projeção, já que essa é realizada continuamente.

Como pode ser visto na Figura 4.6, o bloco recebe dados externos vindos dos processadores. Tais dados consistem na decomposição de stall atual calculado por cada monitor de desempenho, sendo enviado paralelamente para o bloco de projeção. A projeção é realizada continuamente do mesmo modo que o monitoramento. Sendo assim, a cada momento é escolhido, sequenciamente, uma das entradas provindas dos processadores para amostrar o vetor inteiro de decomposição naquele instante. O bloco sched_het_selec_in é responsável por essa escolha sequencial, como também é responsável por amostrar a decomposição e enviá-la serialmente por meio de um barramento para o bloco seguinte. Respeitando o controle de fluxo do barramento, assim que terminar o envio do vetor de stall, o bloco sched_het_selec_in aguarda um sinal positivo do bloco seguinte para que seja enviado o próximo vetor de stalls relacionado ao próximo processador. Esse comportamento encontra-se ilustrado na Figura 4.7. Assim como ilustrado, a primeira palavra a ser enviada é o número total de ciclos, que deve ser utilizado para encontrar a porcentagem de stall para cada componente.

O componente responsável por encontrar a porcentagem de stall de cada componente consiste no sched_norm. Serialmente, na medida que os dados dos componentes vão entrando no bloco, as porcentagens vão saindo alguns ciclos depois devido a uma operação de divisão de numeros inteiros realizada. O bloco sched_corr_wrapper recebe essas porcentagens e busca os pesos do processador corrente e do processador que se deseja realizar a projeção, retornando esses dados serialmente para o próximo bloco, chamado sched_het_goto_base, o qual realiza a normalização, utilizando para isso o vetor de peso do processador corrente. Os dois próximos blocos do modelo, sched_corr e sched_corr, devem realizar a projeção de desempenho do processo para todos os processadores, conforme a Equação 3.6. Por último, o resultado é disponibilizado para o barramento, por meio do bloco sched_corr_out_wrap 


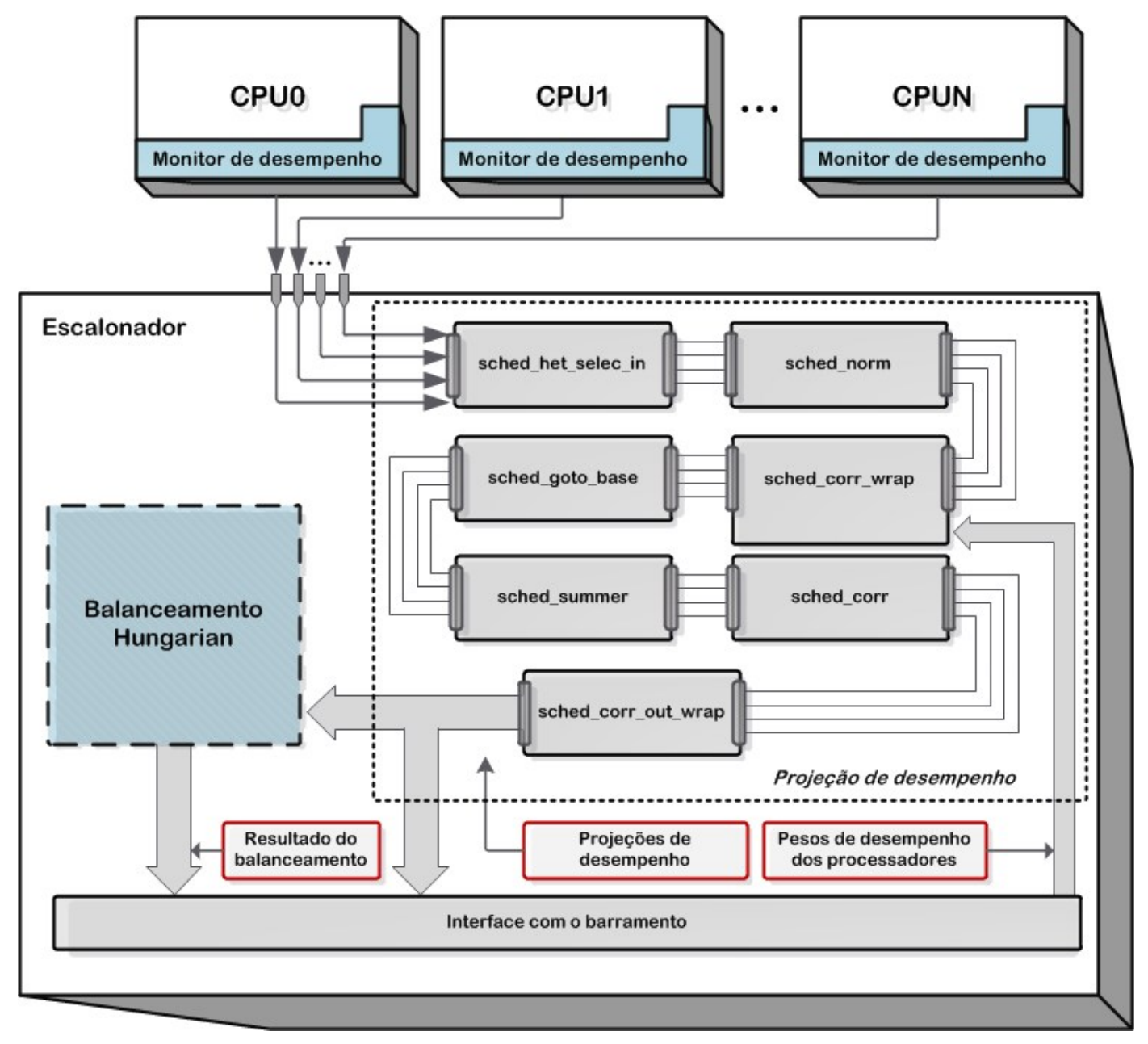

Figura 4.6: Organização dos blocos de escalonamento em HW

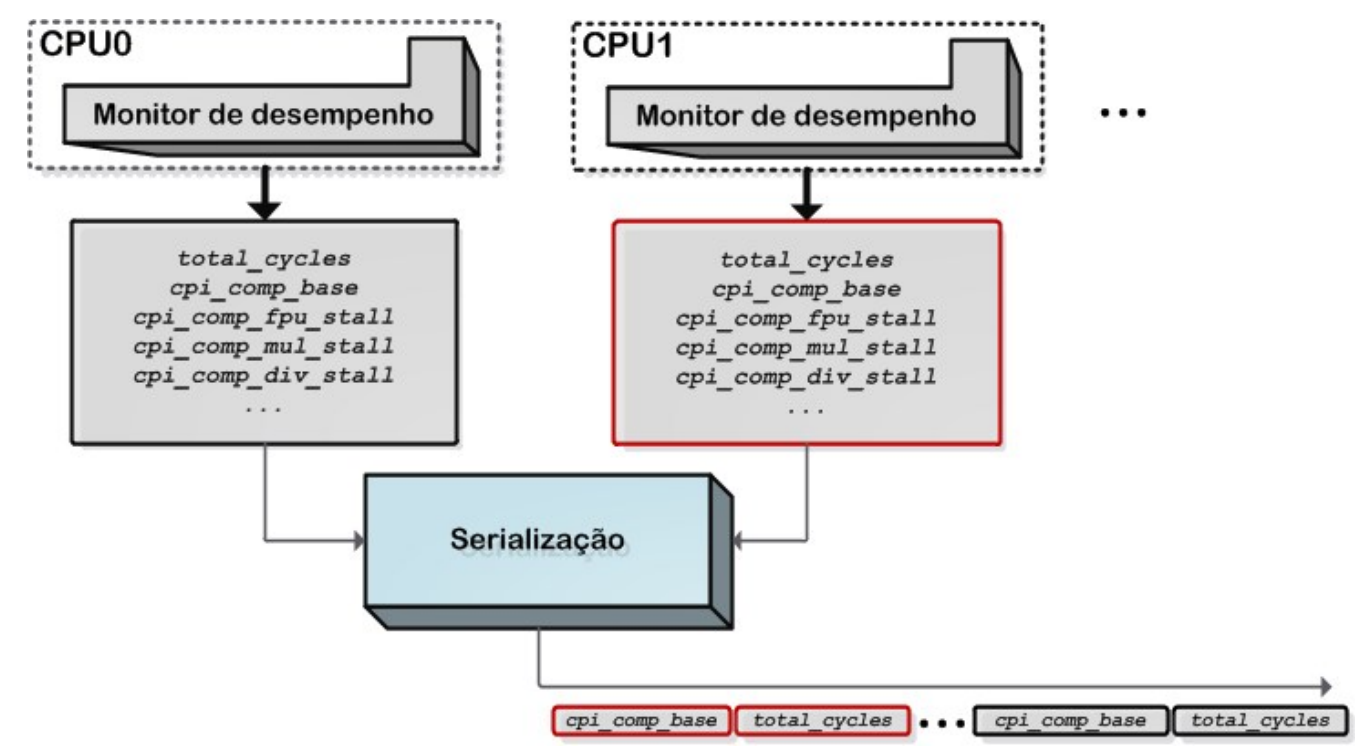

Figura 4.7: Serialização dos dados

que organiza os dados de acordo com a entrada do barramento. Esses mesmos dados devem ser também passados ao bloco de balanceamento, que deve montar uma matriz com as projeções e posteriormente executar o algoritmo hungarian. 


\subsection{Balanceamento}

O componente responsável pelo balanceamento, possui uma matriz contendo as projeções de desempenho de todos os processos para todos os processadores. Esses dados são utilizados para maximizar o desempenho do do sistema. Para realizar essa tarefa, diversos componentes cooperam entre si e compartilham uma memória contendo a matriz de projeções, assim como ilustrado na Figura 4.8 .

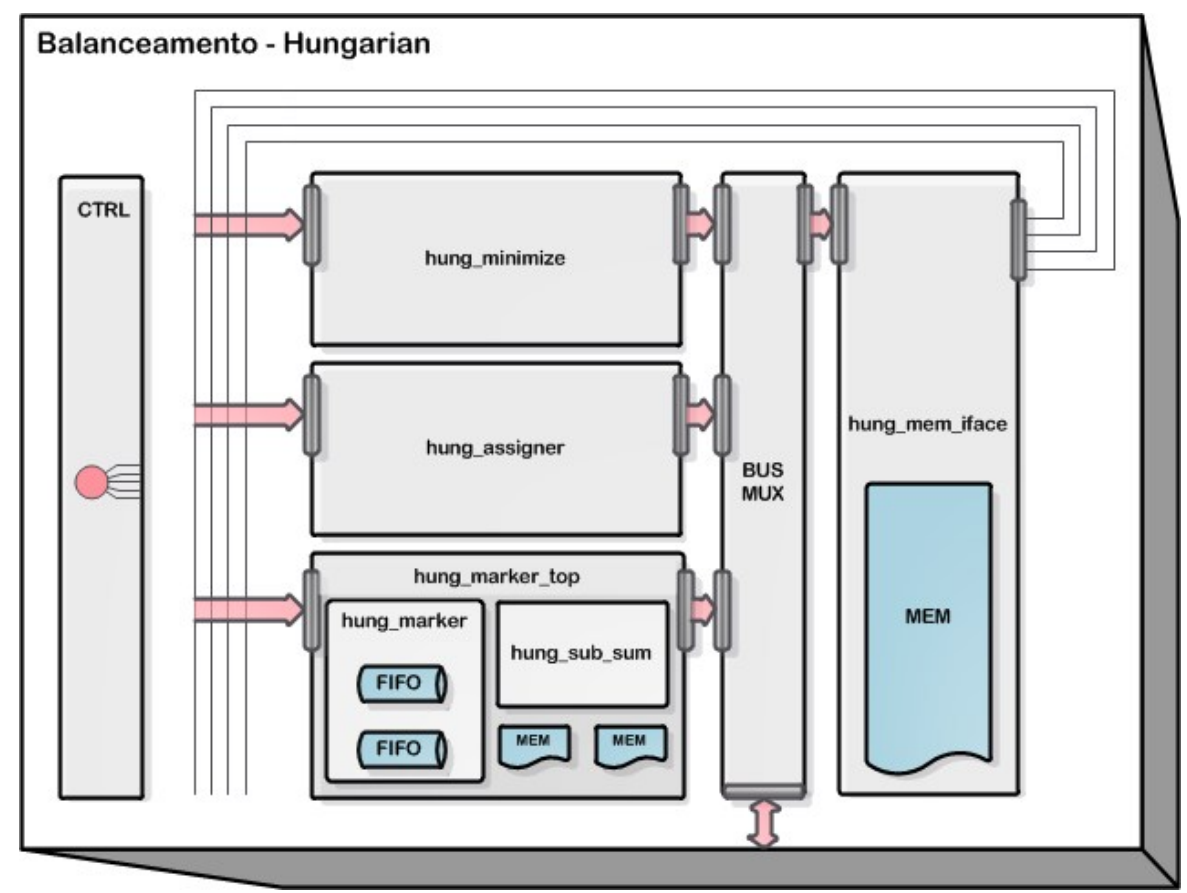

Figura 4.8: Algoritmo Hungarian - Balanceamento em HW

Os principais componentes desse bloco são:

- hung_mem_iface: É o componente responsável pelo controle da memória onde a matriz está armazenada. Por meio desse componente, os dados da matriz podem ser escritos, lidos e atualizados. Essa interface pode receber requisições de leitura ou de escrita paralelamente. As requisições são realizadas por meio do número da linha ou coluna desejável. Caso a requisição seja de leitura, os dados da linha ou coluna são transmitidos pelo barramento de saída, onde todos os demais componentes podem ler. No algoritmo, somente um componente requisita por vez, no entanto a abordagem de um barramento único de saída de dados foi utilizada para evitar a utilização de multiplexadores, diminuindo a área lógica em hardware;

- bus_bux: A memória tem somente uma porta de entrada de dados a serem escritos e de requisições. O objetivo desse multiplexador é selecionar 
a entrada que deve realizar as requisições a memória, assim como quem deve enviar dados de escrita à memória;

- hung_ctrl: Esse componente é responsável pelo controle do algoritmo. É por meio dele que os demais componentes devem saber os momentos de início e fim de processamento.

- hung_minimize: Após a matriz carregada na memória, segundo o algoritmo hungarian, esse é o primeiro componente que deve iniciar a execução. Sua responsabilidade é procurar os mínimos de cada linha e coluna, realizando as operações de subtração para cada linha ou coluna, gerando pelo menos um zero em cada linha e coluna;

- hung_assigner: O objetivo desse componente é realizar designações entre linhas e colunas da matriz, marcando os elementos que possuem zeros, de modo que apenas um elemento por linha ou coluna seja marcado. Se a matriz é de ordem $\mathrm{N}$, o objetivo do algoritmo consiste que esse componente realize $\mathrm{N}$ marcações, fato que determina o final dos cálculos do algoritmo;

- hung_marker_top: Composto por dois outros componentes, esse componente realiza as marcações imaginárias nas linhas e colunas da matriz que tenham zeros. Esse processo é realizado de modo que exista a menor quantidade possível de linhas ou colunas marcadas;

- hung_marker: Com o auxílio de duas memórias que são utilizadas para armazenar as marcações, o hung_marker é um processo iterativo que realiza a leitura de linhas ou colunas, verificando se cada elemento faz parte de alguma linha imaginária, linha ou coluna, e se há necessidade de realizar a marcação; e

- hung_sub_sum: Após as marcações das linhas e colunas, esse componente escolhe o menor elemento que não faz parte de nenhuma linha ou coluna e subtrai todos os demais que também não estão marcados. Posteriormente, esse mesmo elemento é somado a todos os elementos que fazem parte de uma intersecção.

\subsection{Interface com o software}

O controle do monitoramento e projeção realizados em hardware é tarefa do escalonador do sistema operacional, abordado na Seção 4.9. Portanto, o hardware deve oferecer uma interface para a comunicação com o software. Por meio dela, o sistema operacional deve ser capaz de executar tarefas como 
iniciar e parar monitoramento, acompanhar as estatísticas de execução e verificar as projeções para realizar as migrações de processos. A Tabela 4.2 apresenta os principais registradores que a interface do escalonador em hardware deve oferecer ao software por meio do barramento de comunicação. Para cada processador da arquitetura deve existir esse mesmo conjunto de registradores. A tabela está dividida em cinco partes. Os registradores relacionados aos pesos de desempenho são carregados pelo sistema operacional de acordo com a calibração de desempenho e existe um campo para cada componente. Quando um processo entra em execução e é monitorado, a sua decomposição de CPI é continuamente atualizada, podendo ser lida pelo sistema operacional a qualquer momento por meio dos registradores da parte de decomposição do CPI. Nesse grupo de registradores, o total_cycles consiste na medida precisa de quantos ciclos ocorreram desde o momento em que a execução do monitor para aquele processo foi iniciada. O registrador process_id consiste no PID do processo atual executando no processador onde o registro é lido. Para efeito de realizar medições estatísticas no processo, uma parte dos registradores disponibilizados consiste nos contadores de instruções, organizados por classes, para o processo atual em execução. Um dos principais conjuntos de registradores consiste no conjunto de projeções realizadas em hardware. Essas projeções são realizadas continuamente pelo hardware e são disponibilizadas por meio de $\mathrm{N}$ registradores, onde $\mathrm{N}$ consiste no número de processadores. Cada processo tem seu desempenho projetado para os $\mathrm{N}$ processadores da arquitetura, de acordo com os pesos de desempenho e seu desempenho normalizado no processador corrente. Essas projeções devem ser lidas pelo escalonador do sistema operacional para realizar ou não a migração do processo para outro processador que lhe ofereça maior desempenho. Por último, os registradores de controle são utilizados pelo sistema operacional para iniciar e parar o monitoramento do processo. Somente o escalonador dentro do sistema operacional tem conhecimento do momento em que o processo é iniciado e parado. Sendo esses últimos registradores utilizados para esse fim.

\subsection{Suporte do sistema operacional ao escalonamento heterogêneo}

Como mencionado anteriormente, entre os requisitos deste projeto para a definição de camadas de componentes, estão os itens de flexibilidade e competência. Esses são os principais requisitos que definem os componentes a serem implementados dentro do sistema operacional. Um dos principais componentes é o controle dos processos, o qual somente o escalonador do sistema operacional tem o controle. Consequentemente, é por meio dele que toda a 
Tabela 4.2: Principais registradores utilizados na interface com o software

\begin{tabular}{|c|c|}
\hline Entrada/Saída & Nome \\
\hline \multicolumn{2}{|c|}{ Pesos de desempenho dos processadores } \\
\hline Entrada & comp_fpu \\
\hline Entrada & comp_mul \\
\hline Entrada & comp_div \\
\hline Entrada & comp_load \\
\hline Entrada & comp_branch \\
\hline Entrada & comp_dcache \\
\hline Entrada & comp_icache \\
\hline Entrada & comp_dtlb \\
\hline Entrada & comp_itlb \\
\hline \multicolumn{2}{|c|}{ Decomposição do CPI } \\
\hline Saída & process_id \\
\hline Saída & total_cycles \\
\hline Saída & cpi_comp_base \\
\hline Saída & cpi_comp_fpu_stall \\
\hline Saída & cpi_comp_mul_stall \\
\hline Saída & cpi_comp_div_stall \\
\hline Saída & cpi_comp_load_store_stall \\
\hline Saída & cpi_comp_branch_stall \\
\hline Saída & cpi_comp_dcache_stall \\
\hline Saída & cpi_comp_icache_stall \\
\hline Saída & cpi_comp_dtlb_stall \\
\hline Saída & cpi_comp_itlb_stall \\
\hline \multicolumn{2}{|c|}{ Contadores de instruções } \\
\hline Saída & cnt_branch \\
\hline Saída & cnt_load_store \\
\hline Saída & cnt_alu \\
\hline Saída & cnt_mul \\
\hline Saída & cnt_div \\
\hline Saída & cnt_fpu \\
\hline \multicolumn{2}{|r|}{ Projeções } \\
\hline Saída & proj_cpuO \\
\hline Saída & proj_cpu1 \\
\hline Saída & proj_cpu(N-1) \\
\hline \multicolumn{2}{|c|}{ Registradores de controle } \\
\hline Entrada & start_perfcnt \\
\hline Entrada & stop_perfcnt \\
\hline Entrada & pid \\
\hline
\end{tabular}

parte em hardware deve ser controlada. Nesta seção são definidos os principais pontos do sistema operacional que são afetados para a implementação do suporte ao escalonador heterogêneo.

\section{Driver de acesso ao escalonador em hardware}

O sistema operacional, de modo básico, pode ser dividido em três camadas: camada de usuário, núcleo e camada de acesso a hardware. Um 
dos objetivos dessa divisão em camadas é oferecer suporte ao sistema operacional a várias arquiteturas de hardware, sem que o núcleo ou a camada usuário precisem se preocupar com isso. Para tanto, é definida uma interface genérica entre núcleo e camada de hardware, a qual todas as camadas de hardware devem implementar, dependendo do recurso que é abordado. Este projeto segue o mesmo princípio, onde a camada de acesso ao hardware consiste no meio de acesso que o escalonador, localizado no sistema operacional, possui para controlar as projeções de desempenho realizadas em hardware. A Tabela 4.2 apresenta os principais registradores que devem ser acessados para realizar as tarefas de monitoramento e projeção oferecidas pelo hardware.

\section{Abrangência do escalonamento heterogêneo}

Existem duas abordagens principais para a aplicação do escalonamento heterogêneo. A primeira, compreende em aplicar o monitoramento e projeção para todos os processos do sistema, sem distinção. Na segunda, o escalonamento é aplicado somente em um grupo de processos que tenha impacto no desempenho do sistema. Este projeto aborda a idéia de que nem todos os processos sejam monitorados pelo escalonador, apesar de ser possivel monitorar todos. Essa estratégia é utilizada devido ao fato de que a maioria dos processos que pertence ao sistema operacional não possuem uma carga alta de processamento. Assim, assumindo-se apenas o grupo de processos que necessita de maior atenção em relação ao aumento de desempenho, o sistema operacional fica livre para tratar os demais processos, e o escalonamento heterogêneo trabalha especificamente para aumentar o desempenho do grupo de processos designado.

A designação de um processo ao grupo de processos controlados pelo escalonador heterogêneo pode ser realizada pelo próprio sistema operacional, analisando-se a carga computacional do processo, ou pelo próprio usuário, que executa o processo e tem a necessidade aumentar o desempenho de seu processo.

\section{Representação dos processos}

Cada processo, dentro do núcleo do sistema operacional, possui uma representação interna que armazena suas informações, entre as quais podem ser citadas: número de identificação (pid), processo pai, contexto e informações estatísticas. Para a implementação do escalonamento heterogêneo é necessário que as informações relacionadas ao desempenho do processo nos processadores da arquitetura sejam inseridas dentro dessa representação. Este projeto define os seguintes dados como sendo essenciais dentro da representação de cada processo: 
- Processador com melhor desempenho: Após a execução da projeção em hardware, é definido o processador que oferece maior desempenho para a execução do processo. Essa informação deve ser armazenada, de modo que o escalonador tenha controle sobre as migrações do processo. Normalmente, assim que a projeção é medida, o processo não pode ser migrado instaneamente, devido às restrições de operações paralelas dentro do sistema operacional. Como diversos processadores podem executar o mesmo código, ou compartilhar o mesmo recurso do sistema operacional, as operações de migrações são realizadas quando não oferecem riscos de integridade ao sistema. Sendo assim, essa informação deve ser mantida, até o momento em que a migração possa ser realizada com segurança;

- Estatísticas: É importante armazenar as informações relacionadas a execução do processo no último processador (decomposição do CPI), assim como as projeções de desempenho para os demais processadores. Essas estatísticas podem ser utilizadas para a calibração dos pesos de desempenho ou também para acompanhar o desempenho do processo em execução;

- Grupo de escalonamento heterogêneo: Cada processo pode ou não fazer parte do grupo de processos que são monitorados pelo sistema operacional. Portanto, é necessário armazenar essa informação.

\section{Grupo de escalonamento heterogêneo}

Como descrito anteriormente, deve existir um grupo de processos indicados previamente ao monitoramento do escalonador heterogêneo. Cada um dos processos desse grupo deve ser migrado de processador de acordo com o desempenho que o processador lhe ofereça. No entanto, já que o escalonamento heterogêneo deve decidir para qual processador os processos são migrados, é necessário que o sistema operacional não tenha controle de migração sobre eles. Caso contrário, a designação realizada de acordo com a projeção de desempenho pode não ser considerada se o escalonador do sistema operacional, de acordo com sua política, decidir realizar uma balanceamento entre processadores.

\section{Interação com o escalonador do so}

Existem diferentes tipos de escalonadores em diferentes sistemas operacionais, sendo que cada um pode implementar uma política diferente. Entenda-se por política, como sendo a escolha de qual processo vai executar e o quanto vai executar. Nesse sentido, a maioria dos escalonado- 
res é guiado por dois princípios básicos, o timeslice ${ }^{1}$ e a prioridade dos processos, não mutuamente exclusivos. Somente com base nesses dois itens, diversas políticas foram implementadas. Algumas delas podem ser citadas: consideração de agrupamentos de processadores, cálculo do timeslice por prioridade, cálculo do timeslice guiada pela utilização do processador (CPU-bound vs IO-bound), timeslice fixo, preempção por prioridades, agrupamentos por tipos de processos e cálculo do timeslice de acordo com a carga computacional do sistema e prioridades. Como cada sistema operacional pode implementar uma política diferente, é difícil delinear, de modo geral, a interação do escalonador no núcleo com a projeção de desempenho realizada em hardware. No entanto, um ponto comum a todos sistemas operacionais é a função que realiza a tarefa de escolher a nova tarefa e trocar de contexto. Nesse sentido, este trabalho propõe que a partir desse ponto sejam realizadas as modificações para incluir o suporte ao escalonamento heterogêneo. A Figura 4.9 ilustra o fluxo de execução principal para incluir a verificação do processador que oferece melhor desempenho ao processo.

A parte inicial está relacionada a um dos primeiros passos executados dentro da função do escalonador padrão que escolhe o próximo processo e realiza a troca de contexto. De acordo como definido previamente, o monitoramento é ativado somente para os processos pertencentes ao grupo destinado ao escalonador heterogêneo. Assim, o primeiro passo consiste na verificação do grupo do processo. Caso ele não pertença ao grupo, o fluxo normal do escalonador é seguido, caso contrário, o monitoramento do atual processo é finalizado e suas projeções são lidas. A partir das projeções, é realizada a verificação de qual processador deve ser escolhido e este é armazenado na estrutura do processo. Após isso, verifica-se se o processo está para ser retirado da fila de execução, ou seja, se foi parado ou se está terminando sua execução. Caso esteja sendo retirado da fila de execução, o algoritmo também deve retirá-lo do grupo de processos heterogêneos. Em seguida, é realizada a verificação de todos os processos que precisem ser migrados. Caso não estejam sendo executados, entre outras restrições específicas do sistema operacional, os processos podem ser migrados de processador. O próximo processo é escolhido para execução e realiza-se a troca de contexto. A partir desse ponto, um novo processo entra em execução, sendo verificado novamente em relação ao grupo de escalonamento heterogêneo. Caso pertença ao grupo, o monitoramento em hardware é iniciado para aquele processo.

\footnotetext{
${ }^{1}$ timeslice: Também conhecido como quantum, consiste no tempo em que um processo permanece em execução antes de "dormir".
} 


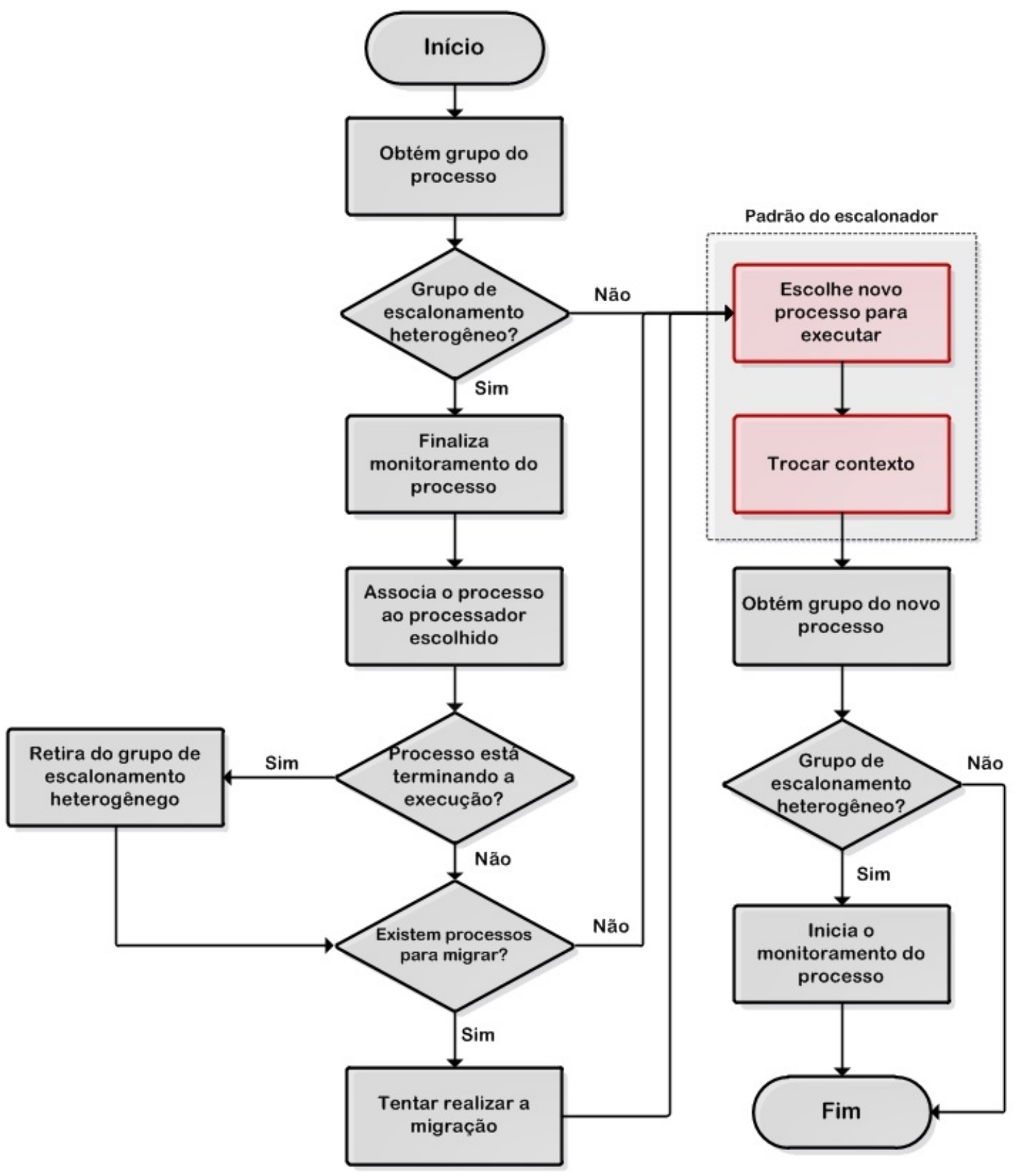

Figura 4.9: Fluxograma da implementação do suporte a escalonador heterogêneo no sistema operacional 


\section{Migração de tarefas}

A migração de tarefa consiste na verificação, entre todos os processos do grupo do escalonador heterogêneo, quais processos estão destinados a executar em um processador diferente do qual executa atualmente. Conforme ilustrado na Figura 4.9, essa verificação é realizada antes da troca de contexto pelo processo que está na eminência de "dormir"2. Caso algum processo, dentro do grupo, estiver executando em um processador diferente do qual ele é destinado, é iniciada uma sequência de passos para a migração do processo de CPU. Essa sequência de passos para a migração de processador não pode ser descrita genericamente, já que cada sistema operacional pode utilizar uma estrutura diferente para determinar qual processo está executando em qual processador. Na Seção 5.3 está descrita a implementação dessa sequência de passos no sistema operacional Linux, versão de kernel 2.6.32, onde cada processador possui uma fila de processos que executam sobre ele. Em versões mais antigas, havia somente uma fila de processos para todos os processadores, o que demonstra a variedade de possibilidades de implementações para essa representação. É importante levar em consideração que nem sempre a migração é realizada. De modo geral, ela pode ser impossibilidata de ser realizada em um momento específico devido ao fato de que o processo a ser migrado está em execução, ou devido a algum mecanismo de sincronização estar protegendo a estrutura a ser modificada para a migração. Essa impossibilidade também pode variar de acordo com a implementação do sistema operacional.

\section{Suporte ao monitoramento de eventos que causam a troca de contexto}

Assim como apresentado no Capítulo 2, diversas implementações de escalonadores para arquiteturas heterogêneas consideram em suas heuristícas a classificação dos processos como sendo CPU-bound ou IO-bound. Grande parte desses escalonadores considera essa classificação determinante para a escolha do melhor processador, obtendo-se um aumento de desempenho por meio dessa heurística. Apesar dessa classificação não ser utilizada neste projeto, é importante considerar que pode trazer ganhos de desempenho se utilizada em conjunto com a heurística apresentada. Muitas informações podem ser monitoradas para também classificar o processo, além dos componentes de CPI mencionados. Alguns exemplos podem ser citados, tais como o monitoramento de interrupções de um processo e monitoramento da faixa de endereço acessado no bar-

\footnotetext{
${ }^{2} \mathrm{O}$ termo "dormir" também é utilizado para designar que um processo não será chamado para a execução até que algum evento que ele espera ocorra. No caso descrito, o termo "dormir" refere-se simplesmente ao fato de que o processo não está em execução, mas está pronto para receber a CPU novamente.
} 
ramento de modo a detectar a comunicação com periféricos. O sistema operacional também pode monitorar e classificar um processo de acordo com a periodicidade que ele é obrigado a "dormir" por acessar algum recurso que necessite de tempo alto de resposta, ou mesmo, por acessar regiões críticas, já que o processo é obrigado a "dormir" caso tente acessar uma região crítica, protegida por um semáforo, bloqueada por outro processo.

\section{Suporte a arquiteturas com ISA's hibridas}

O suporte a processadores com um conjunto diferentes de instruções, porém, compartilhando um conjunto básico delas, considerando que o sistema operacional seja compilado com esse conjunto básico, pode ser implementado utilizando a interrupção de opcode inválido gerada pelo processador quando uma instrução que não faz parte de seu conjunto de instruções tenta ser executada. A partir dessa interrupção, o sistema operacional pode habilitar uma máscara, inserida na representação interna do processo, que indica quais os processadores devem ser proibidos para a execução do processo atual. Essa máscara deve ser sempre consultada pelo escalonador, antes de selecionar o processo para a execução. Caso esteja habilitada, o escalonador deve selecionar o processo para a migração de processador. Outra consideração importante é em relação ao contexto do processo que ocasionou a interrupção. Como a implementação do tratamento dessa interrupção está diretamente relacionada com a arquitetura do processador, em alguns caso pode haver a necessidade de retornar uma instrução anterior no registrador PC, antes de salvar o contexto do processo.

\subsection{Considerações finais}

Neste capítulo foi apresentada a arquitetura proposta para a implementação da heurística do escalonador, descrita a partir do detalhamento dos componentes de hardware e software envolvidos no co-projeto. Essa arquitetura consiste em um modelo genérico, baseada inicialmente na aplicação em sistemas embarcados, mas que pode ser facilmente expandida para atender ambientes de alto desempenho, como também arquiteturas de processadores mais avançados. 


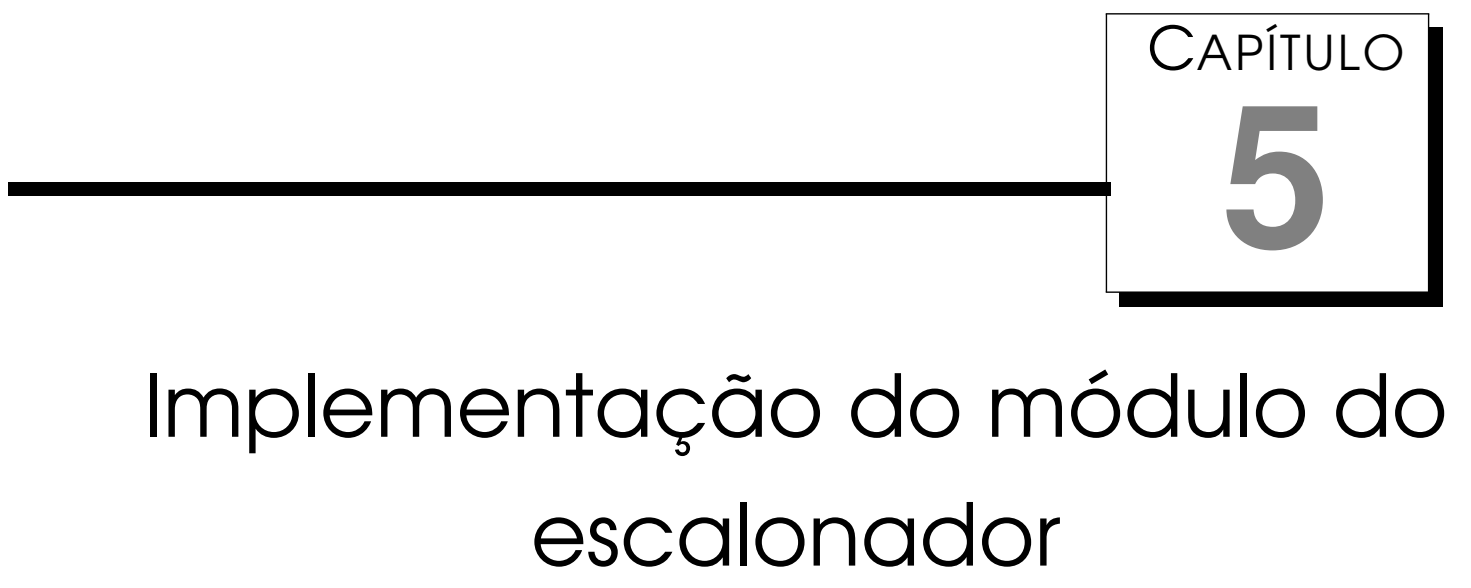

As arquiteturas multiprocessadas heterogêneas são compostas por processadores distintos, usualmente compartilhando o mesmo barramento e dispositivos. A grande vantagem dessas arquiteturas é a potencialização do throughput alcançado com a distribuição eficiente de processos entre os processadores que mais se adequam ao seu comportamento.

O dinamismo dos processos dificulta a tarefa de escalonamento devido suas mudanças de necessidades de recursos ao longo do tempo. No entanto, o projeto de escalonamento apresentado nesta tese busca principalmente extrair esse dinamismo e, a partir dele, realizar projeções de desempenho em tempo real do comportamento atual de um processo para todos os processadores.

Com o objetivo de avaliar a heurística e arquitetura propostas para o escalonamento em arquiteturas heterogêneas, neste capítulo são apresentados os principais detalhes relacionados à implementação da arquitetura descrita no Capítulo 4. Os tópicos citados no co-projeto do escalonador estão apresentados na Tabela 5.1, onde são indicados os tópicos que foram implementados para a avaliação real do escalonador descrito neste projeto.

Este capítulo está organizado do seguinte modo: na Seção [5.1] é descrito como a implementação foi realizada em relação a hardware e software, como também a plataforma de desenvolvimento utilizada para avaliação da arquitetura implementada. Na Seção 5.2 são descritos os principais detalhes relacionados ao hardware do escalonador. Por fim, na Seção 5.3, é apresentado como foi realizada a implementação do suporte ao escalonador no sistema operacional, assim como suas interfaces. 
Tabela 5.1: Itens descritos no co-projeto do escalonador

\begin{tabular}{ccc}
\hline \hline Camada & Tópico & Implementado \\
\hline \multirow{4}{*}{ SW } & Driver de acesso ao escalonador em hardware & $\checkmark$ \\
& Heterogeneidade na representação dos processos & $\checkmark$ \\
& Migração de processos & $\checkmark$ \\
& Interação com o escalonador do SO & $\checkmark$ \\
& Grupo de escalonamento heterogêneo & $\checkmark$ \\
& Monitoramento de eventos de troca de contexto & \\
Suporte a ISA's diferentes & $\checkmark$ \\
HW & $\checkmark$ \\
& Mrmazenamento de pesos de desempenho & $\checkmark$ \\
& Normalização e projeção de desempenho & $\checkmark$ \\
Bnterface de registradores & $\checkmark$ \\
\hline \hline
\end{tabular}

\section{1 Ambiente}

Nesta seção é apresentado todo o ambiente utilizado na implementação do escalonador em hardware, o que envolve a plataforma de desenvolvimento, processador e linguagem de programação. Da parte de software são descritos o sistema operacional e o escalonador utilizados.

\subsubsection{Computação reconfigurável}

A computação reconfigurável consiste em uma tecnologia que busca reduzir a distância existente entre o alto desempenho alcançado por meio de utilização de ASIC (Application Specific Integrated Circuit) e o alto grau de flexibilidade alcançado por meio da execução de tarefas em software (Menotti, 2010).

O FPGA (Field Programable Gate Array), principal tipo de dispositivo dentro desse contexto, permite a arquitetos desenvolverem protótipos de sistemas inteiros, desde pequenos circuitos lógicos, até arquiteturas envolvendo diversos processadores, barramentos e dispositivos diversos, tudo isso em um tempo muito reduzido em relação a circuitos ASICs. Esse tempo menor de desenvolvimento é favorecido principalmente pela quantidade de ferramentas avançadas de projeto e de depuração em auxílio a esta tecnologia (Altera, 2013) (Xilinx, $2013 b)$. Devido à rápida prototipagem, à facilidade de depuração e à flexibilidade de mudanças, é possível reduzir o tempo na resolução de problemas como também reduzir custos envolvidos com problemas detectados após a fabricação. Ao contrário, a tecnologia ASIC envolve ciclos intensivos de desenvolvimento e verificação, mesmo ao custo de maior tempo de projeto, pois um problema detectado após a fabricação acarreta um alto prejuízo.

O FPGA consiste em um arranjo programável contendo essencialmente três 
tipos de blocos: lógicos, de entrada/saída e de interconexões. Nesse arranjo, os blocos lógicos podem assumir desde unidades lógicas e aritméticas, memórias, até blocos de processamento de alto desempenho utilizados em processamento de sinais. Os blocos de interconexão são utilizados para conectar os diferentes tipos blocos lógicos da arquitetura, tendo a possibilidade de construir sistemas complexos (Bonato, 2007). Os blocos de entrada/saída são utilizados para a comunicação com dispositivos externos ao chip, como memórias, portas, LEDs, interfaces seriais de alta velocidade, entre outros.

A construção de arquiteturas multiprocessadas heterogêneas também se beneficia da tecnologia do FPGA. Segundo Agron \& Andrews (2009), devido a alta densidade dos FPGAs, diversos modelos de processadores soft-core podem ser instanciados em um único chip. Isso possibilita aos desenvolvedores criar conjuntos específicos de arquiteturas heterogêneas para serem utilizados em suas aplicações.

\subsubsection{Processador SPARC-V8 Leon3}

Para implementação da arquitetura é utilizado o framework GRLIB desenvolvido pela Gaisler! , o qual contém a implementação em linguagem VHDL do processador Leon3 - SPARC V8 (Gaisler, 2013) (Pedroni, 2004). O Leon3 consiste em um processador soft-core de 32-bits, o qual é baseado na arquitetura SPARC V8. Disponível sob a licença GPL (General Public License), seu código está inteiramente implementado em linguagem VHDL e pode ser sintetizado e também simulado utilizando diversas ferramentas disponíveis no mercado. Seus recursos são totalmente configurados. Dispositivos como caches, FPU e MMU, podem ser configurados individualmente, incluindo mais recursos e maior desempenho. Além disso, a arquitetura também suporta multiprocessamento e conta com diversas ferramentas de software que auxiliam no desenvolvimento de suas aplicações. Os sistemas operacionais Nucleus, RTEMS, uCLinux, VxWorks 5.4/6.5, eCos e Linux, são alguns exemplos de suportes oferecidos para o Leon3.

Entre suas principais características, podem ser citadas:

- Conjunto de instruções SPARC V8 com extenções V8e;

- Pipeline com 7 estágios;

- Multiplicação e divisão em hardware;

- FPU padrão IEEE-754;

- Cache de instruções e dados separados, com suporte a snoop;

\footnotetext{
${ }^{1}$ Aeroflex Gaisler: http://www.gaisler.com
} 
- Caches configuráveis (1-4 ways, 1-256 KBs/way e algoritmos de substituição: Random, LRR ou LRU) ;

- SRMMU (SPARC Reference MMU) com TLBs configuráveis;

- Barramento AMBA-2.0 AHB;

- Suporte a depuramento on-chip com trace de instruções e de dados;

- Suporte a SMP;

- Frequência de operação até 125 MHz em FPGAs e 400 MHz em ASIC; e

- Possui diferentes ferramentas de software, incluindo compiladores, kernels, simuladores e monitores de depuração.

O barramento principal do sistema consiste no barramento AMBA, o qual é responsável por interligar todos os componentes. Assim como ilustrado na Figura 5.1, podem existir vários processadores e diversos outros dispositivos, tais como contradores de memória, ethernet, controladores USB, entre outros.

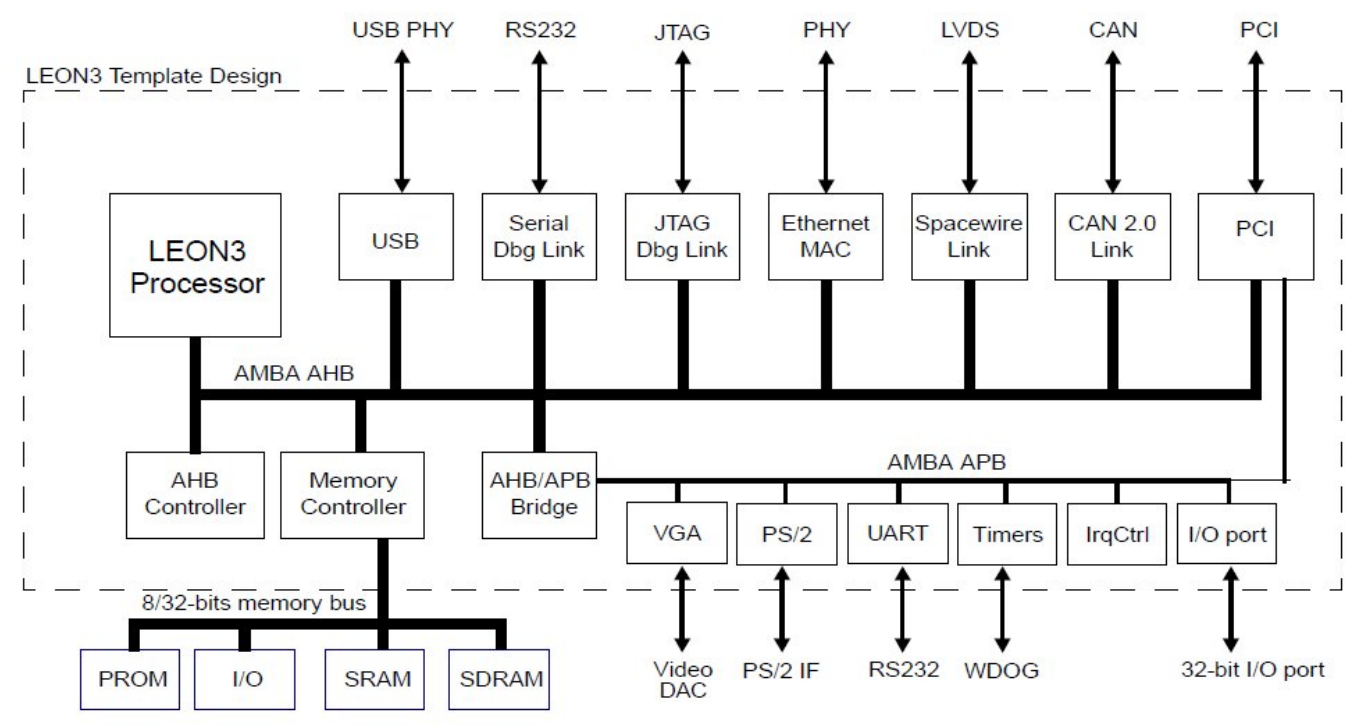

Figura 5.1: Processador, barramento e componentes da GRLIB (Gaisler, 2013)

O propósito principal consiste em centralizar o controle desses dispositivos nos processadores, os quais podem estar executando um sistema operacional com drivers de acesso a todos esses dispositivos. O framework GRLib é organizado de modo que a mesma arquitetura possa ser utilizada em diferentes fabricantes de FPGA, implementando de modo transparente as dependências de mais baixo nível que dependem da tecnologia de FPGA que está sendo utilizada. Todos os seus componentes são programados na linguagem VHDL, assim como o processador Leon3, e dispõem de fóruns e diversas documentações que auxiliam em sua utilização. O fato de se ter um código aberto também 
facilita a depuração dos sinais internos da arquitetura do processador, o qual pode ter seu comportamento inteiramente simulado durante a execução de um programa.

\subsubsection{Build-root - Linux 2.6.32}

Buildroot ${ }^{2}$ consiste em uma ferramenta para gerar um sistema Linux próprio para sistemas embarcados. Por meio dele podem ser gerados: toolchain para compilação cruzada ${ }^{3}$, sistemas de arquivos raiz do Linux (root file system), imagem do kernel ou uma imagem do bootloader.

A ferramenta Buildroot foi utilizada neste projeto para gerar o sistema de arquivos e a imagem do kernel utilizada para carregar o Linux no FPGA. Na ferramenta é possível escolher a versão do kernel do Linux desejada para utilização. Neste projeto foi utilizada a versão 2.6.32, devido ao fato de já utilizar o escalonador CFS - Completely Fair Schedule e por ter seu uso difundido, facilitando encontrar referências de qualquer problema que pudesse ocorrer.

\subsubsection{Escalonador do Linux (a partir da versão 2.6.23)}

Cada processo no Linux é representado por meio de uma estrutura chamada task_struct, a qual armazena todas as informações do processo. Essas informações são relacionadas ao estado do processo atual, número do processo, fila de execução, máscara de afinidade, entre outras. Como cada processo tem uma estrutura, a organização entre elas é realizada por meio de uma lista circular encadeada.

Uma das informações importantes armazenadas nessa estrutura consiste no estado do processo, o qual pode assumir os seguintes estados:

- TASK_RUNNING: O processo é definido como runnable, ou seja, está pronto para execução ou atualmente executando;

- TASK_INTERRUPTIBLE: O processo está bloqueado, esperando por alguma condição para trocar seu estado;

- TASK_UNINTERRUPTIBLE: O processo também está bloqueado, mas está dependente do recebimento de algum sinal para executar;

- TASK_ZOMBIE: O processo terminou sua execução, mas está dependente de uma chamada de wait() pelo processo pai; e

- TASK_STOPPED: O processo está parado e não é elegível para executar.

\footnotetext{
${ }^{2}$ Buildroot: http://buildroot.uclibc.org

${ }^{3}$ Cross-compilation: Compilação para arquiteturas diferentes da qual se está usando para compilar
} 
Esses estados indicam ao escalonador quando um processo deve ou não ser chamado para a execução.

Internamente, cada processador online possui uma fila de execução (runqueue). Nessa fila é armazenada a referência de cada processo que deve executar no processador responsável por essa fila.

A partir da versão de kernel 2.6.23, um novo algoritmo de escalonamento foi adotado. O CFS (Completely Fair Schedule) consiste em um escalonador que busca a igualdade de execução entre todos os processos do sistema. Na visão do algoritmo, o processador ideal seria aquele que pudesse executar paralelamente todas as tarefas com velocidades iguais. Assim, virtualmente, o algoritmo tenta aproximar essa execução ideal, fazendo com que todos os processos possuam uma porção igual de tempo de processador. Para isso é utilizado o conceito de tempo de execução virtual, o qual consiste simplesmente no tempo de processador dado a cada processo. Os processos que possuem os menores tempos de execução virtuais são os próximos a fazer uso do processador (Kernel, 2013).

Cada processo possui uma entidade de escalonamento que o representa no algoritmo. As entidades são armazenadas em uma árvore vermelha e preta, a qual é balanceada justamente pelo tempo de execução virtual de cada processo (Love, 2010).

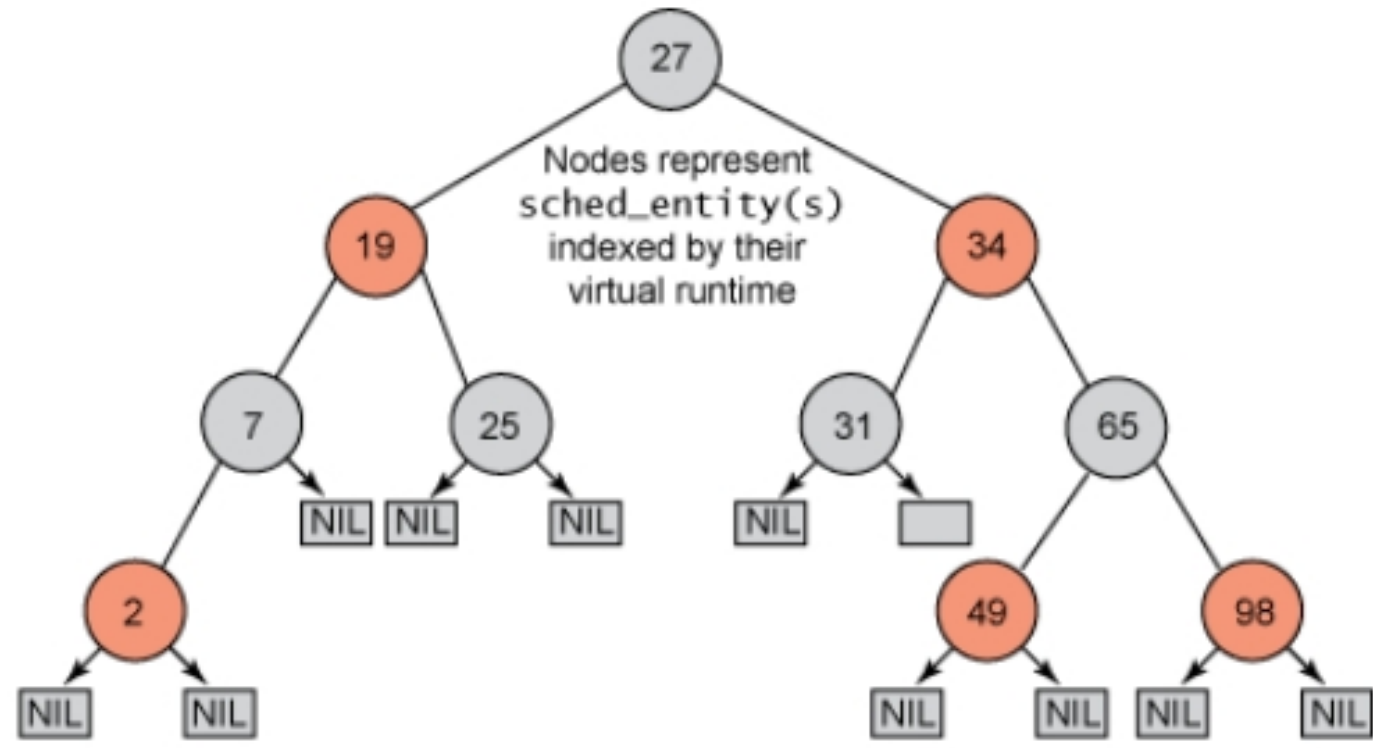

virtual runtime

Most need of CPU

Least need of CPU

Figura 5.2: Organização utilizando árvore vermelha e preta (IBM, 2013a)

Assim como ilustrado na Figura [5.2, os processos representados pelas entidades que estão mais à esquerda da árvore, por terem um tempo menor de uso do processador, são os próximos a serem executados. 


\section{1.5 Plataforma utilizada}

A plataforma de desenvolvimento utilizada neste projeto consiste na placa Xilinx ML507 (Xilinx, 2011). Essa placa possui interfaces seriais de alta velocidade, interfaces de áudio e vídeo, pinos genéricos de entrada e saída, entradas de relógios externos, interface com Flash, interfaces PS/2 e USB, entre outros dispositivos e interfaces para diversos tipos de aplicações. Entre os recursos oferecidos, os principais utilizados neste projeto são

- FPGA Xilinx XC5VFX70: Consiste na FPGA da Xilinx, família Virtex 5. Em resumo, seus principais recursos são: 11200 Slices ${ }^{4}, 820 \mathrm{~Kb}$ de Distributed RAM, 128 blocos de DSP48 5, $5328 \mathrm{~Kb}$ de Block RAM, 640 pinos para utilização do usuário e um processador PowerPC (Xilinx, 2013a);

- Memória DDR2 SODIMM: Chip de memória disponível com 256MB;

- Interface JTAG: Consiste na interface utilizada para o carregamento da imagem a ser gravada na FPGA (hardware) assim como também do software a ser executado (se existir). Essa é a principal interface de depuração da FPGA, por meio da qual se pode verificar a ocorrência de eventos e também amostrar uma saída pré-definida com os sinais a serem monitorados;

- Conector RJ-45: Os pinos desse conector estão ligados diretamente na FPGA. É importante salientar que o componente que recebe os dados desses pinos deve estar inserido na FPGA, sendo utilizado para isso IPs fornecidos pelo fabricante ou IP's geneŕicos providos por meio de licença GPL ou mesmo desenvolvidos pelo usuário; e

- Porta serial RS-232: Conector serial utilizado para depuração de software.

É importante citar que em testes realizados com o processador Leon3, foi possivel utilizar até três processadores com FPUs, com uma pequena folga de recursos para não ocasionar problemas de roteamento e possiveis problemas de temporização, o que limitaria a frequência máxima do sistema.

\subsection{Implementação em hardware}

Neste projeto o hardware é implementado na FPGA Xilinx Virtex5 presente na placa Xilinx-ML507. O framework GrLib, utilizado para projetar a arquitetura com os processadores, não é preparado, em sua versão original, para

\footnotetext{
${ }^{4}$ Slice na Virtex 5: Cada Slice contém quatro LUTs e quatro flip-flops.

${ }^{5} \mathrm{DSP} 48$ : Consiste em um recurso específico para executar mais rapidamente alguns tipos de operações, tal como multiplicação.
} 


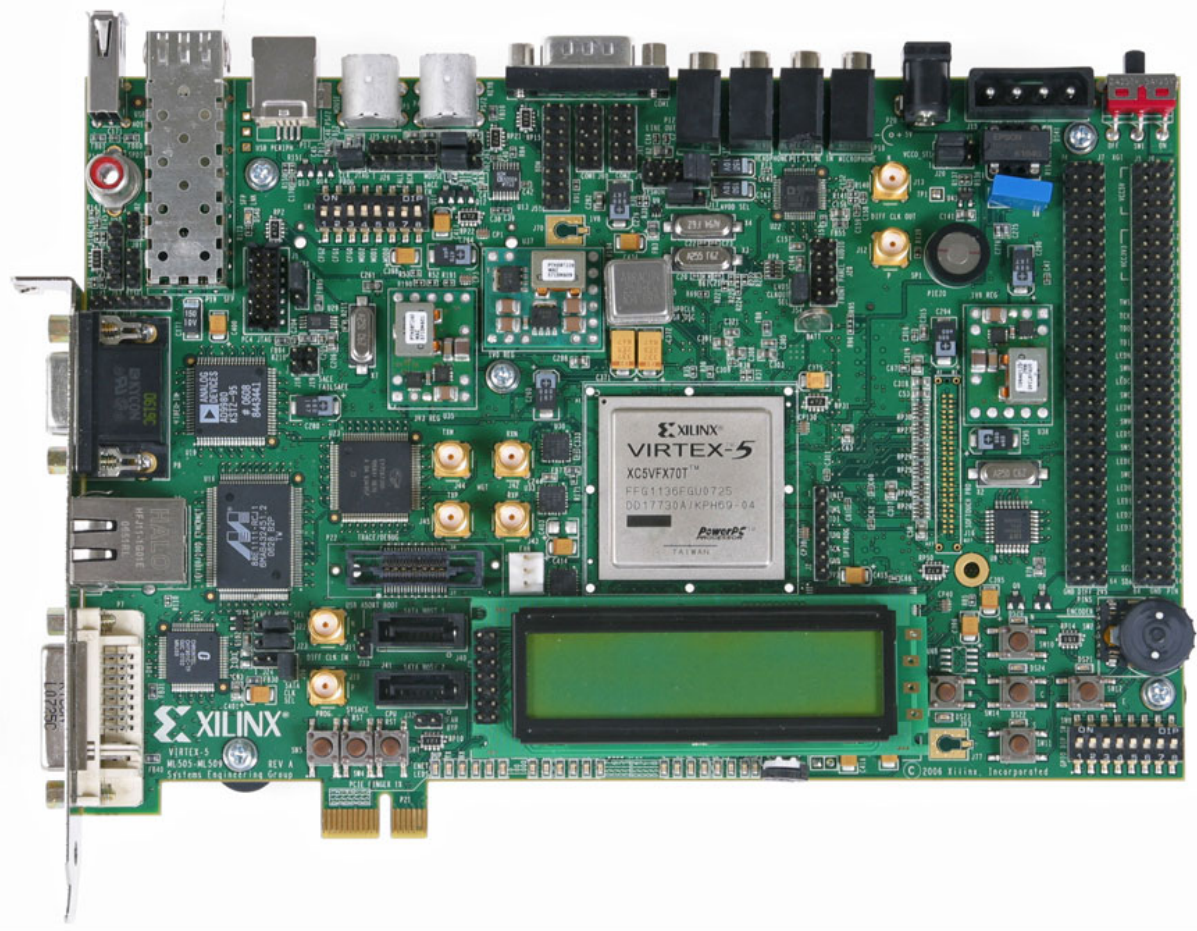

Figura 5.3: Placa Xilinx ML507 utilizada para implementação

comportar diferentes configurações para cada processador. Para realizar a configuração específica de cada processador o framework em VHDL foi modificado, de modo que para cada processador os seguintes itens principais pudessem ser configurados:

- Instruções de multiplicação e divisão;

- Latência da multiplicação;

- Suporte a branch prediction;

- Habilitação da FPU;

- Tipo de FPU;

- Habilitar/Desabilitar cache de dados e de instruções;

- Cache: Quantidade de way, tamanho de way, tamanho da linha e algoritmo de substituição;

- TLB combinada ou dividida entre dados e instruções;

- Algoritmo de substituição da TLB;

- Número de entradas na TLB de dados; e

- Número de entradas na TLB de instruções. 
É importante considerar que essas características influenciam fortemente a quantidade de recursos utilizados na FPGA. Um exemplo é a quantidade de way's da cache, quanto maior o número, maior a quantidade de memória interna necessária e também maior quantidade de lógica na FPGA é utilizada para realizar as comparações das tags. Desse modo, a quantidade de recursos utilizada para os processadores é limitada pelo tipo FPGA utilizada (que pode depender do fabricante e dos diferentes modelos existentes).

O componente principal do escalonador possui uma interface para ligação no barramento amba, por meio da qual o processador pode comunicar-se com o escalonador em hardware. Cada componente possui uma faixa de endereçamento físico no barramento, com isso o processador pode acessar especificamente o bloco que deseja, como é o caso do escalonador.

A seguir é apresentada a descrição dos principais componentes da arquitetura de hardware.

\section{Interface entre componentes}

Os componentes relacionados a projeção de desempenho e balanceamento utilizam como meio de comunicação o protocolo AMBA AXI4-Stream (ARM, 2010). Esse protocolo é utilizado como uma interface para conexão entre dois componentes que trocam dados entre si. Assim como ilustrado na Figura 5.4, um componente mestre, responsável por gerar os dados, envia-os para o componente escravo, que recebe e trata os dados.

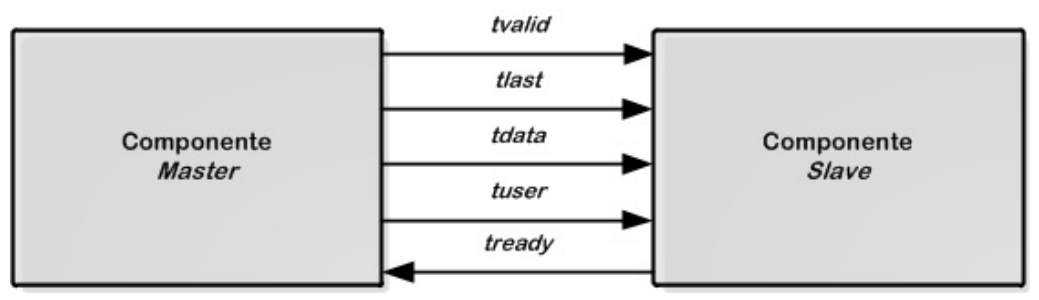

Figura 5.4: Comunicação pela interface AMBA AXI Stream

O protocolo AXI define diversos sinais, cujo o intuito é deixá-lo o mais genérico possível para suportar uma grande variedade de tipos de transferências de dados. No entanto, neste projeto são utilizados apenas os sinais necessários para realizar a comunicação específica entre os componentes. Os sinais utilizados são:

- TVALID: Define o momento em que o componente mestre possui um dado válido para ser utilizado pelo componente escravo;

- TREADY: Define o momento em que o escravo está pronto para receber um dado. Quando o sinal de TVALID e o sinal de TREADY estão habilitados, significa que o dado foi consumido pelo escravo. Em conjunto com o sinal TVALID, o TREADY realiza o controle de fluxo 
de transmissão, limitando a taxa de recepção de dados de acordo com seu tempo de processamento;

- TDATA : Dado a ser enviado. Este sinal somente contém um dado válido quando o sinal TVALID está em alto;

- TLAST : Indica o último dado do pacote, também só deve ser considerado quando o sinal TVALID está em alto; e

- TUSER : Carrega informações específicas entre os blocos. Neste projeto, esse sinal é utilizado para carregar dados como o CPUID, informando os blocos de qual processador os dados são provindos.

Um exemplo do comportamento desses sinais está ilustrado na Figura 5.5.

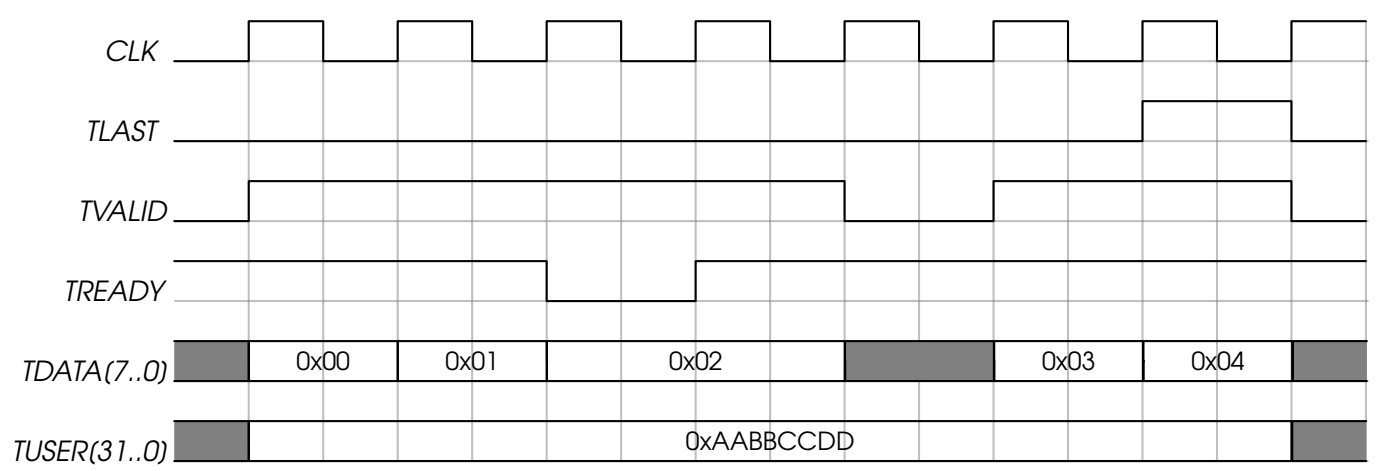

Figura 5.5: Diagrama da forma de onda de um exemplo de comunicação utilizando o protocolo AXI Stream

\section{Monitor de desempenho (Performance Counter)}

O monitor de desempenho é o componente responsável por observar cada instrução executada pelo processador e medir o número de ciclos gastos por ela. Tal medida é utilizada na decomposição do CPI, realizada automaticamente pelo componente. A Figura 5.6 consiste no diagrama de blocos da organização do processador Leon 3.

Localizado dentro do bloco 7-Stage Integer Pipeline, ou somente Integer Unit, o componente de monitoramento possui uma interface na qual recebe a instrução corrente no estágio de execução do pipeline do Leon. O funcionamento básico do monitor de desempenho consiste em decodificar a instrução recebida, de modo que se saiba a qual grupo tal instrução pertence, ou seja, se é uma instrução de branch, de load/store ou de ponto flutuante, por exemplo. A partir da decodificação, o tempo de demora para essa instrução ser efetivada é mensurado. No entanto, as operações de acesso a memória (leitura ou escrita) e instruções de branches possuem um tratamento especial.

Como mencionado anteriormente, os componentes de CPI podem ter dependências entre si. É o caso do cpi_comp_load_store_stall com o com- 


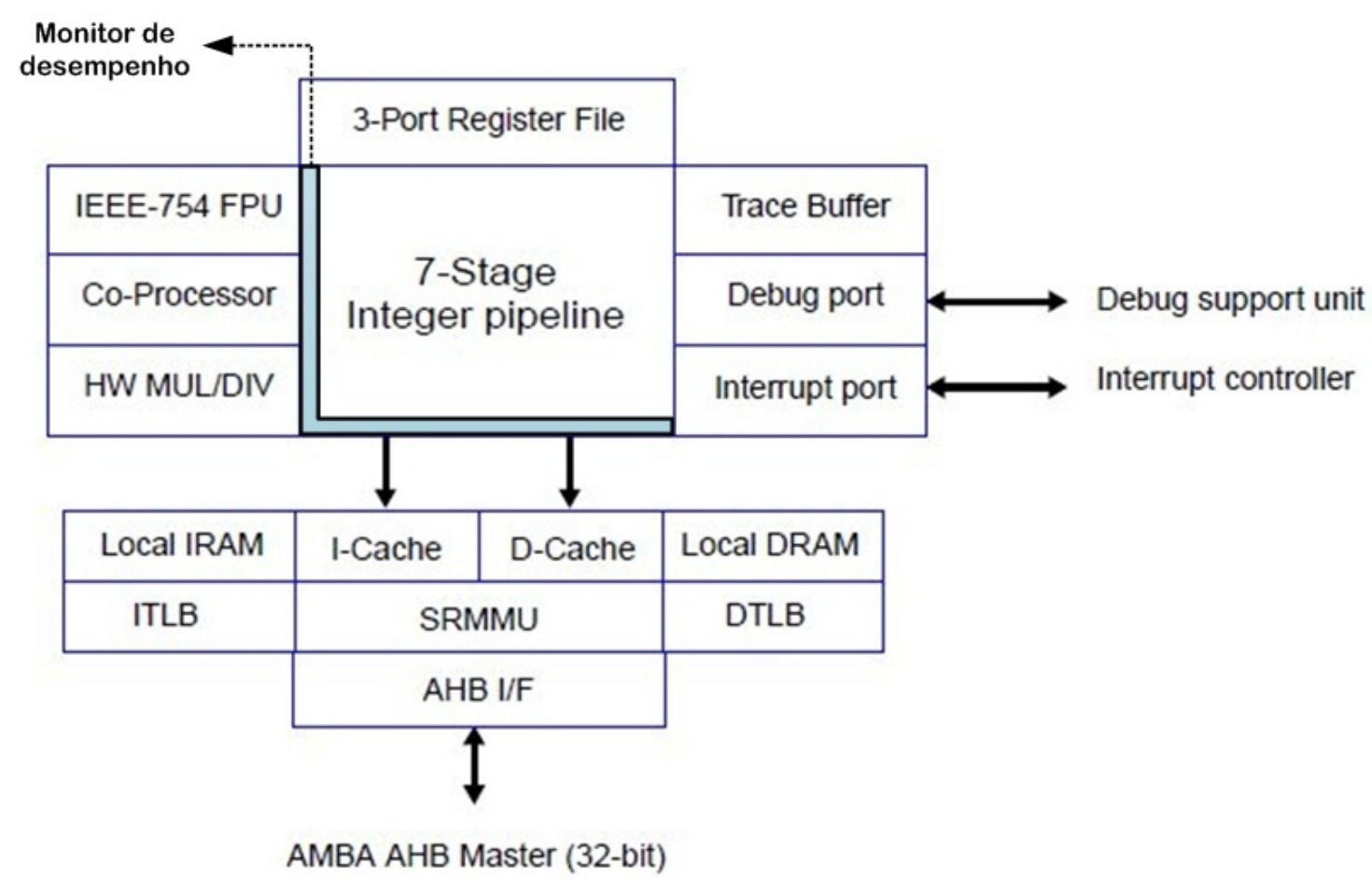

Figura 5.6: Processador SPARC V8 - Leon 3 (Gaisler, 2013)

ponente cpi_comp_dcache_stall. O monitor de desempenho precisa decompor o tempo gasto com instruções de acesso à memória, com o tempo gasto por uma falta de cache, por exemplo. No entanto, pode ser que uma requisição de leitura, além de causar uma falta na cache de dados, também possa causar um falta na TLB de dados da MMU. O mesmo problema pode acontecer na execução de instruções que modificam o endereço presente no registrador PC para um endereço diferente do subquente, causando faltas na cache de instruções ou TLB de instruções. Nesses casos, somente a decodificação de instruções e a medida do tempo de stall não são suficientes para decompor o tempo total de atraso de uma instrução de acesso à memória. Para resolver esse problema, foram implementas interfaces entre os componentes TLB-D (dados), TLB-I (instruções), cache-D (dados), cache-I (instruções) e o monitor de desempenho, de tal modo que o comportamento de cada um deles fosse monitorado. De modo semelhante, com o intuito de obter maior precisão na medida do monitor, também foram implementadas interfaces entre os componentes que realizam a multiplicação e divisão.

O monitor de desempenho possui um sinal de entrada, provindo da interface com o barramento, que indica o início do monitoramento. A partir desse momento, os contadores de stalls fornecem continuamente a decomposição do CPI das instruções executadas do processo em monitoramento. A Figura 5.7 ilustra esse comportamento. Todos os sinais da figura, com exceção do relógio e do sinal de start, são saídas do compo- 


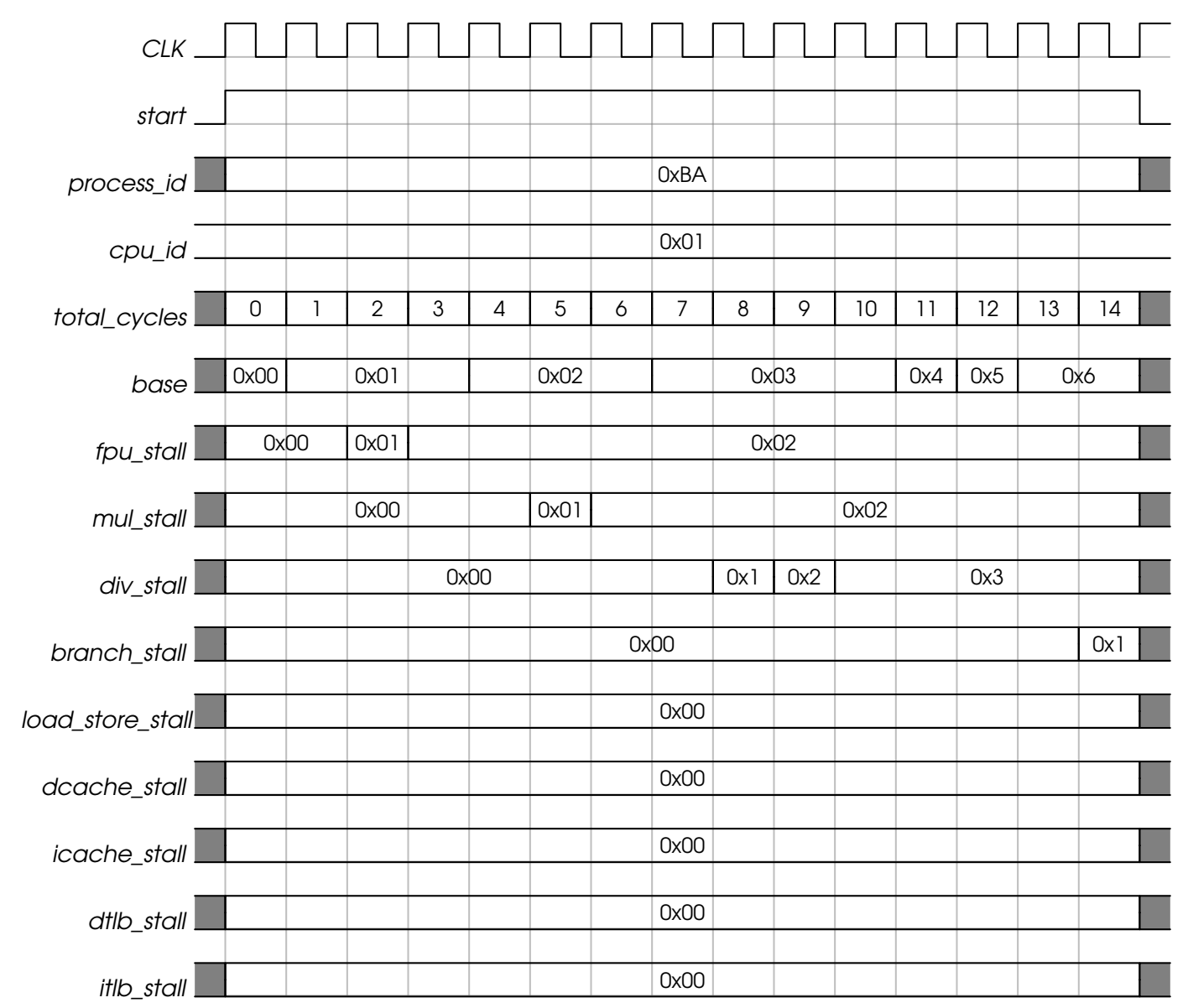

Figura 5.7: Forma de onda do exemplo de comportamento do monitor de desempenho

nente. O sinal de total_cycles está realizando a contagem contínua dos ciclos gastos com a execução do processo, enquanto que os demais são contadores que identificam onde o processo está perdendo tempo. É importante salientar que as execuções de instruções aritméticas de soma e subtração de inteiros (32 bits) são realizadas em um único ciclo e, por isso, não possuem atrasos, sendo contabilizadas diretamente como ciclos base, ou seja, de computação efetiva.

Esses sinais formam um barramento de entrada para o bloco de projeção, o qual é descrito a seguir.

\section{Normalização e projeção de desempenho}

A implementação dos componentes relacionados à normalização e projeção de desempenho segue o comportamento descrito pelo modelo na Seção 4.6. A Figura 5.8 ilustra a interação entre os blocos. Os dados contínuos das decomposições dos processos gerados pelos monitores de desempenho, cada qual presente em cada processador da arquitetura, são entrada para o bloco sched_selec_in, o qual tem uma função de arbitrar entre as entradas das decomposições, amostrá-las inteiramente e enviá-las, serialmente, por meio da interface AXI. Assim como descrito 
anteriormente, todas as interfaces de comunicação seguem o protocolo AXI Stream. A abordagem serial foi adotada principalmente por minimizar a área lógica ocupada na FPGA.

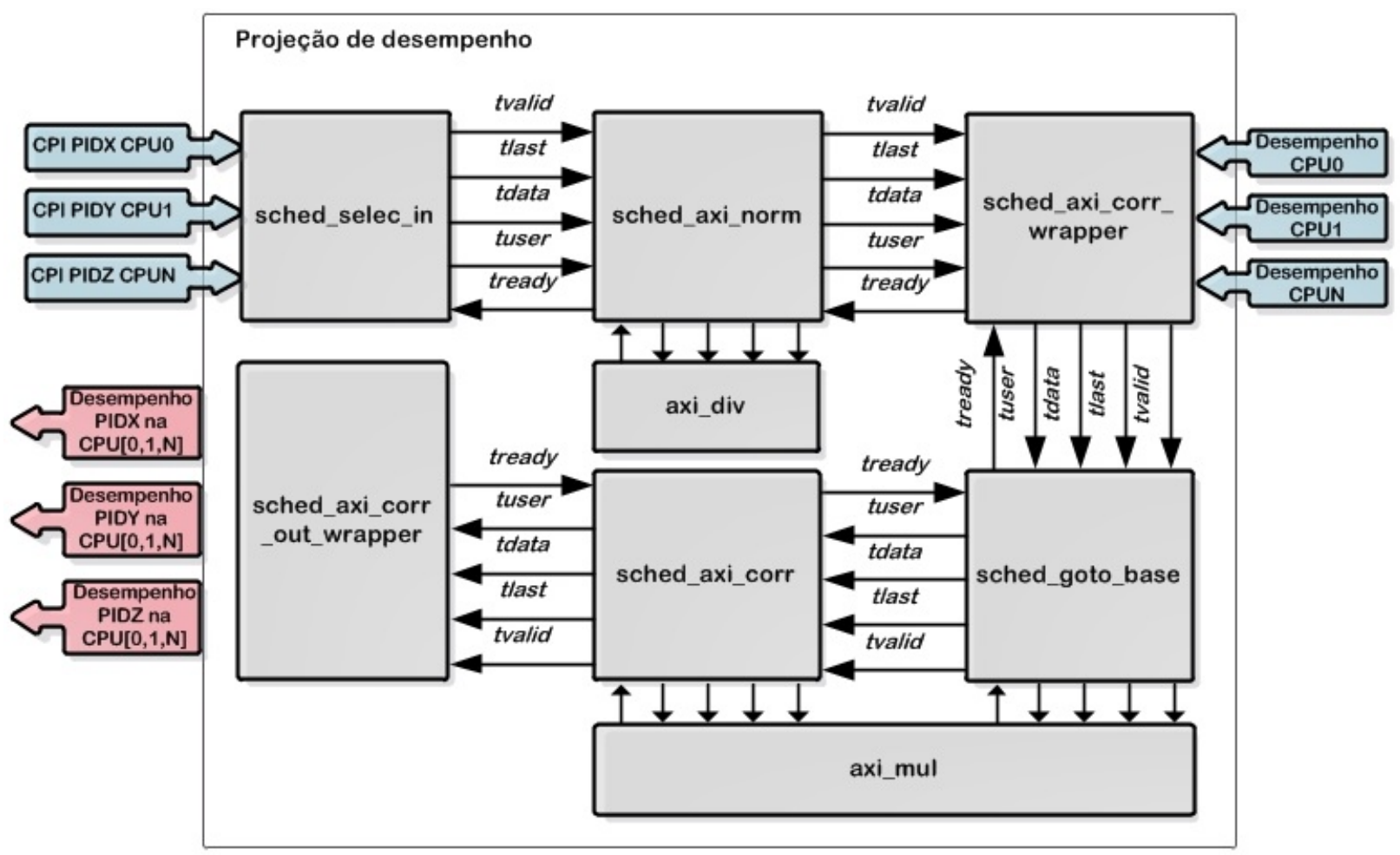

Figura 5.8: Componentes da normalização e projeção de desempenho

O bloco sched_axi_norm contabiliza qual a porcentagem de cada componente sobre o total. Esses dados são calculados com a ajuda de um outro bloco de divisão. Assim que os resultados vão sendo computados, são passados para o bloco sched_axi_corr_wrapper, responsável por armazenar cada pacote e enviá-los para o bloco seguinte, concatenando nos dados os pesos de dois processadores, do corrente e do processador que se deseja fazer a projeção. O mesmo pacote é enviado concatenado $\mathrm{N}$ vezes, sendo $\mathrm{N}$ o número de processadores no sistema. O bloco sched_goto_base recebe esses pacotes e realiza a normalização dos dados, de acordo com os pesos do processador corrente. Após calculados, esses resultados são enviados, juntamente com os pesos do processador a ser projetado, para o bloco sched_axi_corr que realiza a correlação direta entre os dados, gerando um único dado, correspondente à projeção do processo corrente em outro processador. Essas projeções são enviadas para o bloco sched_axi_corr_out_wrapper, o qual disponibiliza-as para serem enviadas para o bloco de balanceamento ou para a interface com o barramento, para serem posteriormente lidas pelo sistema operacional.

\section{Balanceamento}

A implementação do balanceamento por meio do algoritmo Hungarian 
possui o modelo descrito na Seção 4.7 A ideia do algoritmo Hungarian é receber uma matriz e realizar operações aritméticas em todos os elementos, entre linhas e entre colunas, de modo que o número de zeros aumente na matriz até que seja possivel eleger um conjunto de $\mathrm{N}$ elementos (zeros), onde cada elemento seja único em sua linha e coluna. Esse conjunto de $\mathrm{N}$ elementos é o resultado da associação ótima que maximiza (o algoritmo pode tanto maximizar quanto minimizar) a distribuição de desempenho entre processos e processadores.

A matriz deve ser montada com os resultados das projeções de desempenho de todos os processos para todos os processadores. A arquitetura mais detalhada do bloco de balanceamento é ilustrada na Figura 5.9.

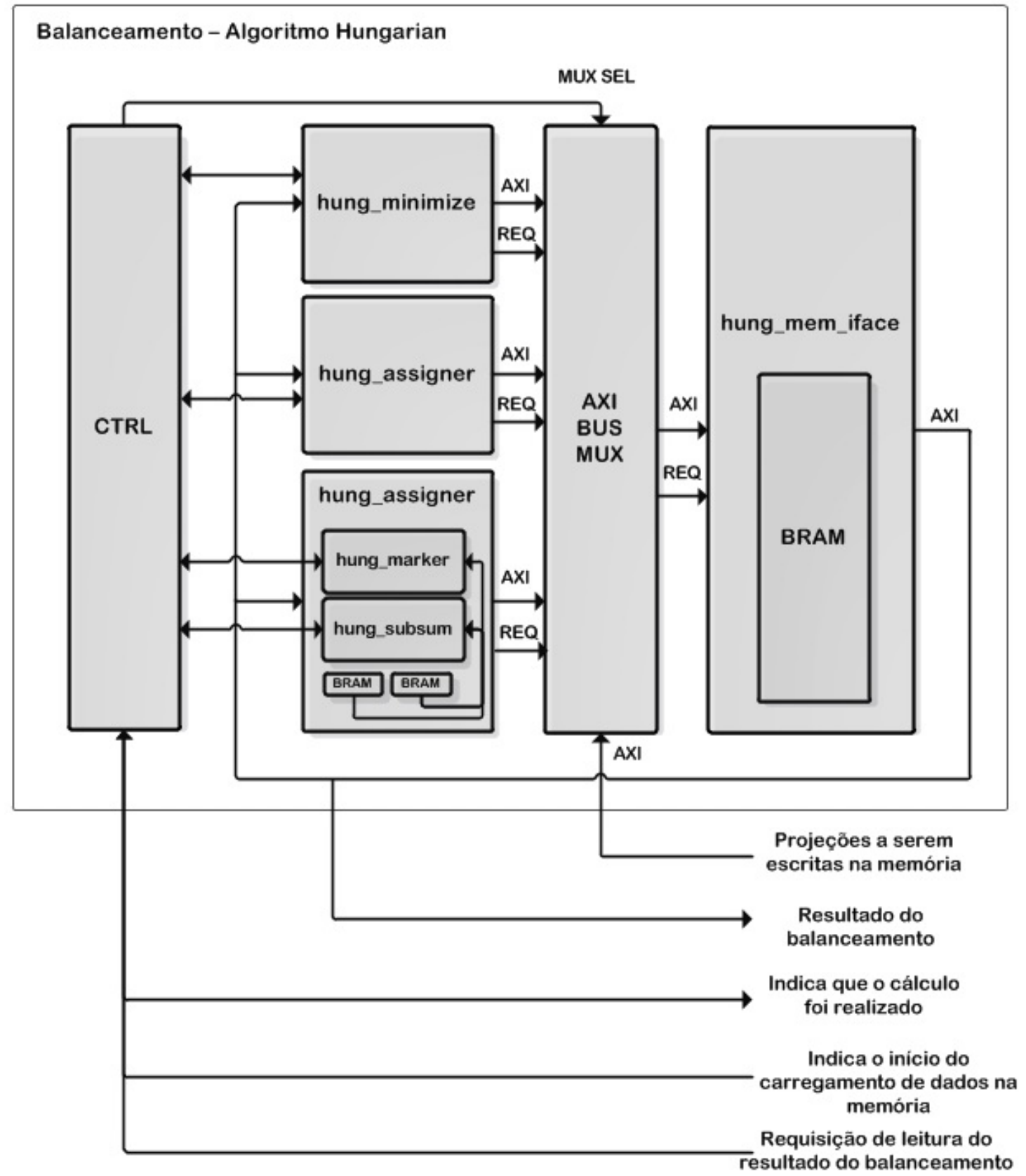

Figura 5.9: Blocos em VHDL do algoritmo Hungarian 
O componente de controle é o responsável por coordenar a execução dos demais componentes. Uma de suas atribuições é controlar o multiplexador central, o qual seleciona qual dos componentes poderá realizar requisições de leitura ou escrita à interface de memória. A memória está implementada com um tamanho configurável utilizando o recurso de Block RAM da FPGA, o qual consiste em um bloco de memória interna do chip, com acesso de escrita e leitura de 1 ciclo. É importante salientar que esse recurso é um considerado nobre e possui um custo alto nas FPGAs. Desse modo, dependendo da quantidade de processos que executa no sistema, pode ser necessário implementar uma interface com um chip de memória externa.

Inicialmente, o algoritmo aguarda pelo preenchimento da memória e, posteriormente, pelo sinal indicando ao bloco de controle que inicie os cálculos.

A memória possui um tamanho de $2^{N}$ palavras, com cada palavra possuindo $S$ bits, sendo $S-2$ bits de dado útil e 2 bits de controle. Como a interface pode escrever ou ler tanto em linhas como em colunas, para facilitar o cálculo do endereço real em função da linha e coluna, evitando operações de multiplicações, a memória é organizada de modo que cada linha e coluna tenham um total de $2^{\lfloor N / 2\rfloor}$ palavras. Com isso, cada linha é representada na memória com um número de colunas em potência de dois, falicitando os cálculos de endereços.

Após receber o sinal indicando que o algoritmo deve começar os cálculos, o bloco de controle libera o primeiro componente a executar, o hung_minimize. Sua função é percorrer os elementos de cada linha, escolher o menor elemento e subtraí-lo dos demais elementos da mesma linha. Após terminar todas as linhas, o mesmo procedimento é executado para cada coluna. Isso é realizado por meio de uma requisição de leitura de linha, para descobrir o menor elemento. Em seguida uma nova requisição de leitura da mesma linha é realizada, juntamente com uma requisição de escrita para essa linha. Assim, na medida em que os dados chegam por meio da interface AXI de entrada, os mesmos dados são subtraídos e enviados pela interface AXI de saída.

O próximo componente a executar consiste no hung_assigner. Sua função é realizar as associações que maximizam o desempenho. Cada palavra de dado possui dois bits a mais de controle, os quais são utilizados para realizar a marcação do dado como associado e o outro para marcar o dado como inválido para associação. O procedimento de associação é realizado varrendo as linhas e colunas da matriz, escolhendo a linha e coluna que possuem a menor quantidade de zeros. As quantidades 
de zeros entre a coluna e a linha escolhidas são comparadas, e a linha ou coluna que tiverem a menor quantidade de zeros tem seus elementos varridos em busca do primeiro zero. O primeiro zero encontrado é marcado como associado. A partir dele, todos os demais zeros pertencentes a mesma linha e coluna que esse elemento são marcados como inválidos e não são mais considerados para a associação. Esse procedimento é repetido até que nenhum zero exista na matriz, ou seja, que todos estejam associados ou marcados como inválidos. Caso o número de elementos associados seja o número da ordem da matriz processada, o algoritmo termina pois a associação ótima de maximização foi encontrada. O bloco hung_assigner realiza esse procedimento varrendo a matriz para encontrar a coluna ou linha com a menor quantidade de zeros. Depois que a matriz foi percorrida, a leitura e escrita da linha ou coluna é requerida, sendo que para cada dado que seja diferente de zero ou marcado como inválido, seu valor é repetido na interface AXI de saída, gravando o mesmo dado na memória. Caso seja um zero, esse valor é marcado como associado e todos os demais zeros encontrados após ele são marcados como inválidos. Ao final da linha ou coluna, uma nova requisição de escrita é realizada. Se caso foi a linha a escolhida para ser escrita da primeira vez, nessa nova requisição a coluna do elemento é requerida, e são marcados como inválidos todos os elementos que tenham valor zero.

Se o número requerido de associações não foi atigindo, o componente de controle requesita que o componente hung_marker inicie seu processamento. O objetivo desse componente é escolher a menor quantidade de linhas e colunas que compreendem todos os zeros da matriz armazenada na memória. Para tanto, o componente conta com o auxílio de duas memórias para armazenar as linhas e colunas marcadas, assim como duas FIFOs internas. O ponto inicial do dessa parte do algoritmo consiste em marcar todas as linhas que não possuem associação. Após isso, todas as colunas com zero nas linhas marcadas são também marcadas. O último passo é marcar todas as linhas que tem associações nas colunas marcadas. Esse procedimento é realizado até que não existam mais colunas ou linhas para marcar. O componente hung_marker realiza essa tarefa, primeiramente requisitando linha por linha da matriz, e todos os elementos da linha são verificados. Caso nenhuma associação é encontrada em uma linha, o componente realiza uma escrita na memória de linhas em sua posição relativa. Esse processo é executado para todas as linhas da matriz. Quando terminado, o componente faz a leitura da memória de linhas verificando todas as linhas marcadas e grava-as na FIFO de linhas. A partir de cada linha gravada nessa FIFO, o compo- 
nente requisita a sua leitura da interface com a memória que armazena a matriz. Paralelamente, também é realizada a leitura da memória que armazena as colunas marcadas. Nesse passo do algoritmo, todas as colunas que possuem zero nas linhas lidas, e que não são marcadas, são gravadas na FIFO de colunas e posteriormente, após o término de cada linha, são gravadas na memória de colunas marcadas. Quando todas as linhas marcadas forem lidas da FIFO de linhas e as respectivas colunas com zero marcadas, o componente realiza a leitura de todas as colunas marcadas, paralalemente com cada elemento da memória de linhas, verificando se existem associações na coluna, e caso tenha um elemento com associação, verificando se já não possui sua linha marcada, se não possui, escreve na FIFO de linhas a respectiva linha, para posteriormente gravá-la na memória. Esses passos são repetidos até que nenhuma linha ou coluna seja marcada.

Quando terminado esse processo, o componente de controle seleciona o componente hung_sub_sum para iniciar a execução. A partir das linhas e colunas marcacas em suas respectivas memórias, o hung_sub_sum requisita a leitura da primeira linha e, paralelamente, também realiza a leitura das duas memórias de marcações, de linhas e de colunas. Isso é realizado para que, paralelamente, para cada elemento da linha, o componente saiba se ele pertence a alguma marcação, tanto de linha ou coluna. Caso não faça parte de nenhuma marcação, o elemento é comparado com o menor elemento encontrado até então, caso seja menor, é armazenado. Após realizar a leitura de todas as linhas da matriz, o componente hung_sub_sum inicia outro procedimento, onde são realizadas requisições de leitura e escrita simultâneas de cada linha, como também as memórias de linhas e colunas são lidas. O objetivo desse novo procedimento é subtrair o menor elemento encontrado de todos os elementos que não fazem parte de marcação, e somá-lo a todos os elementos que estão na intersecção de linha e coluna. À medida que os dados estão sendo lidos, o mesmo dado, ou os resultados da soma, subtração, são enviados para a interface AXI, por meio da qual a interface grava os elementos em cada linha especificada.

Quando terminado, o componente hung_marker é ativado novamente pelo controle, para tentar realizar uma nova associação a partir do acréscimo de zeros na matriz com os últimos passos. Caso não encontre o número requerido de associações, os mesmos passos anteriores são repetidos e o processamento somente acaba quando a quantidade de associações requerida é encontrada. 


\subsection{Implementação em software}

Para a implementação da parte do escalonador em software foi utilizado o sistema operacional Linux - Kernel 2.6.326. A composição dos pacotes do sistema operacional foi realizada por meio da ferramenta Buildroot 7 . A seguir são descritos os principais detalhes de implementação do suporte a escalonamento de processadores heterogêneos no Linux.

\section{Camada de acesso a hardware}

A camada de mais baixo nível do sistema operacional é a responsável pela interface entre o núcleo, desenvolvido genericamente independente de arquitetura, e o hardware. No Linux, para cada tipo de processador, existem diversas funções 8 que implementam a parte mais específica relacionada à arquitetura desses processadores, a partir das quais são oferecidas funções padronizadas acessadas pela camada de mais alto nível do sistema operacional. Este projeto adotou a mesma abordagem para a implementação do acesso ao escalonador em hardware.

Dentro do diretório "arch/sparc" do Kernel 2.6.32, foram realizadas modificações para implementar a camada de acesso ao escalonador em hardware. As funções de acesso são utilizadas para ler e/ou escrever nos registradores descritos na Tabela 4.2. Como o componente do escalonador está ligado ao barramento AMBA e possui um endereço físico específico, o acesso aos registradores deve ser realizado por meio de do bypass da MMU do processador. Esse acesso ao endereço físico é realizado por meio de instruções específicas de load/store onde podem ser passados códigos de identificação ASI 9 (Address Space Identifier) como parâmetros(SPARC, 1992). Entre os identificadores definidos para a arquitetura SPARC-V8, existe um específico para realizar o bypass da MMU, utilizado para implementar todas as funções de acesso aos registradores do escalonador em hardware.

\section{Grupo de processos heterogêneos}

De acordo com o modelo descrito na Seção 4.9, deve existir um modo de representação para o grupo de processos a serem monitorados e controlados pelo escalonador heterogêneo. Esse grupo foi implementado no

\footnotetext{
${ }^{6}$ Kernel 2.6.32: https://www.kernel.org/

${ }^{7}$ Buildroot: http://buildroot.uclibc.org

${ }^{8}$ Os códigos relacionados às implementações específicas de cada arquitetura encontram-se no diretório "arch" dentro do diretório base do kernel.

${ }^{9}$ Address Space Identifier: Quando o unidade central do processador SPARC Leon acessa uma instrução de load/store da memória, ele "concatena"a essa instrução o ASI que identifica se o processador está em modo supervisor ou usuário, como também o tipo de acesso ao dado, se o acesso está relacionado a dado ou instrução. Adicionalmente, são definidos diferentes tipos de ASI na arquitetura, como flush de cache ou TLB, entre outros.
} 
kernel como uma lista duplamente ligada. Essa representação é utilizada devido a facilidade de gerenciar adições e remoções de processos, assim como também devido ao fato de suportar um número ilimitado de processos.

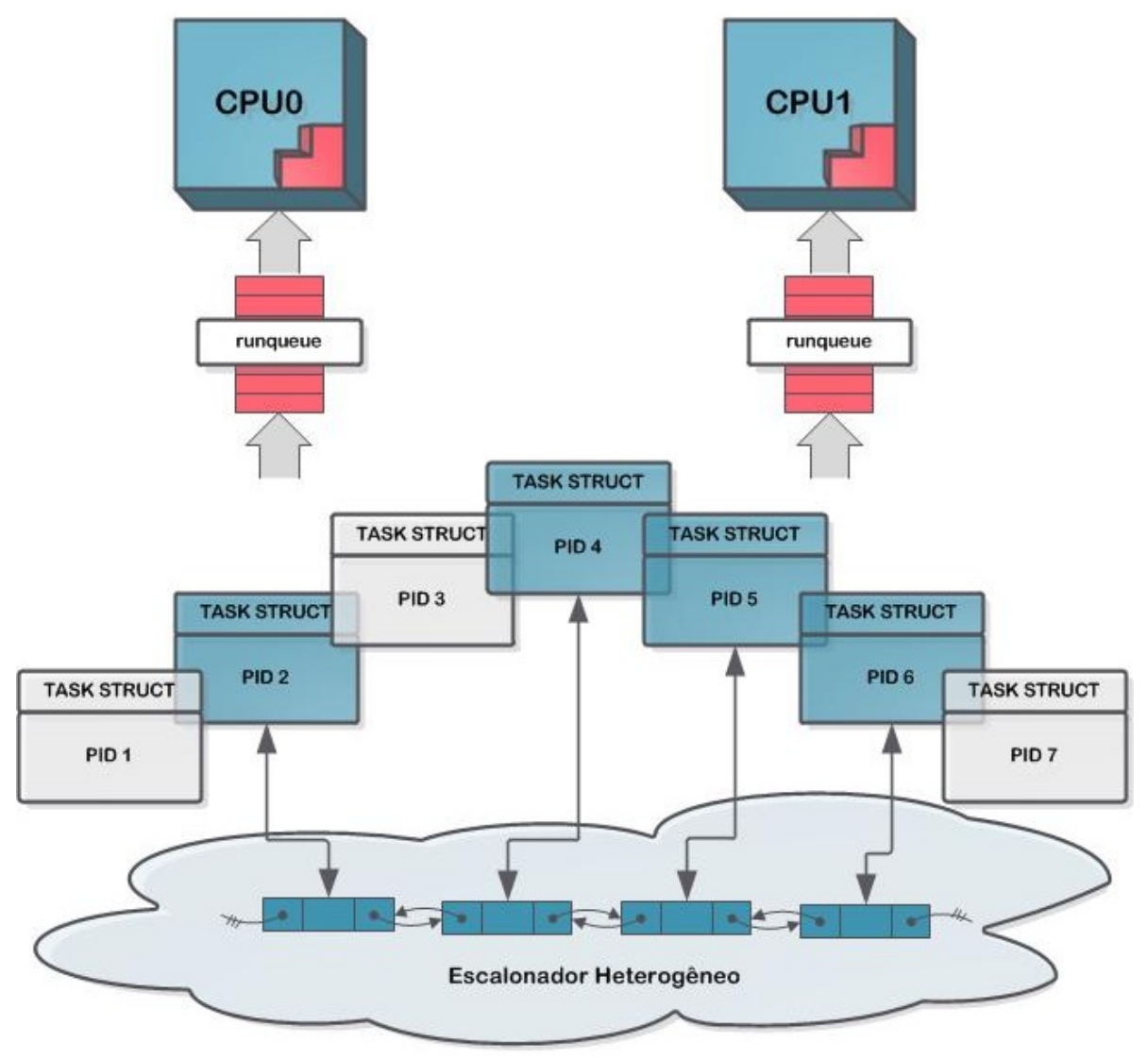

Figura 5.10: Suporte a escalonamento heterogêneo no kernel

Outro fator importante é a dupla referência entre cada nó da lista e a estrutura de representação do processo. Essas referências podem aumentar o desempenho na necessidade de busca dos nós, pois em várias partes do kernel o ponteiro para a representação de processo é utilizado, sendo que a lista é utilizada principalmente nos momentos de verificação na necessidade de migração de processadores. Assim, ambas estruturas podem ser modificadas com uma única referência, sem a necessidade de busca.

Um nó com a referência de um processo é inserida nessa lista no momento em que tal processo é indicado como candidato ao escalonamento heterogêneo. Essa indicação é realizada por meio de uma chamada de sistema, porém, o nó referente ao processo somente é alocado no momento de sua execução, quando o escalonador é chamado para a troca de processo. 


\section{Representação dos processos}

No Linux, cada processo é internamente representado por meio de uma estrutura de dados chamada task_struct. Essa estrutura define todos os dados do processo, entre os quais podem ser citados: PID, estatísticas de execução, informações de threads, informações relacionadas a escalonamento, primitivas de sincronização, prioridades, estado atual do processo, máscara de afinidade de CPUs, entre muitas outras informações.

Neste projeto, é por meio dessa estrutura que as informações relacionadas à execução de cada processo na arquitetura heterogênea são armazenadas. A Figura 5.11 ilustra a organização desses dados na estrutura do processo. É importante salientar que essa estrutura existe para cada processo, independente se o processo faz parte do grupo de processos heterogêneos, descrito anteriormente.

A inicialização da estrutura é realizada no momento que o processo é criado. Em cada processo, que faz parte do grupo heterogêneo, as informações contidas nessa estrutura são atualizadas no momento em que o escalonador é chamado para escolher um novo processo para a execução. Assim que o escalonador é chamado, as novas medidas recolhidas relacionadas às projeções e CPIs são armazenadas na estrutura do processo. A migração de processos entre CPUs é determinada pelas informações nessa estrutura, onde consta qual processador é o melhor para executar, e o quanto melhor é sobre os demais.

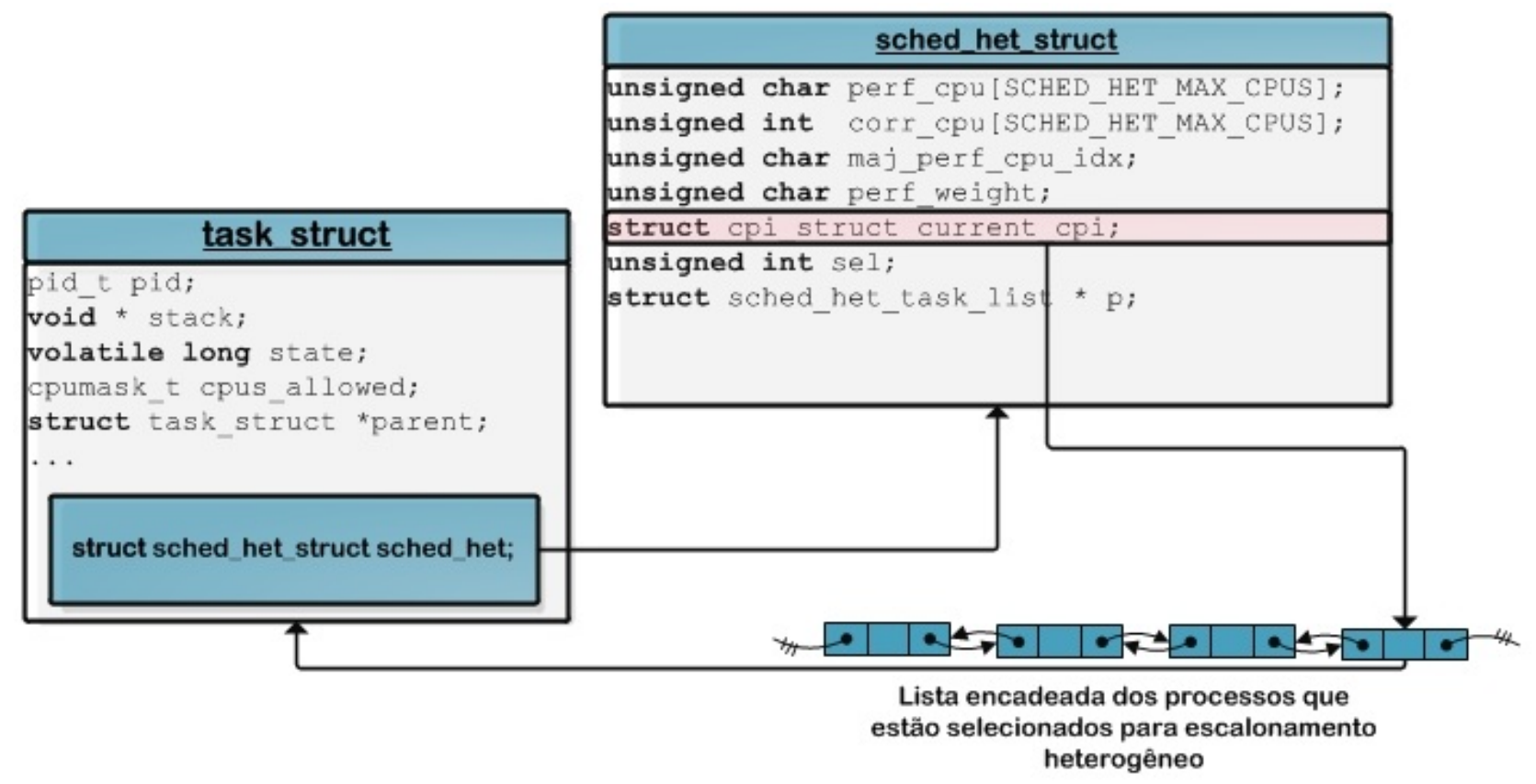

Figura 5.11: Alterações realizadas na estrutura que contém os dados dos processos 


\section{Interação com o escalonador do Linux}

A principal função do Linux que realiza o escalonamento, consiste na schedule(), localizada no arquivo "kernel/sched.c" do Kernel. Essa função é chamada sempre que existe a necessidade de escolher um outro processo para executar, seja por timeslice alcançado ou por preempção por prioridade. A Figura 5.12 ilustra a sequência de chamadas implementada a partir da chamada da função schedule().

Basicamente, a partir da chamada dessa função, o processo é verificado se faz ou não parte do grupo de processos heterogêneos, em caso afirmativo, é realizada uma chamada para uma função localizada na camada de mais baixo nivel do sistema operacional, a qual, por meio de acesso a registradores, ordena ao escalonador em hardware que sua execução deve ser parada para aquele processo/processador. As projeções e o CPI stack do processo corrente são lidos e armazenados na estrutura do processo. A partir dessas informações, é realizada uma média com as últimas projeções recebidas e, a partir dessa média, o cpuid do processador com a melhor projeção é armazenado na estrutura do processo. Após esse passo, ainda no contexto do mesmo processo, a funcão de balanceamento é chamada, a qual tenta trazer para a fila do processador atual os processos que estão executando sobre processadores diferentes dos quais foram melhor projetados. Após essa chamada, são realizadas outras chamadas do sistema operacional, antes de escolher o próximo processo e trocar o contexto corrente pelo contexto do processo escolhido. A partir desse novo contexto de execução, é verificado se o processo pertence ao grupo heterogêneo. Em caso afirmativo, o escalonador em hardware recebe um comando por meio de registrador para iniciar sua execução a partir desse novo processo. Após esses passos, o processo inicia sua execução normal.

\section{Migração de processos}

A migração consiste em verificar, entre todos os processos do grupo heterogêneo, quais estão executando sobre processadores que lhes oferecem menores desempenhos, ou seja, que não executam sobre os processadores para os quais foram melhor projetados. Quando encontrados, esses processos devem ter suas filas de execuções trocadas para as filas dos processadores para os quais foram projetados.

Esse procedimento é realizado percorrendo a lista duplamente ligada dos processos do grupo heterogêneo. Caso exista algum processo que tenha sido executado pela última vez em um processador cujo cpuid seja diferente do cpuid indicado pela projeção (realizada em sua última execução), seu estado é verificado para saber se o processo pode ser exe- 


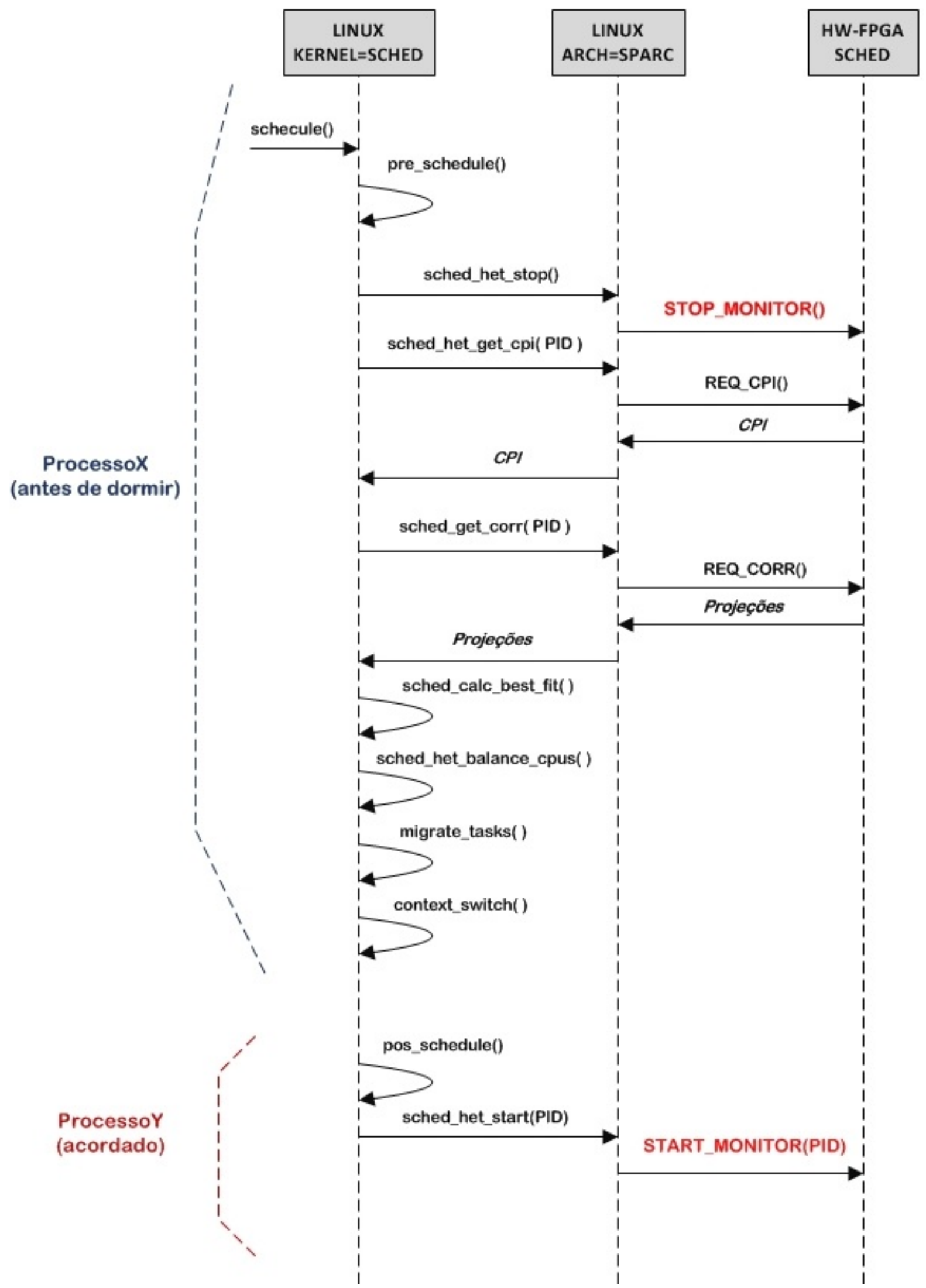

Figura 5.12: Sequência das chamadas de inicio e final de monitoramento 
cutado. Essa verificação é realizada por meio de um campo existente em sua estrutura relacionado a seu estado, o qual deve ser diferente de TASK_UNINTERRUPTIBLE e de TASK_INTERRUPTIBLE. Quando o processo está em um desses estados, ele está "dormindo", aguardando por algum evento para poder "acordar". Consequentemente, não pode ser executado até que seus eventos ocorram. Após esses passos, caso o processo possa ser executado, é realizada uma verificação para saber o número de processos existentes em sua fila de execução. Caso somente exista um único processo, significa que o processo escolhido é o único processo executando sobre seu processador. Nesse caso, ele não é migrado. Caso contrário, as duas filas, de origem e de destino do processo, são bloqueadas e as interrupções são desabilitadas para o processo de migração não ser interrompido no meio e prejudicar o estado do sistema operacional. Na sequência, é realizada uma verificação adicional por meio de uma função específica do Kernel (can_migrate_task) a qual verifica se o processador está em execução, se o processo pode ser migrado para o processador em questão (por meio da máscara cpus_allowed presente na estrutura do processo), e também verifica se a cache do processo no processador é cache-hot, ou seja, se as cache possui os dados daquele processo e a quantidade de faltas na cache é baixa. Caso todas essas asserções sejam negativas, o processo é retirado de sua fila de execução atual e é inserido na fila de execução do processador apropriado. Após esses passos, as filas são desbloqueadas e as interrupções são reativadas e processo retorna para a função schedule().

Os processos que estão no grupo heterogêneo e que estão executando sobre o processador que foram projetados não podem ser migrados novamente pelo algoritmo de balanceamento do Linux. A Figura 5.13 ilustra essa separação de controle.

Assim que o processo tem seu melhor desempenho projetado para um processador diferente do qual ele executa, o algoritmo muda a afinidade do processo, permitindo que ele execute somente no processador indicado. A afinidade é controlada por meio de uma máscara chamada cpus_allowed presente na estrutura principal do processo. O algoritmo de balanceamento do Linux, quando deseja realizar um balanceamento por meio de migrações de processos, verifica a afinidade de cada processo e não permite a migração de processos para processadores que não possuem seu cpuid na máscara de afinidade.

\section{Acesso concorrente no escalonador heterogêneo}

Como todos processadores da arquitetura podem executar o escalonador, todo o acesso ao hardware do escalonador é protegido por meio de spin- 


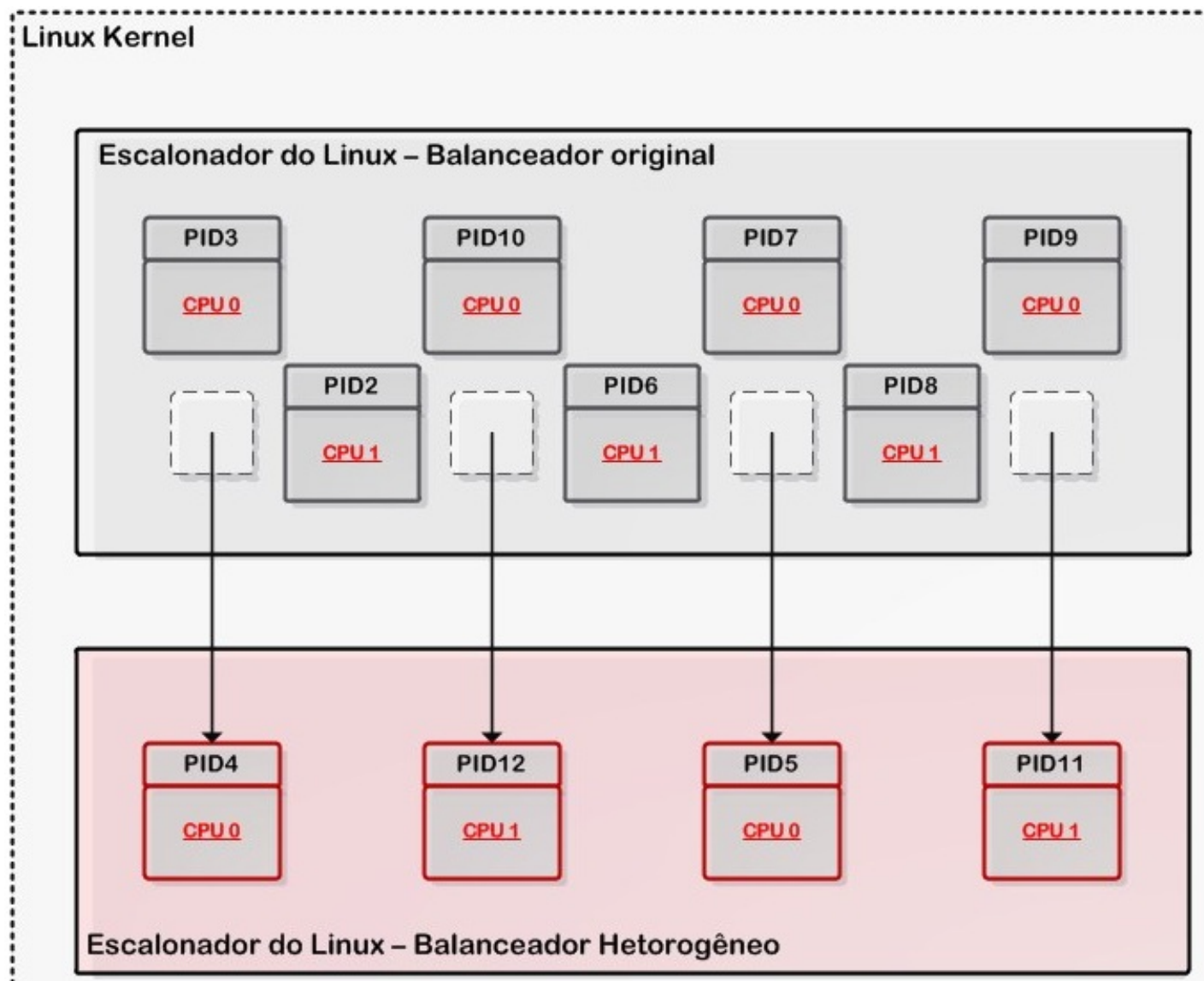

Figura 5.13: Designação dos processos aos processadores 
lock . Sendo assim, somente um processo por vez pode executar qualquer função relacionada ao escalonador heterogêneo.

\section{Chamadas de sistema}

O principal objetivo da criação de chamadas de sistema é possibilitar ao usuário que adicione o processo ao grupo de escalonamento heterogêneo, como também carregar os pesos de desempenho da arquitetura (que pode ser realizado durante a fase de inicialização do sistema operacional). Adicionalmente, também foram criadas chamadas para acompanhar o comportamento de cada processo, de acordo com o monitor de desempenho instalado dentro do processador. As principais chamadas de sistemas criadas são:

I* Os pesos de cada processadores sao armazenados no kernel */ int sys_sched_het_set_perf_cpu(struct cpi_struct cpi, unsigned int cpuid);

I* Carrega os pesos da arquitetura no escalonador em hardware * / int sys_sched_het_load_perf_cpus ();

/* Indica o processo ao escalonador heterogeneo */

int sys_sched_het_setcandidate (pid_t pid, unsigned int bflag);

/* Retorna a decomposicao de stalls para um determinado processo */ int sys_sched_het_get_cpi_pid(struct cpi_struct $*$ cpi, pid_t pid);

I* Retorna os stalls continuos, desde o inicio da execucao do processo */ int sys_sched_het_get_cpi64_pid(struct cpi_struct64 $*$ cpi, pid_t pid);

I* Liga a contagem continua de stalls (causa overhead no kernel) */ int sys_sched_het_turn_cpi64(int b);

/* Habilita migracao de processos utilizando somente a projecao */ int sys_sched_het_enable_migration (int b);

/* Habilita a migracao com base no resultado do balanceamento em $H W *$ / int sys_sched_het_enable_balance (int b);

\section{Estatisticas de escalonamento}

O Linux possibilita que diversas estatísticas de escalonamento relacionadas a cada processo sejam providas caso a opção CONFIG_SCHEDSTATS do kernel esteja habilitada. Elas são armazenadas dentro da própria estrutura de cada processo e são disponbilizadas partir do arquivo "/proc/(pid)/sched". Nesse sentido, com o intuito de obter o comportamento atual dos processos em execução por meio da linha de comando, as informações fornecidas pelo monitor de desempenho, extraídas na última execução do processo, estão sendo continuamente atualizadas e podem 
ser lidas por meio desse caminho. Assim, o usuário pode monitorar todos os processos do grupo de processos heterogêneos e verificar onde está sendo gasta a maior quantidade de ciclos.

\subsection{Considerações finais}

A arquitetura do escalonador foi implementada utilizando como processador o SPARC-V8 Leon em FPGA. O processador foi modificado para extrair estatísticas da execução de cada processo. Essas estatísticas são utilizadas pelo bloco de projeção de desempenho, desenvolvido em VHDL, que possui interfaces de comunicação com o bloco de balanceamento e com o barramento do sistema. O kernel do sistema operacional Linux também foi modificado para introduzir as verificações de projeções e migrações de processos, de modo a alcançar maior desempenho durante sua execução.

A implementação apresentada neste capítulo pode também ser realizada em outras arquiteturas, por meio do modelo apresentado no Capítulo 4. 


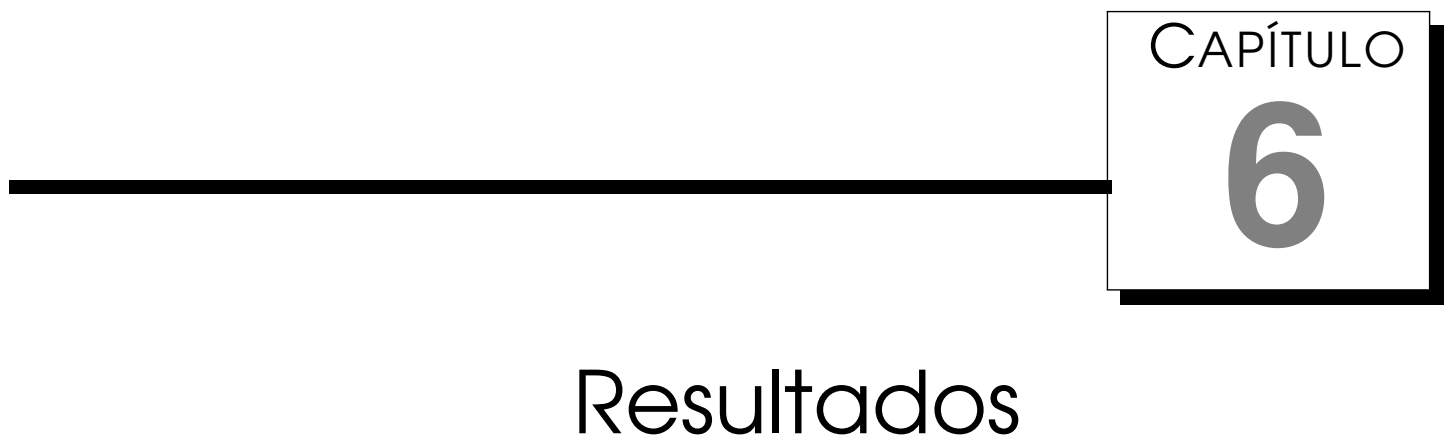

Neste capítulo são apresentados os resultados experimentais obtidos da comparação entre a execução de benchmarks utilizando e não utilizando a projeção de desempenho proposta por este projeto. O objetivo principal dessa comparação é mensurar os ganhos de desempenho que podem ser obtidos por meio da implementação de uma heurística no escalonador específica para os casos de arquiteturas heterogêneas.

Para extração dos resultados, foi utilizada a plataforma de desenvolvimento Xilinx ML507 com dois processadores Leon3. Devido à capacidade do FPGA utilizado, não foi possível utilizar três ou mais processadores com FPU, juntamente com a lógica do escalonador implementada. No entanto, segundo pesquisadores da Intel, Koufaty et al. (2010), a utilização de 2 processadores é suficiente para a avaliação:

"Nós focaremos somente em dois tipos de núcleos por diversas razões. Primeira, arquiteturas heterogêneas com dois tipos de processadores já capturam a maioria dos beneficios de desempenho e consumo da assimetria. Segunda, projetos de dois núcleos diferentes para um processador já desafia os recursos de projetos e é improvável que o projeto com mais núcleos diferentes seja comercialmente viável. Finalmente, não está claro que projetos envolvendo mais tipos de núcleos sejam desejáveis."

Em Georgakoudis et al. (2013) também existe uma referência da utilização de dois núcleos diferentes em uma arquitetura:

"Nós descobrimos que dois tipos de núcleos oferecem mais beneficios de desempenho da heterogeneidade, isto é, utilizar números maiores 
de núcleos distintos não contribui muito."

O restante deste capítulo está organizado do seguinte modo: inicialmente são apresentados os benchmarks utilizados nos experimentos o modo em que são executadas, na sequência são descritas todas as configurações das arquiteturas de processadores utilizados nos testes e, por último, são apresentados os resultados do experimento.

\section{1 Benchmarks}

A plataforma embarcada utilizada neste projeto oferece poucos recursos quando comparada a um computador pessoal atual, sendo que muitos benchmarks no mercado são desenvolvidos para executar em um ambiente com maior quantidade de recursos. Alguns benchmarks fornecidos pela SPEC ${ }^{1}$ foram testados na plataforma e não terminaram sua execução por necessitarem mais memória do que estava disponível. Devido a essa limitação em recursos da plataforma utilizada, como também da baixa frequência de operação do processador e demais dispositivos, os benchmarks foram selecionados de diferentes fontes, de modo que estivessem de acordo com o ambiente embarcado utilizado. Nesse contexto, os seguintes benchmarks foram utilizados:

- bzip2: Algoritmo de compressão que faz parte do grupo de benchmarks inteiros do pacote SPEC-CPU2006. A compressão é realizada inteiramente na memória, sendo que cada entrada é comprimida e descomprimida em três níveis diferentes de compressão. No final de cada passo o resultado é comparado com a entrada original;

- libquantum: Biblioteca para a simulação de um computador quântico, os quais são baseados em princípios da mecânica quântica e resolvem algumas tarefas computacionalmente complexas em tempo polinominal. Um dos algoritmos presentes nesse benchmark é a resolução da fatorização de números em tempo polinominal, o qual é aplicado à área de criptografia. O libquantum também faz parte do grupo de benchmarks de inteiros do pacote SPEC-CPU2006;

- dhrystone: Realiza diversas operações numéricas inteiras e tem por objetivo medir o desempenho de um processador. O Dhrystone é baseado em operações matemáticas e lógicas típicas realizadas por uma aplicação. Ele basicamente é composto por um laço principal o qual é executado por um número de vezes específico;

\footnotetext{
${ }^{1}$ SPEC - Standard Performance Evaluation Corporation: http://www.spec.org
} 
- stanford: É composto por operações inteiras e ponto-flutuantes. Vários algoritmos são implementados nesse benchamark: permutações recursivas, resolução do problema das torres de Hanoi, resolução do problema das oito rainhas, multiplicação de matrizes inteiras e ponto flutuante, cálculo de FFT e ordenações utilizando quick sort, bubble sort e tree sort.

- fbench: Implementa o algoritmo Ray tracing de computação gráfica utilizando para renderização de imagens tridimensionais. Esse benchmark realiza diversas operações trigonométrias, fazendo bastante uso de operações de ponto flutuante;

- inverse: Realiza a inversão de uma matriz (operações de ponto flutuante);

- sphinx: Esse benchmark faz parte do grupo de ponto flutuante do CPU2006. Ele implementa um sistema de reconhecimento de voz e para isso executa diversas operações de ponto flutuante; e

- whetstone: Assim como o Dhrystone, o objetivo desse benchmark é a avaliação de um processador, porém, mais enfaticamente a FPU. Esse algoritmo implementa diversas operações de ponto flutuante.

\subsection{Modo de execução}

Para a execução dos experimentos foi desenvolvida uma ferramenta que recebe como entrada um arquivo contendo as linhas de comando para executar cada um dos benchmarks. A ferramenta é capaz de executar tanto um único benchmark por inúmeras vezes, como também um conjunto deles por diversas vezes (parametrizável). Para cada linha de comando é executada a chamada de sistema fork() do Linux para criar um processo filho, o qual executa em seguida a chamada de sistema execv(...) com a linha de comando do benchmark em questão. A chamada de sistema execv(...) realiza a troca da imagem corrente do processo pela imagem nova do processo contido na linha de comando, mantendo o mesmo PID retornado pelo fork(). Assim, por meio do PID de cada processo, a ferramenta é capaz de monitorar todos os benchmarks, verificando as estatísticas do escalonador geradas pelo Linux, como também as estatísticas criadas neste projeto que são geradas para cada processo em execução.

No modo de operação de depuração, a ferramenta, juntamente com as chamadas dos benchmarks, inicia uma thread responsável por monitorar, periodicamente (parametrizável), cada um dos processos, recolhendo as principais estatísticas para serem posteriormente analisadas. No modo de operação de medida, a thread não é iniciada, para envolver a menor quantidade de processamento adicional possível ao sistema. Após realizar as chamadas de fork(), 
a ferramenta aguarda por meio da chamada de sistema wait(). A partir desse momento, o processo relacionado à ferramenta "dorme" e somente é acordado quando todos os processos filhos (os benchmarks) terminarem a execução. Quando acordado, a ferramenta realiza uma chamada de sistema para receber um conjunto de recursos que foram utilizados por todos os processos filhos. Esse conjunto de recursos é disponibilizado por meio da função getrusage(), a qual retorna a seguinte estrutura de dados:

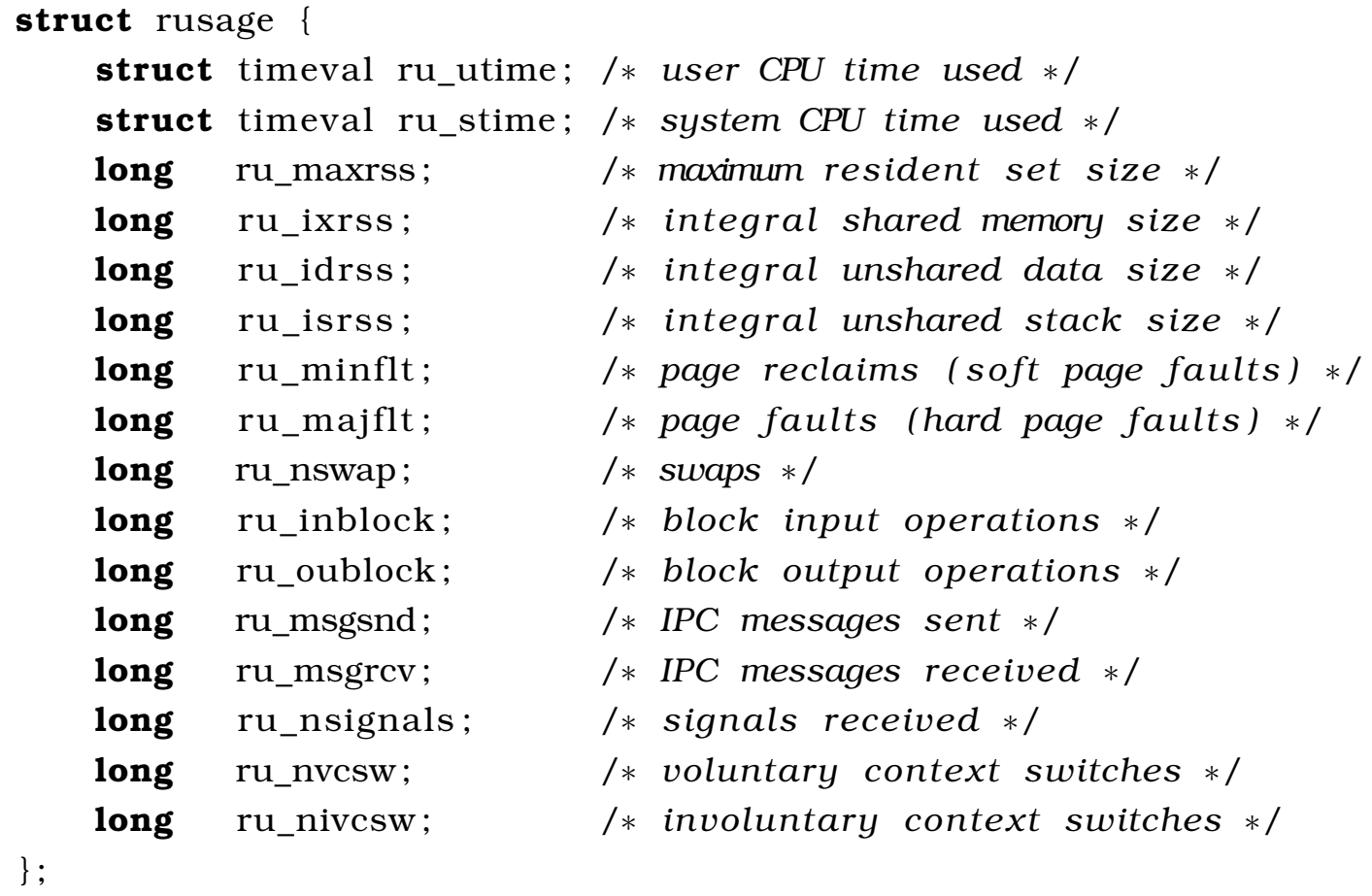

Essa estrutura foi herdada do BSD 4.3 Reno, sendo que na versão de 2.6.32 do kernel do Linux nem todos os dados contidos nessa estrutura são utilizados, apesar de presentes no kernel. Entre os principais dados implementados, a ferramenta utiliza o ru_utime e o ru_stime para medir, respectivamente, o tempo efetivo de CPU utilizado pelos benchamarks e o tempo gasto pelo sistema operacional para gerenciar esses processos. Como os dados retornados são o acúmulo de todos os dados obtidos das execuções anteriores, para cada medida, o tempo acumulado anterior é descontado. Sendo assim, ao final de cada sequência de medidas é possível obter o tempo efetivo de CPU utilizado por cada processo.

É importante enfatizar que, quando um conjunto de processos é avaliado utilizando a função getrusage(), caso exista mais que um processador no sistema, o tempo efetivo de CPU retornado pode ser maior que o tempo real de execução de todos os processos. Como exemplo, pode ser citado a execução dos processos P0, P1, P2, P3. Supondo uma arquitetura contendo dois processadores, CPU0 e CPU1, o escalonador pode determinar que PO e P1 executem na CPU0, e P2 e P3 executem na CPU1. Supondo que cada um desses processos necessite de um tempo $T$ de CPU, o tempo retornado pela função getru- 
sage0 para esse conjunto de processos é $4 T$, que consiste no tempo efetivo de CPU desses processos. No entanto, o tempo real de execução, considerando o paralelismo alcançado com a divisão dos processos entre os dois processadores, pode ser de $2 T$. Devido a esse fato, é importante levar em consideração a diferença entre tempo efetivo e tempo real de processamento.

O tempo efetivo de CPU é utilizado pela ferramenta para avaliar principalmente as projeções de desempenho. O tempo real não pode ser utilizado nesse caso. Como exemplo, pode ser citado o caso que existam quatro benchmarks para realizar medidas de desempenho para analisar a projeção em uma arquitetura contendo dois processadores, sendo que um deles tem um poder maior para realizar operações de ponto flutuante. Desses quatro benchmarks, considera-se que três deles fazem uso intensivo da FPU. Quando forem executados utilizando o escalonador heterogêneo implementado neste projeto, esses três benchmarks podem ser migrados para executar no processador que possui a FPU de maior desempenho. Devido à carga de três benchmarks executando em um único processador, enquanto outro processador possui somente um, é evidente que o tempo real de execução desse modelo deve ser maior comparado ao cenário que os mesmos benchmarks são escalonados pelo Linux, que realiza o balanceamento de processos. No entanto, se for analisar somente a projeção de desempenho, os processos foram corretamente escalonados e terão um tempo efetivo de CPU menor do que se executassem no processador com menores recursos na FPU. Por isso, neste projeto o tempo efetivo é utilizado para avaliar a projeção isoladamente.

Por outro lado, o tempo real é utilizado para mensurar os tempos de execução de processo sob o balanceamento heterogêneo. Nesse caso, é tarefa do balanceamento distribuir os processos entre os processadores que melhor se adequam, realizando a maximização do desempenho por meio da projeção gerada.

\subsection{Configurações das arquiteturas}

Para a avaliação experimental, foram utilizadas 4 arquiteturas distintas, contendo dois processadores cada. As arquiteturas dos processadores estão descritas nas Tabelas 6.1, 6.2, 6.3 e 6.4.

A Arquitetura 1, apresentada na Tabela 6.1, é composta pela CPU0 que se destaca pelo tamanho de cache de instruções e de dados, hardware de multiplicação e predição de desvios. A CPU1 somente se destaca pelo hardware de FPU, o qual possui uma quantidade maior de recursos podendo diminuir o tempo gasto com instruções de ponto flutuante.

A Arquitetura 2, apresentada na Tabela 6.2, tem seu hardware muito pare- 
Tabela 6.1: Configurações da Arquitetura 1

\begin{tabular}{ccc}
\hline \hline Recurso & CPUO & CPU1 \\
& (SPARC V8 - Leon 3) & (SPARC V8 - Leon 3) \\
\hline Frequência & $80 \mathrm{MhZ}$ & $80 \mathrm{MhZ}$ \\
Suporte a Branch Prediction & Sim & Não \\
Latência da multiplicação & 2 ciclos & 5 ciclos \\
Cache de dados & 4 Sets / Way 1KB & 1 Sets / Way 1KB \\
Substituição & LRU & sem \\
Cache de instruções & 4 Sets / Way 1KB & 1 Sets / Way 1KB \\
Substituição & LRU & sem \\
Entradas na TLB de dados & 8 & 8 \\
Entradas na TLB de instruções & 8 & 8 \\
FPU & FPU-LITE & FPU FULL \\
\hline \hline
\end{tabular}

cido com a Arquitetura 1. A única mudança na CPUO é o aumento do número de entradas na TLB de instruções. As principais mudanças na CPU1 consistem no aumento do tamanho da cache de dados da CPU1 e no aumento das entradas de TLB de dados.

Tabela 6.2: Configurações da Arquitetura 2

\begin{tabular}{ccc}
\hline \hline Recurso & CPUO & CPU1 \\
& (SPARC V8 - Leon 3) & (SPARC V8 - Leon 3) \\
\hline Frequência & $80 \mathrm{Mhz}$ & $80 \mathrm{Mhz}$ \\
Suporte a Branch Prediction & Sim & Não \\
Latência da multiplicação & 2 ciclos & 5 ciclos \\
Cache de dados & 4 Sets / Way 1KB & 4 Sets / Way 1KB \\
Substituição & LRU & Random \\
Cache de instruções & 4 Sets / Way 1KB & 1 Sets / Way 1KB \\
Substituição & LRU & sem \\
Entradas na TLB de dados & 8 & 32 \\
Entradas na TLB de instruções & 32 & 8 \\
FPU & FPU-LITE & FPU FULL \\
\hline \hline
\end{tabular}

A Arquitetura 3, apresentada na Tabela 6.3, possui como principais diferenças da Arquitetura 2 os tamanhos das entradas das TLBs dos dois processadores, como também a diminuição do tamanho da cache de dados da CPU1 e o aumento de sua cache de instruções.

Tabela 6.3: Configurações da Arquitetura 3

\begin{tabular}{ccc}
\hline \hline Recurso & CPUO & CPU1 \\
& (SPARC V8 - Leon 3) & (SPARC V8 - Leon 3) \\
\hline Frequência & $80 \mathrm{Mhz}$ & $80 \mathrm{Mhz}$ \\
Suporte a Branch Prediction & Sim & Não \\
Latência da multiplicação & 2 ciclos & 5 ciclos \\
Cache de dados & 4 Sets / Way 1KB & 2 Sets / Way 1KB \\
Substituição & LRU & LRR \\
Cache de instruções & 4 Sets / Way 1KB & 4 Sets / Way 1KB \\
Substituição & LRU & LRR \\
Entradas na TLB de dados & 32 & 16 \\
Entradas na TLB de instruções & 16 & 32 \\
FPU & FPU-LITE & FPU FULL \\
\hline \hline
\end{tabular}

A Arquitetura 4, apresentada na Tabela 6.4, tem as configurações dos dois processadores muito parecidas. As principais diferenças estão na velocidade do hardware de multiplicação da CPUO e na FPU mais rápida da CPU1.

Os vetores de desempenho para essas arquiteturas foram calculados inicialmente utilizando o procedimento descrito na Seção 3.6. Com o conheci- 
Tabela 6.4: Configurações da Arquitetura 4

\begin{tabular}{ccc}
\hline Recurso & CPUO & CPU1 \\
& (SPARC V8 - Leon 3) & (SPARC V8 - Leon 3) \\
\hline Frequência & 80Mhz & 80Mhz \\
Suporte a Branch Prediction & Não & Não \\
Latência da multiplicação & 2 ciclos & 5 ciclos \\
Cache de dados & 4 Sets / Way 1KB & 4 Sets / Way 1KB \\
Cache de dados & LRU & LRU \\
Cache de instruções & 4 Sets / Way 1KB & 4 Sets / Way 1KB \\
Cache de instruções & LRU & LRU \\
Entradas na TLB de dados & 8 & 8 \\
Entradas na TLB de instruções & 8 & 8 \\
FPU & FPU-LITE & FPU FULL \\
\hline \hline
\end{tabular}

mento das arquiteturas, o vetor de peso resultante do procedimento anterior foi ajustado manualmente em alguns recursos para cada arquitetura.

\subsection{Resultados da heurística}

Nesta seção, são apresentados os resultados alcançados a partir da projeção de desempenho dos processos. Para a execução dos experimentos é necessário considerar dois pontos importantes: o modo em que o escalonador heterogêneo realiza a migração de processos e a política de escalonamento do CFS do Linux.

A projeção é realizada continuamente sobre os processos que executam no grupo de processos heterogêneos. Quando o desempenho de um determinado processo é projetado em um processador diferente do qual ele executa, pode ser apontado pelo escalonador que o processo deve executar sobre esse outro para obter maior desempenho. Nesse caso, existe a necessidade de realizar a migração desse processo para a fila de processos desse outro processador. No entanto, assim como descrito no Capítulo 4, a migração somente é realizada a partir de um processo diferente do que se deseja migrar, pois o próprio processo não pode executar a sua própria migração, já que está em execução. Consequentemente, para um processo ser migrado, um outro processo, executando no processador destino, deve tentar retirar o processo de sua fila atual e inserí-lo na própria fila, desde que o processo a ser migrado não esteja em execução. Esse modelo de migração proposto e implementado é o mesmo modelo seguido pelo sistema operacional Linux.

Assim como descrito na Seção 5.1.4, o algoritmo de escalonamento CFS ao invés de utilizar o conceito de timeslice para determinar a quantia de tempo que cada processo deve executar, ele possui um conceito diferente, o de distribuição justa de porções de tempo da CPU para cada processo. No sistema operacional Linux, enfaticamente versões embarcadas, é existente um número pequeno de processos do sistema. Esses processos normalmente não possuem uma taxa alta utilização da CPU, já que a maioria deles está destinado a tra- 
tar eventos do sistema operacional ou de hardware. Quando esses eventos ocorrem, o tempo de utilização do processador é baixa, já que são processos de sistema e, por requisitos evidentes que qualquer sistema operacional deve prover, não devem comprometer o desempenho do sistema. Se um processo que possui uma taxa alta de utilização do processador entra em execução, considerando que os demais processos do sistema utilizam muito pouco do processador ou estão na wait queue ${ }^{2}$, esse novo processo evidentemente ocupará o processador em uma proporção muito maior que os demais. Quando um processo diferente entra em execução, o algoritmo CFS reestabelece sua proporção da CPU levando em consideração a nova carga do sistema. Nesse caso, o processo que ocupa muito mais o processador, considerando que os demais necessitam muito pouco, recebe uma proporção maior do processador.

Considerando uma arquitetura com dois processadores, esse processo em execução pode ser indicado pelo escalonador heterogêneo para migrar para o outro processador. No entanto, essa migração somente é realizada quando o processo não está em execução. Considerando que o processo possui maior proporção de CPU entre os demais processos, ele tem a menor taxa do sistema de execução de switches (trocas de contexto), ou seja, ele possui o menor tempo aguardando na fila de execução enquanto outro processo executa em seu lugar em sua CPU. Nesse contexto, para esse processo conseguir migrar para outro processador, algum outro processo executando no processador destino, devido a ocorrência de algum evento, deve executar o escalonador no momento exato que o processo a ser migrado está com seu contexto salvo e aguardando na fila para executar. Esse momento pode demorar muito, já que depende de eventos e de uma série de variáveis muito difíceis de serem mensuradas. Além disso, outro fator também relacionado à migração de processos na arquitetura desenvolvida consiste na utilização de uma função própria do kernel para decidir se a migração deve ou não ocorrer. Essa função é a can_migrate_task(0. Uma de suas atribuições é verificar se a cache do processador atual, que executa o processo a ser migrado para outro processador, possui cache-hot para esse processo, ou seja, verifica se a migração desse processo pode ocasionar perda de desempenho devido às faltas que ocorrerão na cache do novo processador.

Considerando o mesmo exemplo do processo anterior, se ele demora para ser migrado (o que é muito provável devido às circunstâncias citadas previamente), a função can_migrate_task() pode indicar ao procedimento de migração que o processo deve permanecer no processador atual. Portanto, se somente um processo com alta utilização de processador está executando em uma ar-

\footnotetext{
${ }^{2}$ Wait Queue: Armazena a referência de processos que estão esperando por algum evento e não são considerados runnable, ou seja, estão em um dos estados: TASK_INTERRUPTIBLE ou TASK_UNINTERRUPTIBLE
} 
quitetura com mais de um processador, caso o escalonador indique a necessidade de migração, ele somente é migrado quando todos os eventos citados forem favoráveis à migração.

Nesse sentido, visando alcançar uma maior precisão nas medidas de projeção de desempenho dependendo menos de ocasionalidades, para mensurar o tempo efetivo de cada benchmark, são executadas quatro cópias do mesmo processo. Isso não garante que as migrações ocorrerão conforme o esperado. Mas devido a existência de quatro processos que possuem alto poder de processamento, a probabilidade do favorecimento às migrações aumenta. É necessário enfatizar que caso as quatro cópias de um processo forem migradas para o mesmo processador, a ocorrência de faltas na cache, tanto de instruções, quanto de dados, pode ser maior, prejudicando o desempenho medido da projeção.

Os experimentos são realizados executando quatro cópias do mesmo benchmark simultaneamente. Esse cenário é repedido dez vezes utilizando o escalonador do linux e mais dez vezes executando com a atuação do escalonador heterogêneo sobre os processos. Esse procedimento é repetido para as quatro arquiteturas apresentadas previamente. Além da execução simultânea das cópias do mesmo benchmarks, foram utilizados três grupos de benchmarks distintos. Os benchmarks de cada grupo são:

- Grupo 0: dhry, fbench, stanford e inverse;

- Grupo 1: libquantum, whetstone, bzip2 e fbench; e

- Grupo 2: dhry, stanford, bzip2 e sphinx.

A Tabela 6.5 apresenta os resultados da execução dos benchmarks na Arquitetura 1, os quais estão ilustrados na Figura 6.1. A tabela apresenta a média em milissegundos das dez execuções para cada cenário, sem e com o escalonador heterogêneo. Ao lado da média é apresentado o desvio padrão amostral expresso em número e também em porcentagem em relação à media.

Tabela 6.5: Estatísticas para Arquitetura 1 (tempos em ms)

\begin{tabular}{l|cc|ccc}
\hline \hline \multicolumn{2}{c}{ Benchmark } & \multicolumn{2}{c}{ Escalonador do Linux } & \multicolumn{3}{c}{ Escalonador heterogêneo } \\
& $2332970 \pm 4902,62$ & $(0,21 \%)$ & $1994500 \pm 43687,85$ & $(2,19 \%)$ & $14,51 \%$ \\
\hline bzip2 & $52860 \pm 24,40$ & $(0,05 \%)$ & $46150 \pm 50,95$ & $(0,11 \%)$ & $12,69 \%$ \\
dhry & $193095 \pm 61,14$ & $(0,03 \%)$ & $190960 \pm 71,66$ & $(0,04 \%)$ & $1,11 \%$ \\
fbench & $122755 \pm 1582,90$ & $(1,29 \%)$ & $115460 \pm 1526,52$ & $(1,32 \%)$ & $5,94 \%$ \\
inverse & $51300 \pm 57,58$ & $(0,11 \%)$ & $47255 \pm 66,04$ & $(0,14 \%)$ & $7,88 \%$ \\
libquantum & $2857575 \pm 2945,39$ & $(0,10 \%)$ & $2739945 \pm 12420,54$ & $(0,45 \%)$ & $4,12 \%$ \\
sphinx & $2635 \pm 28,98$ & $(1,10 \%)$ & $2395 \pm 24,06$ & $(1,00 \%)$ & $9,11 \%$ \\
stanford & $434235 \pm 529,75$ & $(0,12 \%)$ & $432090 \pm 13595,19$ & $(3,15 \%)$ & $0,49 \%$ \\
whetstone & $97090 \pm 8263,82$ & $(8,51 \%)$ & $99665 \pm 11910,18$ & $(11,95 \%)$ & $-2,65 \%$ \\
grupo0 & $629985 \pm 2151,79$ & $(3,41 \%)$ & $565790 \pm 7088,94$ & $(1,25 \%)$ & $10,19 \%$ \\
grupo 1 & $1296980 \pm 40161,90$ & $(3,10 \%)$ & $1218785 \pm 778,10$ & $(0,06 \%)$ & $6,03 \%$ \\
grupo2 & \multicolumn{7}{c}{ Desvo } \\
\hline \hline
\end{tabular}


Conforme apresentado, o desempenho foi alcançado para a maioria das execuções, variando de 0.49\% a $14.51 \%$ de ganho em relação ao tempo médio da execução sem o escalonador heterogêneo. No entanto, um dos resultados apresentou um desempenho negativo de $-2.65 \%$, ou seja, a utilização do escalonamento heterogêneo para o Grupo 0 causou uma degradação de desempenho em relação ao escalonamento nativo do Linux. Esse fato pode estar relacionado ao compartilhamento dos recursos do processador por muitos processos ou também pode ter sido resultado de tentativas frustradas de migrações. Como pode ser visto na Tabela 6.5, o desvio padrão para o Grupo 1 na execução utilizando o escalonador heterogêneo tem um valor maior comparado ao desvio padrão da execução com o escalonador nativo. Devido a esse fato, de modo a analisar melhor o baixo desempenho do algoritmo heterogêneo, a seguir são apresentados os tempos de execução do Grupo 1 extraídos para ambos os cenários:

- Escalonador nativo (ms): [100290, 83360, 100980, 99110, 87470, 98410, 84350, 82750, 104160, 95770, 97090]; e

- Escalonador heterogêneo (ms): [99800, 99800, 99970, 76710, 99740, 99710, 76690, 76700, 99620, 76740, 99665].

De acordo com os tempos de execução, pode ser visto que na execução com o algoritmo heterogêneo foram alcançados tempos mínimos que não foram alcançados em nenhuma das execuções do escalonador nativo. Com isso, possivelmente o desempenho do algoritmo heterogêneo foi influenciado pelas migrações não realizadas, deixando os processos nos processadores em que possuem pior desempenho.

Por outro lado, os resultados obtidos para a Arquitetura 2 foram diferentes para o Grupo 0. Esses resultados estão apresentados na Tabela 6.6 e estão ilustrados na Figura 6.2. Na Arquitetura 2, a CPU1 deve oferecer maior desempenho a processos que fazem bastante uso de dados e de instruções de ponto flutuante, como é o caso do algoritmo de inversão de matrizes e do benchmark sphinx.

Assim como descrito na Tabela 6.6, o Grupo 0 obteve um dos maiores desempenhos entre os demais benchmarks quando é executado sob o controle do escalonador heterogêneo. Além disso, ofereceu resultados mais estáveis, diminuinto o desvio padrão amostral em relação ao escalonador nativo do Linux. Os resultados dos desempenhos do escalonador heterogêneo variaram entre $0.07 \%$ e 9.95\%. No entanto, na execução do Grupo 1 foi observado uma degradação de desempenho de $-4.62 \%$. Analisando as amostras, um número muito baixo de tempos menores foram obtidos com a execução do escalonador heterogêneo em relação ao nativo. Um dos fatores que podem influenciar 


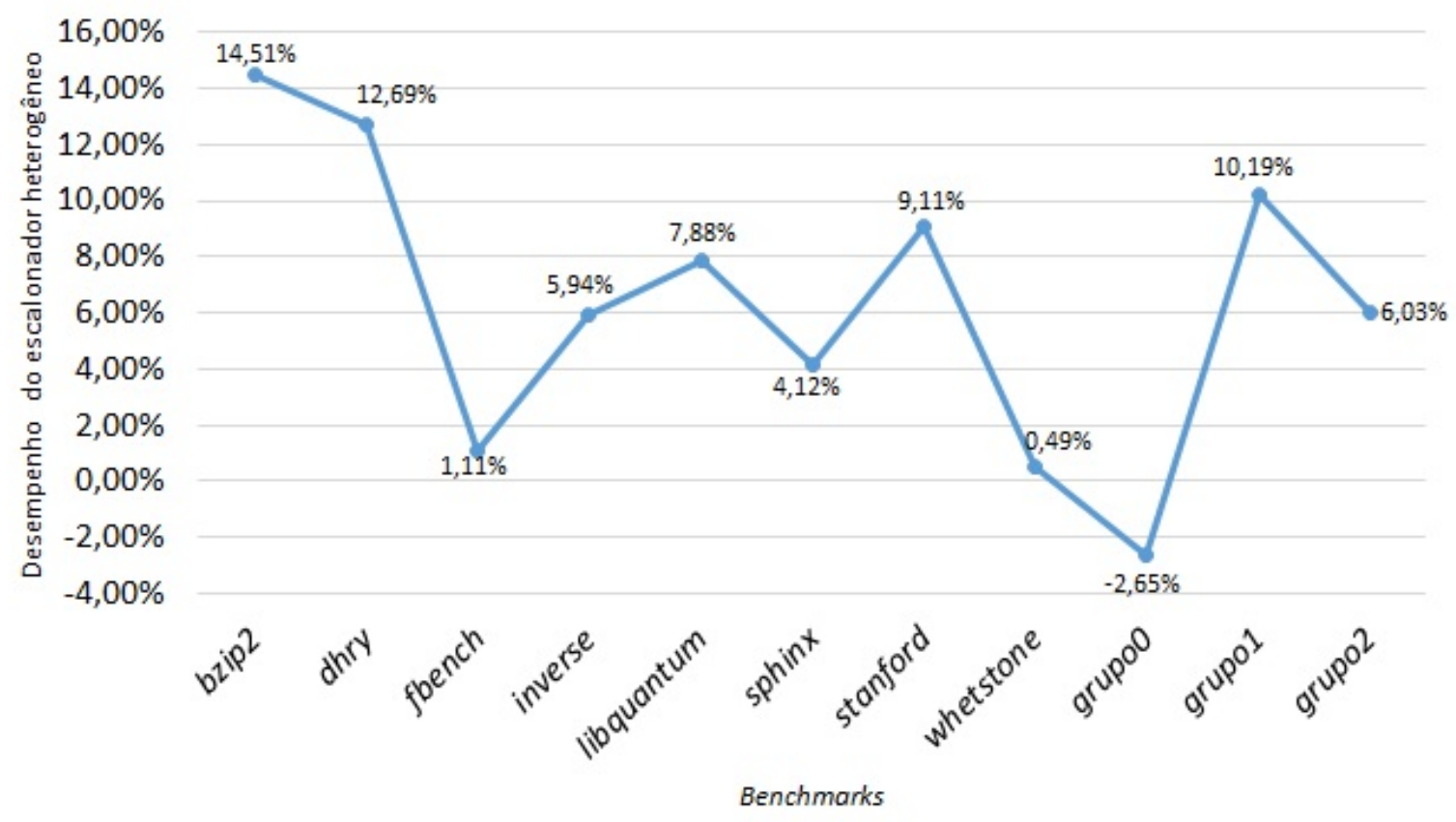

Figura 6.1: Resultados para a Arquitetura 1

Tabela 6.6: Estatísticas para Arquitetura 2 (tempos em ms)

\begin{tabular}{l|cc|ccc}
\hline \hline \multicolumn{2}{c}{ Benchmark } & \multicolumn{2}{c}{ Escalonador do Linux } & \multicolumn{3}{c}{ Escalonador heterogêneo } \\
& \multicolumn{2}{c}{ Média \pm Desvio (Desvio \%) } & \multicolumn{2}{c}{ Média \pm Desvio (Desvio \%) } & Desempenho \\
\hline bzip2 & $2229255 \pm 546,80$ & $(0,02 \%)$ & $2051040 \pm 8536,52$ & $(0,42 \%)$ & $7,99 \%$ \\
dhry & $56800 \pm 34,98$ & $(0,06 \%)$ & $55170 \pm 510,30$ & $(0,92 \%)$ & $2,87 \%$ \\
fbench & $174555 \pm 176,51$ & $(0,10 \%)$ & $172465 \pm 481,33$ & $(0,28 \%)$ & $1,20 \%$ \\
inverse & $99415 \pm 1147,29$ & $(1,15 \%)$ & $90250 \pm 1244,45$ & $(1,38 \%)$ & $9,22 \%$ \\
libquantum & $49755 \pm 17,29$ & $(0,03 \%)$ & $45945 \pm 99,64$ & $(0,22 \%)$ & $7,66 \%$ \\
sphinx & $2513450 \pm 8796,07$ & $(0,35 \%)$ & $2263375 \pm 54341,79$ & $(2,40 \%)$ & $9,95 \%$ \\
stanford & $2305 \pm 41,15$ & $(1,79 \%)$ & $2210 \pm 40,88$ & $(1,85 \%)$ & $4,12 \%$ \\
whetstone & $428060 \pm 418,41$ & $(0,10 \%)$ & $428015 \pm 8541,04$ & $(2,00 \%)$ & $0,01 \%$ \\
grupo0 & $75260 \pm 9595,01$ & $(12,75 \%)$ & $68440 \pm 370,71$ & $(0,54 \%)$ & $9,06 \%$ \\
grupo 1 & $584125 \pm 19919,86$ & $(3,41 \%)$ & $611100 \pm 18062,48$ & $(2,96 \%)$ & $-4,62 \%$ \\
grupo2 & $1208560 \pm 57278,00$ & $(4,74 \%)$ & $1207700 \pm 2287,89$ & $(0,19 \%)$ & $0,07 \%$ \\
\hline \hline
\end{tabular}


fortemente os resultados obtidos é o vetor de desempenho utilizado para as arquiteturas. Como cada processo tem um comportamento diferente, alguns processos podem ser influenciados negativamente dependendo dos pesos utilizados.

Os resultados das execuções da Arquitetura 3 encontram-se descritos na Tabela 6.7 e ilustrados na Figura 6.3.

Tabela 6.7: Estatísticas para Arquitetura 3 (tempos em ms)

\begin{tabular}{l|cc|ccc}
\hline \multirow{2}{*}{ Benchmark } & \multicolumn{2}{c}{ Escalonador do Linux } & \multicolumn{3}{c}{ Escalonador heterogêneo } \\
& \multicolumn{2}{c}{ Média \pm Desvio (Desvio \%) } & \multicolumn{2}{c}{ Média \pm Desvio (Desvio \%) } & Desempenho \\
\hline bzip2 & $2008910 \pm 1165,43$ & $(0,06 \%)$ & $1971520 \pm 9940,12$ & $(0,50 \%)$ & $1,86 \%$ \\
dhry & $47245 \pm 41,97$ & $(0,09 \%)$ & $40000 \pm 2293,21$ & $(5,73 \%)$ & $15,33 \%$ \\
fbench & $157090 \pm 40,29$ & $(0,03 \%)$ & $149595 \pm 40,61$ & $(0,03 \%)$ & $4,77 \%$ \\
inverse & $113150 \pm 1372,28$ & $(1,21 \%)$ & $107440 \pm 982,21$ & $(0,91 \%)$ & $5,05 \%$ \\
libquantum & $49675 \pm 34,14$ & $(0,07 \%)$ & $45860 \pm 64,37$ & $(0,14 \%)$ & $7,68 \%$ \\
sphinx & $2451115 \pm 4499,64$ & $(0,18 \%)$ & $2425140 \pm 2100,07$ & $(0,09 \%)$ & $1,06 \%$ \\
stanford & $2400 \pm 36,22$ & $(1,51 \%)$ & $2190 \pm 25,03$ & $(1,14 \%)$ & $8,75 \%$ \\
whetstone & $428080 \pm 38,93$ & $(0,01 \%)$ & $415680 \pm 498,73$ & $(0,12 \%)$ & $2,90 \%$ \\
grupo0 & $75530 \pm 2718,11$ & $(3,60 \%)$ & $80015 \pm 4951,20$ & $(6,19 \%)$ & $-5,94 \%$ \\
grupo1 & $551960 \pm 25454,53$ & $(4,61 \%)$ & $533060 \pm 4094,05$ & $(0,77 \%)$ & $3,42 \%$ \\
grupo2 & $1123350 \pm 42167,40$ & $(3,75 \%)$ & $1035330 \pm 407,78$ & $(0,04 \%)$ & $7,84 \%$ \\
\hline \hline
\end{tabular}

Os desempenhos obtidos nessa arquitetura variaram de $1.06 \%$ a $15.33 \%$. Assim como as arquiteturas 1 e 2, ela também obteve um desempenho negativo. As amostras são apresentadas a seguir:

- Escalonador nativo (ms): [75190, 78800, 81200, 77690, 81230, 74410, 75270, 75460, 75600, 73820, 75530]; e

- Escalonador heterogêneo (ms): [81680, 80100, 80010, 70830, 80020, 70800, 80150, 70800, 80180, 70830, 80015].

Análogo ao caso da Arquitetura 1, pode-se perceber que os menores tempos obtidos pelo escalonamento heterogêneo não foram obtidos pelo escalonador nativo. Desse modo pode-se concluir que o escalonamento heterogêneo contribui para o aumento de desempenho quando as migrações podem ser realizadas. Normalmente, dois principais fatores restringem essa migração: a restrição de cache-hot ou o processo a ser migrado está em execução.

A Arquitetura 4 possui dois processadores com configurações muito parecidas. As duas únicas diferenças estão na quantidade de ciclos para a execução de multiplicação (CPUO oferece maior desempenho) e a FPU FULL, que oferece desempenho a processos que executam instruções de ponto flutuante (CPU 1). Evidentemente, espera-se que os processos que possuem instruções de ponto flutuante se beneficiem mais da CPU1, obtendo maiores desempenhos. Os resultados das execuções estão apresentados na Tabela 6.8, sendo o desempenho ilustrado na Figura 6.4.

Assim como o esperado, os benchmarks fbench, inverse, sphixh e Grupo 0 (possui fbench e inverse) obtiveram maior desempenho, pois o escalonador 


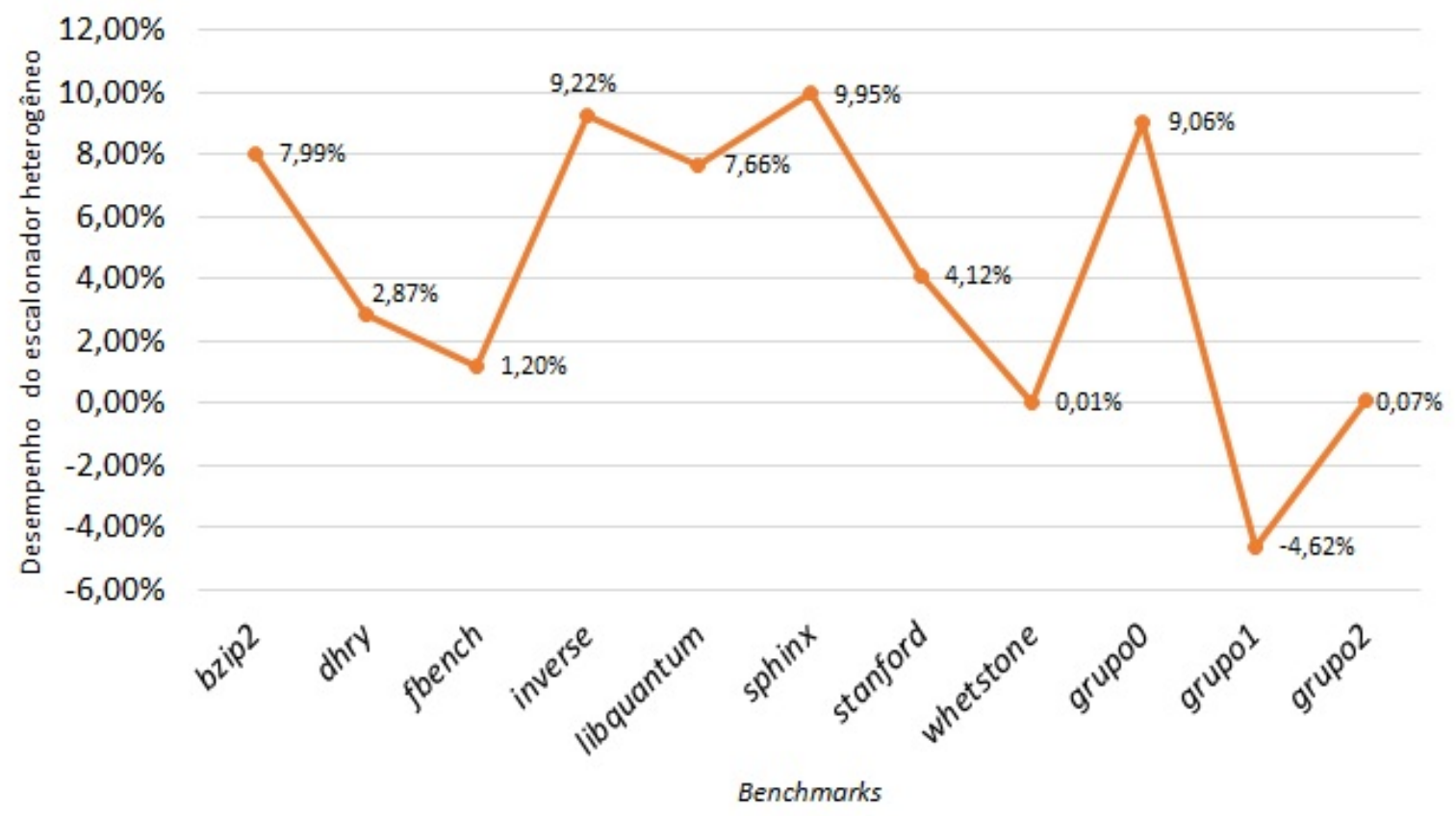

Figura 6.2: Resultados para a Arquitetura 2

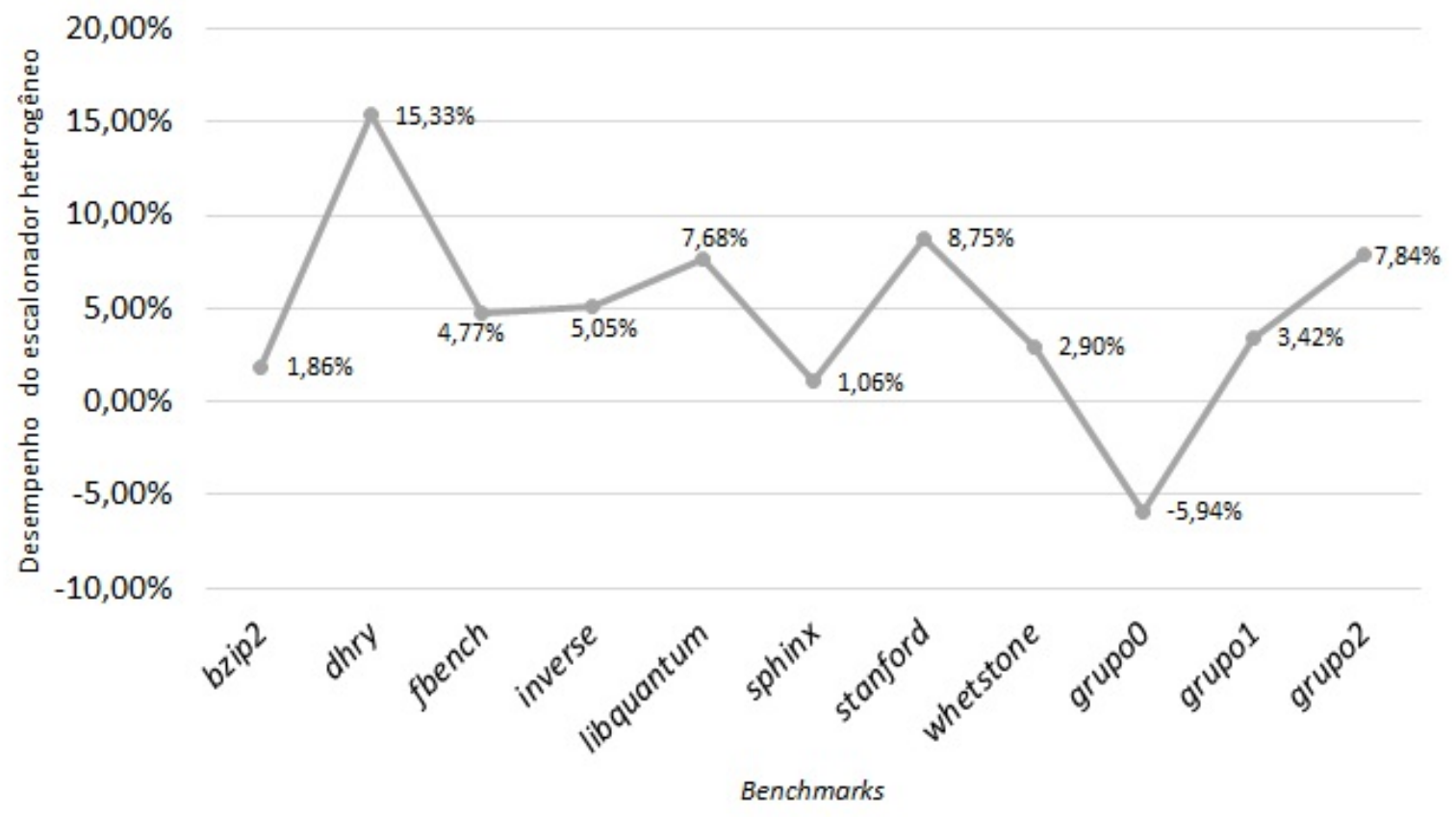

Figura 6.3: Resultados para a Arquitetura 3 


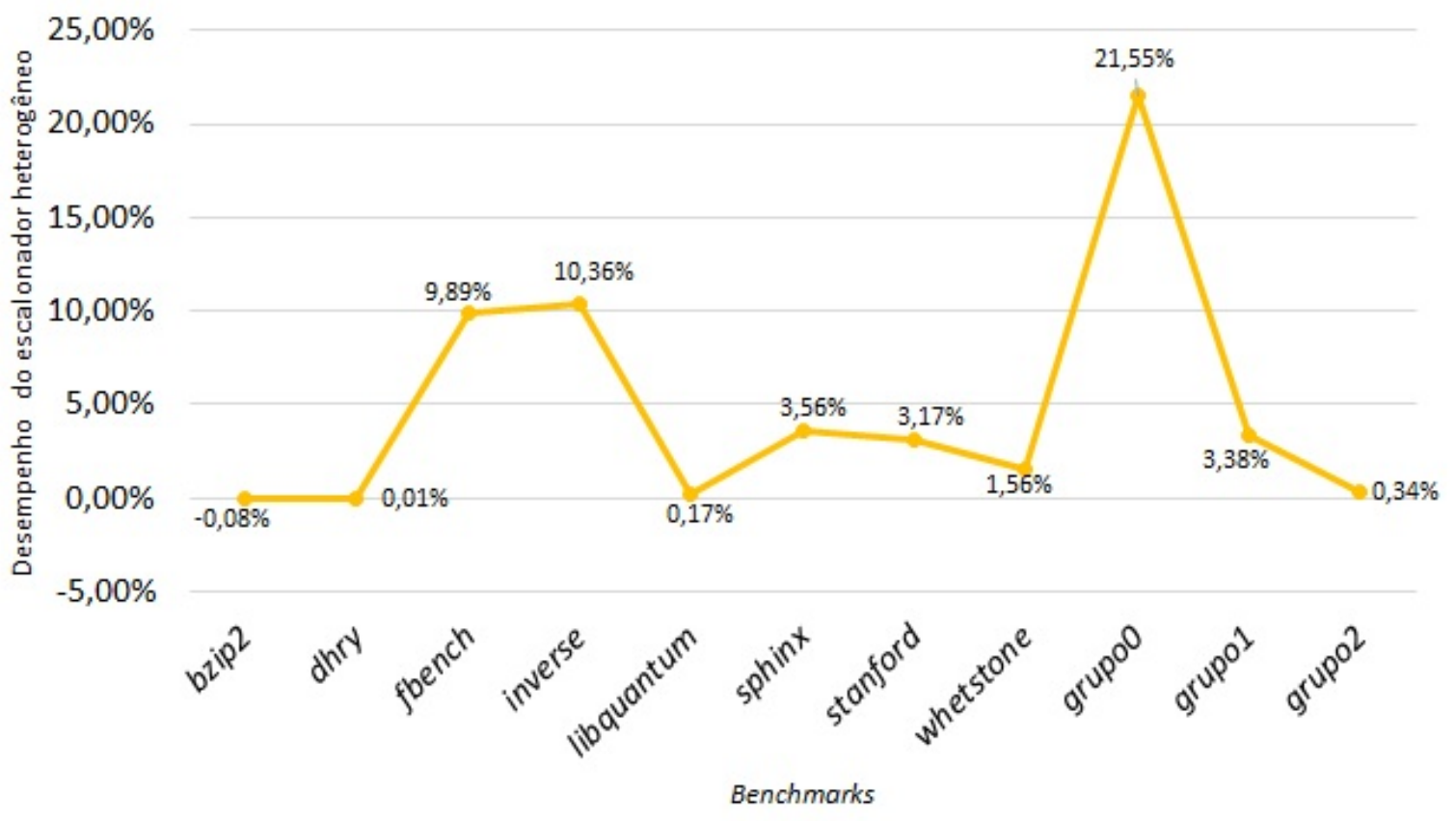

Figura 6.4: Resultados para a Arquitetura 4

Tabela 6.8: Estatísticas para Arquitetura 4 (tempos em ms)

\begin{tabular}{l|cc|ccc}
\hline \multirow{2}{*}{ Benchmark } & \multicolumn{2}{c}{ Escalonador do Linux } & \multicolumn{3}{c}{ Escalonador heterogêneo } \\
& $2085055 \pm 1833,15$ & $(0,09 \%)$ & $2086725 \pm 1538,79$ & $(0,07 \%)$ & $-0,08 \%$ \\
\hline bzip2 & $35805 \pm 25,14$ & $(0,07 \%)$ & $35800 \pm 41,97$ & $(0,12 \%)$ & $0,01 \%$ \\
dhry & $118530 \pm 25,14$ & $(0,02 \%)$ & $106805 \pm 27,00$ & $(0,03 \%)$ & $9,89 \%$ \\
fbench & $102865 \pm 878,43$ & $(0,85 \%)$ & $92205 \pm 94,33$ & $(0,10 \%)$ & $10,36 \%$ \\
inverse & $51045 \pm 31,64$ & $(0,06 \%)$ & $50960 \pm 35,67$ & $(0,07 \%)$ & $0,17 \%$ \\
libquantum & $2477540 \pm 2042,97$ & $(0,08 \%)$ & $2389250 \pm 40499,78$ & $(1,70 \%)$ & $3,56 \%$ \\
sphinx & $2210 \pm 49,49$ & $(2,24 \%)$ & $2140 \pm 40,55$ & $(1,89 \%)$ & $3,17 \%$ \\
stanford & $422685 \pm 422,59$ & $(0,10 \%)$ & $416075 \pm 362,36$ & $(0,09 \%)$ & $1,56 \%$ \\
whetstone & $65600 \pm 2243,71$ & $(3,42 \%)$ & $51460 \pm 3402,55$ & $(6,61 \%)$ & $21,55 \%$ \\
grupo0 & $557320 \pm 31460,95$ & $(5,65 \%)$ & $538505 \pm 798,19$ & $(0,15 \%)$ & $3,38 \%$ \\
grupo1 & $1063880 \pm 41433,68$ & $(3,89 \%)$ & $1060235 \pm 38276,60$ & $(3,61 \%)$ & $0,34 \%$ \\
grupo2 & \multicolumn{5}{c}{ Desempenho } \\
\hline \hline
\end{tabular}

heterogêneo, detectando que o processador CPU1 ofereceria maior desempenho, conseguiu realizar as migrações para obter as medidas apresentadas. O desempenho do bzip2 foi negativo (-0.08\%). Esse benchmark executa somente instruções de operações com inteiros. Com isso, devido o processador CPUO oferecer maior desempenho a processos que executem multiplicação, a maioria dos processos podem ter sido migradas pra esse processador. Assim, considerando que o bzip2 executa a compactação e descompactação em memória, com a migração dos processos para um único processador, obteve-se uma maior concorrência da cache de dados. Com isso, a probabilidade de faltas na cache aumenta, fazendo com que o processo obtivesse um desempenho de $0.08 \%$ menor quando utilizado o escalonador heterogêneo. A Figura 6.5 ilustra os resultados para todas as arquiteturas.

Assim como comentado, uma das verificações do escalonador, tanto nativo como heterogêneo, antes de realizar uma migração consiste na cache. Se um 


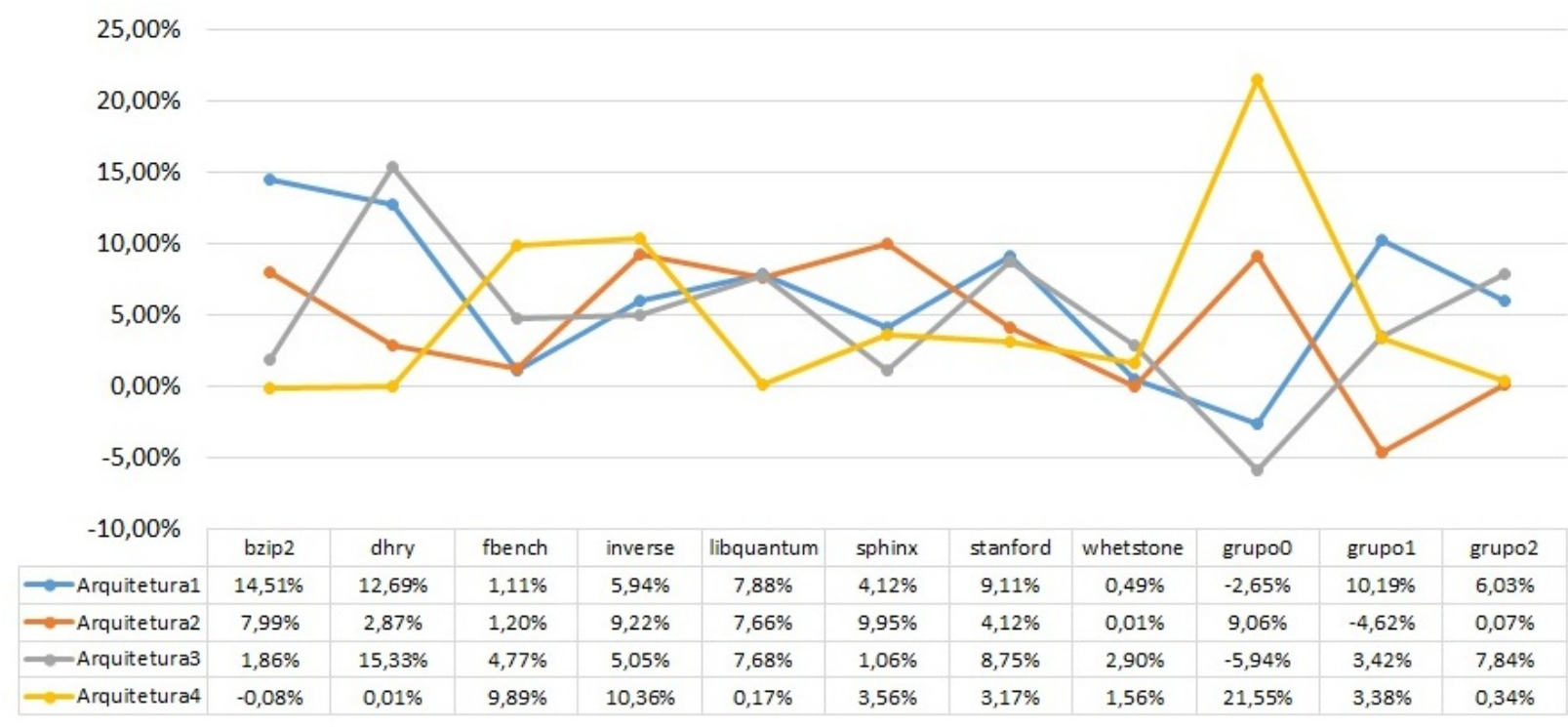

Figura 6.5: Resultados para todas as arquiteturas

processador já possui uma cache-hot para um processo, os escalonadores não realizam a migração. No entanto, essa abordagem quando utilizada em um sistema multiprocessado heterogêneo pode trazer a desvantagem de deixar de aproveitar o desempenho que o processo ganharia em outro processador, apesar de possuir cache-cold para o processo. Em muitos casos, dependendo dos recursos que o novo processador tem a oferecer ao processo a ser migrado, pode compensar a migração, independente da cache. Com isso, foram realizados novos experimentos, seguindo o mesmo método anterior, porém, sem a verificação de cache-hot na migração. É importante salientar, que a utilização desse procedimento pode acarretar algumas perdas de desempenho justamente devido a falta de verificação da cache.

Os resultados utilizando essa abordagem para a Arquitetura 1 é apresentada na Figura 6.6 e na Tabela 6.9. Esses resultados do escalonador heterogêneo são comparados aos resultados do escalonador nativo. Na Tabela 6.9 existe duas colunas que informam, respectivamente, o desempenho com o escalonador heterogêneo sem a verificação de cache-hot e com a verificação. Assim como pode ser notado, houve um aumento de desempenho para a maioria dos benchmarks, chegando a $31.57 \%$ do bzip2 e $41.53 \%$ no dhrystone. Para o Grupo 0, cujo resultado antes era negativo, teve suas amostras mais comportadas com um desvio padrão menor, e apresentou um pequeno ganho de desempenho.

Para a Arquitetura 2 também foi possivel observar uma melhora significativa para alguns benchmarks, mas a maioria permaneceu com resultados muito próximos dos resultados obtidos com o escalonador heterogêneo com a verificação de cache-hot.

Os resultados para a Arquitetura 2 são apresentados na Figura 6.7 e na 


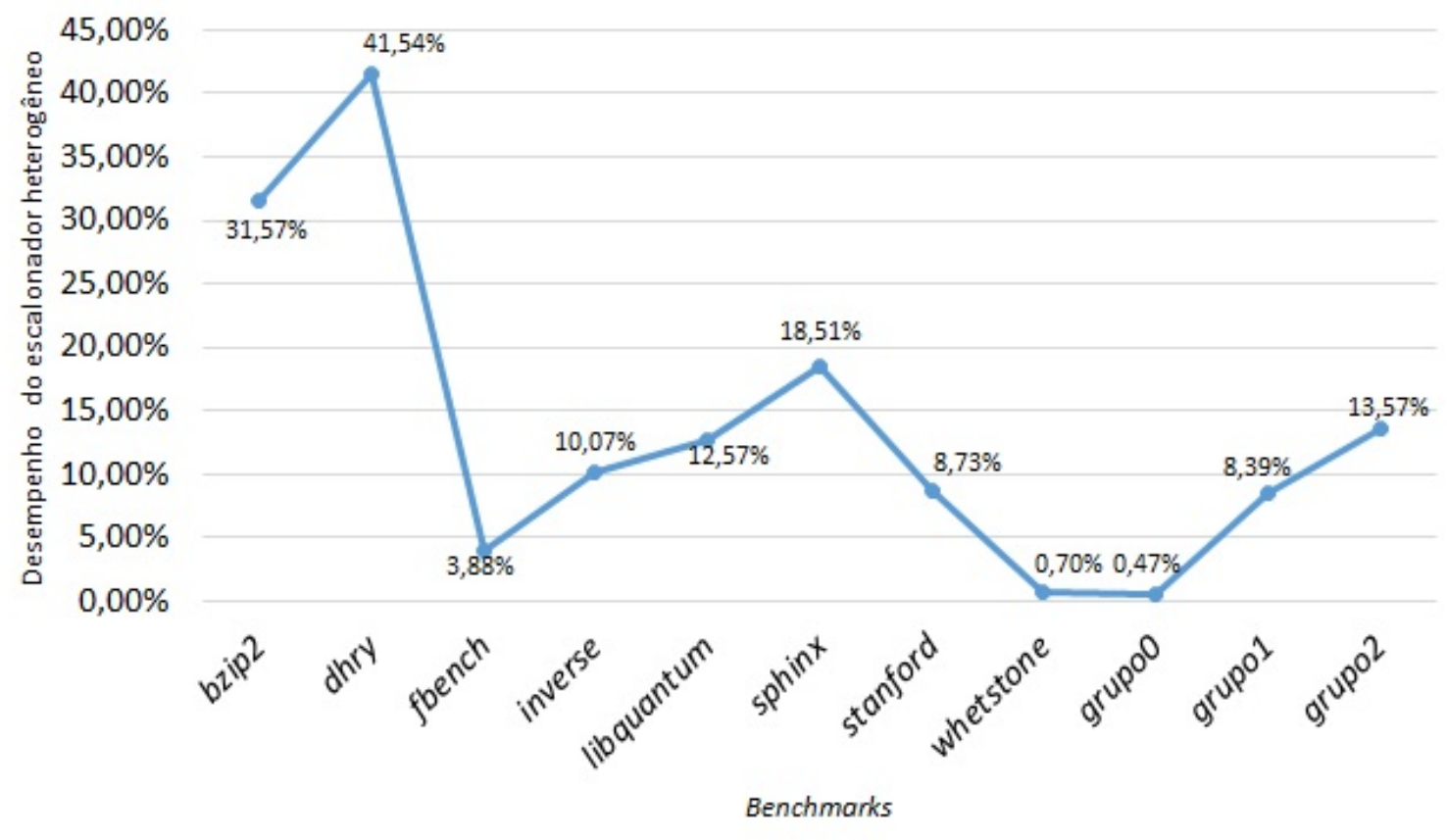

Figura 6.6: Resultados para a Arquitetura 1 (sem cache-hot check)

Tabela 6.9: Estatísticas para Arquitetura 1 sem verificação de cache-hot (tempos em $m s$ )

\begin{tabular}{|c|c|c|c|c|c|c|}
\hline \multirow[t]{3}{*}{ Benchmark } & \multirow{3}{*}{\multicolumn{2}{|c|}{$\begin{array}{c}\text { Escalonador do Linux } \\
\text { Média } \pm \text { Desvio (Desvio \%) }\end{array}$}} & \multicolumn{4}{|c|}{ Escalonador heterogêneo (sem cache-hot check) } \\
\hline & & & \multicolumn{2}{|c|}{ Média \pm Desvio (Desvio \%) } & \multicolumn{2}{|c|}{ Desempenho } \\
\hline & & & & & Antes & Depois \\
\hline bzip2 & $2332970 \pm 4902,62$ & $(0,21 \%)$ & $1596500 \pm 158,75$ & $(0,01 \%)$ & $14,51 \%$ & $31,57 \%$ \\
\hline dhry & $52860 \pm 24,40$ & $(0,05 \%)$ & $30900 \pm 1308,63$ & $(4,24 \%)$ & $12,69 \%$ & $41,54 \%$ \\
\hline fbench & $193095 \pm 61,14$ & $(0,03 \%)$ & $185595 \pm 591,16$ & $(0,32 \%)$ & $1,11 \%$ & $3,88 \%$ \\
\hline inverse & $122755 \pm 1582,90$ & $(1,29 \%)$ & $110390 \pm 1597,32$ & $(1,45 \%)$ & $5,94 \%$ & $10,07 \%$ \\
\hline libquantum & $51300 \pm 57,58$ & $(0,11 \%)$ & $44850 \pm 642,23$ & $(1,43 \%)$ & $7,88 \%$ & $12,57 \%$ \\
\hline sphinx & $2857575 \pm 2945,39$ & $(0,10 \%)$ & $2328560 \pm 6423,97$ & $(0,28 \%)$ & $4,12 \%$ & $18,51 \%$ \\
\hline stanford & $2635 \pm 28,98$ & $(1,10 \%)$ & $2405 \pm 144,26$ & $(6,00 \%)$ & $9,11 \%$ & $8,73 \%$ \\
\hline whetstone & $434235 \pm 529,75$ & $(0,12 \%)$ & $431180 \pm 7310,71$ & $(1,70 \%)$ & $0,49 \%$ & $0,70 \%$ \\
\hline grupo0 & $97090 \pm 8263,82$ & $(8,51 \%)$ & $96630 \pm 1465,98$ & $(1,52 \%)$ & $-2,65 \%$ & $0,47 \%$ \\
\hline grupo 1 & $629985 \pm 21511,79$ & $(3,41 \%)$ & $577100 \pm 11323,43$ & $(1,96 \%)$ & $10,19 \%$ & $8,39 \%$ \\
\hline grupo2 & $1296980 \pm 40161,90$ & $(3,10 \%)$ & $1120970 \pm 32551,16$ & $(2,90 \%)$ & $6,03 \%$ & $13,57 \%$ \\
\hline
\end{tabular}

Tabela 6.10. Dos resultados, os principais destaques são o benchmark sphinx, com um aumento de mais de 10\%, e o Grupo 2, com um aumento de 5.01\%.

Tabela 6.10: Estatísticas para Arquitetura 2 sem verificação de cache-hot (tempos em $m s$ )

\begin{tabular}{|c|c|c|c|c|c|c|}
\hline \multirow[t]{3}{*}{ Benchmark } & \multirow{3}{*}{\multicolumn{2}{|c|}{$\begin{array}{c}\text { Escalonador do Linux } \\
\text { Média } \pm \text { Desvio (Desvio \%) }\end{array}$}} & \multicolumn{4}{|c|}{ Escalonador heterogêneo (sem cache-hot check) } \\
\hline & & & \multirow{2}{*}{\multicolumn{2}{|c|}{ Média \pm Desvio (Desvio \%) }} & \multicolumn{2}{|c|}{ Desempenho } \\
\hline & & & & & Antes & Depois \\
\hline bzip2 & $2229255 \pm 546,80$ & $(0,02 \%)$ & $2051415 \pm 6309,40$ & $(0,31 \%)$ & $7,99 \%$ & $7,98 \%$ \\
\hline dhry & $56800 \pm 34,98$ & $(0,06 \%)$ & $55525 \pm 488,21$ & $(0,88 \%)$ & $2,87 \%$ & $2,24 \%$ \\
\hline fbench & $174555 \pm 176,51$ & $(0,10 \%)$ & $172145 \pm 306,18$ & $(0,18 \%)$ & $1,20 \%$ & $1,38 \%$ \\
\hline inverse & $99415 \pm 1147,29$ & $(1,15 \%)$ & $89915 \pm 3311,79$ & $(3,68 \%)$ & $9,22 \%$ & $9,56 \%$ \\
\hline libquantum & $49755 \pm 17,29$ & $(0,03 \%)$ & $45870 \pm 262,00$ & $(0,57 \%)$ & $7,66 \%$ & $7,81 \%$ \\
\hline sphinx & $2513450 \pm 8796,07$ & $(0,35 \%)$ & $1967935 \pm 93254,42$ & $(4,74 \%)$ & $9,95 \%$ & $21,70 \%$ \\
\hline stanford & $2305 \pm 41,15$ & $(1,79 \%)$ & $2230 \pm 54,46$ & $(2,44 \%)$ & $4,12 \%$ & $3,25 \%$ \\
\hline whetstone & $428060 \pm 418,41$ & $(0,10 \%)$ & $415990 \pm 6269,68$ & $(1,51 \%)$ & $0,01 \%$ & $2,82 \%$ \\
\hline grupo0 & $75260 \pm 9595,01$ & $(12,75 \%)$ & $67500 \pm 734,06$ & $(1,09 \%)$ & $9,06 \%$ & $10,31 \%$ \\
\hline grupo 1 & $584125 \pm 19919,86$ & $(3,41 \%)$ & $613110 \pm 15756,13$ & $(2,57 \%)$ & $-4,62 \%$ & $-4,96 \%$ \\
\hline grupo2 & $1208560 \pm 57278,00$ & $(4,74 \%)$ & $1147205 \pm 51458,63$ & $(4,49 \%)$ & $0,07 \%$ & $5,08 \%$ \\
\hline
\end{tabular}




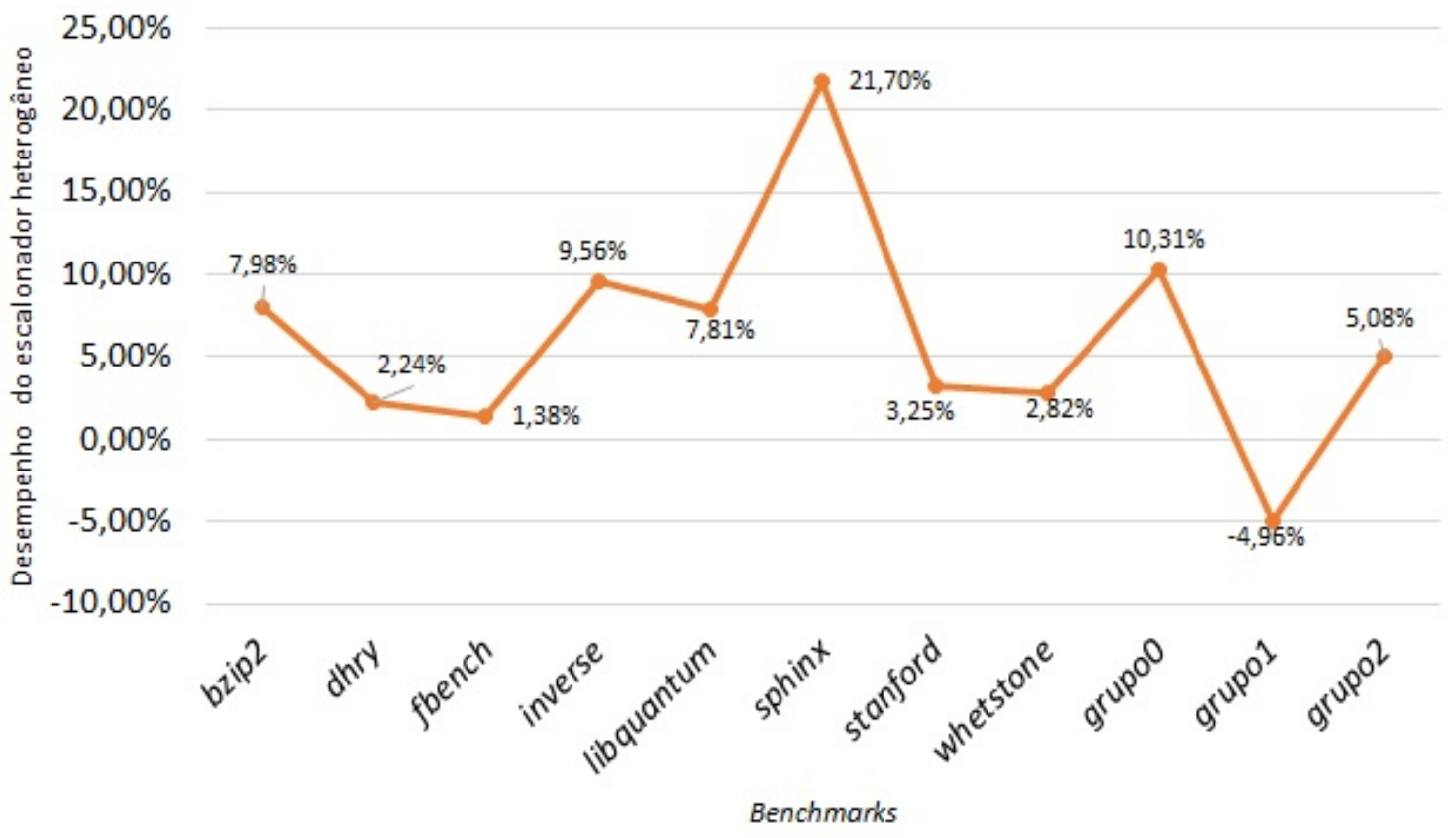

Figura 6.7: Resultados para a Arquitetura 2 (sem cache-hot check)

Os resultados para a Arquitetura 3 são apresentados na Figura 6.8 e na Tabela 6.11.

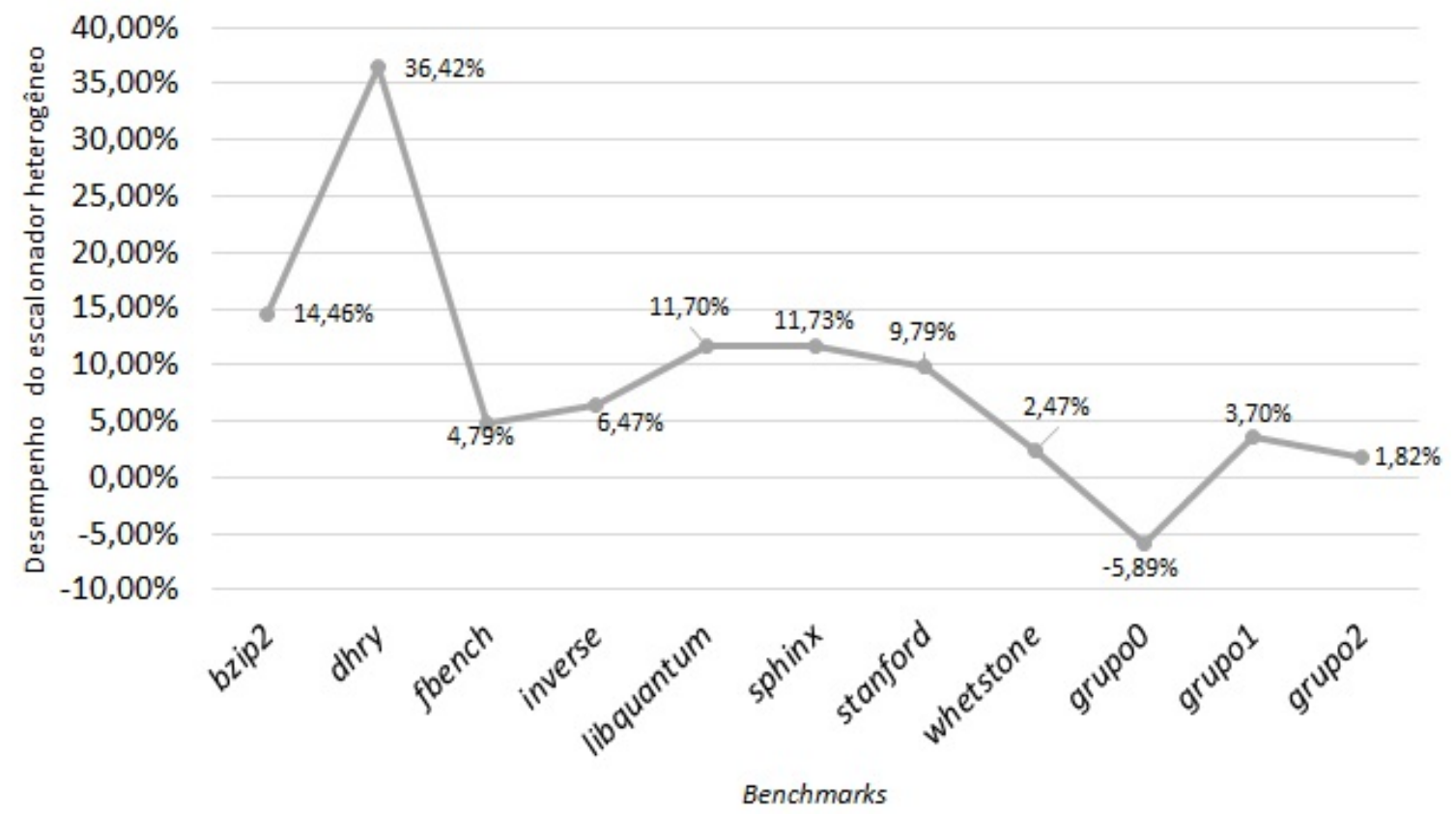

Figura 6.8: Resultados para a Arquitetura 3 (sem cache-hot check)

Os benchmarks bzip2, dhrystone e sphinx apresentaram os maiores aumentos de desempenho, que variaram de $10 \%$ a $20 \%$, sendo que os demais benchmarks apresentaram um desempenho similar ao desempenho obtido com a verificação de cache-hot. No entanto, como pode-se observar, houve um decaimento de desempenho considerável para o Grupo 2. As amostras 
Tabela 6.11: Estatísticas para Arquitetura 3 sem verificação de cache-hot (tempos em ms)

\begin{tabular}{|c|c|c|c|c|c|c|}
\hline \multirow[t]{3}{*}{ Benchmark } & \multirow{3}{*}{\multicolumn{2}{|c|}{$\begin{array}{c}\text { Escalonador do Linux } \\
\text { Média } \pm \text { Desvio (Desvio \%) }\end{array}$}} & \multicolumn{4}{|c|}{ Escalonador heterogêneo (sem cache-hot check) } \\
\hline & & & \multicolumn{2}{|c|}{ Média \pm Desvio (Desvio \%) } & \multicolumn{2}{|c|}{ Desempenho } \\
\hline & & & & & Antes & Depois \\
\hline bzip2 & $2008910 \pm 1165,43$ & $(0,06 \%)$ & $1718325 \pm 8629,63$ & $(0,50 \%)$ & $1,86 \%$ & $14,46 \%$ \\
\hline dhry & $47245 \pm 41,97$ & $(0,09 \%)$ & $30040 \pm 4683,97$ & $(15,59 \%)$ & $15,33 \%$ & $36,42 \%$ \\
\hline fbench & $157090 \pm 40,29$ & $(0,03 \%)$ & $149570 \pm 1190,04$ & $(0,80 \%)$ & $4,77 \%$ & $4,79 \%$ \\
\hline inverse & $113150 \pm 1372,28$ & $(1,21 \%)$ & $105825 \pm 2485,47$ & $(2,35 \%)$ & $5,05 \%$ & $6,47 \%$ \\
\hline libquantum & $49675 \pm 34,14$ & $(0,07 \%)$ & $43865 \pm 697,29$ & $(1,59 \%)$ & $7,68 \%$ & $11,70 \%$ \\
\hline sphinx & $2451115 \pm 4499,64$ & $(0,18 \%)$ & $2163660 \pm 9229,63$ & $(0,43 \%)$ & $1,06 \%$ & $11,73 \%$ \\
\hline stanford & $2400 \pm 36,22$ & $(1,51 \%)$ & $2165 \pm 100,53$ & $(4,64 \%)$ & $8,75 \%$ & $9,79 \%$ \\
\hline whetstone & $428080 \pm 38,93$ & $(0,01 \%)$ & $417505 \pm 3294,73$ & $(0,79 \%)$ & $2,90 \%$ & $2,47 \%$ \\
\hline grupo0 & $75530 \pm 2718,11$ & $(3,60 \%)$ & $79975 \pm 1412,87$ & $(1,77 \%)$ & $-5,94 \%$ & $-5,89 \%$ \\
\hline grupo 1 & $551960 \pm 25454,53$ & $(4,61 \%)$ & $531550 \pm 3859,76$ & $(0,73 \%)$ & $3,42 \%$ & $3,70 \%$ \\
\hline grupo2 & $1123350 \pm 42167,40$ & $(3,75 \%)$ & $1102885 \pm 69341,46$ & $(6,29 \%)$ & $7,84 \%$ & $1,82 \%$ \\
\hline
\end{tabular}

para esse grupo são apresentadas a seguir:

- Escalonador nativo (ms): [1 124310, 1036180, 1036850, 1035760, 1123310 , 1123800, 1123390, 1123940, 1122340, 1123760 ];

- Escalonador heterogêneo (ms): [1035760 103579010352601034700 10350901035280103572010357001034740 1035380];

- Escalonador heterogêneo sem cache-hot check (ms): [1 106160, 1104860, 1102470, 1109520, 1092570, 1109970, 937940, 1103300, 1093080, 939820].

Como pode ser observado, com a utilização do escalonador heterogêneo sem a verificação de cache-hot, obteve-se os menores valores em tempo efetivo, mas na média não houve favorecimento.

A Arquitetura 4 obteve os resultados mais estáveis e muito próximos aos resultados obtidos anteriormente, conforme pode ser observado na Figura 6.9 e na Tabela 6.12.

Tabela 6.12: Estatísticas para Arquitetura 4 sem verificação de cache-hot (tempos em ms)

\begin{tabular}{|c|c|c|c|c|c|c|}
\hline \multirow[t]{3}{*}{ Benchmark } & \multirow{3}{*}{\multicolumn{2}{|c|}{$\begin{array}{c}\text { Escalonador do Linux } \\
\text { Média } \pm \text { Desvio (Desvio \%) }\end{array}$}} & \multicolumn{4}{|c|}{ Escalonador heterogêneo (sem cache-hot check) } \\
\hline & & & \multirow{2}{*}{\multicolumn{2}{|c|}{ Média \pm Desvio (Desvio \%) }} & \multicolumn{2}{|c|}{ Desempenho } \\
\hline & & & & & Antes & Depois \\
\hline bzip2 & $2085055 \pm 1833,15$ & $(0,09 \%)$ & $2087815 \pm 99206,23$ & $(4,75 \%)$ & $-0,08 \%$ & $-0,13 \%$ \\
\hline dhry & $35805 \pm 25,14$ & $(0,07 \%)$ & $35810 \pm 28,07$ & $(0,08 \%)$ & $0,01 \%$ & $-0,01 \%$ \\
\hline fbench & $118530 \pm 25,14$ & $(0,02 \%)$ & $106970 \pm 40,57$ & $(0,04 \%)$ & $9,89 \%$ & $9,75 \%$ \\
\hline inverse & $102865 \pm 878,43$ & $(0,85 \%)$ & $92120 \pm 1317,11$ & $(1,43 \%)$ & $10,36 \%$ & $10,45 \%$ \\
\hline libquantum & $51045 \pm 31,64$ & $(0,06 \%)$ & $50925 \pm 1302,01$ & $(2,56 \%)$ & $0,17 \%$ & $0,24 \%$ \\
\hline sphinx & $2477540 \pm 2042,97$ & $(0,08 \%)$ & $2332260 \pm 43812,98$ & $(1,88 \%)$ & $3,56 \%$ & $5,86 \%$ \\
\hline stanford & $2210 \pm 49,49$ & $(2,24 \%)$ & $2120 \pm 70,25$ & $(3,31 \%)$ & $3,17 \%$ & $4,07 \%$ \\
\hline whetstone & $422685 \pm 422,59$ & $(0,10 \%)$ & $416340 \pm 25573,81$ & $(6,14 \%)$ & $1,56 \%$ & $1,50 \%$ \\
\hline grupo0 & $65600 \pm 2243,71$ & $(3,42 \%)$ & $50160 \pm 1433,26$ & $(2,86 \%)$ & $21,55 \%$ & $23,54 \%$ \\
\hline grupo 1 & $557320 \pm 31460,95$ & $(5,65 \%)$ & $538430 \pm 984,76$ & $(0,18 \%)$ & $3,38 \%$ & $3,39 \%$ \\
\hline grupo2 & $1063880 \pm 41433,68$ & $(3,89 \%)$ & $1059860 \pm 25030,80$ & $(2,36 \%)$ & $0,34 \%$ & $0,38 \%$ \\
\hline
\end{tabular}

A maior variação de resultados para a Arquitetura 4 foi de $2 \%$, com algumas variações de 1\%. A Figura 6.10 ilustra todos os resultados das arquiteturas sem a verificação de cache-hot. Entre as arquiteturas utilizadas nos 


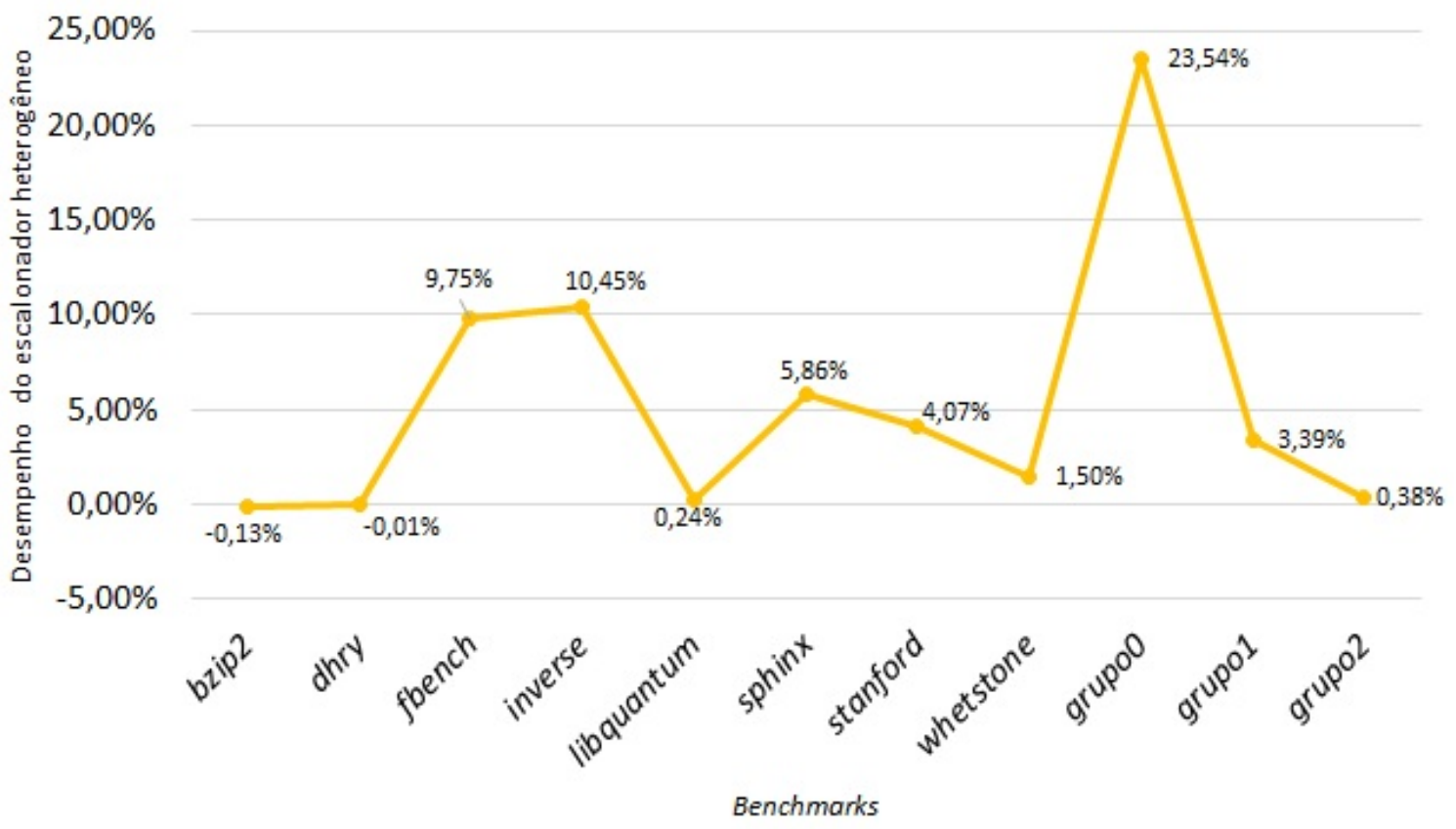

Figura 6.9: Resultados para a Arquitetura 4 (sem cache-hot check)

experimentos, a Arquitetura 4 apresentou os resultados mais estáveis na comparação entre o escalonador heterogêneo com e sem a verificação de cache-hot.

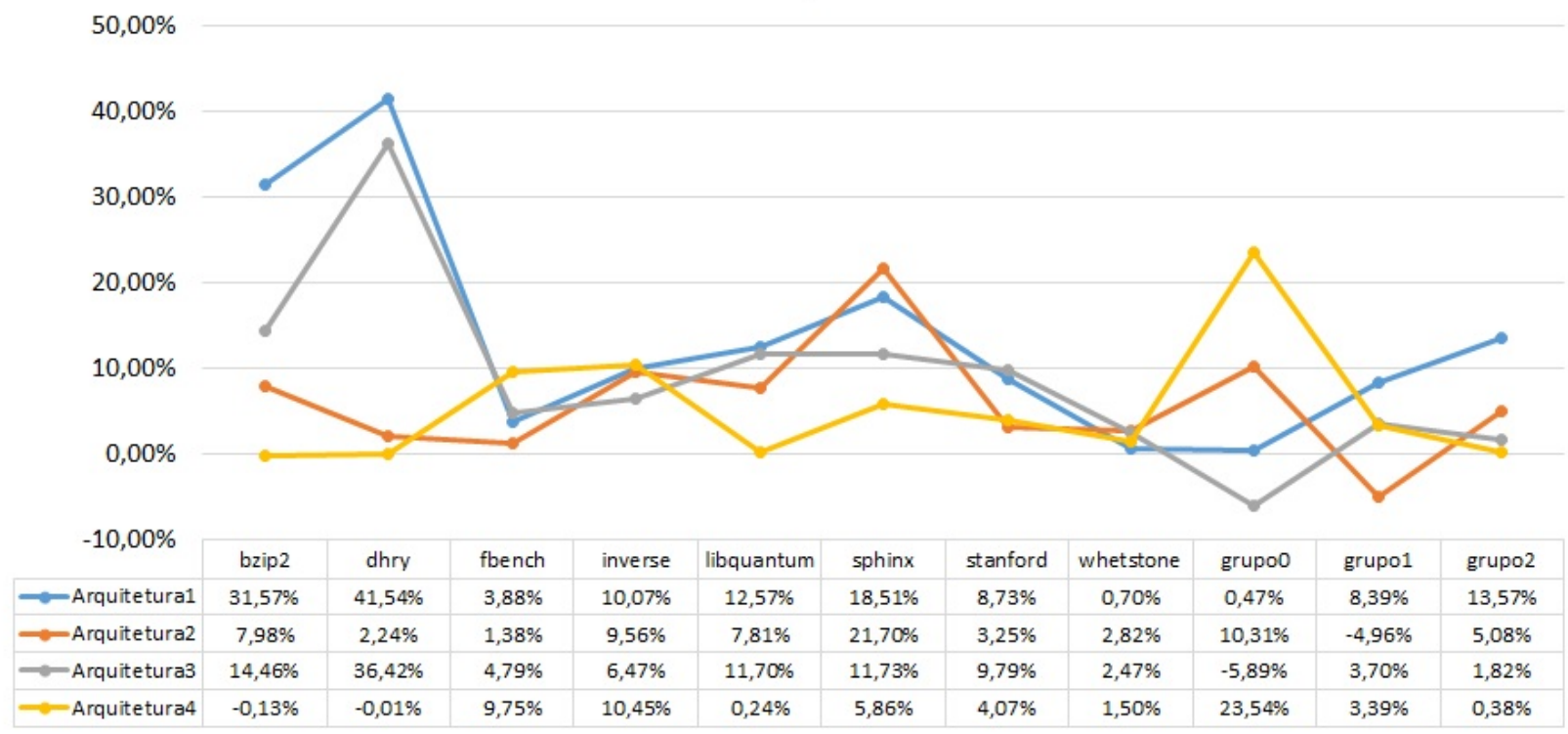

Figura 6.10: Resultados para todas as arquiteturas (sem cache-hot check)

\subsection{Resultados para o algoritmo Hungarian em soft- ware e em hardware}

Nesta seção são apresentados os resultados para a execução do algoritmo Hungarian em C, sobre o processador Leon 3, e em VHDL, executado em hard- 
ware na FPGA. Os relógios do processador e da lógica do algoritmo na FPGA são ambos $80 \mathrm{MHz}$. Foram utilizadas matrizes quadradas com tamanhos: 20, 50, 100 e 128. Não foram utilizadas matrizes com tamanhos maiores pois a memória da FPGA foi limitada para aceitar uma quantidade máxima de $64 \mathrm{~K}$ palavras (limitada pela síntese, porém os blocos do algoritmo são configuráveis), devido a quantidade de recursos já ocupada pelos demais componentes da arquitetura (processadores, barramento, entre outros).

O software de teste gera matrizes com valores inteiros aleatórios, sendo que cada matriz é submetida à execução em software e também em hardware. Esse ciclo é repetido 30 vezes para cada tamanho de matriz. A Tabela 6.13 e a Figura 6.11 apresentam os resultados das 30 execuções para cada configuração.

Tabela 6.13: Estatísticas da execução do algoritmo Hungarian (tempos em us)

\begin{tabular}{l|cc|ccc}
\hline \hline N da Matriz & \multicolumn{2}{c}{ Hungarian em C } & \multicolumn{3}{c}{ Hungarian em VHDL } \\
& \multicolumn{1}{c}{ Média \pm Desvio (Desvio \%) } & Média \pm Desvio (Desvio \%) & Desempenho \\
\hline 20 & $13000 \pm 4660$ & $(35 \%)$ & $10000 \pm 0$ & $(0 \%)$ & $23.08 \%$ \\
50 & $168666 \pm 50700$ & $(30 \%)$ & $58666 \pm 17366$ & $(29 \%)$ & $65.22 \%$ \\
100 & $666000 \pm 113246$ & $(17 \%)$ & $330333 \pm 50819$ & $(15 \%)$ & $50.40 \%$ \\
128 & $1032333 \pm 176804$ & $(17 \%)$ & $592000 \pm 93675$ & $(15 \%)$ & $42.65 \%$ \\
\hline \hline
\end{tabular}

Os desempenhos das execuções do algoritmo em hardware variam de $23.08 \%$ a 65.22\%. Pode-se perceber que o desvio padrão indica que há muita variação no tempo de execução de cada matriz. A maximização pode demorar ou ser rápida, dependendo do conjunto de dados de cada matriz, fato que explica o valor alto no desvio padrão.

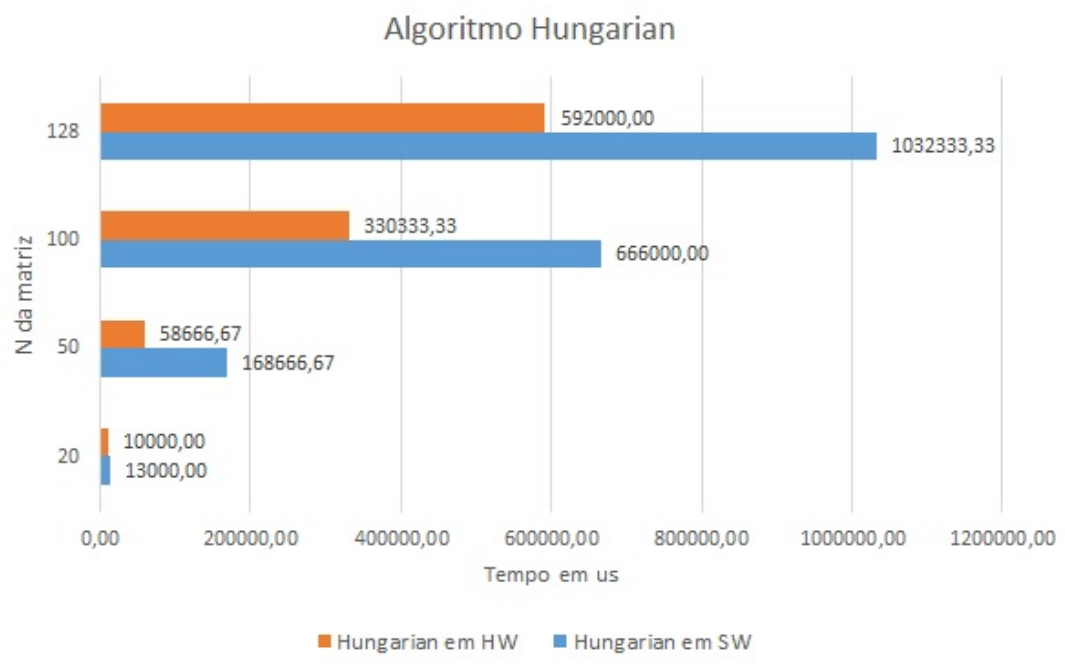

Figura 6.11: Resultados para a execução do algoritmo Hungarian em software e em hardware 


\subsection{Resultados do balanceamento}

Na Seção 6.4 está descrita os resultados relacionados à heurística, ou seja, o quão bem o algoritmo está associando um processo ao processador que lhe é mais apropriado. Nesse caso foi utilizado como métrica o tempo efetivo, o qual consiste no tempo de CPU utilizado por cada processo. Para os resultados do balanceamento, que reune ao mesmo tempo a projeção e a distribuição de processos entre os processadores, é utilizado o tempo real de duração de processamento para cada benchmark. Para isso, quatro grupos de benchmarks executando paralelamente são utilizados no experimento. Com o objetivo de que cada grupo esteja balanceado quanto às necessidades de recursos dos benchmarks, eles possuem a seguinte distribuição:

- Grupo 0: dhrystone, fbench, stanford e inverse;

- Grupo 1: libquantum, whetstone, bzip2 e fbench;

- Grupo 2: $2 x$ dhrystone, $2 x$ fbench, $2 x$ inverse, $2 x$ libquantum e $2 x$ whetstone; $\mathrm{e}$

- Grupo 3: $4 x$ fbench e 4x libquantum.

Esses grupos foram executados um por vez sobre as arquiteturas 1 e 4 . As arquiteturas 2 e 3 não foram utilizadas devido à quantidade de recursos utilizada após acrescentar o algoritmo Hungarian na lógica da FPGA, a qual excede a capacidade do chip utilizado. Da parte do sistema operacional, como a retirada da verificação de cache-hot trouxe benefícios ao desempenho, essa abordagem foi também utilizada para a geração dos resultados do balanceamento. A Figura 6.12 ilustra os resultados da execução de 10 vezes cada grupo.

Como pode ser visto, todos os grupos apresentaram resultado positivo no desempenho do tempo de execução quando utilizado o escalonador heterogêneo, apesar das poucas diferenças arquiteturais entre os processadores. Em alguns casos não houveram ganho de desempenho, denotando que a associação dos processadores aos processos não trouxe ganho de recursos suficientes aos processos. Isso pode ocorrer devido ao fato que os processos estão balanceados entre os recursos, como também, devido ao número de migrações que o algoritmo ocasiona. Por se basear na necessidade de recursos de cada processo, o escalonador pode realizar diversas migrações de processo, o que de certo modo poderia prejudicar o desempenho ou inibí-lo, como ocorreu no Grupo 1 e Grupo 2 para a Arquitetura 4, a qual não possui uma diferença significativa de recursos entre os dois processadores. Para investigar a quantidade extra de migrações que estão sendo realizadas devido o escalonador heterogêneo, a Seção 6.7 descreve esses resultados. 


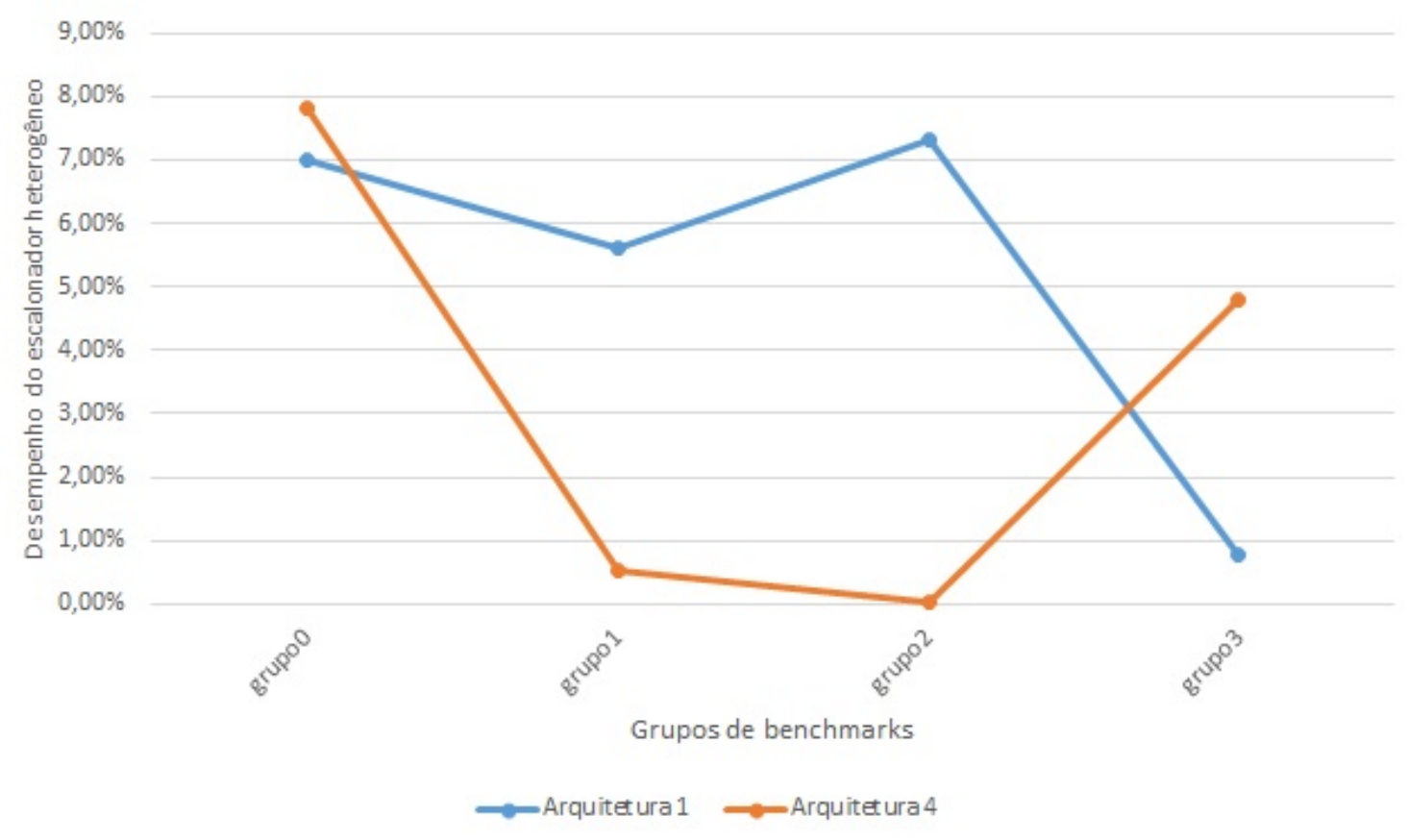

Figura 6.12: Resultado do escalonamento utilizando balanceamento (algoritmo Hungarian)

Apesar dos resultados positivos no desempenho alcançados com os grupos de benchmarks descritos nesta seção, esse experimento não testa o comportamento dinâmico dos processos. A maioria dos benchmarks tem seu comportamento constante durante seu tempo de execução, não exigindo muita variação de necessidade de recursos. Para gerar resultados com o comportamento dinâmico dos processos, um único processo, contendo todos os benchmarks, é executado em diversas instâncias, onde cada instância executa os benchmarks em uma ordem diferente. Foram realizados experimentos com três e quatro processos paralelos, executando cada qual, uma ordem diferente dos seguintes benchmarks: dhrystone, stanford, float-point test (executa diversas operações de ponto flutuante sem necessitar de matrizes ou estruturas que necessitam de uso intenso de cache de dados), icache-test, whetstone e inverse. A Arquitetura 1 foi utilizada para esse experimento devido ao fato de possuir maior distinção entre os recursos dos processadores. Para as 10 execuções, foram obtidos um desempenho médio de $5.64 \%$ para a execução com 3 instâncias e $8.96 \%$ para a execução com 4 instâncias. Com esse resultado pode-se inferir que o algoritmo está aproveitando as fases de cada processo para determinar em qual processador ele deve executar, de acordo com a demanda de recursos exigido em cada fase. 


\subsection{Resultados das migrações}

Uma das principais vantagens do escalonador heterogêneo é a associação entre processo e processador que melhor aproveite os recursos disponíveis no hardware de acordo com a necessidade. Apesar disso, essa associação, devido às variações nas fases dos processos, pode ocasionar um aumento do número de migrações de processos entre os processadores, influenciando no desempenho devido às invalidações de linhas nas caches e TLBs de dados e instruções. Para mensurar a quantidade adicional de migrações ocasionada pelo algoritmo, foram executados os mesmos grupos de benchmarks da seção anterior (Grupos 0, 1, 2 e 3) sobre a Arquitetura 4, por dez vezes. Essas execuções foram realizadas sobre o sistema operacional sem o escalonador e com o escalonador heterogêneo. Durante essas execuções, o número de migrações de cada processo foi contabilizado, gerando as seguintes quantidades de migrações para cada configuração:

- Sem o escalonamento heterogêneo: 1309 migrações; e

- Com o escalonamento heterogêneo: 22215 migrações.

O número de migrações aumentou aproximadamente 17 vezes com a utilização do escalonador heterogêneo. Esse resultado explica alguns desempenhos negativos alcançados com a utilização do escalonador.

\subsection{Recursos de hardware e consumo de energia}

A Tabela 6.14 descreve a quantidade dos principais recursos utilizados pelo escalonador heterogêneo implementado em FPGA. Como exemplo de comparação, também está descrito a quantidade de recursos utilizados por um dos processadores da Arquitetura 1.

Tabela 6.14: Utilização de recursos de hardware

\begin{tabular}{ccccccc}
\hline \hline Recurso & Slices & Slice REG & LUTs & LUTRAM & BRAM & DSP48 \\
\hline CPU1 & 6835 & 7027 & 17108 & 132 & 8 & 16 \\
\hline \multicolumn{7}{c}{ Escalonador heterogêneo } \\
Monitor de desempenho & 314 & 568 & 1083 & 0 & 0 & 0 \\
Módulo de escalonamento & 1376 & 1919 & 2793 & 8 & 8 & 0 \\
Algoritmo Hungarian & 445 & 700 & 1117 & 0 & 13 & 0 \\
Total & 2135 & 3187 & 4993 & 8 & 21 & 0 \\
\hline \hline
\end{tabular}

Pode-se notar, que o escalonador ocupa cerca de um terço dos recursos gastos com o processador. Apesar de ser uma quantidade alta de recursos, essa quantidade pode ser diminuida, pois existem muitos módulos de depuração implementados. 
Para mensurar o consumo de energia adicionado pelo módulo do escalonador, foi utilizada a ferramenta XPower Analyzer, a qual realiza uma estimativa do consumo de energina na FPGA de acordo com a arquitetura implementada (Xilinx, 2013b). Os seguintes valores foram estimados:

- Sem o escalonador heterogêneo: 4.58W; e

- Com o escalonador heterogêneo: 4.70W

\subsection{Considerações finais}

Neste capítulo, o escalonador heterogêneo, especificamente a projeção de desempenho, foi avaliado por meio da execução de diversos benchmarks paralelamente. Para isso, foram utilizadas 4 arquiteturas distintas contendo dois processadores com o objetivo de demonstrar a versatilidade do algoritmo em meio a diferentes configurações de arquiteturas e processos. Por meio da análise dos resultados, a maioria dos benchmarks obteve um elevado desempenho quando executados sobre dois processadores, com pequenas diferenças de arquitetura entre si. É importante ressaltar que na avalição de benchmarks unitários, quatro cópias do mesmo processo executavam simultaneamente. Considerando que a projeção provavelmente apontou o mesmo processador para todos os processos, esse fato ocasionou em alguns casos a migração de todos esses processos para esse mesmo processador, aumentando a probabilidade de faltas na cache de dados. Apesar desse fato, nos resultados da heurística, o algoritmo de escalonamento conseguiu extrair até $41 \%$ de desempenho, o que demonstra que outros recursos do processador podem ser mais importantes que a cache, sendo essa importância diagnosticada pela sua análise em tempo real para cada processo em execução.

Com o balanceamento por meio do algoritmo Hungarian, foi possivel diminuir o tempo de processamento de todas os grupos de benchmarks, chegando a melhorar o desempenho em até $7.82 \%$ em relação ao escalonador sem o suporte à heterogeneidade de processadores.

Esses resultados alimentam a importância de um escalonador específico para arquiteturas heterogêneas visando a extração de maior desempenho das aplicações. 


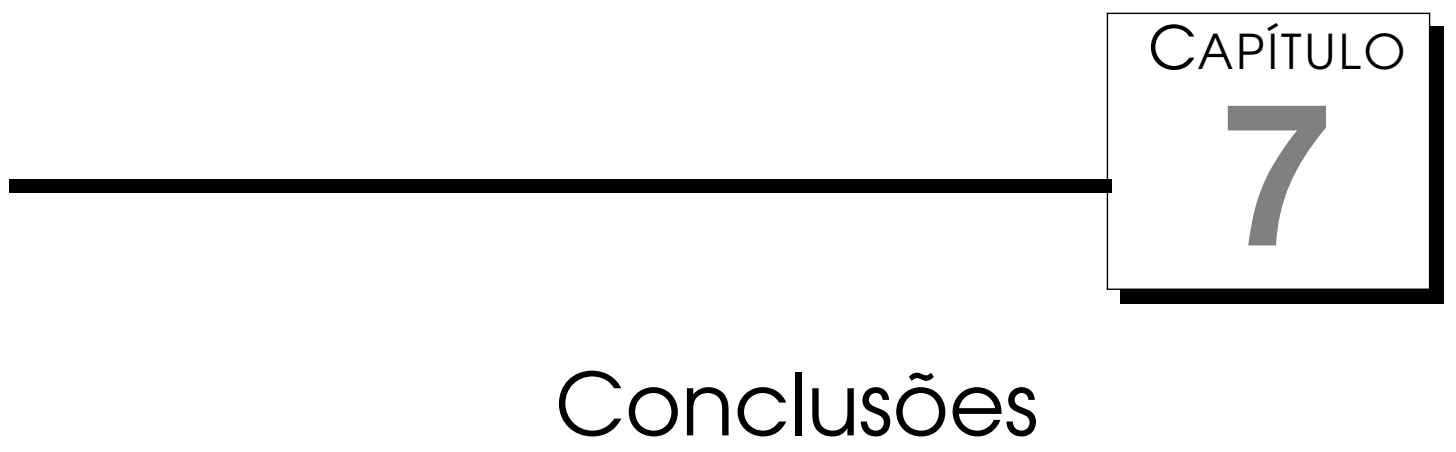

A utilização de arquiteturas com processadores de diferentes especificidades consiste em uma tendência atual no mercado. Em um ambiente genérico com processadores heterogêneos, devido a variedade de recursos exigidos por cada processo, assim como a variação das fases de um mesmo processo em seu tempo de execução, torna complexa a tarefa de mapear suas necessidades ao encontro dos processadores que lhe ofereçam maior desempenho. Nesse sentido, muitas pesquisas foram propostas em relação a designação de processos diretamente para os melhores processadores, provando que um mapeamento eficiente aumenta o desempenho do sistema. No entanto, grande parte dessas pesquisas é realizada em um ambiente controlado, com mapeamento estático, o que não aplicável em um ambiente genérico.

Em busca de melhorar o desempenho dos processos em uma arquitetura multiprocessada heterogêna, este trabalho apresentou a arquitetura de um escalonador heterogêneo que determina em tempo real as projeções de desempenho de qualquer processo em execução para todos os processadores da arquitetura. Por meio dessa projeção os processos são migrados para os processadores que possuem os recursos mais adequados a cada processo, fazendo com que os tempos efetivos de execução para esses processos sejam reduzidos. A implementação da arquitetura do escalonador foi particionada em hardware e software. O processador SPARC V8 Leon3 foi modificado para a adição de um monitor de desempenho, por meio do qual o escalonador tem conhecimento do comportamento atual do processo. Por meio desse comportamento são calculadas as projeções do processo para todos os processadores. Essas projeções chegam até o sistema operacional Linux, o qual por meio do suporte ao escalonador heterogêneo aplicado ao escalonador CFS, realiza as 
migrações dos processos. A parte em hardware foi desenvolvida inteiramente em linguagem VHDL e executado em FPGA, o que trouxe grande flexibilidade durante o desenvolvimento.

As principais contribuições deste projeto, limitações encontradas e trabalhos futuros sugeridos são apresentados a seguir.

\subsection{Contribuições}

A seguir são apresentadas as principais contribuições deste trabalho:

1. Modelo de implementação transparente no sistema operacional: Com a arquitetura proposta e implementada neste trabalho, o sistema operacional não precisa ter ciência do hardware que executa para a designação dos processos. Com o auxilio de hardware para realizar a projeção e a implementação do driver na parte específica da arquitetura, o sistema operacional já sabe qual processo deve executar em qual processador. Com isso, a arquitetura proposta nesta tese pode também ser utilizada em arquiteturas homogêneas, sem precisar de nenhuma modificação para isso.

2. Método de projeção: A utilização do método de projeção alcançou desempenho na maioria dos testes realizados, chegando a $41 \%$ de ganho. O método proposto é genérico e pode ser aplicado para diferentes tipos de processadores. Uma das principais vantagens de sua arquitetura é o fato de não precisar ter conhecimento dos recursos dos processadores. A configuração dos processadores é inserida no escalonador por meio de vetores de desempenho. Sendo assim, o mesmo escalonador pode ser utilizado sem a necessidade de modificações para diferentes arquiteturas.

3. Acompanhamento em tempo real: O escalonador do sistema operacional tem conhecimento em tempo real do comportamento de um processo. Além disso, a projeção de cada processo é continuamente realizada para todos os processadores da arquitetura, assim, em qualquer momento de sua execução é possível saber o desempenho esperado em cada processador.

4. Desempenho da execução em hardware: Este trabalho mostrou que o auxílio do hardware no escalonamento em arquiteturas heterogêneas é fundamental. Além disso, com as projeções sendo realizadas continuamente, a única preocupação do sistema operacional é obter essas informações, não necessitando gastar ciclos para realizar nenhum cálculo. 
5. Implementação em hardware do algoritmo Hungarian: O algoritmo Hungarian foi inteiramente desenvolvido em VHDL. Essa foi uma das primeiras implementações desse algoritmo de otimização em VHDL já que não foi possivel encontrar referências de artigos publicados relacionados.

6. Modelo do monitor: Este projeto apresentou uma arquitetura genérica para a implementação de um monitor de desempenho em um processador. Esse monitor foi implementado no Leon 3 e utilizado na projeção de desempenho, o qual pode também ser utilizado em outras pesquisas para estudar o comportamento do software.

7. Suporte a heterogeneidade no sistema operacional: Por último, este trabalho também colaborou realizando um estudo de como realizar a implementação de suporte a heterogeneidade no sistema operacional, enfaticamente no Linux.

\subsection{Trabalhos futuros}

A seguir são apresentados os principais direcionamentos para trabalhos futuros relacionados a esta tese:

1. Consideração de frequência: Em algumas arquiteturas propostas por pesquisas recentes tem sido utilizado processadores com diferentes frequências. Um dos projetos futuros a serem realizados nesse sentido consiste em considerar no escalonador um fator associado à frequência de cada processador. Com isso, além dos recursos, o escalonamento também seria guiado pelo desempenho em ciclos de cada processador.

2. Considerações de consumo de energia: Em muitas arquiteturas é necessário implementar o DVFS (Dynamic Voltage Frequency Scaling) para diminuir o consumo de processadores. Desse modo, a implementação de um controle de frequência guiado pela utilização do processador poderia trazer grandes ganhos em economia no consumo de energia. Além disso, considerando processadores com arquiteturas diferentes e que implementam DVFS, seria possível controlar a escala de frequência de cada um de acordo com o desempenho necessário em cada processador.

3. Consideração do desvio padrão nos cálculos: Uma adição importante a ser realizada consiste na consideração de cálculo de desvio padrão para as amostras de desempenho. Como os processos podem variar sua necessidade de recursos de acordo com o tempo, a consideração do desvio padrão dessas amostras poderia trazer maior precisão na projeção de desempenho. 
4. Migração por falta de opcode: Em alguns tipos de arquiteturas podem haver processadores que implementam diferentes conjuntos de instruções. Em muitos casos, essas instruções não compartilhadas entre os processadore implementam funções específicas com maior desempenho. Nesse sentido, para extrair maior desempenho dessas arquiteturas, é necessário compilar os processos com as instruções específicas, mas primeiramente, o sistema operacional deve ter a capacidade de tratar essa diferença. Um dos trabalhos futuros propostos é a implementação do sistema operacional da migração automática do processo quando é detectado uma interrupção por opcode não implementado.

5. Diminuir quantidade de migrações: De acordo com os resultados, o escalonador heterogêneo aumentou o número de migrações entre processadores, podendo aumentar também o tempo gasto com faltas nas caches e TLBs. Uma melhoria no algoritmo poderia diminuir esse número, contribuindo para alcançar maiores desempenhos.

6. Generalização para $\mathrm{N}$ processadores: De modo a provar que a heurística utilizada funciona para $\mathrm{N}$ processadores, um direcionamento futuro seria emular outro processadores para verificar o comportamento do escalonador.

7. Utilizar CPI como métrica: Implementação de uma heurística envolvendo somente o CPI como métrica para efeito de comparação de desempenho com a heurística apresentada neste trabalho.

8. Arquiteturas envolvendo processadores com mais recursos: Em algumas organizações existem processadores com muito mais recursos executando juntamente com um processador com um numero de recursos reduzido. Essa organização é realizada para obter mais economia no consumo de energia. Um dos trabalhos propostos é realizar um estudo de como esse modelo pode ser inserido no escalonador proposto por este projeto. 


\section{Referências Bibliográficas}

Adve, V., Lattner, C., Brukman, M., Shukla, A., \& Gaeke, B. (2003). LLVA: A Low-level Virtual Instruction Set Architecture. Em Proceedings of the 36th annual ACM/IEEE international symposium on Microarchitecture (MICRO-36), San Diego, California. Citado na página 25.

Agron, J. \& Andrews, D. (2009). Building heterogeneous reconfigurable systems with a hardware microkernel. Em Proceedings of the 7th IEEE/ACM international conference on Hardware/software codesign and system synthesis, CODES+ISSS '09, páginas 393-402, New York, NY, USA. ACM. Citado nas páginas 24 and 89.

Akhter, S. \& Roberts, J. (2006). Multi-Core Programming: Increasing Performance Through Software Multi-Threading. Books by engineers, for engineers. Intel Press. Citado na página 12 .

Allam, O., Eyerman, S., \& Eeckhout, L. (2012). An efficient CPI stack counter architecture for superscalar processors. Em Proceedings of the great lakes symposium on VLSI, GLSVLSI '12, páginas 55-58, New York, NY, USA. ACM. Citado na página 71 .

Altera (2013). FPGA CPLD and ASIC from Altera. http://www.altera.com. Acessado em: 01-07-2013. Citado na página 88.

Anderson, J. M., Berc, L. M., Dean, J., Ghemawat, S., Henzinger, M. R., Leung, S.-T. A., Sites, R. L., Vandevoorde, M. T., Waldspurger, C. A., \& Weihl, W. E. (1997). Continuous profiling: where have all the cycles gone? ACM Trans. Comput. Syst., 15(4):357-390. Citado na página 11.

ARM (2010). Amba $₫ 4$ axi4-stream protocol. http://www.arm.com/ products/system-ip/amba/amba-open-specifications.php. Acessado em: 01-07-2013. Citado na página 95 . 
ARM, P. G. (2011). big.little processing with arm cortex-a15 \& cortex-a7. http://www.arm.com/products/processors/technologies/ biglittleprocessing.php. Acessado em: 01-07-2013. Citado nas páginas xix, xxiii, 19, 20, and 25.

Baumann, A., Barham, P., Dagand, P.-E., Harris, T., Isaacs, R., Peter, S., Roscoe, T., Schüpbach, A., \& Singhania, A. (2009). The multikernel: a new OS architecture for scalable multicore systems. Em Proceedings of the ACM SIGOPS 22nd symposium on Operating systems principles, SOSP '09, páginas 29-44, New York, NY, USA. ACM. Citado nas páginas xix, 23, and 24.

Becchi, M. \& Crowley, P. (2006). Dynamic thread assignment on heterogeneous multiprocessor architectures. Em Proceedings of the 3rd conference on Computing frontiers, CF '06, páginas 29-40, New York, NY, USA. ACM. Citado nas páginas 27, 28, 29, 37, 38, and 40.

Bertsekas, D. P. (1992). Auction algorithms for network flow problems: A tutorial introduction. Computational Optimization and Applications, 1:7-66. Citado na página 64 .

Bonato, V. (2007). Proposta de uma arquitetura de hardware em FPGA implementada para SLAM com multi-câmeras aplicada à robótica móvel. Tese de Doutorado, ICMC - USP. Citado na página 89.

Borkar, S. \& Chien, A. A. (2011). The future of microprocessors. Commun. ACM, 54(5):67-77. Citado nas páginas 5 and 6 .

Bower, F. A., Sorin, D. J., \& Cox, L. P. (2008). The impact of dynamically heterogeneous multicore processors on thread scheduling. IEEE Micro, 28(3):1725. Citado nas páginas 11 and 39 .

Bueno, M. (2007). Análise e implementação de suporte a smp (multiprocessamento simétrico) para o sistema operacional ecos com aplicação em robótica móvel. Dissertação de Mestrado, ICMC - USP. Citado na página 12.

Chen, J. \& Liu, J.-H. (2006). Developing embedded kernel for system-ona-chip platform of heterogeneous multiprocessor architecture. Em Proceedings of the 12th IEEE International Conference on Embedded and RealTime Computing Systems and Applications, RTCSA '06, páginas 246-250, Washington, DC, USA. IEEE Computer Society. Citado na página 21 .

Chen, Y.-S., Liao, H. C., \& Tsai, T.-H. (2013). Online real-time task scheduling in heterogeneous multicore system-on-a-chip. IEEE Transactions on Parallel and Distributed Systems, 24(1):118-130. Citado nas páginas 1, 12, 32, 37, 38, and 40, 
Cong, J. \& Yuan, B. (2012). Energy-efficient scheduling on heterogeneous multi-core architectures. Em Proceedings of the 2012 ACM/IEEE international symposium on Low power electronics and design, ISLPED '12, páginas 345-350, New York, NY, USA. ACM. Citado na página 36.

Eyerman, S. \& Eeckhout, L. (2009). Per-thread cycle accounting in smt processors. SIGPLAN Not., 44(3):133-144. Citado na página 70.

Flynn, M. (1995). Computer Architecture: Pipelined and Parallel Processor Design. Computer Science Series. Jones and Bartlett Publishers. Citado na página 6.

Gaisler, A. (2013). Grlib ip library user's manual. http://www.gaisler. com/products/grlib/grlib.pdf. Acessado em: 01-07-2013. Citado nas páginas $\mathrm{xx}, 89,90$, and 97 .

Geer, D. (2005). Industry trends: Chip makers turn to multicore processors. Computer, 38(5):11-13. Citado na página 12 .

Georgakoudis, G., Nikolopoulos, D. S., \& Lalis, S. (2013). Fast dynamic binary rewriting to support thread migration in shared-isa asymmetric multicores. Em Proceedings of the First International Workshop on Code OptimiSation for Mult and many Cores, COSMIC '13, páginas 4:1-4:10, New York, NY, USA. ACM. Citado nas páginas 25, 39, and 113 .

Gschwind, M. (2007). The cell broadband engine: exploiting multiple levels of parallelism in a chip multiprocessor. Int. J. Parallel Program., 35(3):233-262. Citado na página 22.

Guerin, X. \& Petrot, F. (2009). A system framework for the design of embedded software targeting heterogeneous multi-core socs. Em Proceedings of the 2009 20th IEEE International Conference on Application-specific Systems, Architectures and Processors, ASAP '09, páginas 153-160, Washington, DC, USA. IEEE Computer Society. Citado nas páginas 20 and 24.

Gupta, A., Im, S., Krishnaswamy, R., Moseley, B., \& Pruhs, K. (2012). Scheduling heterogeneous processors isn't as easy as you think. Em Proceedings of the Twenty-Third Annual ACM-SIAM Symposium on Discrete Algorithms, SODA '12, páginas 1242-1253. SIAM. Citado na página 25.

Gupta, V., Knauerhase, R., Brett, P., \& Schwan, K. (2013). Kinship: efficient resource management for performance and functionally asymmetric platforms. Em Proceedings of the ACM International Conference on Computing Frontiers, CF '13, páginas 16:1-16:10, New York, NY, USA. ACM. Citado nas páginas 32, 37, 38, and 40. 
Hennessy, J. \& Patterson, D. (2011). Computer Architecture: A Quantitative Approach. The Morgan Kaufmann Series in Computer Architecture and Design. Elsevier Science. Citado nas páginas xix, 10, and 11.

Hill, M. D. \& Marty, M. R. (2008). Amdahl's law in the multicore era. Computer, 41(7):33-38. Citado na página 12.

HSA, F. (2013). Hsa programmer's reference manual: Hsail virtual isa and programming model, compiler writer's guide, and object format (brig). https: //hsafoundation.box.com/s/m6mrsjv8b7r50kqeyyal. Acessado em: 0107-2013. Citado nas páginas 20 and 25.

IBM (2013a). Inside the Linux 2.6 Completely Fair Scheduler. http://www . ibm.com/developerworks/library/l-completely-fair-scheduler/.

Acessado em: 01-07-2013. Citado nas páginas $\mathrm{xx}$ and 92 .

IBM, R. (2013b). The cell project. http://www.research.ibm.com/cell/. Acessado em: 01-07-2013. Citado na página 16.

Iyer, R., Srinivasan, S., Zhao, L., \& Illikkal, R. (2012). Application scheduling in heterogeneous multiprocessor computing platforms. http://http:// WwW.google.com/patents/US20120079235. Patent US20120079235. Citado na página 34 .

Kernel (2013). Cfs scheduler. https://www.kernel.org/doc/ Documentation/scheduler/sched-design-CFS.txt. Acessado em: 01-07-2013. Citado na página 92.

Koufaty, D., Reddy, D., \& Hahn, S. (2010). Bias scheduling in heterogeneous multi-core architectures. Em Proceedings of the 5th European conference on Computer systems, EuroSys '10, páginas 125-138, New York, NY, USA. ACM. Citado nas páginas xix, 34, 35, 37, 38, 40, 70, and 113 .

Kuhn, H. W. \& Yaw, B. (1955). The hungarian method for the assignment problem. Naval Res. Logist. Quart, páginas 83-97. Citado na página 64.

Kumar, R., Tullsen, D. M., \& Jouppi, N. P. (2006). Core architecture optimization for heterogeneous chip multiprocessors. Em Proceedings of the 15th international conference on Parallel architectures and compilation techniques, PACT '06, páginas 23-32, New York, NY, USA. ACM. Citado na página 16.

Kumar, R., Tullsen, D. M., Jouppi, N. P., \& Ranganathan, P. (2005). Heterogeneous chip multiprocessors. Computer, 38(11):32-38. Citado nas páginas खix, 15, and 16. 
Kumar, R., Tullsen, D. M., Ranganathan, P., Jouppi, N. P., \& Farkas, K. I. (2004). Single-isa heterogeneous multi-core architectures for multithreaded workload performance. SIGARCH Comput. Archit. News, 32(2):64-. Citado nas páginas xix, 12, 15, 16, 17, 26, 27, 28, 37, 38, and 40.

Li, J. M., Jiao, P., \& Men, C.-G. (2009). The heterogeneous architecture of multi-core research and design. Em MASS '09: International Conference on Management and Service Science, 2009., páginas 1-6. Citado na página 16.

Li, T., Baumberger, D., Koufaty, D. A., \& Hahn, S. (2007). Efficient operating system scheduling for performance-asymmetric multi-core architectures. Em Proceedings of the 2007 ACM/IEEE conference on Supercomputing, SC ’07, páginas 53:1-53:11, New York, NY, USA. ACM. Citado nas páginas xix, 12, 29, 30, 37, 38, and 40.

Li, T., Brett, P., Hohlt, B., Knauerhase, R., McElderry, S. D., \& Hahn, S. (2008). Operating System Support for Shared-ISA Asymmetric Multi-core Architectures. Em Proceedings of the Fourth Annual Workshop on the Interaction between Operating Systems and Computer Architecture (WIOSCA '08), páginas 19-26. Citado na página 23.

Li, T., Brett, P., Knauerhase, R. C., Koufaty, D. A., Reddy, D., \& Hahn, S. (2010). Operating system support for overlapping-isa heterogeneous multicore architectures. Em Jacob, M. T., Das, C. R., \& Bose, P., editores, 16th International Conference on High-Performance Computer Architecture (HPCA-16 2010), 9-14 January 2010, Bangalore, India, páginas 1-12. IEEE Computer Society. Citado nas páginas 12, 19, and 23.

Love, R. (2010). Linux Kernel Development - Third Edition. Addison-Wesley Professional, 3rd edição. Citado na página 92.

Menotti, R. (2010). LALP: uma linguagem para exploração do paralelismo de loops em computação reconfigurável. Tese de Doutorado, ICMC - USP. Citado na página 88 .

Narayanan, A., Nagarathnam, B. B., Meyyappan, M., \& Mongkolsri, S. (2000). Experimental comparison of hungarian and auction algorithms to solve the assignment problem. http://chalamy.tripod.com/Report.pdf. Acessado em: 01-07-2013. Citado na página 64.

Nightingale, E. B., Hodson, O., McIlroy, R., Hawblitzel, C., \& Hunt, G. (2009). Helios: heterogeneous multiprocessing with satellite kernels. Em Proceedings of the ACM SIGOPS 22nd symposium on Operating systems principles, SOSP '09, páginas 221-234, New York, NY, USA. ACM. Citado na página 24. 
NVIDIA (2010). Nvidia $\AA$ tegra ${ }^{\mathrm{TM}}$ multi-processor architecture. http://www.nvidia.com/docs/IO/90715/Tegra_Multiprocessor_ Architecture_white_paper_Final_v1.1.pdf. Acessado em: 01-072013. Citado na página 20.

NVIDIA (2013). CUDA C programming guide. http://docs.nvidia.com/ cuda/cuda-c-programming-guide/index.html. Acessado em: 01-072013. Citado na página 22.

Pedroni, V. (2004). Circuit Design With VHDL. Mit Press. Citado na página 89.

Petrucci, V., Loques, O., \& Mossé, D. (2012a). Lucky scheduling for energyefficient heterogeneous multi-core systems. Em Proceedings of the 2012 USENIX conference on Power-Aware Computing and Systems, HotPower'12, páginas 7-7, Berkeley, CA, USA. USENIX Association. Citado na página 36.

Petrucci, V., Loques, O., Mosse, D., Melhem, R., Gazala, N. A., \& Gobriel, S. (2012b). Thread assignment optimization with real-time performance and memory bandwidth guarantees for energy-efficient heterogeneous multicore systems. Em Proceedings of the 2012 IEEE 18th Real Time and Embedded Technology and Applications Symposium, RTAS '12, páginas 263-272, Washington, DC, USA. IEEE Computer Society. Citado nas páginas 11, 12, 36, 37, 38, and 40.

Qualcomm, I. (2011). Snapdragon s4 processors: System on chip solutions for a new mobile age. http://www.qualcomm.com/media/documents/ snapdragon-s4-processors-system-chip-solutions-new-mobile-age. Acessado em: 01-07-2013. Citado na página 20.

Reddy, D., Koufaty, D., Brett, P., \& Hahn, S. (2011). Bridging functional heterogeneity in multicore architectures. SIGOPS Oper. Syst. Rev., 45(1):2133. Citado na página 14 .

Saez, J. C., Fedorova, A., Koufaty, D., \& Prieto, M. (2012). Leveraging core specialization via OS scheduling to improve performance on asymmetric multicore systems. ACM Trans. Comput. Syst., 30(2):6:1-6:38. Citado nas páginas xix, 35, 36, 37, 38, and 40.

Senouci, B., Kouadri.M, A. M., Rousseau, F., \& Petrot, F. (2008). Multi$\mathrm{cpu} /$ fpga platform based heterogeneous multiprocessor prototyping: New challenges for embedded software designers. Em Proceedings of the 2008 The 19th IEEE/IFIP International Symposium on Rapid System Prototyping, RSP '08, páginas 41-47, Washington, DC, USA. IEEE Computer Society. Citado nas páginas 20 and 21 . 
Shelepov, D., Saez Alcaide, J. C., Jeffery, S., Fedorova, A., Perez, N., Huang, Z. F., Blagodurov, S., \& Kumar, V. (2009). HASS: a scheduler for heterogeneous multicore systems. SIGOPS Oper. Syst. Rev., 43(2):66-75. Citado nas páginas 28, 37, 38, and 40 .

Shen, H. \& Pétrot, F. (2009). Novel task migration framework on configurable heterogeneous mpsoc platforms. Em Proceedings of the 2009 Asia and South Pacific Design Automation Conference, ASP-DAC '09, páginas 733-738, Piscataway, NJ, USA. IEEE Press. Citado nas páginas xix, 17, and 18.

Singh, J. \& Singh, H. (2011). Efficient tasks scheduling for heterogeneous multiprocessor using genetic algorithm with node duplication. Indian Journal of Computer Science and Engineering, 2(3):402-410. Citado na página 29.

Sondag, T., Krishnamurthy, V., \& Rajan, H. (2007). Predictive thread-to-core assignment on a heterogeneous multi-core processor. Em Proceedings of the 4th workshop on Programming languages and operating systems, PLOS '07, páginas 7:1-7:5, New York, NY, USA. ACM. Citado na página 29.

SPARC (1992). The SPARC Architecture Manual - version 8. Citado na página 104 .

Srinivasan, S., Iyer, R., Zhao, L., \& Illikkal, R. (2011a). HeteroScouts: hardware assist for os scheduling in heterogeneous CMPs. SIGMETRICS Perform. Eval. Rev., 39(1):341-342. Citado na página 34.

Srinivasan, S., Zhao, L., Illikkal, R., \& Iyer, R. (2011b). Efficient interaction between os and architecture in heterogeneous platforms. SIGOPS Oper. Syst. Rev., 45(1):62-72. Citado nas páginas 13, 34, 37, 38, and 40.

Stallings, W. (2010). Computer Organization and Architecture - Designing for Performance (8. ed.). Pearson / Prentice Hall. Citado nas páginas Xix. 7, 8, and 11 .

Stevens, A. (2011). Introduction to AMBA 4 ACE. http://www.arm.com/ files/pdf/CacheCoherencyWhitepaper_6June2011.pdf. Acessado em: 01-07-2013. Citado na página 20.

Texas Instruments,
form. snapdragon-s4-processors-system-chip-solutions-new-mobile-age. Acessado em: 01-07-2013. Citado na página 20. 
Van Craeynest, K. \& Eeckhout, L. (2013). Understanding fundamental design choices in single-ISA heterogeneous multicore architectures. ACM Trans. Archit. Code Optim., 9(4):32:1-32:23. Citado na página 39.

Van Craeynest, K., Jaleel, A., Eeckhout, L., Narvaez, P., \& Emer, J. (2012). Scheduling heterogeneous multi-cores through performance impact estimation (PIE). SIGARCH Comput. Archit. News, 40(3):213-224. Citado nas páginas खix, 31, 37, 38, and 40.

Wang, P. H., Collins, J. D., Chinya, G. N., Jiang, H., Tian, X., Girkar, M., Yang, N. Y., Lueh, G.-Y., \& Wang, H. (2007). EXOCHI: architecture and programming environment for a heterogeneous multi-core multithreaded system. Em Proceedings of the 2007 ACM SIGPLAN conference on Programming language design and implementation, PLDI '07, páginas 156-166, New York, NY, USA. ACM. Citado nas páginas Xix and 22.

Xilinx (2011). M1505/ml506/ml507 evaluation platform user guide. http://wWw.xilinx.com/support/documentation/boards_and_kits/ ug347.pdf. Acessado em: 01-07-2013. Citado na página 93.

Xilinx (2013a). Virtex-5 family overview. http://www.xilinx.com/support/ documentation/data_sheets/ds100.pdf. Acessado em: 01-07-2013. Citado na página 93.

Xilinx (2013b). Xilinx Inc. http://www.xilinx.com, Acessado em: 01-072013. Citado nas páginas 88 and 136 .

Zhu, P., Zhang, C., Li, H., Cheung, R. C. C., \& Hu, B. (2012). An FPGA-based acceleration platform for auction algorithm. Em ISCAS, páginas 1002-1005. IEEE. Citado na página 64 . 